UNIVERSIDADE DE SÃO PAULO

FACULDADE DE ECONOMIA, ADMINISTRAÇÃO E CONTABILIDADE DEPARTAMENTO DE ADMINISTRAÇÃO PROGRAMA DE PÓS-GRADUAÇÃO EM ADMINISTRAÇÃO

INOVAÇÃO EM MICRO E PEQUENAS EMPRESAS DO SETOR DE SERVIÇOS: ESTUDO DE CASO DAS LAVANDERIAS DOMÉSTICAS DA CIDADE DE SÃO PAULO

Marcelo Meirelles de Souza Freitas

Orientador: Prof. Dr. Guilherme Ary Plonski

SÃO PAULO

2015 
Prof. Dr. Marco Antonio Zago

Reitor da Universidade de São Paulo

Prof. Dr. Adalberto Américo Fischmann

Diretor da Faculdade de Economia, Administração e Contabilidade

Prof. Dr. Roberto Sbragia

Chefe do Departamento de Administração

Prof. Dr. Moacir de Miranda Oliveira Junior Coordenador do Programa de Pós-Graduação em Administração 
MARCELO MEIRELLES DE SOUZA FREITAS

\title{
INOVAÇÃO EM MICRO E PEQUENAS EMPRESAS DO SETOR DE SERVIÇOS: ESTUDO DE CASO DAS LAVANDERIAS DOMÉSTICAS DA CIDADE DE SÃO PAULO
}

\begin{abstract}
Tese apresentada ao Programa de Pós-Graduação em Administração da Faculdade de Economia, Administração e Contabilidade da Universidade de São Paulo, para obtenção do título de Doutor em Ciências.
\end{abstract}

Orientador: Prof. Dr. Guilherme Ary Plonski

Versão Corrigida

(versão original disponível na Faculdade de Economia, Administração e

Contabilidade)

\section{SÃO PAULO}


FICHA CATALOGRÁFICA

Elaborada pela Seção de Processamento Técnico do SBD/FEA/USP

Freitas, Marcelo Meirelles de Souza.

Inovação em micro e pequenas empresas do setor de serviços :

estudo de caso das lavanderias domésticas da cidade de São Paulo / Marcelo Meirelles de Souza Freitas. -- São Paulo, 2015.

$287 p$.

Tese (Doutorado) - Universidade de São Paulo, 2015.

Orientador: Guilherme Ary Plonski.

1. Microempresas. 2. Pequenas e médias empresas. 3. Inovação. 4. Serviços. 5. Lavanderia. I. Universidade de São Paulo. Faculdade de Economia, Administração e Contabilidade. II. Título. 


\section{AGRADECIMENTOS}

Agradeço primeiramente a Deus pela capacitação para desenvolver este trabalho e por estar comigo nos momentos mais difíceis.

Agradeço a minha esposa Claudia e minha filha Ana Beatriz por terem orado por mim e pela paciência nos momentos que estive ausente do convívio familiar.

Agradeço ao meu orientador, Prof. Guilherme Ary Plonski, pelas orientações e por ter acreditado em mim e compartilhado sua experiência.

Agradeço a Sonia, secretária do Prof. Plonski, pelas orientações e apoio.

Agradeço a amiga Maria Isabel Marcantonio pelas sugestões e troca de informações.

Agradeço a todos os entrevistados tanto na parte da pesquisa qualitativa quanto quantitativa, que se dispuseram a ceder parte do seu precioso tempo para me atender.

Agradeço a ANEL (Associação Nacional das Empresas de Lavanderias) e SINDILAV (Sindicato Intermunicipal de Lavanderias no Estado de São Paulo) pelo apoio.

Agradeço a Profa. Ivone Borelli pela paciente correção ortográfica. 
"...mas os que esperam no Senhor renovam as suas forças, sobem com asas como águias, correm e não se cansam, caminham e não se fatigam." Isaías 40.31 (Biblia de Estudo Almeida RA 2a. Edição) 


\section{RESUMO}

A inovação no setor de serviços vem sendo estudada de modo mais intenso no meio acadêmico nas últimas décadas. Mas, a pesquisa sobre a inovação em micro e pequenas empresas de serviços ainda é baixa, embora esse grupo de empresas seja relevante em termos numéricos e por sua capacidade de gerar empregos. $\mathrm{O}$ presente estudo tem como objetivo verificar a percepção dos proprietários de lavanderias domésticas sobre a influência da adoção da inovação na competitividade e produtividade de seus negócios. As práticas que conduzem à inovação nessas empresas, os tipos de inovação adotados e como a inovação impacta na melhora da competitividade e produtividade, são analisadas. As inovações de processo (com foco em sustentabilidade e tecnologia), de marketing e organizacional (com foco em modelos de negócios e linhas de frente e retaguarda), foram estudadas. A pesquisa também foi direcionada à análise do interrelacionamento entre os diversos tipos de inovação adotados, a competitividade e a produtividade nas empresas. A metodologia escolhida usou a pesquisa bibliográfica teórico-documental, a pesquisa de campo qualitativa (por meio de entrevistas semiestruturadas com especialistas do segmento de lavanderias) e a pesquisa quantitativa (por meio de um questionário de campo com amostra das lavanderias da cidade de São Paulo, com perguntas fechadas e a escala Likert). As hipóteses formuladas foram oriundas da teoria, comparadas com os resultados quantitativos de campo e analisadas as relações entre a adoção dos diversos tipos de inovação, a competitividade e a produtividade. As entrevistas semiestruturadas, assim como a pesquisa quantitativa, foram organizadas para indicarem o inter-relacionamento entre os tipos de inovação e as variáveis competitividade e produtividade. As tipologias da inovação escolhidas da teoria foram aderentes às práticas de inovação das lavanderias domésticas. Os resultados indicaram que existem relações positivas entre todos os tipos de inovação estudados, a competitividade e a produtividade das empresas. Assim como permitiram constatar que a adoção de mais de um tipo de inovação e o inter-relacionamento entre os diversos tipos têm uma relação positiva com o desempenho das empresas, expresso na melhora da competitividade e produtividade. Uma estrutura conceitual básica (framework) que inter-relaciona os diferentes tipos de inovação e estes com as variáveis competitividade e produtividade, foi desenvolvida.

Palavras-chave: inovação; setor de serviços; micro e pequenas empresas; lavanderias domésticas. 


\begin{abstract}
The innovation in the service sector has been studied in a more intense way in the academic environment in the last few decades. However, the research about the innovation in micro and small services is still low, although this group of enterprises may be relevant in numeric terms and by its capacity of generating jobs. The purpose of this study is to verify the perception of the owners of commercial laundries over the influence in the adoption of competitiveness innovation and productivity of its business. The practices that lead to the innovation of process (with focus on sustainability and technology), of marketing and organizational (with focus on business models and front and back lines were studied. The research was also guided towards the analysis of the interrelationship among the many types of innovation adopted, the competiveness and the productivity in companies. The methodology chosen used the theoretical - documental bibliographic research, the qualitative field research (by demi-structured interviews with experts in the laundry area) and the quantitative research (by use of a field inquire with laundry samples in the city of São Paulo, with closed questions and the Likert scale). The hypothesis that were raised were originated from the theory, compared to the quantitative field results and analyzed the relationship between the adoption of several innovation types, the competiveness and productivity. The demi-structured interviews, thus as the quantitative research were organized as to show there are positive relations among these types of innovation studied, the competiveness and the productivity of the companies. Thus as allowed to infer that the adoption of one more type of innovation and the inter-relationship among its several types has a positive relation with the development of companies, expressed in the improvement of competiveness and productivity. A basic conceptual structure (framework) was developed that interrelates the different types of innovation and these with the variants, competiveness and productivity
\end{abstract}

Keywords: innovation, service sector, micro and small companies, domestic laundries. 


\section{SUMÁRIO}

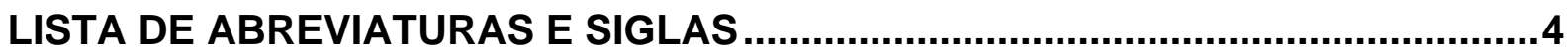

LISTA DE FIGURAS

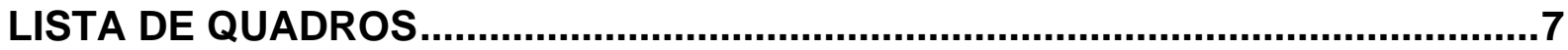

LISTA DE GRÁFICOS

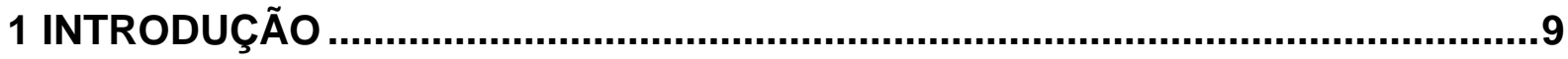

1.1 A Inovação e a Competitividade das Micro e Pequenas Empresas do Setor de

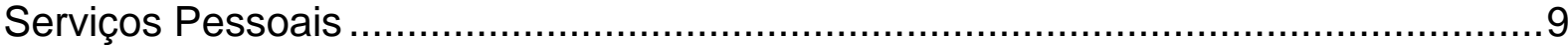

1.2 O Segmento das Lavanderias Domésticas ……….....................................16

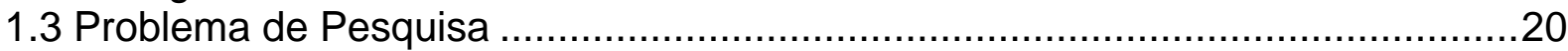

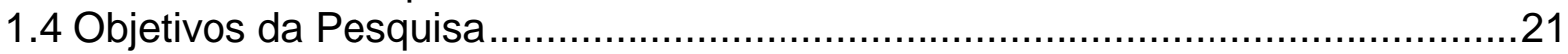

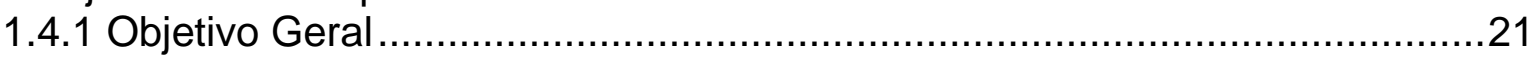

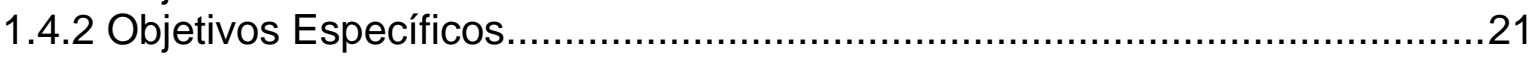

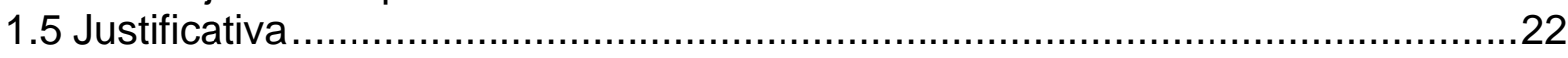

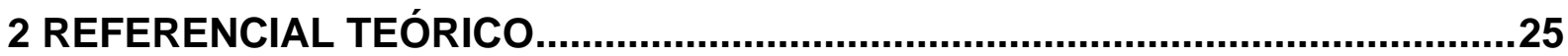

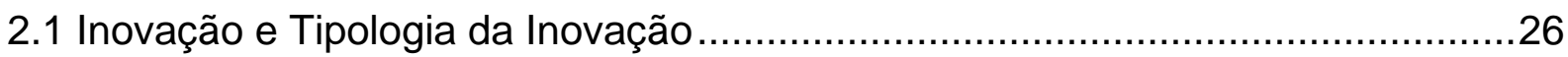

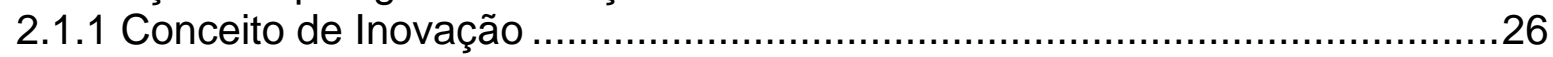

2.1.2 Tipologia da Inovação e seu Inter-relacionamento ..................................28

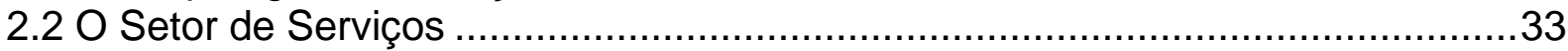

2.2.1 Definição e Abrangência do Setor de Serviços...........................................33

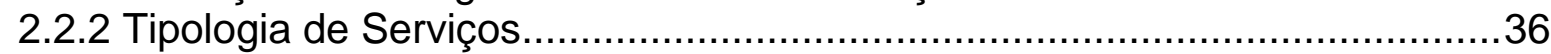

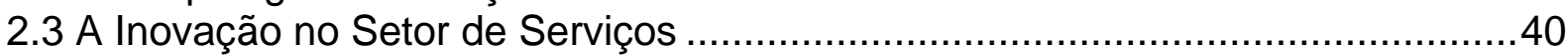

2.3.1 Visão schumpeteriana de Inovação em Serviços ........................................40

2.3.2 Conceito e Processo de Inovação em Serviços........................................41

2.3.3 Desenvolvimento de Novos Serviços.....................................................49

2.3.4 Inovação em Serviços x Inovação em Produtos ...........................................55

2.4 Tipologia da Inovação em Serviços e seu Inter-relacionamento ........................59

2.4.1 Resumo da Tipologia da Inovação Geral e de Serviços e Escolha dos Tipos de Inovação para a Pesquisa ........................................................................63

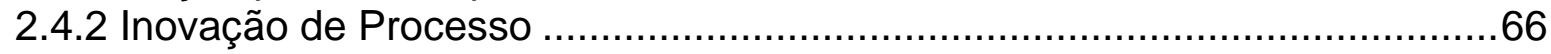

2.4.2.1 Conceito de Inovação de Processo ...................................................66

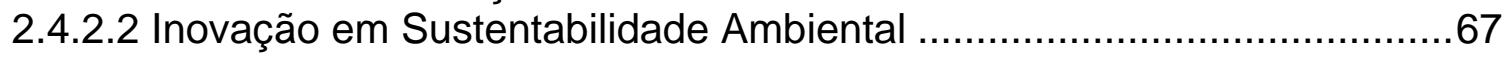

2.4.2.3 Inovação Tecnológica em Serviços ....................................................71

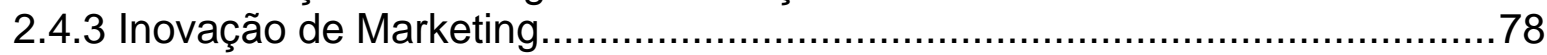

2.4.3.1 Conceito de Inovação de Marketing ....................................................78

2.4.3.2 Inovação de Marketing em Serviços ...................................................79

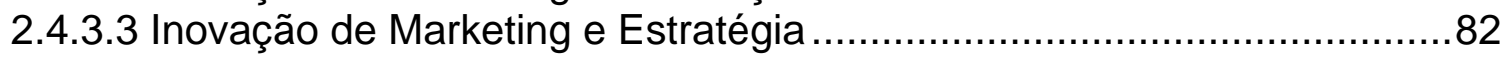

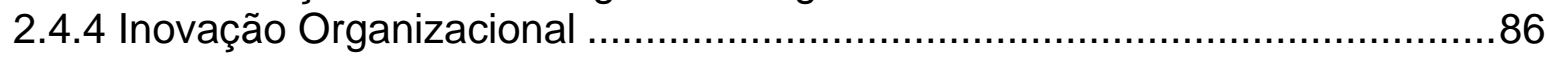

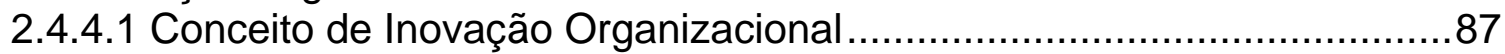

2.4.4.2 Inovação de Modelo de Negócio ..................................................... 89

2.4.4.3 Inovação no Processo de Recepção e Entrega (Linha de Frente ou Front

Office) e Produção (Retaguarda ou Back Office) ...........................................93

2.5 Inovação em Micro e Pequenas Empresas (MPEs) do Setor de Serviços ...........98 
2.5.1 Dados Estatísticos das MPEs do Setor de Serviços ................................. 99

2.5.2 Inovação em MPEs do Setor de Serviços ................................................. 101

2.6 Tipologia da Inovação e as MPEs do Setor de Serviços ................................ 105

2.7 Contextualização do Segmento de Lavanderias Domésticas ........................... 106

2.8 A Inovação e o segmento das Lavanderias Domésticas ................................ 114

2.8.1 Inovação de Processo nas Lavanderias Domésticas ................................ 116

2.8.1.1 Inovação em Sustentabilidade Ambiental nas Lavanderias Domésticas

118

2.8.1.2 Inovação Tecnológica em Lavanderias Domésticas .......................... 122

2.8.1.2.1 Equipamentos .................................................................. 125

2.8.1.2.2 Produtos Químicos............................................................ 126

2.8.1.2.3 Tecnologia da Informação (TI) ........................................... 127

2.8.2 Inovação de Marketing em Lavanderias Domésticas ............................... 128

2.8.3 Inovação Organizacional nas Lavanderias Domésticas .......................... 133

2.8.3.1 Inovação de Modelo de Negócios nas Lavanderias Domésticas......... 133

2.8.3.2 Inovação na Linha de Frente (Front Office) e de Retaguarda (Back

Office) nas Lavanderias Domésticas ..................................................... 135

2.9 Inovação, Competitividade e Produtividade .............................................. 137

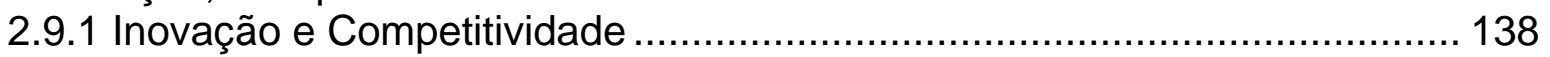

2.9.2 Inovação e Produtividade ............................................................... 140

2.9.3 Competitividade e Produtividade no Setor de Serviços.............................. 141

2.9.4 Competitividade e Produtividade em MPEs .......................................... 143

2.9.5 Competitividade e Produtividade nas Lavanderias................................... 146

2.9.6 Trabalhos de Helena Forsman (2011) (Inovação, Competitividade e

Produtividade em Pequenas Empresas) .................................................. 147

2.10 Resumo do Referencial Teórico ....................................................... 151

3 METODOLOGIA....................................................................................... 154

3.1 Pesquisa Bibliográfica Teórico-Documental ............................................ 156

3.2 Pesquisa Qualitativa Prévia por intermédio de Entrevistas Semiestruturadas.. 156

3.3 Pesquisa Quantitativa de Campo ...................................................... 158

3.3.1 Bancos de Dados Estatísticos Utilizados para Delimitação da Amostra .... 158

3.3.1.1 Instituto Brasileiro de Geografia e Estatística (IBGE) ......................... 158

3.3.1.2 Estudo do Ministério do Comércio Exterior da Itália ............................ 161

3.3.1.3 Federação das Indústrias do Estado de São Paulo (FIESP) ............... 162

3.3.1.4 Ministério do Trabalho e Emprego (MTE) do Brasil ............................. 163

3.3.1.5 SINDILAV (Sindicato Intermunicipal de Lavanderias no Estado de São

Paulo) ....................................................................................... 163

3.3.1.6 Resumo dos Resultados dos Bancos de Dados Estatísticos Utilizados

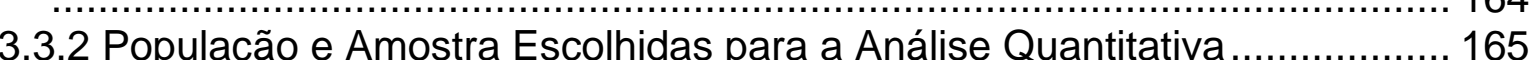

3.3.2 População e Amostra Escolhidas para a Análise Quantitativa ..................... 165

3.3.3 Estabelecimento das Hipóteses para Análise Quantitativa ....................... 168

3.3.4 Questionário como Instrumento para Pesquisa de Campo Quantitativa .... 173

3.3.5 Uso de Testes Não-Paramétricos com Escala Likert ............................... 177

3.3.6 Teste de Hipóteses e Técnica Estatística Não Paramétrica Utilizada ........ 179

4 RESULTADOS OBTIDOS E ANÁLISE............................................................. 183

4.1 Resultados Obtidos na Pesquisa Qualitativa (Entrevistas Semiestruturadas com

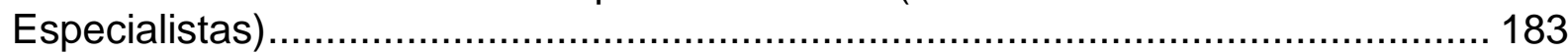

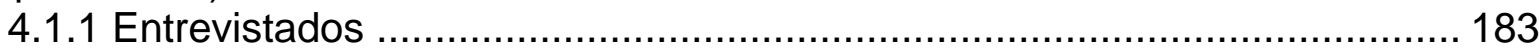


4.1.2 Resumo dos Resultados Obtidos nas Entrevistas Semiestruturadas (Apêndice A)

4.1.2.1 Localização Geográfica das Lavanderias.......................................186

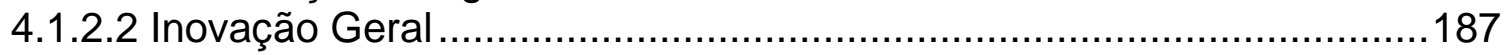

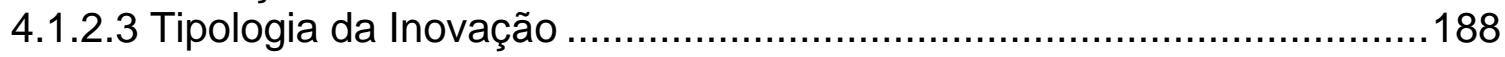

4.2 Pesquisa Quantitativa ......................................................................194

4.2.1 Resultados Obtidos e Análise das Respostas do Questionário Enviado ....194

4.2.1.1 Resultados a Respeito das Características e Práticas das Lavanderias da Amostra (Apêndice B: Questionário - Dados Preliminares)........................194

4.2.1.2 Resultados Questões via Escala Likert ...........................................204

4.2.2 Resultados dos Testes de Hipóteses a partir da Técnica Qui-Quadrado ...217

4.3 Estrutura Conceitual (Framework) Relacionando os Tipos de Inovação,

Competitividade e Produtividade 226

4.3.1 Evidências do Inter-Relacionamento Com Base na Pesquisa Qualitativa

(Entrevistas Semiestruturadas) .227

4.3.2 Evidências do Inter-Relacionamento a partir da Pesquisa Quantitativa

(Respostas Ítem 7 do Questionário do Apêndice B) ...........................................235

4.3.3 Desenvolvimento da Estrutura Conceitual (framework) ............................236

5 CONCLUSÕES

5.1 Atendimento ao Objetivo Específico 1

5.2 Atendimento ao Objetivo Específico 2

5.3 Atendimento ao Objetivo Específico 3

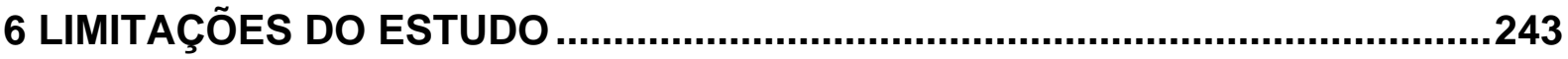

7 RECOMENDAÇÕES PARA ESTUDOS FUTUROS .............................................244

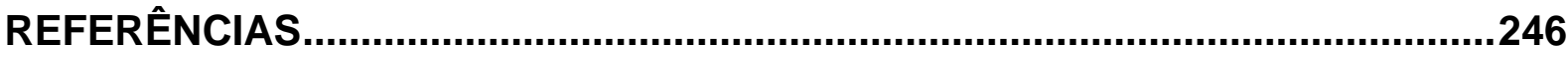

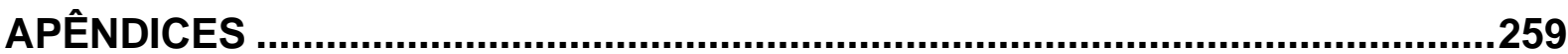




\section{LISTA DE ABREVIATURAS E SIGLAS}

ANEL: Associação Nacional das Empresas de Lavanderias

CAGED: Cadastro Geral de Empregados e Desempregados

CEMPRE: Cadastro Central de Empresas

CNAE: Cadastro Nacional de Atividades Econômicas

CNPJ: Cadastro Nacional da Pessoa Jurídica

CRM: Customer Relationship Management

DNP: Desenvolvimento de Novos Produtos

DNS: Desenvolvimento de Novos Serviços

EPI: Equipamentos de Proteção Individual

EUROSTAT: European Statistics

EVCM: Environmental Value Chain Management

FECOMERCIO: Federação do Comércio de Bens, Serviços e Turismo do Estado de

São Paulo

FIESP: Federação das Indústrias do Estado de São Paulo

IBGE: Instituto Brasileiro de Geografia e Estatística

IFI: International Fabricare Institute

IPEA: Instituto de Pesquisa Econômica e Aplicada

ITA: Italian Trade Agency

MPEs: Micro e Pequenas Empresas

MTE: Ministério do Trabalho e Emprego

NPD: New Product Development

NSD: New Service Development

OCDE: Organização para Cooperação e Desenvolvimento Econômico

OECD: Organisation for Economic Co-operation and Development

PDTE: Programa de Disseminação de Estatísticas do Trabalho

PINTEC: Pesquisa de Inovação Tecnológica

PMEs: Pequenas e Médias Empresas

RAIS: Relação Anual de Informações Sociais

SEBRAE: Serviço Brasileiro de Apoio às Micro e Pequenas Empresas

SENAC: Serviço Nacional de Aprendizagem Comercial

SENAI: Serviço Nacional de Aprendizagem Industrial

SINDILAV: Sindicato Intermunicipal de Lavanderias no Estado de São Paulo

SQS: Selo de Qualidade e Sustentabilidade 


\section{LISTA DE FIGURAS}

Figura 1: Macroáreas de Abrangência da Pesquisa

Figura 2: Estrutura Básica Referencial Teórico, Problema de Pesquisa e Objetivos 26

Figura 3: Tipologias de Inovação, do passado ao presente …………………..........30

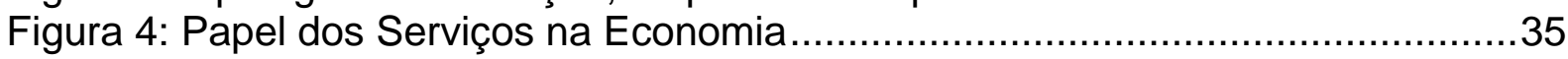

Figura 5: Relacionamentos em Serviços .........................................................36

Figura 6: Dimensões da Tipologia de Serviços e seu Inter-relacionamento................37

Figura 7: Desafios na Gestão dos Diferentes Tipos de Empresas de Serviços .........38

Figura 8: Framework Conceitual para o Processo de Inovação em Serviços ............49

Figura 9: Classificação de pesquisa e desenvolvimento para os setores de bens e serviços

Figura 10: Processo de Inovação em Serviços ...................................................51

Figura 11: Modelo Normativo de Desenvolvimento de Novos Serviços ....................53

Figura 12: Desenvolvimento de Novos Serviços ..................................................54

Figura 13: Modelo Conceitual para Inovação de Produtos e Serviços .......................58

Figura 14: Determinantes da Ecoinovação ……………………………............68

Figura 15: Ecoinovação e as dimensões econômicas e sociais................................69

Figura 16: Padrões setoriais de mudança tecnológica em serviços..........................73

Figura 17: Os quatro tipos de inovações de serviço de criação de mercado .............81

Figura 18: Modelo da influência da inovação na satisfação e lealdade ......................82

Figura 19: Dimensões da inovação, orientação estratégica e desempenho .............83

Figura 20: Modelo Conceitual interligando orientação estratégica, inovação em

serviços e desempenho de mercado................................................................... 84

Figura 21: Atividades das linhas de frente e retaguarda .....................................93

Figura 22: Modelo Conceitual dos Níveis Hierárquicos da Motivação.......................96

Figura 23: Modelo da Influência das Características do Trabalho na Criatividade do

Funcionário.

Figura 24: Framework Conceitual: Fatores Organizacionais e Individuais e Geração

de Ideias para Melhora do Serviço ..................................................................98

Figura 25: Relação entre exploração, explotação e desempenho do negócio ........104

Figura 26: Blueprint para lavanderias domésticas.............................................114

Figura 27: Cruzamento das implicações das estratégias no cruzamento da estrutura

de processos e estrutura de pacote de serviços ................................................129

Figura 28: Relação entre estratégia competitiva, estratégia de inovação e valor

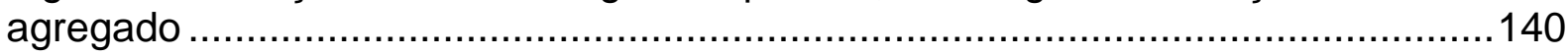

Figura 29: Relações sugeridas entre as categorias de efeitos na inovação em

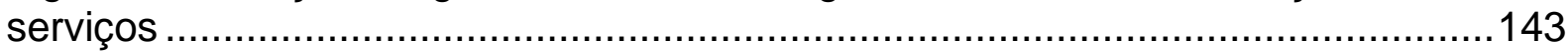

Figura 30: Hipóteses formuladas e variáveis relacionadas na pesquisa .................173

Figura 31: Questão DP 3 Questionário ..........................................................194

Figura 32: Questão DP 6 Questionário ………………...............................195

Figura 33: Questão DP 7 Questionário ……………..................................196

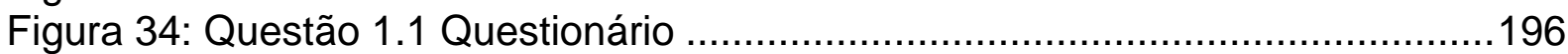

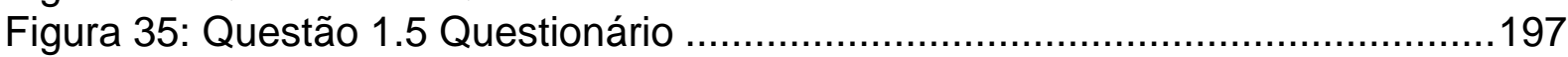

Figura 36: Questão 1.4 Questionário ...........................................................197

Figura 37: Questão 1.3 Questionário .........................................................198

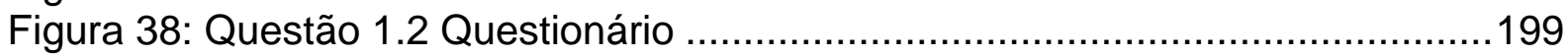

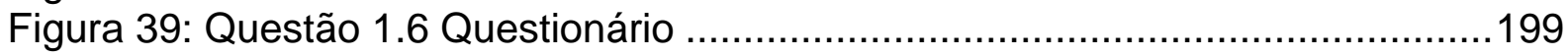

Figura 40: Questão 1.7 Questionário .........................................................200 


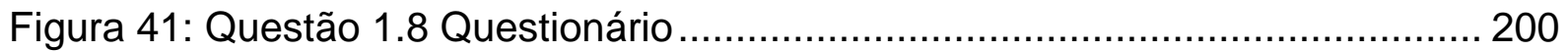

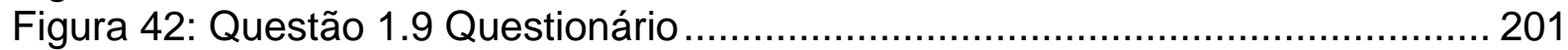

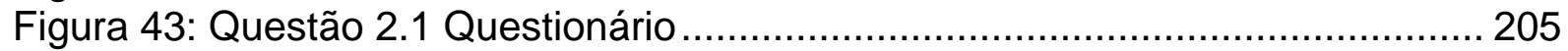

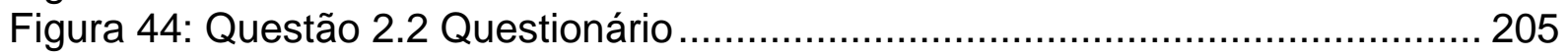

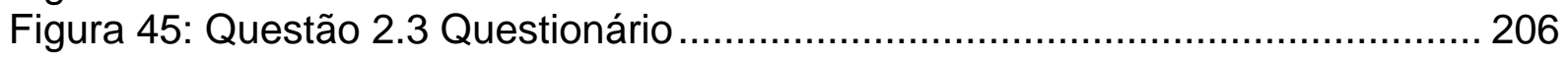

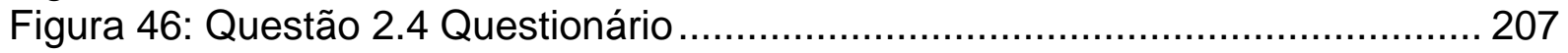

Figura 47: Questão 2.5 Questionário …………………............................... 207

Figura 48: Questão 2.6 Questionário ……………….................................... 208

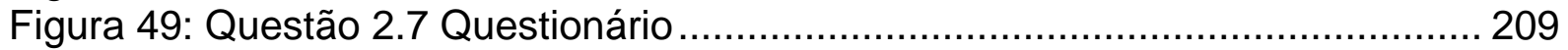

Figura 50: Questão 3.1 Questionário ............................................................. 209

Figura 51: Questão 3.2 Questionário ………………................................. 210

Figura 52: Questão 3.3 Questionário ........................................................ 211

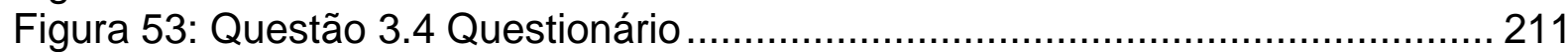

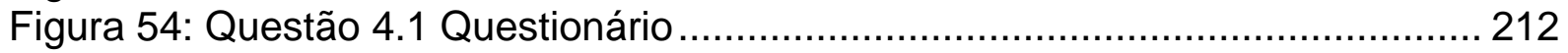

Figura 55: Questão 4.2 Questionário ........................................................... 212

Figura 56: Questão 4.3 Questionário ………………….............................. 213

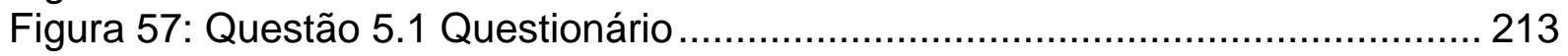

Figura 58: Questão 5.2 Questionário .......................................................... 214

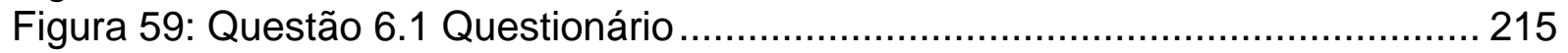

Figura 60: Questão 6.2 Questionário ......................................................... 216

Figura 61: Questão 7.1 Questionário ………………................................ 216

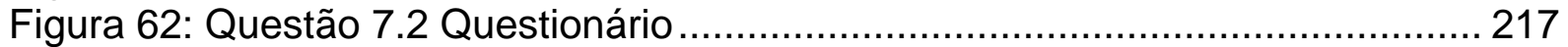

Figura 63: Hipóteses formuladas e variáveis relacionadas na pesquisa ............... 218

Figura 64: Framework proposto: interelacionamento entre os tipos de inovação e produtividade/competitividade em lavanderias domésticas ................................... 236 


\section{LISTA DE QUADROS}

Quadro 1: Referências utilizadas na pesquisa documental teórica 151 Quadro 2: Resumo dos Dados Estatísticos como base para a escolha da população e amostra 165 Quadro 3: Resultados Obtidos nos Testes de Hipóteses 219 


\section{LISTA DE GRÁFICOS}

Gráfico 1: Distribuição de ME e EPP por Regiões ............................................. 100

Gráfico 2: Distribuição de ME e EPP por setores ........................................... 101

Gráfico 3: Regiões de Rejeição e Não Rejeição .................................................... 221 


\section{INTRODUÇÃO}

É importante salientar, antes de iniciar a apresentação da presente pesquisa, que o título mais adequado, por sugestão da comissão julgadora, não deveria conter "estudo de caso das lavanderias" e sim "estudo das lavandeiras". A justificativa, que foi acatada, indica que o presente estudo não está enquadrado como estudo de caso, por sua abrangência (segmento de lavanderias domésticas) e características quantitativas, com utilização de técnica estatística e proposição de obter resultados específicos da população estudada.

\subsection{A Inovação e a Competitividade das Micro e Pequenas Empresas do Setor de Serviços Pessoais}

A inovação vem sendo considerada como um dos fatores mais importantes para o ganho de vantagem competitiva pelas organizações. A inovação naquelas de serviços tem sido um importante tópico no estudo da competitividade, pelo crescimento e dinamismo do setor de serviços em termos de atividade econômica (MC DERMOTT; PRAJOGO, 2012).

Com a crescente importância econômica do setor de serviços no cenário internacional, a inovação em serviços vem sendo um tema discutido nos trabalhos acadêmicos de modo mais intenso nas últimas décadas. Mas, a literatura é mais restrita quando são abordados segmentos de prestação de serviços que não estão envolvidos na geração de tecnologia. Apesar da importância, a produção acadêmica sobre o tema "inovação em serviços" ainda é pequena, se comparada com "inovação tecnológica". No caso da inovação em micro e pequenas empresas de serviços a literatura é escassa. Forsman e Temel (2011, p. 642) referem que "relativamente poucos trabalhos tem sido publicados sobre a relação entre inovação e desempenho no contexto de pequenos negócios". Os autores questionam se "existem diferenças de desempenho entre empresas que desenvolveram tipos diferentes de inovação?" e indicam que a inovação de produto reflete nas mudanças do produto ou serviço final, e inovações de processo representam mudanças na forma que as empresas produzem produtos e serviços. Os autores explicam que a 
inovação de produto tem por objetivo melhorar o posicionamento de mercado, ao passo que as de processo melhoram 0 custo/beneficio e a produtividade. Adicionalmente, apontam que, com frequência, as inovações de serviços nas chamadas indústrias de serviço são consideradas similares às inovações de produto desenvolvidas pelas indústrias de manufatura.

Para Fitzsimmons e Fitzsimmons (2010), o setor de serviços vem sendo responsável por uma mudança em nível global, tanto na migração da mão de obra dos setores industrial e agrícola como na criação de oportunidades de novas áreas de atuação, que demandam recursos humanos com aptidões específicas e apoio às inovações tecnológicas. Os autores supracitados ponderam que existe um desenvolvimento natural dos serviços na sociedade pós-industrial para sustentar o desenvolvimento industrial, como manutenção, transportes e empresas de serviços públicos. O crescimento populacional também alavanca o comércio varejista, bancário e de habitação, assim como o aumento da renda, sobretudo pela demanda de serviços pessoais. Drejer (2004) destaca que os Estados Unidos da América foram a primeira economia a tornar-se uma "economia de serviços", termo usado para descrever o domínio da empregabilidade da população americana no setor de serviços. $O$ autor afirma que, desde os anos 1950, somente uma pequena parcela da população americana estava envolvida na produção de bens tangíveis e ressalta o papel do consumidor, como agente de cooperação no processo de inovação na produção dos serviços. O estudo da Organisation for Economic Co-operation and Development (OECD, 2005) sobre a inovação em serviços ressalta que o mercado de serviços tornou-se o principal agente para a criação de empregos nos países membros da organização, compensando as perdas de cargos no setor de manufatura.

De acordo com o IPEA (2006), o forte desempenho do setor de serviços deve-se à crescente importância da globalização em muitos serviços, trazendo uma mudança nos modelos de negócios, de modo que as empresas busquem fornecedores especializados de serviços no país de origem e no exterior. O estudo ainda afirma que vêm sendo investigadas as particularidades da produtividade no setor de serviços e o impacto no crescimento econômico, já que o setor tem importante influência no balanço de pagamentos e no equilíbrio macroeconômico. Outro aspecto analisado no estudo (IPEA, 2006), foi a tendência do setor industrial adquirir 
cada vez mais receita apoiado em serviços complementares a seus produtos, o que poderia deslocar recursos para as atividades prestadoras de serviço, em detrimento das produtivas. Os autores complementam que existe uma tendência de apresentar o setor de serviços, como de baixa produtividade (com difícil mensuração e de consumo imediato) e com pobre desempenho tecnológico, exceto quando se refere a setores de serviços intensivos em tecnologia, como tecnologia da informação ou intensivos em conhecimento, como consultoria técnica e transferência de conhecimento.

Em sua análise sobre a competitividade das nações, Porter (1993) dedica um capítulo sobre o crescimento e a importância do setor de serviços em nível mundial e a crescente competição internacional em serviços, a exemplo do que ocorre com os produtos manufaturados. Acentua que, em razão da natureza do setor de serviços, muitas atividades da cadeia de valores desse setor devem ser realizadas onde está o comprador, levando as empresas a instalarem-se fisicamente nos países onde atuam. Zeithaml e Bitner (2011) mostram as características do setor de prestação de serviços, enfatizando o lado humano desta atividade na entrega ao mercado consumidor, o que o diferencia da tangibilidade da indústria e comércio.

Em resposta ao crescimento do setor de serviços, o interesse acadêmico na gestão de empresas de serviços também cresceu, conforme Oke (2007). Assim, os trabalhos iniciais em inovação em serviços, foram direcionados à difusão e à adoção dos serviços inovadores e, apesar das diferenças entre serviços e produtos manufaturados (intangibilidade, perecibilidade, heterogeneidade e simultaneidade), as pesquisas têm seguido a linha mais estável e conhecida da inovação em produtos manufaturados. $\mathrm{O}$ autor indica que os termos "inovação em produtos de serviços" e "inovação em produtos" vêm sendo usados na literatura de modo intercambiável para descrever um grupo particular de inovações nas empresas de serviços.

Jong et al. (2003) cita que, apesar de sua importância econômica, o setor de serviços tem recebido pouca atenção na pesquisa de inovação, sendo descartado pela inovação tecnológica, que é relevante para as empresas de manufatura. Mas, ressalta que vêm sendo reconhecido que as empresas de serviços não são meros 
destinatários das inovações manufaturadas, pois existe o reconhecimento da importância dos elementos não tecnológicos de inovação nessas empresas, tais como a capacidade humana e a organizacional. Para o autor, a inovação em serviços não está totalmente integrada à literatura acadêmica se comparada com o setor de manufatura. Nesse contexto, Ettlie e Rosenthal (2011) estudaram as razões da pouca formalização da inovação em serviços e apontam:

a) Existe pouca padronização e pouco ou nenhum planejamento no desenvolvimento de novos serviços. Além disso, as métricas são mais problemáticas, pois são variáveis;

b) Existe pouco investimento em pesquisa e desenvolvimento para serviços, o que contribui para a natureza informal da inovação; e

c) O setor de serviços vem sendo mais reativo às mudanças na demanda de consumo ou disponibilidade de novos métodos de entrega, faltando estratégia para direcionar a inovação.

Embora a grande maioria das empresas prestadoras de serviços seja composta por micro e pequenas empresas (MPEs) (IBGE, 2003; SEBRAE, 2011), a literatura acadêmica que aborda a inovação neste grupo de empresas é ainda mais restrita, exceto, conforme citado, em áreas intensivas em tecnologia e conhecimento. $\mathrm{Na}$ presente pesquisa, constatou-se que a literatura é escassa quando o tema enfoca a inovação das micro e pequenas de serviços que atendem diretamente ao consumidor final, a exemplo daquelas que prestam serviços pessoais. Oke; Burke e Myers (2007) indicam que existem poucos estudos sobre a inovação nas pequenas e médias empresas, enfatizando que a maior parte dessas pesquisas é direcionada a dois campos: inovação em pequenas e médias empresas e o crescimento econômico e os tipos de inovação que essas empresas adotam.

Tamura (2005) pondera que as pesquisas de inovação indicam que as empresas do setor de serviços são inovadoras, embora menos que as indústrias de manufatura. Com relação ao porte, o autor utiliza pesquisas em países da OECD (EUROPEAN COMMITION e EUROSTAT (European Statistics); 2014b) e cita que existem 
diferenças significativas no desempenho inovador das empresas. Empresas de serviços de grande porte parecem ser consideravelmente mais inovadoras que as empresas de médio e pequeno portes. Com relação a investimentos em pesquisa e desenvolvimento, o autor indica que as empresas de serviços investem menos em um departamento formal de pesquisa e desenvolvimento, optando mais por adquirir conhecimento para inovação em fontes externas.

A European Comission (2014a) estabelece o seguinte critério para classificar micro, pequenas e médias empresas:

- Microempresa: menos que dez funcionários e volume de negócios menor que 2 milhões de euros;

- Pequena Empresa: menos que 50 funcionários e volume de negócios menor que 10 milhões de euros; e

- Média Empresa: menos que 250 funcionários e volume de negócios menor que 50 milhões de euros.

Conforme o SEBRAE (2014), as micro e pequenas empresas (MPEs) estão classificadas, de acordo com seus níveis de faturamento para efeito fiscal e número de funcionários:

Faturamento:

- Empreendedor Individual - El - Lei $n^{0} 123 / 06$ - Até $R \$ 60.000,00$

- Microempresa - ME - Lei n ${ }^{0}$ 123/06 - Até R\$360.000,00

- Empresa de Pequeno Porte - EPP - Lei $n^{0} 123 / 06$ - De $R \$ 360.000,01$ até $R \$$ $3.600 .000,00$

Número de Funcionários:

- Indústria:

Micro: com até 19 empregados

Pequena: de 20 a 99 empregados

Média: 100 a 499 empregados

Grande: mais de 500 empregados 
- Comércio e Serviços

Micro: até nove empregados

Pequena: de 10 a 49 empregados

Média: de 50 a 99 empregados

Grande: mais de 100 empregados

Para o presente estudo, será utilizada a classificação do SEBRAE (2014) para micro, pequena e média empresas.

No Brasil, conforme o IBGE (2010) na Pesquisa Anual de Serviços, em 2010, as 992.808 empresas de serviços obtiveram $R \$ 869$,3 bilhões de receita operacional líquida, ocuparam 10.622 mil pessoas e despenderam $R \$ 172,5$ bilhões em salários, retiradas e outras remunerações. Com relação à participação das grandes empresas de serviços, este universo contém 54.827 empresas (5,5\% do total), que foram responsáveis por $77,9 \%$ da receita operacional líquida gerada nos serviços ( $R \$$ 677,0 bilhões), $66,0 \%$ do pessoal ocupado (7.012 mil) e 76,1\% da massa salarial ( $R \$ 131,3$ bilhões). Para o mesmo estudo, a maior parte das empresas atua no segmento de serviços prestados às famílias (310.958 ou $31,3 \%$ do total), no qual o segmento de lavanderias está inserido, ou seja, Serviços pessoais com CNAE (Cadastro Nacional de Atividades Econômicas) 96.01-7.

De acordo com o citado estudo do IBGE (2010), a maior parte da receita operacional líquida do setor de serviços é gerada por somente $5,5 \%$ do total de empresas, indicando forte presença de empresas de médio e grande porte, permitindo inferir que a grande maioria das empresas de serviços (mais de 90\%) são empresas de menor faturamento (micro e pequenas empresas). O estudo anterior (IBGE, 2003) indicou que as micro e pequenas empresas participaram de $97,6 \%$ do número total de empresas do setor de comércio e serviços. De acordo com o estudo do SEBRAE (2011), a grande maioria das pequenas empresas (EPPs) está concentrada no setor de comércio (59\% do total de estabelecimentos), seguidos pela indústria (20\%) e serviços (19\%). Mas, esta distribuição muda quando as microempresas (MEs) são abordadas: a participação no comércio mantém-se (59\%), mas, no setor de serviços cresce para $27 \%$ e, na indústria, recua para $12 \%$. 
As micro e pequenas empresas (MPEs), categoria que inclui a maior parte das lavanderias domésticas, tipicamente têm pautado suas ações e soluções nos problemas a curto prazo. No caso das MPEs de serviços, as dificuldades em planejar a longo prazo são ainda maiores, pois, normalmente, entregam seus produtos intangíveis no momento da venda. Dessa maneira, assumem uma postura mais pragmática no cotidiano, tentando defender-se das condições adversas do ambiente externo (sobretudo a guerra de preços com a concorrência) e respondendo pontualmente à medida que as demandas e problemas surgem.

O presente estudo busca entender a adoção da inovação em micro e pequenas empresas de serviços, particularizando a análise dos tipos de inovação utilizados nas lavanderias domésticas ${ }^{1}$. A pesquisa parte do conhecimento na inovação em serviços e, seguindo a classificação da Pesquisa Anual de Serviços do IBGE (2010), afunila para o estudo da inovação em micro e pequenas empresas prestadoras de serviços pessoais às famílias (subitem serviços pessoais/lavanderias e tinturarias), para finalmente particularizar para o estudo da inovação nas lavanderias domésticas, conforme a classificação do SINDILAV (Sindicato Intermunicipal de Lavanderias no Estado de São Paulo), e os dados da Figura 1 a seguir.

\footnotetext{
${ }^{1}$ Lavanderias domésticas ou comerciais são aquelas que prestam serviços de lavagem diretamente ao consumidor final.
} 


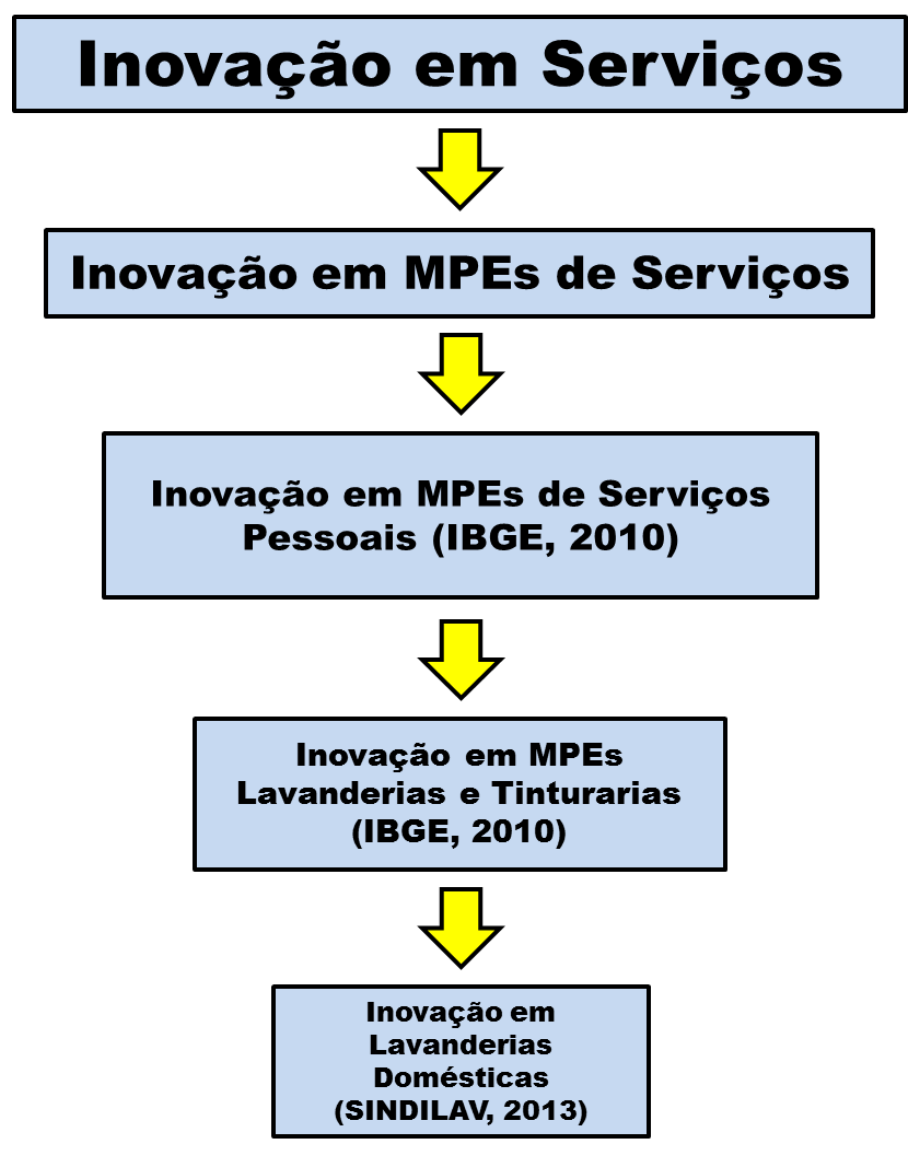

Figura 1: Macroáreas de Abrangência da Pesquisa

Elaborado pelo autor

\subsection{O Segmento das Lavanderias Domésticas}

Caetano (2013), pontua que o setor das lavanderias domésticas no Brasil tem forte presença das micro e pequenas empresas (MPEs). Gallucci (2011, p. 32) cita que o "setor de lavanderias no Brasil é formado por um número grande e não mensurável de micro e pequenas empresas (formais e informais)".

A escolha do segmento das lavanderias domésticas foi motivada pela importância desse grupo de empresas no Brasil, notadamente, após a entrada das redes internacionais de lavanderias domésticas no País, a partir do final do século passado. As redes internacionais (franquias) trouxeram um projeto de lavanderia rápida, introdução de novas tecnologias de lavagem (lavagem a seco e 
wetcleaning ${ }^{2}$ ), salientaram o cuidado com o aspecto das lojas e o padrão visual, além de praticarem uma politica inicial de preços baixos ao consumidor final (MENDONÇA, 2003).

O segmento das lavanderias domésticas presta serviços por intermédio do processamento de bens que pertencem ao cliente final (peças de roupas). A prestação de serviços e o processo de inovação ocorrem com baixa participação do cliente beneficiário. O papel do cliente resume-se a trazer a peça a ser processada (ou seja, lavada, passada ou para retirada de manchas) e examinar o resultado do serviço, após o prazo de entrega estipulado pela lavanderia. A escolha do método de lavagem/retirada de manchas, passadoria e acabamento final é decidida, na maior parte dos casos, pela própria lavanderia, com baixa interferência do cliente final.

As lavanderias estão inseridas, de acordo com a classificação do Instituto Brasileiro de Geografia e Estatística (IBGE), no grupo de Serviços Pessoais (Lavanderias e Tinturarias) com código CNAE (Cadastro Nacional de Atividades Econômicas) 96.017 e têm a seguinte tipologia, conforme o SINDILAV (Sindicato Intermunicipal de Lavanderias no Estado de São Paulo):

a) Lavanderias Domésticas: direcionadas ao consumidor final, estas são responsáveis pela higienização de roupas do dia a dia, roupas sociais, vestidos de festa e roupas de cama, mesa e banho; e

b) Lavanderias Industriais: direcionadas ao consumidor institucional, responsáveis pela higienização de têxteis utilizados por empresas. São divididas em:

- Lavanderias de Decoração: higienização de carpetes, tapetes, cortinas, sofás, poltronas, cadeiras e estofados em geral;

- Lavanderias de Hotel, Motel e Restaurante: limpeza de roupas de cama, mesa e banho para estabelecimentos que precisam de agilidade;

\footnotetext{
${ }^{2}$ Lavagem a seco: termo utilizado para sistema de lavagem sem água e com o uso de solventes orgânicos, como o percloroetileno e a isoparafina.

Lavagem wetcleaning: termo utilizado para sistema de lavagem com pouca água e desenvolvido para lavagem de roupas delicadas, como opção ao sistema de lavagem a seco (que utiliza solventes orgânicos).
} 
- Lavanderias de Equipamentos de Proteção Individual (EPI): higienização e descarte de resíduos nocivos, que estão presentes em uniformes e EPI de funcionários de empresas;

- Lavanderias Hospitalares: Higienização de lençóis, fronhas, cobertores, toalhas, colchas e roupas hospitalares; e

- Lavanderias de Jeans: promovem a higienização como também o tingimento de artigos têxteis por meio de diversas modalidades e técnicas.

As lavanderias domésticas podem ainda ser classificadas, conforme sua origem em:

a) Lavanderias Independentes: são lavanderias não pertencentes a franquias (nacionais ou internacionais); e

b) Lavanderias de Rede: são lavanderias pertencentes a franquias (nacionais ou internacionais).

Nos últimos anos, o segmento das lavanderias domésticas vem sendo afetado de modo especial por fatores ambientais peculiares:

a) $A$ ascensão da classe $C$ a patamares de consumo típicos da classe $B$, tem aumentado o tamanho do mercado-alvo com a mudança de hábito no uso das lavanderias (apesar de trazer consigo a cultura de "lavar roupa em casa como prérequisito de cuidado com o lar") (MENDONÇA, 2010);

b) $O$ aumento da participação feminina no mercado de trabalho, a presença desse público também no aperfeiçoamento de sua capacitação em cursos noturnos e a redução das áreas das moradias típicas de grandes cidades dificultam 0 processamento de roupas nas residências;

c) As características das redes de lavanderias domésticas internacionais influenciaram diretamente 0 modo de prestar serviços das lavanderias independentes, já que o novo modelo de negócios não só atraiu clientes que não utilizavam o serviço, como aumentou a competitividade no setor. Kon (2004) destaca o aumento observado no número de franquias estrangeiras no período entre 1996 e 
2000, em segmentos variados, dentre eles, os das lavanderias. Essas empresas utilizam padrões da matriz e, por vezes, atuam com estratégia de redução dos preços dos serviços, visando o aumento da demanda;

d) A mudança de comportamento do consumidor típico das lavanderias domésticas (classes $\mathrm{A}$ e B), que hoje consome peças de vestuário com uma série de tecidos mais variada se comparados com o final do século passado, demanda o aperfeiçoamento maior das lavanderias nos processos de lavagem, conhecimentos especiais na área têxtil e na operação de retirada de manchas;

e) A aprovação das alterações nas leis trabalhistas dos empregados domésticos em regime de jornada de trabalho mensal provocou aumento no custo desse serviço às famílias de classe média, tornando inviável financeiramente sua continuidade em muitos lares. Este cenário apontou para um aumento na demanda de serviços de lavanderias pelas famílias que não contam mais com empregados domésticos em regime contínuo;

f) Órgãos de preservação ambiental, controle sanitário e controle de efluentes têm voltado seus olhos, ainda que de modo tímido, no tocante a carga de efluentes líquidos lançados pelas lavanderias domésticas na rede de esgotos municipais;

g) Mudanças na legislação trabalhista vêm aumentando o custo da mão de obra em lavanderias e, consequentemente $o$ aumento das despesas fixas e do preço final dos serviços;

h) Presença de empresas não legalizadas com custos mais baixos em razão do não pagamento dos tributos e obrigações legais reduzem as margens de lucro das empresas legalizadas por estabelecerem patamares de preços mais baixos no mercado; e

i) Os negócios mais antigos são afetados por empresários que adentram agora no mercado e que, em parte, são oriundos de empresas multinacionais ou nacionais, onde ocupavam cargos administrativos com foco na competitividade e gestão financeira. 


\subsection{Problema de Pesquisa}

O setor de serviços tem peculiaridades que o diferenciam no tocante à sua relação com o mercado consumidor, se comparado ao setor industrial. $O$ acirramento da concorrência em serviços diretos ao consumidor final leva a um cenário de elevada competição com a perda de lucratividade e pouca diferenciação entre as micro e pequenas empresas de serviços. Por outro lado, a mudança contínua do mercado e a formação de grupos de consumidores com necessidades específicas, muitas vezes, não atendidas, aumentam as oportunidades para criação de serviços diferenciados. Nesse contexto, o processo de inovação ainda não é claro, pois as empresas optam por atuarem em diversas frentes em áreas diferentes ao mesmo tempo, sem um planejamento de como gerir esse processo de modo a maximizar os resultados rumo à melhora de seu desempenho. Não é claro também que os diferentes tipos de inovação melhorem o desempenho das empresas de serviços, particularmente, as pequenas e médias empresas (PMEs) (MC DERMOTT; PRAJOGO, 2012).

O entendimento da adoção da inovação e os resultados obtidos após a introdução da inovação em empresas de serviços vêm sendo sido estudado com maior ênfase por pesquisadores nas últimas duas décadas. A necessidade de compreender 0 processo de inovação nas empresas de serviços norteou o trabalho de Vasconcellos e Marx (2011), cuja questão principal do estudo foi "como ocorrem as inovações no setor de serviços?". Por outro lado, as pesquisas e estudos sobre a adoção da inovação por micro e pequenas empresas de serviços, sobretudo aquelas que se dedicam à prestação de serviços pessoais, como as lavanderias domésticas, são raros.

Mansury e Love (2008) referem que as métricas, que são padrões nas pesquisas de manufatura de bens, como produção de pesquisa e desenvolvimento e número de patentes, podem ser pouco significativas para serviços. Em seu estudo sobre empresas de serviços, os autores utilizam métricas de desempenho por meio de valor adicionado por funcionário (receitas menos custos operacionais divididas pelo número de funcionários) como medida indireta da produtividade por funcionário e crescimento em vendas (\%), como medida indireta de competitividade. 
Assim, o problema de pesquisa buscou entender quais são as práticas que levam à inovação e quais são os tipos de inovação utilizado pelas micro e pequenas lavanderias domésticas, classificadas como prestadoras de serviços pessoais (IBGE, 2007 e 2010) em suas áreas de atuação, assim como os impactos decorrentes da adoção desses tipos de inovação com relação à competitividade e produtividade:

"Qual é a percepção dos empresários sobre as práticas de inovação no segmento das lavanderias domésticas que contribuem para a melhora da produtividade e competitividade?"

\subsection{Objetivos da Pesquisa}

\subsubsection{Objetivo Geral}

Este estudo tem o seguinte Objetivo Geral:

Verificar a percepção dos proprietários das lavanderias domésticas sobre a influência da adoção da inovação na competitividade e produtividade de seus negócios.

\subsubsection{Objetivos Específicos}

Este estudo tem como Objetivos Específicos:

a) Estudar a adoção de Inovações de Processo, Marketing e Organizacional pelas lavanderias domésticas e seu inter-relacionamento;

b) Verificar a influência das Inovações de Processo, Marketing e Organizacional na melhora da competitividade e produtividade nas lavanderias domésticas; 
c) Desenvolver uma estrutura conceitual (framework), inter-relacionando os tipos de inovação adotados com a competitividade e produtividade para o negócio nas lavanderias domésticas.

\subsection{Justificativa}

Conforme aponta Jacobini (2011), a justificativa de um projeto de pesquisa indica a relevância do estudo proposto ou dos ganhos que ele possa trazer em conhecimentos teóricos ou problemas práticos. Os estudos acadêmicos sobre inovação em micro e pequenas empresas de serviços têm maior foco nas empresas que atuam em segmentos que desenvolvem primariamente tecnologia (ex.: tecnologia da informação, comunicação). Mas, segmentos como o de serviços pessoais, que atua diretamente prestando serviços ao consumidor final (ex.: lavanderias domésticas), podem utilizar a combinação de diversos tipos de inovação como fator de diferenciação. Também não foi encontrado um modelo que pudesse explicar porque micro e pequenas empresas de serviços adotam múltiplos tipos de inovação concomitantemente, se existe inter-relação entre eles e o impacto da inovação na competitividade e produtividade dessas empresas.

As micro e pequenas empresas de serviços vêm sendo expostas a uma intensa concorrência, sobretudo nas grandes cidades, o que leva a uma necessidade premente de reavaliação do negócio, não só na área operacional, mas, notadamente estratégica, objetivando ganho de participação de mercado, aumento de lucratividade e sustentabilidade do negócio.

O segmento das lavanderias domésticas é representado, predominantemente, por micro e pequenas empresas (FIESP, 2010; SEBRAE, 2011), ao passo que as lavanderias industriais (hoteleira, institucional e hospitalar) têm portes variados, podendo estar enquadradas como micro, pequenas, médias e grandes empresas, a depender do faturamento anual. Conforme discutido na introdução deste estudo, a necessidade de mudança do foco imediatista e operacional para o inovador/estratégico, como uma condição de sobrevivência e longevidade das micro 
e pequenas empresas prestadoras de serviços de lavagem de roupas, é evidenciada pelas associações representativas desse setor.

A utilização da inovação como ferramenta para a diferenciação e melhora da competitividade poderá trazer benefícios palpáveis a esse segmento, mesmo às redes internacionais de lavanderias, que trouxeram novos conceitos em termos tecnológicos e administrativos quando iniciaram suas atividades no País.

A escolha da cidade de São Paulo foi alicerçada pela diversidade dos tipos de lavanderias domésticas (franquias, independentes, em bairros próximos ou mais distantes do centro, em locais tipicamente residenciais ou comerciais, entre outros) e por ser a cidade que concentra o maior número de lavanderias do País (item 3.3.1). Alguns autores estudaram a inovação e os grandes aglomerados urbanos como amostras escolhidas em suas pesquisas.

A relação entre inovação, aglomeração e desenvolvimento regional de clusters de pequenas empresas foi estudada por Gordon e Mc Cann (2005). Os autores relacionaram geografia e aglomeração com inovação e estudaram uma cidade de grande porte (Londres). As razões alegadas pelos autores para a escolha de uma cidade de grande porte foi a qualificação da força de trabalho, melhores conexões internacionais, o acesso mais rápido a decisores em áreas diversas, fornecedores especializados e proximidade de universidades e instituições públicas de pesquisa.

Porter (1993), ao abordar o papel da concentração geográfica na competitividade, afirmou que as empresas por estarem próximas geograficamente estão ligadas à concentração de clientes significativos, proximidade com fornecedores, fluxo de informações e visibilidade, o que auxilia no desenvolvimento de eficiências e especialização. Mas, o autor enfatiza que o mais importante na concentração geográfica é a melhoria e inovação. Com relação à indústria de serviços, Porter (1993) indica que a localização geográfica exerce papel significativo em algumas indústrias pela proximidade com uma grande massa de consumidores e fornecedores especializados (p. ex.: automação de serviços) leva a uma maior competitividade nos segmentos onde atuam. 
A inovação em pequenas e médias empresas (PMEs) em economias locais foi estudada por Martínez-Roman, Gamero e Tamayo (2011). Os autores direcionaram sua pesquisa para uma cidade (Sevilha, na Espanha) e analisaram a capacidade inovadora (relacionada à cultura organizacional, processos internos e capacidade de responder a mudanças ambientais) das pequenas empresas daquela região. $E$ concluíram que os indicadores que medem a inovação em nível regional não oferecem dados suficientes para analise das características organizacionais das empresas e planejamento de políticas para inovação territorial. 


\section{REFERENCIAL TEÓRICO}

A abrangência do tema inovação em micro e pequenas empresas de serviços nos remete a definições e conceitos teóricos relevantes que serão discutidos no presente estudo. A pesquisa documental teve como objetivo afunilar os conceitos, desde os dois grandes temas "inovação" e "serviços" e sua relação com as micro e pequenas empresas (particularizando para lavanderias domésticas), assim como a influência na competitividade e produtividade dessas empresas. As bases pesquisadas foram:
a) ISI of Knowlege/Web of Science
b) Pro-Quest
c) Portal CAPES
d) Scopus
e) Science Direct
f) Wiley On Line Library
g) Scielo
h) CrNET Base
i) Mendeley
j) Dedalus (Banco de Dados Bibliográficos da USP)
k) Biblioteca Digital da Produção Intelectual da Universidade de São Paulo (BDPI)
I) Biblioteca Brasileira de Teses e Dissertações
m) FGV Catálogo On-Line

Os periódicos pesquisados foram:
a) Journal of Service Research
b) Journal of Product Innovation Management
c) Future Studies Research Journal: Trends and Strategies
d) Portal de Periódicos Unisul
e) RAC (Revista de Administração Contemporânea)
f) RAl (Revista de Administração e Inovação)
g) RAUSP (Revista de Administração da Universidade de São Paulo)
h) REAd (Revista Eletrônica da Universidade Federal do Rio Grande do Sul)
i) Revista de Administração Mackenzie 
Os dados da Figura 2 mostram a estrutura básica dos tópicos do referencial teórico e sua interação com o problema de pesquisa e objetivos (geral e específicos).

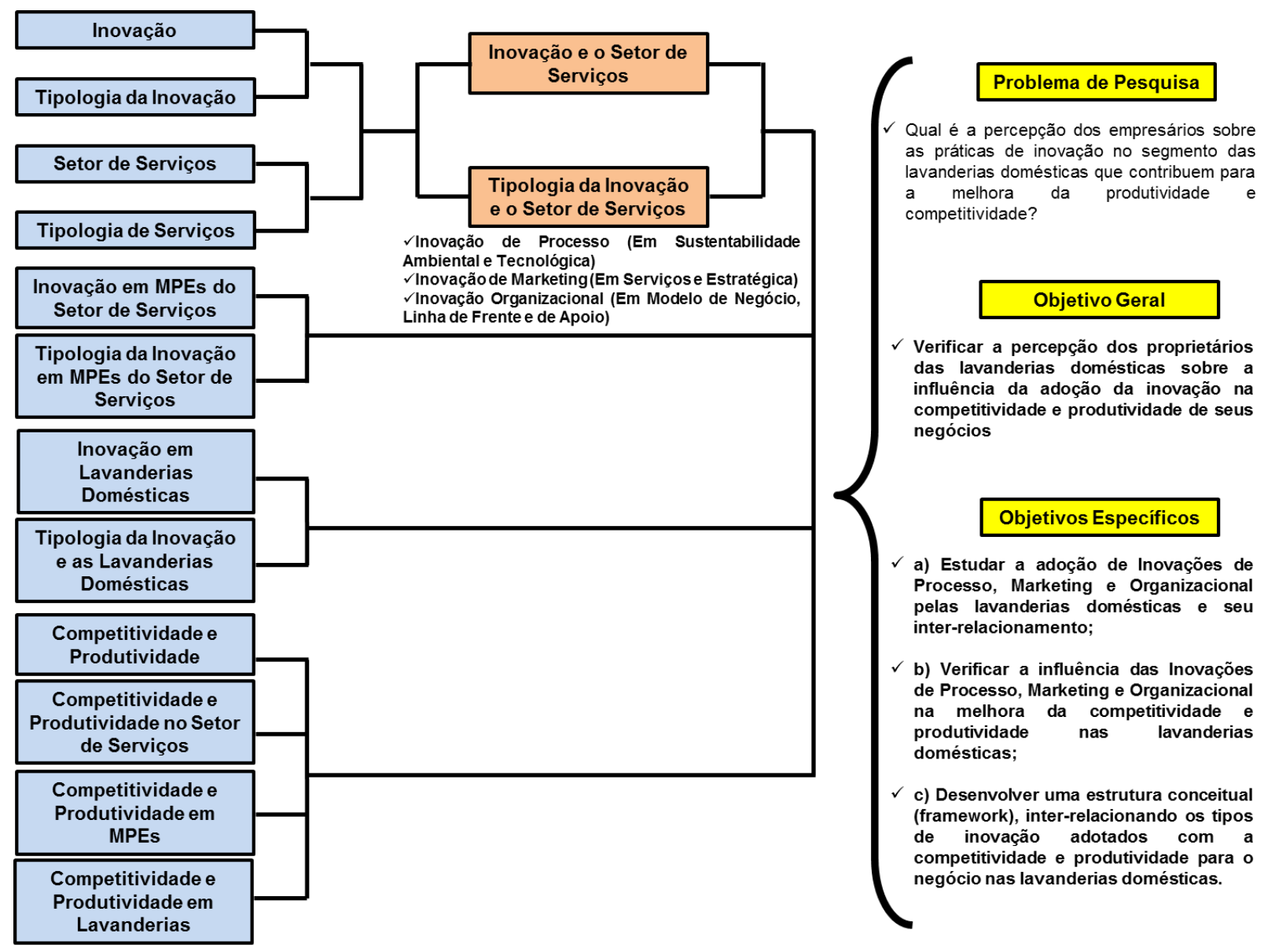

Figura 2: Estrutura Básica Referencial Teórico, Problema de Pesquisa e Objetivos Elaborado pelo autor

\subsection{Inovação e Tipologia da Inovação}

\subsubsection{Conceito de Inovação}

Inicialmente, a definição de inovação foi associada a um novo produto/serviço ou a um novo processo para produzi-lo, a fim de obter vantagem estratégica por meio da destruição criativa defendida por Schumpeter (1942). A insatisfação do autor, considerado o pai dos estudos de inovação (TIDD; BESSANT; PAVITT, 2008), com 
a acomodação da tecnologia na década 1950 foi traduzida na frase "o progresso tecnológico está tornando-se um negócio de times de especialistas treinados que produzem o que é necessário e o faz trabalhar de modo previsível". Mas, com a presença da inovação em setores como os de serviços e as mudanças nas áreas mercadológica e organizacional, esta definição foi sendo ampliada progressivamente, de modo a adaptar-se aos novos modelos de negócios.

Ao estudar a inter-relação entre os tipos de inovação, Walker (2007) ampliou o conceito e definiu inovação como o processo pelo qual novas ideias, objetos e práticas são criados, desenvolvidos ou reinventados, e que são novos para a unidade de adoção.

Em sua primeira edição em 1992, o Manual de Oslo estava centrado na inovação tecnológica de produto e processo na indústria de transformação. No entanto, foram realizados estudos utilizando o Manual para pesquisar a natureza e os impactos da inovação no setor comercial, que levaram a mudanças em conceitos, definições e metodologia e que foram abrangidos na segunda edição do Manual em 1997, expandindo o escopo também ao setor de serviços, mas, ainda tendo como alvo principal a indústria de transformação. Já a terceira edição (2005), adiciona a questão das inovações chamadas não tecnológicas ou voltadas a indústrias menos intensivas em pesquisa e desenvolvimento, como o setor de serviços, o que levou a mudanças em definições, de modo a abranger também este setor:

Uma inovação é a implementação de um produto (bem ou serviço) novo ou significativamente melhorado, ou um processo, ou um novo método de marketing, ou um novo método organizacional nas práticas de negócios, na organização do local de trabalho ou nas relações externas (Manual de Oslo, 2005, p.55).

Na opinião dos autores do Manual, a inovação em serviços difere da inovação em indústrias de transformação por serem organizadas de modo menos formal, de natureza mais incremental e menos tecnológica. As mudanças levaram também à inclusão de dois novos tipos de inovação: inovação organizacional e inovação de marketing. 
Com esta definição mais abrangente, os autores argumentam que "o requisito mínimo para se definir uma inovação é que o produto, o processo, o método de marketing ou organizacional sejam novos (ou significativamente melhorados)..." (Manual de Oslo, 2005, p. 56).

A literatura que trata da inovação enfatiza o fato da inovação ser capaz de trazer resultados ou agregue valor, tanto na área social como na geração de riqueza ou lucro para quem a adota. Tidd; Bessant e Pavitt (2008, p.23) enfatizam que "a inovação é movida pela habilidade de estabelecer relações, detectar oportunidades e tirar proveito das mesmas".

\subsubsection{Tipologia da Inovação e seu Inter-relacionamento}

A distinção entre os tipos de inovação é uma condição essencial para entender a adoção da inovação. Para Walker (2007), se a inovação baseia-se em atividades incrementais, é necessário considerar as relações complementares entre os diferentes tipos de inovação. Em seu trabalho, estudou os antecedentes dos processos organizacionais e ambientais em serviços com um exame dessas relações complementares entre os tipos de inovação, identificados como: inovações em serviços, inovações no processo organizacional (com foco em inovações de mercado e inovações na organização) e inovações auxiliares (fora das fronteiras da empresa). Os resultados revelaram que os antecedentes dos diversos tipos de inovação são complexos e que as relações complementares não são generalizadas, exemplificando que estruturas orgânicas facilitam a adoção de inovações de serviço e organizacional, mas não inovações de marketing e auxiliares.

O autor supracitado também estabeleceu uma relação direta com os usuários da inovação, identificando três tipos de inovações em serviços com base nessa relação: inovações totais (envolvendo novos serviços para novos usuários), inovações expandidas (envolvendo serviços existentes para novos usuários) e inovações evolutivas (envolvendo novos serviços para usuários existentes). Ao abordar as inovações com foco na organização, definiu as inovações em processos 
organizacionais como aquelas que afetam a gestão e a estrutura e estão relacionadas em como os serviços são prestados. As inovações em processos organizacionais são subdivididas em dois tipos: inovações de mercado, que envolvem os processos operacionais da organização e sistemas e aumentam a eficiência em produzir e entregar seus serviços aos usuários e as inovações da organização, relacionadas à estrutura, estratégia e processos administrativos. $O$ autor identificou um grupo chamado inovações auxiliares, que são diferenciadas de outros tipos de inovação, pois estão relacionadas com o ambiente externo (outros provedores de serviços, usuários e outras organizações) e ligadas a outros tipos de inovação.

Andreassi (2007) definiu quatro tipos básicos de inovação: de produto (introdução de um novo produto ou serviço ou melhoria substancial dos já existentes), de processo (introdução de novos processos produtivos ou alterações nos já existentes), de gestão (introdução de novidades que modificam os processos administrativos, o modo como as decisões são tomadas, alocação de recursos, atribuição de responsabilidades, relacionamentos com pessoas e outras organizações, sistema de recompensas e outras ligadas à gestão da organização) e inovação de modelo de negócios (quando ocorre a modificação na essência do negócio).

Rowley; Baregheh e Sambrook (2011) argumentam que um fator-chave na literatura sobre inovação é o tipo de inovação, pois a grande quantidade de modelos, frameworks, classificações e definições dos tipos de inovação torna difícil entender as definições dos diferentes tipos e a relação entre eles. Os autores analisam os modelos e estruturas básicas (frameworks) dos tipos de inovação:

a) Modelos Iniciais: inovação na estrutura organizacional, processo de produção, pessoas e produtos/serviços;

b) Modelos das décadas de 1970 e 1980: inovação administrativa, técnica, incremental, radical, de produto e de processo;

c) Modelos integrativos: inovação de produto (radical e incremental), de serviço e de processo (incluindo administrativo, serviço e produção), de posição e de paradigma; 
d) Modelos com foco binário: produto/processo, administrativo/técnico, radical/incremental; e

e) Modelos clássicos: novos produtos, novos processos, novos métodos de produção, abertura de novos mercados, novas fontes de suprimentos e novas maneiras de organizar.

Com base nesta revisão bibliográfica, Rowley, Baregheh e Sambrook (2011) indicaram um diagrama abrangente dos tipos de inovação e os autores principais, buscando uma ferramenta de mapeamento dos tipos de inovação, conforme dados da Figura 3 apresentam:

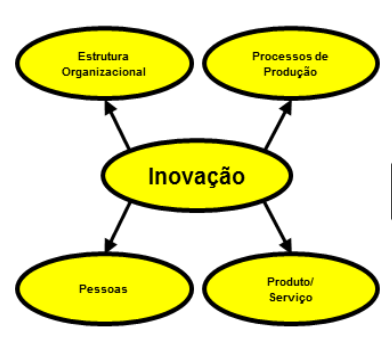

Knight (1967)
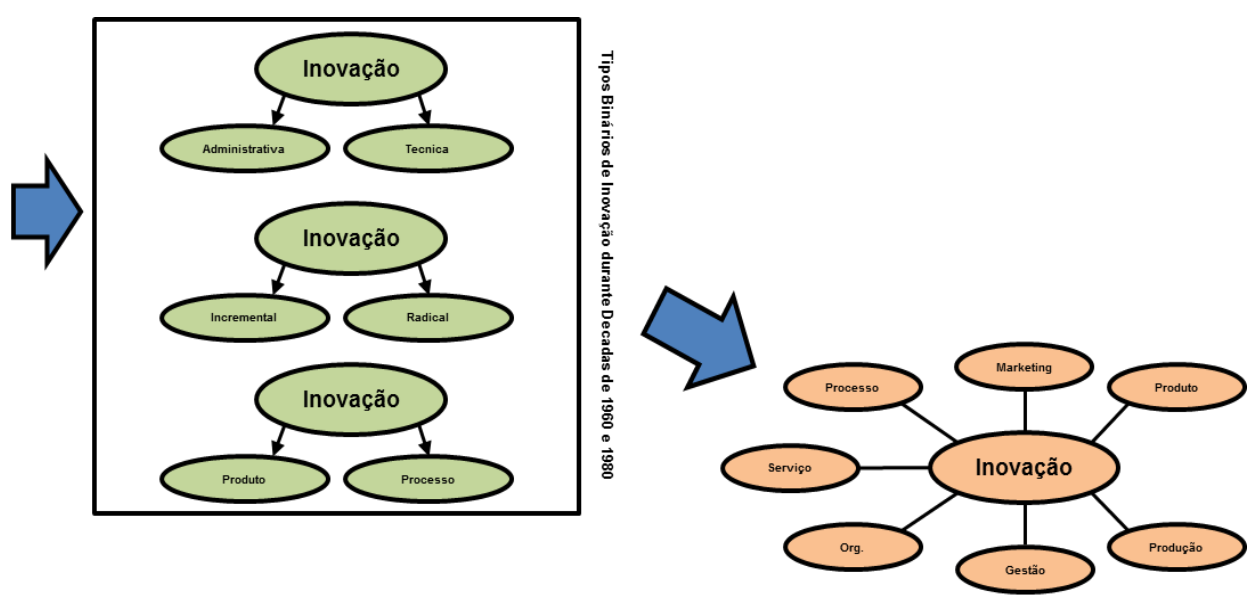

Trott(2005)

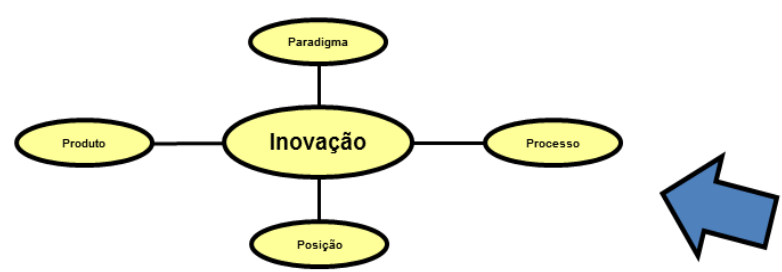

Francis e Bessant(2005)

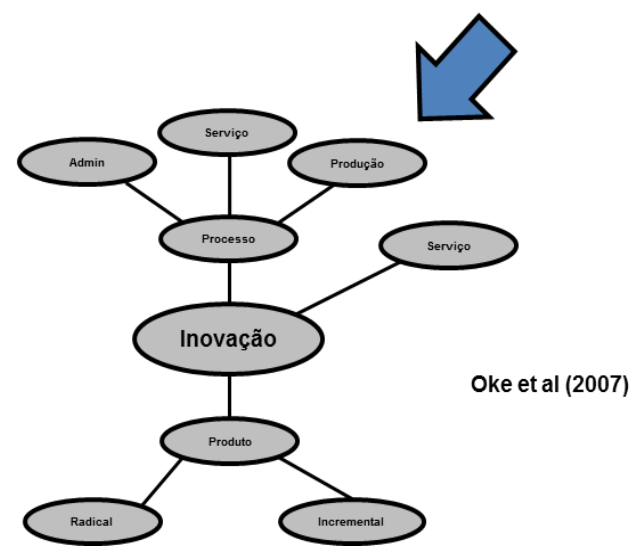

Figura 3: Tipologias de Inovação, do passado ao presente

Fonte: Rowley; Baregheh e Sambrook; (2011, p. 81). 
O Manual de Oslo (2005) traz em sua terceira edição quatro tipos básicos de inovação atrelados às atividades das empresas: inovações de produto, inovações de processo, inovações organizacionais e inovações de marketing.

Damanpour; Walker e Avellaneda (2009) estudaram os efeitos combinados dos tipos de inovação e desempenho organizacional em organizações de serviços, adotando quatro tipos básicos de inovação nessas empresas: inovações de serviço, de processos, de processos tecnológicos e de processos administrativos. Ainda na linha do inter-relacionamento entre os tipos de inovação, Zmoginski et al. (2009) referem que a interação entre inovação tecnológica e inovação em modelo de negócio (usada pelos autores como sinônimo de inovação organizacional) mostra que uma pode ser decorrente da outra e também podem ser combinadas.

Os autores supracitados acrescentaram que, em seu estudo, também a inovação em modelo de negócio esteve aliada a outros tipos de inovação, como inovação de produto e de serviço, abrangendo um leque de oportunidades e não só um tipo de inovação. Ades e Plonski (2009) estudaram a visão integrada do portfólio de inovações e inseriram a inovação de modelo de negócio no portfólio de inovações das empresas, como uma alternativa importante no redirecionamento dos vetores competitivos, salientando a sinergia entre as inovações adotadas (tecnológicas, processos, entre outras).

Hipp e Grupp (2005) também estudaram a mensuração da inovação no setor de serviços, e a introdução de uma nova tipologia para o entendimento da inovação nesse setor, tomando por base o tipo de empresa e o comportamento inovador: inovação intensiva em conhecimento (considera clientes, universidades e institutos de pesquisa como fontes de conhecimento externo), inovação em rede (informação e comunicação em rede), inovação intensiva em escala (dependem de padronização) e inovação por domínio de fornecedores (inovação suprida de fora da empresa).

Gunday et al (2011) exploraram três tipos de inovação (de processos organizacionais, de produto e marketing) no desempenho da empresa, estabelecendo hipóteses que inter-relacionam os tipos de inovação e o desempenho 
inovador, que é a combinação de vários aspectos na inovatividade, como processos, produtos e estrutura organizacional nas empresas.

Os supracitados autores indicam que as empresas precisam estar atentas a muitos aspectos simultaneamente, como novos produtos, novas práticas organizacionais e de marketing, sistemas administrativos e novos processos tecnológicos. Ponderam ainda que, embora a literatura sobre inovação não conclua que uma inovação específica impacta mais ou menos no desempenho corporativo, pode-se afirmar que as inovações influenciam-se entre si e devem ser aplicadas em conjunto. Algumas das conclusões do estudo de campo foram relevantes para a análise do interrelacionamento entre os diversos tipos de inovação (tipologia baseada no Manual de Oslo de 2005): primeiro, a relação entre inovação organizacional e inovação de produto não foi significativa, porém a inovação organizacional prepara um ambiente adequado para outros tipos de inovação e também tem um impacto forte e direto no desempenho inovador; segundo, a inovação de produto atua como uma ponte com um impacto positivo na inovação de processo no desempenho inovador.

O desempenho das PMEs (Pequenas e Médias Empresas) em crescimento e os tipos de inovação foram estudados por Oke; Burke e Myers (2007a). Os autores constataram a falta de literatura sobre inovação em PMEs, sobretudo a respeito dos tipos de inovação adotados por essas empresas e a conexão entre inovação em PMEs e desempenho/crescimento econômico. Os tipos de inovação abordados pelos autores foram inovação de produto, de serviços, de processo e organizacional, direcionando as perguntas da pesquisa empírica quantitativa a uma amostra de 784 PMEs, com uma taxa de retorno de respostas de $13,8 \%$.

Os autores supracitados concluíram que existe um maior direcionamento das PMEs para a inovação incremental (traduzida em melhora de produtos, serviços e/ou processos em resposta às necessidades dos consumidores) do que para a inovação radical. Estes resultados mostram a tendência das PMEs em alcançar crescimento introduzindo mais seus produtos e serviços para seu mercado existente, via inovação incremental. Não foi encontrada relação entre a idade das empresas e as inovações radicais ou incrementais que, de certa maneira, não segue a intuição de 
que PMEs mais novas são mais direcionadas à inovação radical que as mais antigas no mercado.

\subsection{O Setor de Serviços}

\subsubsection{Definição e Abrangência do Setor de Serviços}

A análise da inovação de serviços passa por uma definição mais abrangente e atualizada da atividade de serviços. Kon (2004, p.25), quando analisou a teoria e a evolução da economia de serviços e seu impacto no Brasil, definiu serviços como "atividades econômicas que produzem utilidades relativas a tempo, lugar, forma e benefícios psicológicos" e ponderou que as atividades de serviços, "tanto facilitam a produção e distribuição de bens quanto atendem a necessidades da vida pessoal dos indivíduos".

A autora supracitada indica que as características particulares na produção de serviços acarretam uma dificuldade em mensurar o volume real de serviços conhecidos, já que são intangíveis e que o sentimento comum é que produzem utilidade imediata ou em curto espaço de tempo. Em seu estudo, resume as definições existentes na literatura:

a) Indústria de serviços: indústria que produz serviços em lugar de bens;

b) Serviços: bens de consumo ou intermediários intangíveis e, em geral, consumidos ao mesmo tempo em que são produzidos e intensivos em trabalho; e

c) Serviços têm como característica serem consumidos no ponto de sua produção.

Zeithaml e Bitner (2011, p.39) resumiram a definição de serviços com foco na entrega como "atos, processos e atuações oferecidos ou coproduzidos por uma entidade ou pessoa, para outra entidade ou pessoa". Os autores comparam produtos e serviços, ressaltando as quatro características de serviços: 
a) Intangibilidade (versus a tangibilidade dos produtos): não podem ser tocados como um bem tangível;

b) Heterogeneidade (versus a padronização dos produtos): são ações muitas vezes executadas por seres humanos e dependem de muitos fatores incontroláveis;

c) Produção e consumo simultâneos (versus a produção separada do consumo nos produtos): normalmente, são vendidos com antecedência e depois gerados e consumidos simultaneamente, com a participação dos clientes e funcionários, afetando o desfecho do serviço; e

d) Perecibilidade (versus a não perecibilidade dos produtos): não podem ser armazenados, gravados, revendidos ou devolvidos.

Com relação às operações de serviços, Gianesi e Corrêa (1996) definiram como a parte da organização que é responsável por produzir serviços e com interface com outras funções da empresa, tendo diferenças básicas com as operações em manufatura por suas especificidades, a saber: ênfase dada a pessoas ou equipamentos no processo, grau de contato com o cliente (front office ou linha de frente com alto contato e back office ou back room ou retaguarda com baixo contato), participação do cliente no processo, personalização, julgamento pessoal dos funcionários e grau de tangibilidade do serviço.

Existem muitas definições de serviços, conforme citam Fitzsimmons e Fitzsimmons (2010, p.26), e todas consideram a intangibilidade e o consumo simultâneo como características. Os autores definem serviços levando em conta algumas características chamadas diferenciadoras dos mesmos (perecibilidade, intangibilidade e participação dos clientes): "um serviço é uma experiência perecível, intangível, desenvolvida para um consumidor que desempenha o papel de coprodutor"; assim, relevam a importância dos serviços na economia, conforme é mostrado nos dados da Figura 4. 


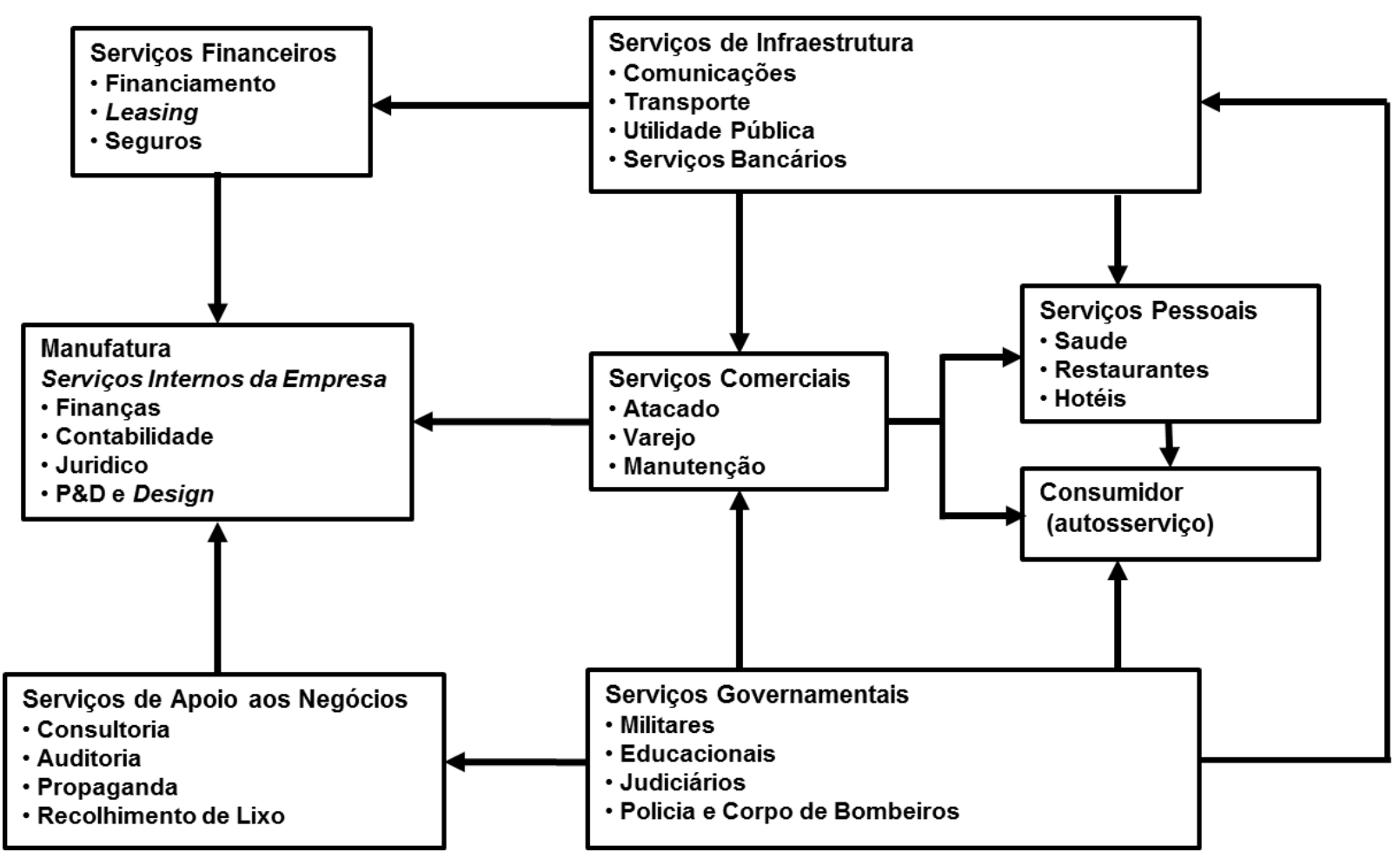

Figura 4: Papel dos Serviços na Economia

Fonte: Fitzsimmons, J. A; Fitzsimmons, M. J., (2010, p. 27).

Kandampully (2002) indica que a competência de uma empresa de serviços é derivada de várias redes de relacionamentos das partes interessadas, como consumidores, funcionários, varejistas, fornecedores e acionistas, conforme mostram os dados da Figura 5. 


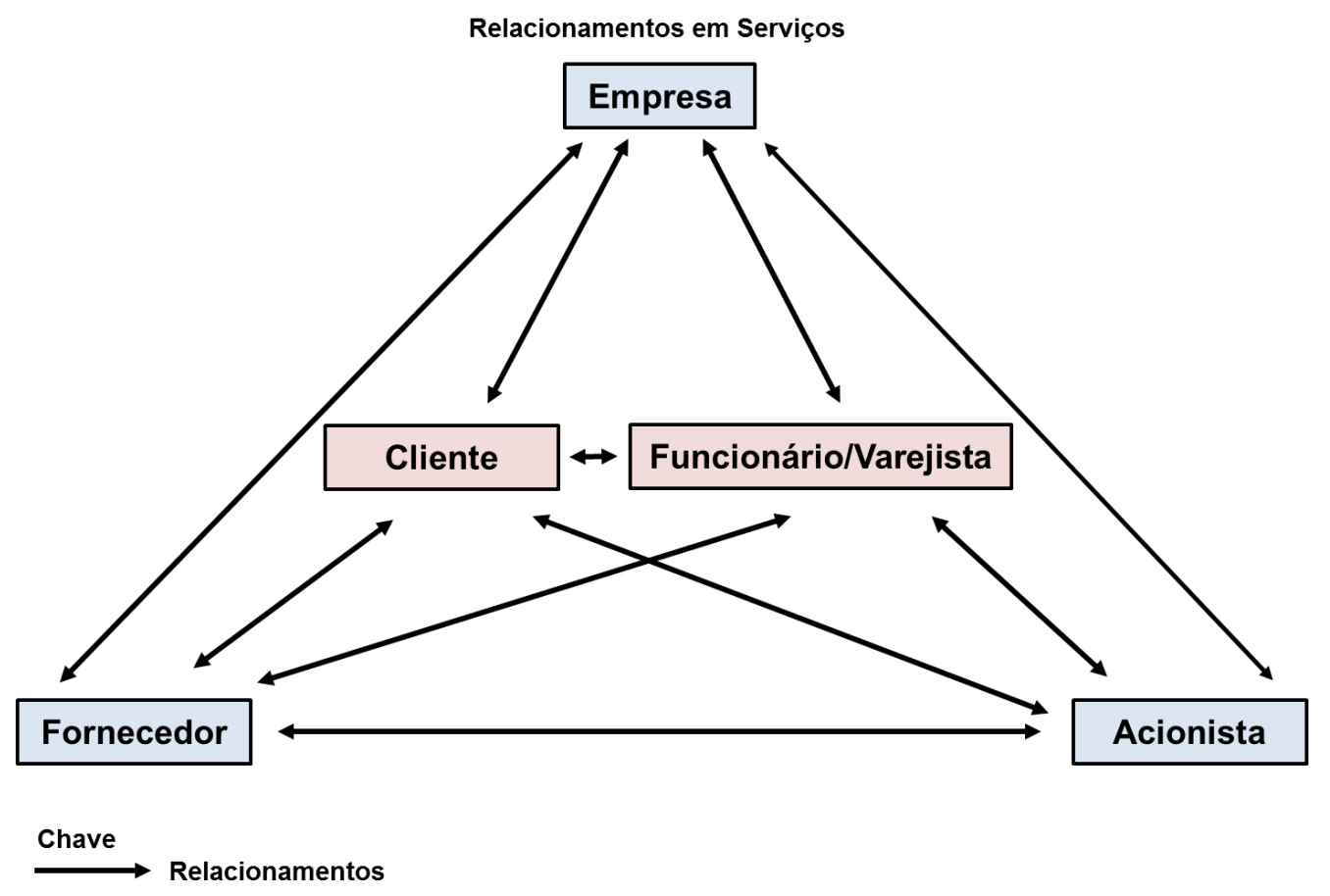

Figura 5: Relacionamentos em Serviços

Fonte: Kandampully, J., (2002, p. 22).

\subsubsection{Tipologia de Serviços}

Cook, Goh e Chung (1999) ponderaram que, embora os termos tipologia, taxonomia e classificação tenham sentidos diferentes, são usados de modo livre e intercambiável na literatura. Os autores direcionaram seu estudo para o termo "tipologia" e realizaram uma revisão bibliográfica sobre o tema "tipologia de serviços" na literatura acadêmica, abrangendo um período de quatro décadas. Utilizaram perspectivas históricas com o objetivo de entender as características que diferenciam as organizações de serviços. Os autores indicaram que o termo tipologia de serviços apareceu, formalmente, na literatura na década de 1960, a partir da divisão da economia, na década de 1940, em primária (agricultura), secundária (manufatura) e terciária (serviços).

Após a década de 1970, os serviços aproximaram-se de uma perspectiva de gestão de operações. Houve um crescimento na literatura de um grande número tipologias de serviços no período de 1970 até metade da década de 1980, com uma diminuição na pesquisa nessa área até o final da década de 1980. Outra 
constatação dos referidos pesquisadores foi que a maioria das tipologias de serviços tem foco nas saídas (serviços entregues pelas empresas) e poucos autores consideram a organização que fornece o serviço. Após essa análise histórica sobre a tipologia de serviços, os pesquisadores desenvolveram uma representação esquemática unificada, que capturou todas as dimensões importantes relatadas historicamente na literatura acadêmica sobre o tema, conforme mostram os dados da Figura 6.

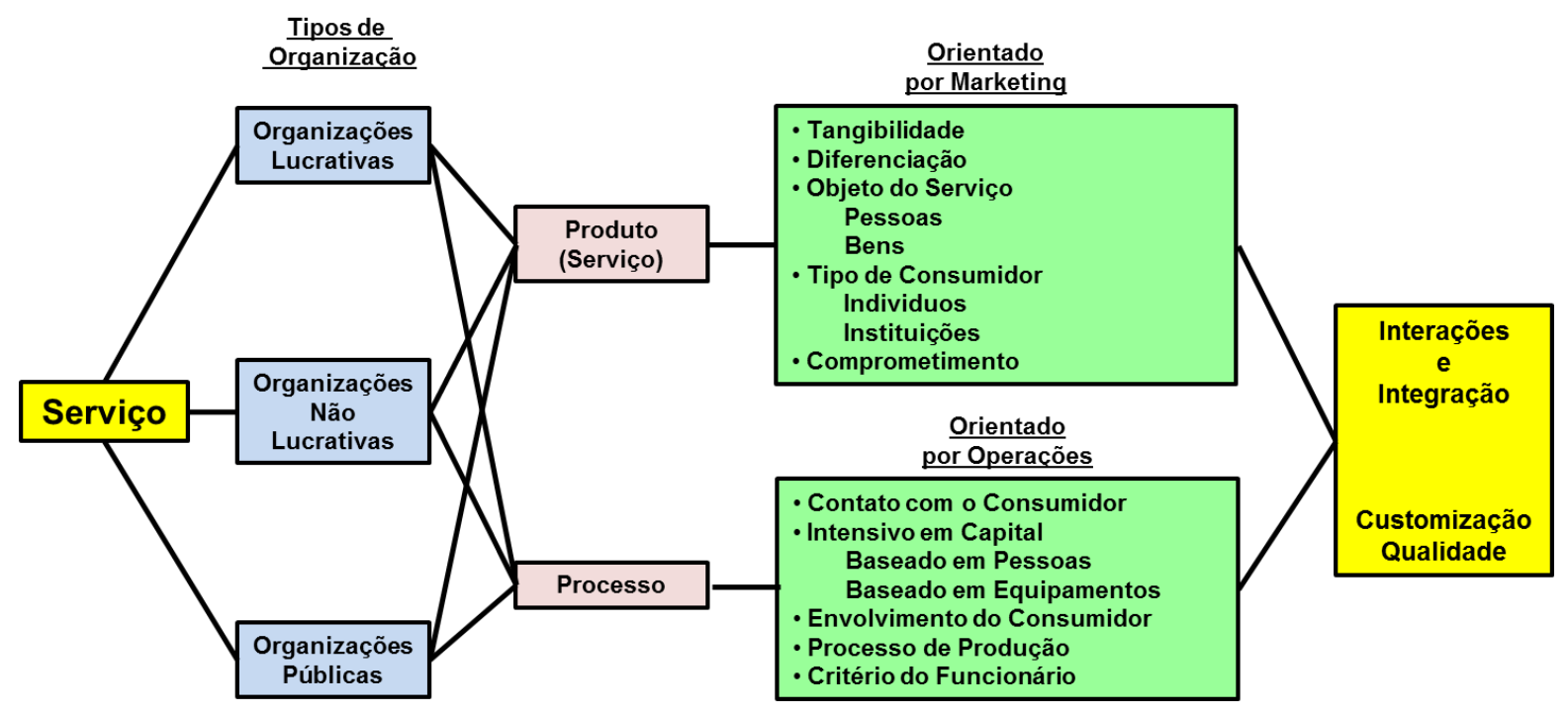

Visão Macro

Visão Micro

Ambiente Social/Econômico

Figura 6: Dimensões da Tipologia de Serviços e seu Inter-relacionamento Fonte: Cook, Goh e Chung, (1999, p. 325).

As dimensões estudadas (Figura 6) pelos pesquisadores foram: tipo de organização (lucrativas, não lucrativas, públicas); pacote de produto (tangíveis e intangíveis) e processo pelo qual o serviço é entregue; orientado por marketing (tangibilidade, diferenciação, objeto do serviço, tipo de consumidor, envolvimento) e orientado por operações (contato com o consumidor, intensivo em capital, envolvimento do consumidor, processo de produção do serviço, funcionários). 
Verma (2000) estudou os desafios de gestão dos quatro tipos de empresas de serviços classificados por Schmenner (1986) em sua matriz de processo de serviço. Com base nessa matriz, o autor desenvolveu um diagrama, como mostra a Figura 7, correlacionando as características dos quatro tipos de empresas (fabrica de serviços, loja de serviços, serviços de massa e serviços profissionais) com as variáveis que abrangem 0 universo empresa/consumidor e 0 tipo de tarefa (intensidade da tarefa, contato com o consumidor e customização do serviço). O diagrama contempla em sua periferia a inter-relação entre essas variáveis e os desafios na gestão de cada tipo de empresa de serviço.

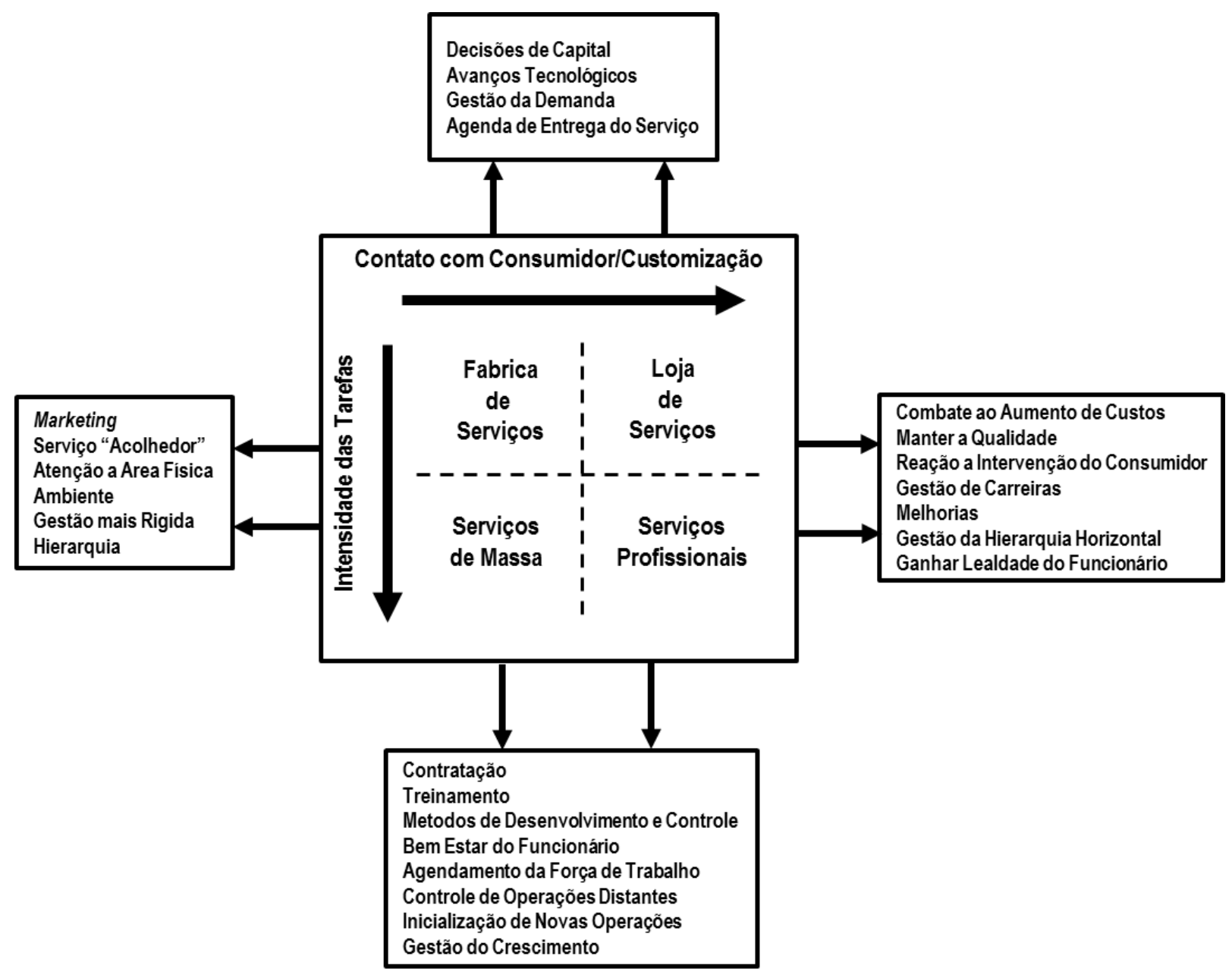

Figura 7: Desafios na Gestão dos Diferentes Tipos de Empresas de Serviços Fonte: Verma, (2000, p. 20).

O setor de serviços inclui atividades de baixa complexidade, como serviços de limpeza, mas também serviços pessoais especializados (BESSANT; TIDD, 2009), 
que demandam conhecimento específico que os diferencia. Nessa direção, Hauknes (1998) afirma que a relação entre inovação e o setor de serviços é complexa, sendo necessário classificar o setor de serviços por meio de várias dimensões voltadas ao uso de tecnologias e habilidades profissionais e tácitas:

a) Serviços que utilizam tecnologias manufaturadas e bens de capital (ex.: distribuição, serviços financeiros, serviços de manutenção e reparos);

b) Serviços baseados na criação e uso de capacidades tecnológicas e funcionais (consultoria de negócios, serviços de pesquisa e desenvolvimento, desenho industrial, consultoria em engenharia, desenvolvimento de softwares e sistemas e serviços ambientais);

c) Serviços baseados na aplicação de habilidades profissionais e competências (serviços legais e contábeis); e

d) Serviços baseados em habilidades humanas tácitas (cabeleireiros, restaurantes, desenho de moda e serviços de limpeza)

Bowen (1990) apresentou uma taxonomia de serviços com base empírica, explorando as características comuns aos serviços e baseadas na análise da percepção do consumidor, a saber: importância dos funcionários, customização, habilidade de mudanças, contato funcionário/consumidor, serviços direcionados a pessoas, benefícios contínuos e serviços diferenciados. Pautado nessas características, o autor classificou os serviços em três grupos:

a) Grupo 1: consumidores consideram os funcionários importantes na prestação do serviço (alto contato, customização e serviços personalizados), englobando, por exemplo, alternativas de quartos em hotéis e hospitais, menus diferenciados em restaurantes, entre outros;

b) Grupo 2: nível de contato moderado com o consumidor final e serviços com baixa customização, englobando serviços, como lavanderias domésticas, sapatarias, consertos de roupas, entre outros; e 
c) Grupo 3: nível de contato moderado com o consumidor final e serviços padronizados, englobando cafeterias, restaurantes tipo fast food, estacionamentos, entre outros.

\subsection{A Inovação no Setor de Serviços}

\subsubsection{Visão schumpeteriana de Inovação em Serviços}

Em seu estudo, Drejer (2004) aponta que o conceito original de inovação de Schumpeter (1942) é amplo o suficiente para englobar serviços e manufatura. Ao analisar a perspectiva schumpeteriana, o autor afirma:

a) A inovação na teoria de Schumpeter está relacionada com o desenvolvimento econômico, que é guiado pela emergência de novas combinações (inovações diversas combinadas), que são mais viáveis economicamente que o modo antigo de fazer as coisas;

b) A abrangência do conceito de Schumpeter para a inovação cobre áreas que vão além de um novo produto, mas também de inovação de processo, de mercado, de nova fonte de matéria prima e inovação organizacional; e

c) As consequências de negligenciar os estudos de inovação de Schumpeter com relação a serviços pode prolongar o tratamento do setor como secundário na análise econômica, o que não se justifica pelo volume e crescimento das atividades de serviços.

Para Gallouj (1998), o setor de serviços, que comporta a maior parte do emprego e o valor agregado das economias, não pode estar fora de uma "visão schumpeteriana" clássica de inovação, que é abrangente para produtos e processos. O autor supracitado discute a aplicabilidade das teorias neo-schumpeterianas para serviços (GALLOUJ, 1997). Estas teorias, na prática, adotam uma definição mais ampla de 
inovação em relação à teoria tradicional de Schumpeter (1942), defendendo que as inovações dependem não só da visão econômica dos setores, mas, de um processo institucionalizado (firma). Nesse processo, o empresário inovador influencia o mercado para a demanda da inovação, e a concorrência e competitividade atuam induzindo a inovação.

Em seu estudo, Gallouj (1997) discute a visão de serviços, como elementos pertencentes ao novo paradigma socioeconômico, no qual se criam tecnologias tangíveis e intangíveis. O pesquisador exemplifica o serviço pós-venda na indústria, como uma inovação em serviços, que é originada pela otimização da inovação industrial, a qual é subordinada.

\subsubsection{Conceito e Processo de Inovação em Serviços}

Ao analisarem a inovação no setor de serviços, Tamura et al (2005) indicaram que, dado o papel-chave do setor de serviços na economia, a intensificação das capacidades inovadoras do setor é importante para a melhora do desempenho econômico. Os referidos autores afirmam ainda que o setor de serviços investe menos em pesquisa e desenvolvimento formal e mais na busca da aquisição de conhecimento em fontes externas.

Gallouj (2002) estudou os "mitos" em relação à inovação no setor de serviços. O autor afirma que os serviços são responsáveis por grande parte do emprego nas economias desenvolvidas, mas são descritos como atividades residuais, caracterizadas por baixa produtividade, baixo capital intensivo e baixos níveis de habilidade, além da baixa capacidade inovadora. As ponderações de Gallouj (2002) sobre os chamados "mitos" foram as seguintes:

a) Com relação à visão negativa de setor "residual", periférico e patológico, o autor afirma que as afirmações vêm sendo justificadas, normalmente, por observações que já foram refutadas por fatos que contradizem essas afirmações e pelo crescimento do setor; 
b) Com relação ao mito de baixa produtividade e baixo capital intensivo: os serviços não requerem construção de fábricas e linhas de produção em larga escala com aplicação de recursos, porém, muitas atividades em serviços demandam tecnologias pesadas, como transportes de fluidos, provisão de energia, ar, trem e estradas. Muitos serviços são usuários de tecnologias de informação e comunicação (serviços de processamento de dados, bancos, seguros, entre outros). Por outro lado, as definições de produtividade da indústria não podem ser facilmente aplicadas a serviços, como por exemplo, a elevada produtividade das empresas de distribuição e transporte nos Estados Unidos da América (EUA) e França, sistemas self-service, maquinas de lavagem de carros, entre outros, que utilizam eficientes sistemas tecnológicos para entrega de serviços. A proposta de uma definição menos "industrializada" de produtividade poderia auxiliar na revisão do julgamento de produtividade em serviços; e

c) Sobre a especificidade dos serviços em relação a produtos: serviços não são um "resultado" físico como produto, mas um ato ou processo. Assim, o "produto" nas atividades de serviços é, frequentemente, nebuloso e denota um processo. A relação entre inovação tecnológica e bens manufaturados não é a mesma que entre inovação e serviços. A primeira é intrínseca (provê as características do uso) e a segunda deve considerar a inovação organizacional (serviços podem conter tecnologias a serem usadas, mas, sobretudo contêm competências, sendo interativa entre os diferentes departamentos da empresa).

O autor concluiu que o setor de serviços está se tornando, gradualmente, industrializado e o setor industrial mais orientado a serviços, ou seja, está existindo uma convergência entre bens e serviços com relação à inovação. A inovação em serviços pode tomar diferentes formas, como inovação de processo (que é mais difícil separar da inovação de produto) e uma quantidade considerável de inovação customizada.

Em seu clássico artigo que teve como objetivo auxiliar na formação de uma teoria sobre inovação em serviços, Barras (1986) introduziu o conceito de "ciclo reverso de produto" para as empresas de serviços usuárias de tecnologia. $\mathrm{O}$ autor estudou a adoção e o impacto da tecnologia da informação em empresas de serviços, partindo 
do ciclo clássico de desenvolvimento de produtos (introdução, crescimento e maturidade). A proposta de um modelo de inovação em serviços parte de uma imagem espelhada do clássico, ou seja, o ciclo proposto opera em direção oposta ao ciclo clássico em empresas usuárias de tecnologia. Assim, a nova tecnologia é aplicada no primeiro estágio para aumentar a eficiência dos serviços existentes (já maduros). No segundo estágio, a tecnologia é utilizada para aumentar a qualidade dos serviços (estágio intermediário) e, no terceiro estágio, a tecnologia é usada para auxiliar na geração e introdução de novos serviços. O autor tem como foco a aplicação de tecnologia (sobretudo a tecnologia da informação) no desenvolvimento e melhora de novos serviços. Esta abordagem restringe a abrangência do processo de inovação em serviços que contempla também, por exemplo, o ambiente organizacional e de mercado.

Conforme Gallouj (1997), o modelo de Barras (1986) não leva em conta as tecnologias adotadas que não estão relacionadas à logística de materiais, como nas empresas de limpeza, refrigeração e gastronomia. Ainda discutindo a inovação em serviços sob a ótica do ciclo reverso de Barras, o mesmo autor em outro trabalho (GALLOUJ, 1998) analisou as especificidades do setor de serviços, classificando as empresas de serviços em três categorias: orientação para serviços (intangibilidade em oposição à trajetória tecnológica), integração entre produtos e serviços (em uma só teoria) e orientação tecnológica (introdução de equipamentos e sistemas técnicos em empresas de serviços). O modelo de Barras pertence a esta última categoria. Gallouj (1998) evidencia duas limitações do modelo: visão tecnológica com um viés para inovação de produto via tecnologia da informação e telecomunicações e a análise da terceira fase do ciclo reverso (inovação de produto/serviço) mostra que a empresa necessita efetuar mudanças na infraestrutura e estratégias, já que se refere à produção de novos serviços e não à melhora na eficiência e qualidade dos serviços existentes.

O autor supracitado concluiu que no modelo de Barras (1986) a inovação em serviços não é visualizada independente das possibilidades tecnológicas, ou seja, é limitada em termos de tipo de atividade de serviço e tem uma visão reducionista para novos serviços. Assim, ao analisar o escopo mais abrangente do setor de serviços, observa-se que existem empresas com foco tecnológico, mas também e 
sobretudo empresas em que o relacionamento ocupa posição central (ex.: consultoria e serviços intensivos em conhecimento).

Em seu clássico artigo sobre inovação em serviços, Gallouj e Weinstein (1997), direcionaram seu estudo ao estabelecimento dos fundamentos de uma teoria que pudesse interpretar o processo de inovação em serviços. Os autores tiveram o cuidado de não comparar inovações em serviços e inovação em manufatura, mas investigar como as especificidades de serviços podem levar a reformular a análise da inovação em suas formas. Abaixo, são relacionadas algumas conclusões do estudo:

a) Produtos adquirem uma existência física e fornecem (entregam serviços). Serviços, por sua vez, também podem entregar outros serviços;

b) Os clientes envolvem-se na provisão dos serviços por meio de uma interface física ou virtual, trocando informações (interação) e coproduzindo o serviço;

c) Para bens, assim como para serviços, as características técnicas são conhecimento (competências), porém a provisão de um serviço é, geralmente, o resultado de uma combinação de mecanismos de utilização (tangível ou intangível) de características técnicas que são por si só baseadas em competências;

d) A participação do consumidor na produção de um serviço, de uma forma ou de outra (coprodução ou serviço de relacionamento), é uma das maiores características da provisão de serviços;

e) A melhora de um serviço ou procedimento pode tomar diferentes formas e variar grandemente em escopo. Os autores denominam inovação de aperfeiçoamento a melhora de certas características do serviço sem mudar a estrutura do sistema;

f) A inovação incremental é definida como aquela que pode envolver a adição de novas características a certo tipo de serviço (por mobilização de certas competências ou pela adição de novas características técnicas); 
g) Inovação ad hoc é definida como uma construção interativa de uma solução para um problema particular de um dado cliente, produzindo novos conhecimentos e competências, estando conectada ao processo cumulativo de aprendizado;

h) A inovação recombinada ou inovação de arquitetura explora as possibilidades abertas por novas combinações de várias características técnicas do serviço, derivadas de um estoque de conhecimento e de uma base ou definição de trajetória tecnológica; e

i) A inovação de formalização não é caracterizada por uma variação em quantidade, mas, à visibilidade e ao grau de padronização das várias características dos serviços. No modelo de formalização, as características dos serviços são colocadas em ordem, especificadas, tornando-as concretas e com forma. Esse processo envolve a transformação de uma função em subfunções ou características do serviço (ex.: organização do trabalho em um restaurante fast food, entre outros).

Evangelista (2000) ampliou a abrangência das características da inovação em serviços e estabelece um quadro mais empírico e balanceado da natureza das atividades da inovação em serviços. O autor utilizou os resultados de uma pesquisa efetuada na Itália em seu estudo (entre 1993 e 1995) e confrontou com a literatura:

a) As atividades econômicas do setor de serviços consistem, em grande parte, na customização de tecnologias específicas para atender a uma série de necessidades dos usuários;

b) O papel predominante dos fatores humanos na organização e entrega da maior parte dos serviços é associado com investimento substancial em recursos humanos, melhora de suas competências e capacitação no uso da tecnologia;

c) Ao avaliar o setor de limpeza (que inclui também as prestadoras de serviços de limpeza), a pesquisa mostrou que somente 10,5\% das empresas eram inovadoras e, para 54,7\%, a distinção entre inovação de produto e serviço não eram aplicáveis; 
d) As fontes de informação externa que auxiliam na inovação, representadas por clientes, fornecedores de equipamentos, materiais e componentes, foram mencionados na pesquisa, como fonte de informação muito importante para $30 \%$ das empresas;

e) A melhora da qualidade dos serviços é indicada como um objetivo de inovação muito importante para $76,1 \%$ das empresas pesquisadas;

f) O aumento da participação de mercado é indicado como muito importante por, aproximadamente, $60 \%$ das empresas pesquisadas; $\mathrm{e}$

g) Os obstáculos à inovação declarados pelas empresas incluem: falta de financiamento $(22,9 \%)$ e elevados custos de inovação com longos períodos de retorno $(21,9 \%)$.

Em seu trabalho, Sundbo (1997) questiona a base da inovação em serviços: as empresas de serviços realmente inovam? Se positivo, como elas gerenciam e organizam suas atividades de inovação? O autor separa as empresas de tecnologia da informação, como inovadoras lideres e inclui as empresas de eletrônica que têm um departamento de pesquisa e desenvolvimento organizado e conectado com a ciência. O autor aponta que, no caso de serviços, a concorrência rapidamente imita o novo serviço.

Quando analisaram a inovação em serviços, Fitzsimmons e Fitzsimmons (2010) afirmaram que o modelo de inovação de produtos por intermédio da tecnologia e engenharia caracteriza-se por uma "inovação empurrada" (push innovation) ao mercado, com uma solução à procura de um problema, ao passo que, na inovação em serviços, o conceito é de "inovação puxada" (pull innovation) pelo mercado. Os autores ressaltam que "os inovadores em serviços enfrentam dificuldades em testar suas ideias", já que, têm limitações em construir protótipos em laboratório para realizar testes, antes de produzir em maior escala, como ocorre no desenvolvimento de produtos. Também apontaram para desafios peculiares à inovação em serviços, como a capacidade de proteger tecnologias (facilidade de imitação e dificuldade de se obter patentes), a natureza incremental da inovação (inovação tende a ser 
evolutiva e não radical), o grau de integração exigida (entre pessoas, produtos e tecnologia) e a capacidade de construir protótipos e testar em ambientes controlados (serviços não podem ser testados em laboratório e podem fracassar após o lançamento).

Visando a propor uma agenda de pesquisa sobre o tema inovação em serviços, Guimarães e Resende Júnior (2010) efetuaram uma revisão bibliográfica, buscando artigos no período entre 2005 e 2010. O estudo foi direcionado a trabalhos que constituíssem um relato de pesquisa empírica e seus resultados mostraram os seguintes fatos:

a) A pesquisa acadêmica sobre o tema inovação em serviços tem ganhado espaço na literatura, mas o setor ainda carrega alguns "mitos", como a improdutividade da atividade terciária, redução da importância de serviços (classificado como atividade residual ou periférica da indústria de produtos), baixa intensidade de capital, setor com atuação de profissionais menos qualificados e a dificuldade de relacionar serviços com algo "quantificável";

b) Muitas pesquisas enxergam a inovação em serviços nas características finais do serviço prestado, como o resultado da mobilização da capacidade técnica, das competências do fornecedor e das competências do cliente no processamento do serviço; e

c) Os temas mais abordados pela literatura pesquisada com relação à inovação em serviços foram: antecedentes e determinantes da inovação (23\%), desempenho econômico e produtividade das empresas (23\%), estratégias de inovação e tecnologia $(21 \%)$, desenvolvimento de capacidades em rede e colaboração entre organizações (13\%) e conhecimento intensivo/pesquisa e desenvolvimento (11\%).

Abordando as necessidades dos consumidores, Damanpour, Walker e Avellaneda (2009, p.654) reiteraram que a natureza da inovação em serviços é mais bem entendida por meio da relação com o usuário do serviço. Com base nesse ponto de vista, os autores definem inovações em serviços como "a introdução de novos serviços em clientes existentes ou novos clientes e oferecer serviços existentes a 
novos clientes", com a visão de novo para a empresa e/ou para o mercado escolhido. Nessa mesma direção, a conexão da percepção do usuário final com a inovação, seja de caráter radical ou incremental, levou à proposição de uma definição de inovação em serviços por Vasconcellos e Marx:

É a introdução de uma característica ou um conjunto de características (tecnológicas ou não tecnológicas) que propiciem a prestação de um serviço para o usuário final de uma nova maneira, ou de uma maneira melhorada. $\mathrm{O}$ usuário final deve reconhecer que o conjunto dessas características seja traduzido como benefício e tenha impacto em sua avaliação da prestação do serviço (VASCONCELOS; MARX, 2011, p.445).

Os autores da definição acima reconhecem, entretanto, que as inovações organizacionais puras, de caráter interno, estariam fora da abrangência dada, pois não seriam percebidas pelos consumidores finais.

Elche-Hotelano (2011) analisou os fatores que influenciam a intensidade da inovação em empresas de serviços, constatando que as fontes de conhecimento (ex.: funcionários), aquisição de tecnologia externa, projeto interno da inovação e proteção estratégica têm efeitos positivos no desempenho da inovação.

Ao analisar o processo de inovação em serviços, Omachonu e Einspruch (2010) sugerem um framework conceitual po meio de estágios bem demarcados (Figura 8): convocação da equipe para o estudo do novo serviço; criação de um serviço que o mercado necessite (estágio I); melhorar o serviço para ir ao encontro do que o mercado quer e o que demandará (estágio II); criação de serviços que o consumidor nunca pediu (estágio III) (a tecnologia tem papel importante nesse estágio). 


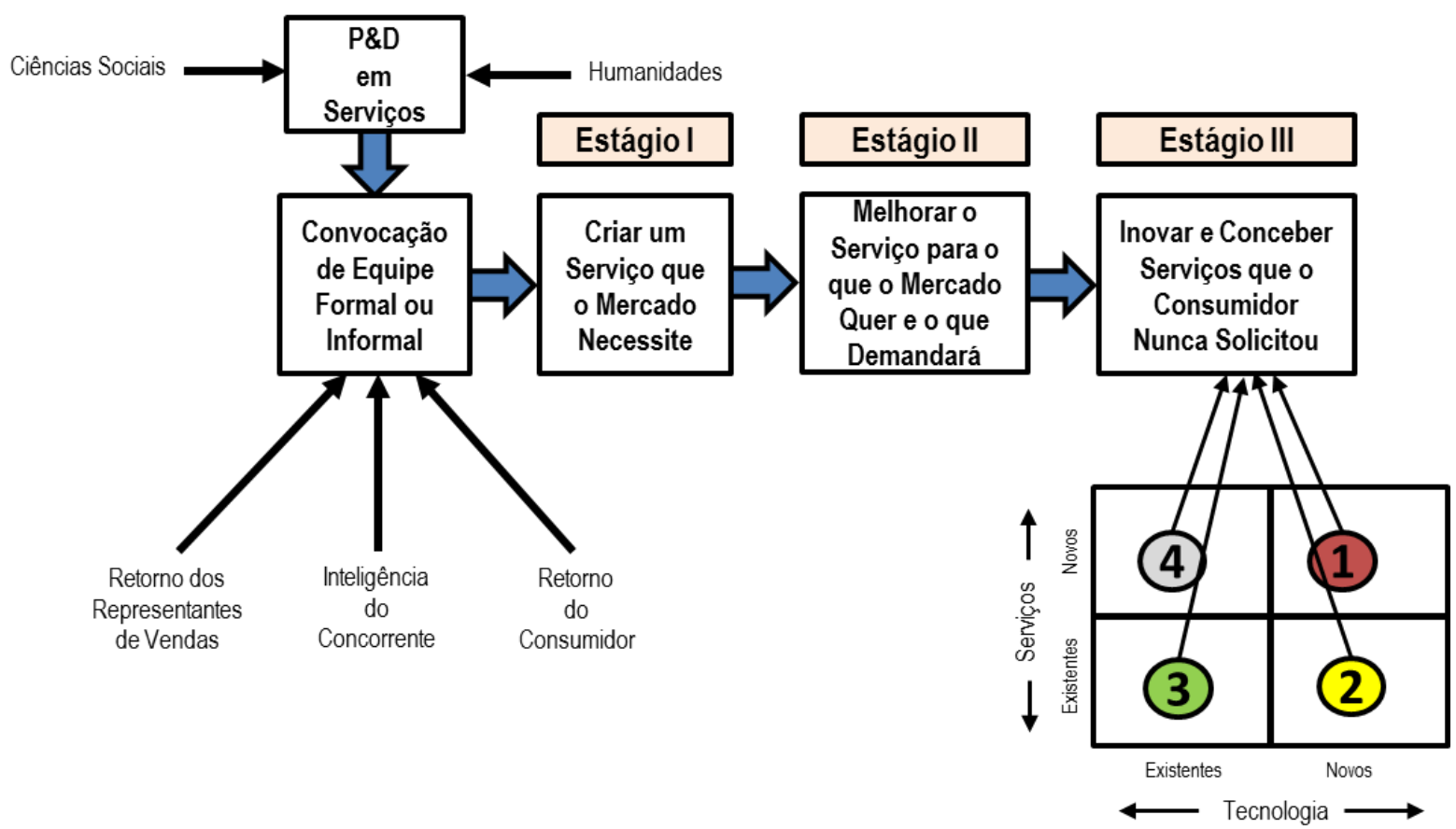

Figura 8: Framework Conceitual para o Processo de Inovação em Serviços

Fonte: Omachonu e Einspruch, (2010, p. 114).

\subsubsection{Desenvolvimento de Novos Serviços}

Ao comparar o desenvolvimento de novos serviços com o de novos produtos, Mello (2006) afirma que o desenvolvimento de novos produtos é difundido na literatura acadêmica e que, no caso de serviços, o tema ainda é incipiente. $O$ autor defende que o desenvolvimento de novos serviços ocorre com um modelo de referência, mais amplo e com uma visão integrada do processo, especificando etapas, estratégias, atividades e recursos para produção e entrega do serviço. Fitzsimmons e Fitzsimmons (2010) afirmam que ideias para o desenvolvimento de inovações podem vir de várias fontes, tais como clientes (sugestões), funcionários (pontos de escuta na linha de frente), banco de dados de clientes para serviços adicionais, tendências demográficas e avanços tecnológicos.

Com base no reconhecimento da importância do setor de serviços na economia e do estudo de como ocorre e se processa a inovação no setor, alguns pesquisadores 
direcionaram seus estudos buscando o entendimento da relação entre a indústria de bens manufaturados e a de serviços com relação ao tema inovação.

Desse modo, Omachonu e Einsprunch (2010) examinaram a inovação no contexto de bens e serviços. A comparação é baseada em três áreas: definição (inovação e tipologia, pesquisa e desenvolvimento e patentes), processo (de inovação para serviços e bens) e medidas (da inovação e patentes). E afirmam que a inovação em serviços é mais fácil de replicar e ser imitada pela concorrência do que a de produtos, porém existem mais dimensões para a inovação em serviços do que para a de produtos (ex.: um novo conceito de serviços, um novo modo de interagir com os consumidores, uma nova maneira de entregar o serviço ou um novo suporte tecnológico).

Os autores supracitados analisaram as áreas de conhecimento acadêmico e pesquisa e desenvolvimento tipicamente adotadas pelos setores de produtos e serviços. Nos dados da Figura 9, os autores observaram que áreas de especialização acadêmica, como física, ciências da vida e engenharia são tipicamente voltadas ao desenvolvimento de novos produtos para a indústria de bens. Por outro lado, as ciências sociais e humanidades são o foco do setor de serviços. Esse direcionamento aponta para as áreas de pesquisa e desenvolvimento de novos produtos e serviços. No caso do setor de bens, as indústrias estão direcionadas ao desenvolvimento de produtos tangíveis, ancoradas na tecnologia e no caso do setor de serviços, a abrangência aponta para as áreas relacionadas às esferas sociais e econômicas.

Omachonu e Einsprunch (2010) complementam que a área de pesquisa e desenvolvimento em serviços não é, formalmente, organizada como a de produtos. Observam também que as ligações entre o setor de serviços e as universidades são fracas e existe uma tendência maior em usar consultores externos na busca de fontes de conhecimento. 


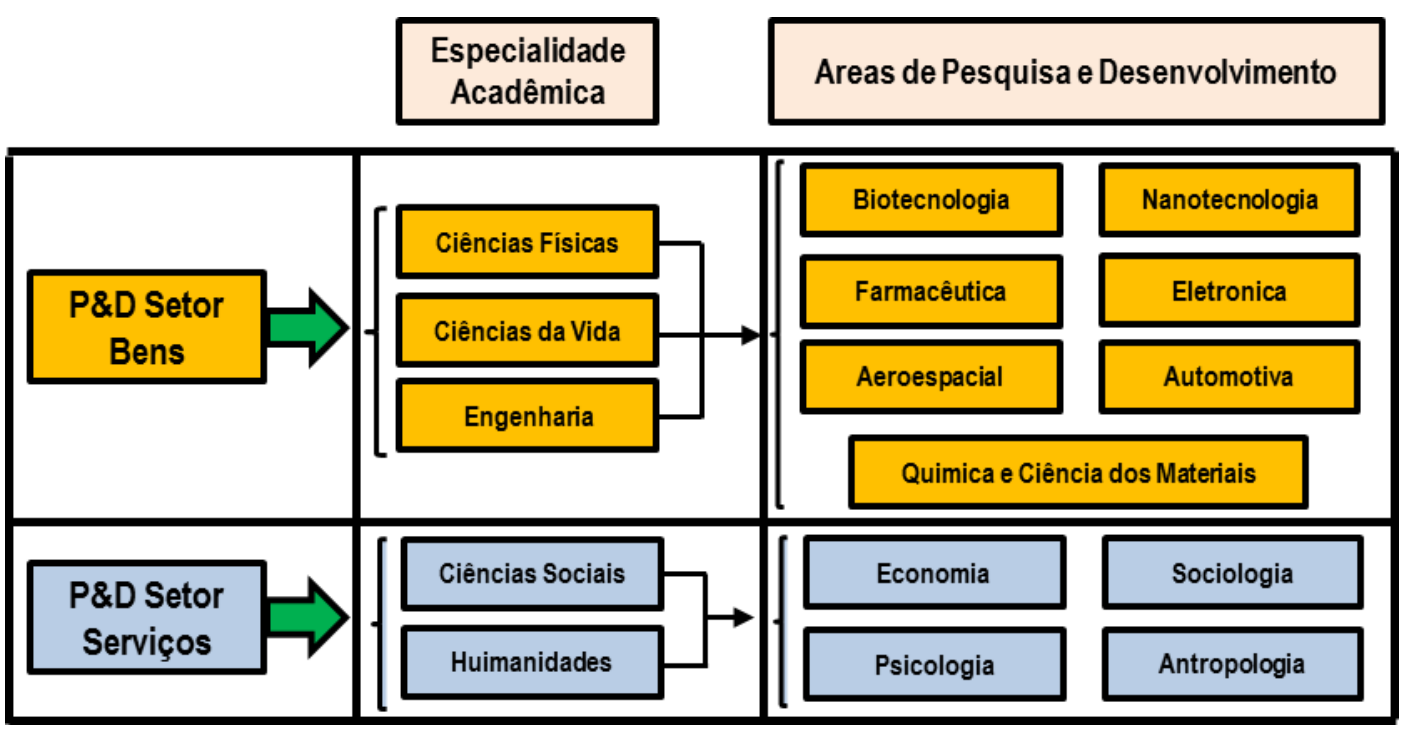

Figura 9: Classificação de pesquisa e desenvolvimento para os setores de bens e serviços

Fonte: Omachonu e Einspruch, (2010, p. 115).

Ao estudarem o processo de inovação em serviços, Schulteß et al (2010) desenvolveram um diagrama genérico semelhante aos frameworks tradicionais aplicados à inovação em produtos, conforme é apresentado nos dados da Figura 10.

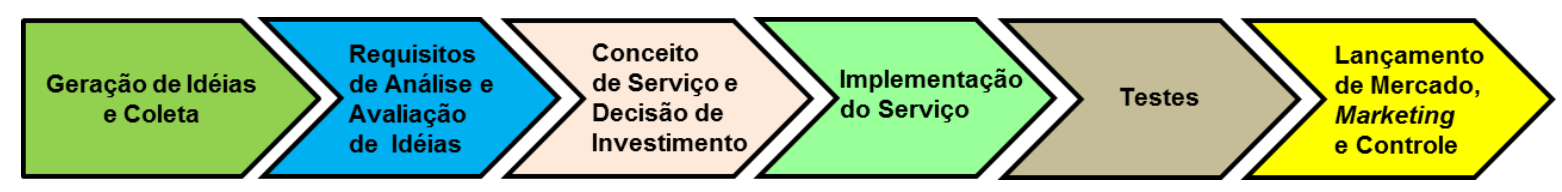

Figura 10: Processo de Inovação em Serviços

Fonte: Schulte $\beta$ et al, (2010, p. 6504).

As fases do processo de inovação em serviços foram analisadas pelos pesquisadores (SCHULTE $\beta$ et al., 2010):

a) Geração de ideias e coleta: as fontes podem ser internas (funcionários) ou externas (clientes e parceiros). Métodos podem ser usados para gerar certo número de ideias, que serão analisadas e selecionadas; 
b) Avaliação de ideias: utilizando os requisitos de mercado e o usuário final, assim como a estratégia e a capacitação da empresa. O objetivo é selecionar as ideias mais promissoras para posterior detalhamento;

c) Conceito de serviço e decisões de investimento: a ideia é detalhada visando à implementação. $O$ detalhamento permite decisões de investimento;

d) Implementação do serviço: definição das estruturas organizacionais, alocação de recursos e comunicação do novo serviço na organização. A gestão dos envolvidos que irão apoiar o novo serviço é uma das tarefas centrais nessa fase;

e) Testes: nessa fase, o objetivo é garantir a qualidade do serviço oferecido. $O$ autor sugere testes internos com os funcionários, já que testes com os consumidores finais têm o risco de expor o novo serviço a concorrentes, que poderão copiá-los; e

f) Lançamento de mercado e controle: uso de ferramentas de marketing e indicadores de desempenho. Nessa fase o retorno rápido das informações do campo e internas (clientes e funcionários) é crucial para a antecipação de problemas.

Scheuning e Johnson (1989) propuseram um modelo sistemático para o desenvolvimento de novos serviços (DNS ou NSD em inglês), baseado na literatura sobre o desenvolvimento de novos produtos, mas com a estrutura e processo que refletem as condições que prevalecem no setor de serviços. Os dados da Figura 11 mostram o modelo normativo de desenvolvimento de novos serviços, destacando-se quatro estágios: direção (curso do processo), projeto (refinamento do novo serviço, sistema de entrega e programa de marketing), testes (determinação da aceitação de clientes potenciais e ajustes) e introdução do serviço no mercado (lançamento e revisão pós-lançamento). 


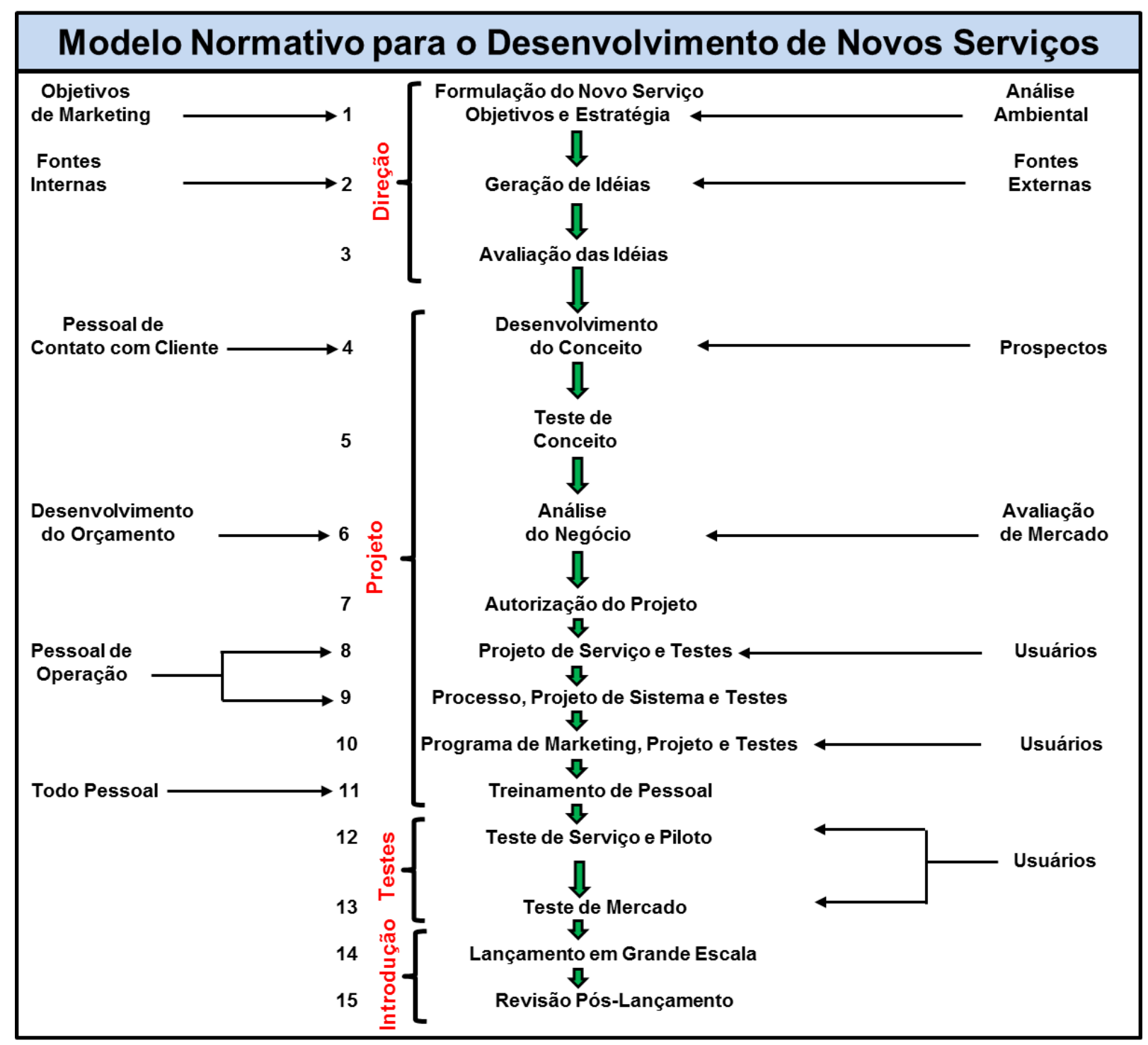

Figura 11: Modelo Normativo de Desenvolvimento de Novos Serviços

Fonte: Scheuing, E.E; Johnson, E. M., 1989, p. 30.

Jong e Vermeulen (2003) organizaram o desenvolvimento de novos serviços em dois estágios evolucionários: gestão das atividades-chave no processo de desenvolvimento de novos serviços e criação de um clima para a inovação contínua. Os autores desenvolveram um digrama com esses dois estágios, inter-relacionando as características organizacionais e o processo de inovação, conforme são apresentados nos dados da Figura 12. 
Pessoas

- Envolvimento dos funcionários do front line

- Presença de produtos campeões

- Suporte da Gestão

Estrutura

- Ferramentas em funil

- Times multifuncionais

- Disponibilidade de Recursos

- Teste pré-lançamento

- Pesquisa de marketing e lançamento

Implementação

Estágio 2: criando um clima inovador

Pessoas

- Contatos externos

- Compartilhamento de informações

- Autonomia dos empregados

Estrutura

- Foco estratégico

- Treinamento e Educação

- Organização interna e rotatividade de tarefas

- Tecnologia da Informação
Iniciação e Implementação

Figura 12: Desenvolvimento de Novos Serviços

Fonte: Jong, J. P. J ; Vermulen, P.A.M, (2003, p. 850).

$\mathrm{Na}$ Figura 12, os autores apontam que a distinção entre os dois estágios evolucionários foi desenvolvida para uma melhor organização do desenvolvimento de novos serviços. Os estágios estão relacionados a pessoas chave, desde os funcionários da linha de frente até o suporte da gestão e os arranjos estruturais, utilizando times multifuncionais, conseguindo recursos suficientes e atentando para os testes de mercado e lançamento. A atenção para a criação de um clima inovador à empresa é reforçada pelos autores, incluindo compartilhamento de informações e contatos externos, além de foco estratégico, educação e treinamento, rotatividade de tarefas e tecnologia da informação.

As presenças de uma cultura de inovação e de comportamento inovador são importantes fatores na adoção da inovação pelas empresas de serviços. Para Chen (2011), a inovação em serviços é o desenvolvimento de ideias novas e úteis, 
visando a melhorar a efetividade do serviço. O autor afirma que a inovação no setor é impactada positivamente pela cultura da inovação em serviços. Ao estudarem o comportamento inovador de empresas de serviços, Hortelano e González-Moreno (2007) relacionaram o grau de interação entre produtor e o consumidor de serviços com o grau de customização do serviço, considerando essa integração como fator chave para a inovação.

Com relação aos objetivos considerados importantes para a adoção da inovação em empresas de serviços, Evangelista e Sirilli (1998) constataram que a melhora na qualidade dos serviços e a redução dos custos foram os dois objetivos considerados mais relevantes para a adoção da inovação. Por outro lado, os autores avaliaram também os obstáculos à inovação e verificaram em sua pesquisa que $46 \%$ das empresas de serviços inovadoras consideravam que os custos para implantar a inovação eram muito elevados e $38 \%$ que a resistência a mudanças dentro das empresas era um obstáculo importante na adoção da inovação.

A especificidade da inovação em serviços vem sendo analisada pela literatura acadêmica. Vargas e Zawislak (2006, p.156) discutiram a pertinência do uso da abordagem dos sistemas de inovação (oriundos e aplicados na manufatura), para o caso da inovação em serviços e a conveniência de uma teoria específica para o tema. Os autores consideram que "as abordagens teóricas sobre inovação em serviços já acumularam evidências empíricas que não permitem mais nenhuma dúvida sobre a capacidade inovadora das organizações do setor de serviços..." e defendem que a integração das teorias sobre inovação (que reconcilie bens e serviços) depende de uma análise das especificidades, heterogeneidade e o caráter relacional dos serviços.

\subsubsection{Inovação em Serviços x Inovação em Produtos}

O setor de serviços é distinto do setor de produtos manufaturados em vários aspectos. Com relação à inovação, os fatores que mais influenciam essa distinção são a intangibilidade, sobretudo no controle da qualidade final, e a interação entre produção e consumo, que torna difícil a diferenciação entre inovação de produto e 
de processo (BESSANT; TIDD, 2009). Berry et al. (2006) afirmam que a inovação em serviços difere da inovação de produto em três pontos: no caso de serviços intensivos em trabalho ou interativos, os fornecedores do serviço são partes da experiência do consumidor; os serviços que requerem a presença física do consumidor necessitam de capacidade local de produção (ex.: quando existe distância de um restaurante dos consumidores); normalmente, os inovadores de serviço não têm um produto tangível que carregue uma marca. Dörner; Gassmann e Gebauer (2011) consideraram que a inovação em serviços é um tema importante, não somente às empresas de serviços, mas também às de manufatura, já que estas últimas dedicam pouco tempo à pesquisa e desenvolvimento de novos serviços associados a produtos.

Cook; Goh e Chung (1999) afirmaram que os serviços não podem ser completamente divorciados de bens manufaturados, já que todos os serviços são acompanhados de bens manufaturados facilitadores para o processamento do serviço. Nessa linha, Drejer (2003) defende que as atividades de serviços e a manufatura estão se tornando cada vez mais ligadas, e é necessário desenvolver um framework comum para estudar essas atividades, em lugar de manter a dicotomia entre elas. Ao estudar como empresas de serviços e manufatura diferenciam-se quando inovam, Ettlie e Rosenthal (2011) analisaram 38 novos produtos e 29 novos serviços desenvolvidos e oferecidos ao mercado. Os autores concluem que: as empresas de produto são mais direcionadas a estratégias e estruturas, quando os produtos são novos, porém as empresas de serviços são mais propensas a converter novos serviços em sucesso. Com relação à tendência de transformar as ideias do consumidor em novos produtos e serviços ao mercado, os autores concluem que ambos os setores têm a mesma tendência.

Conforme Damanpour; Walker e Avellaneda (2009), os pesquisadores, geralmente, distinguem entre inovações de produto ou de serviço. Os autores afirmaram que, a exemplo das inovações em produto, as inovações em serviços são sobretudo a demanda de clientes por novos serviços, com a criação de novos serviços para mercados existentes ou a busca de novos nichos de mercado para os serviços existentes. 
Para Hipp e Grupp (2005), o caráter das atividades de inovação e sua organização no setor de serviços diferem substancialmente das encontradas no setor industrial. Os autores explicam que esse conceito é válido para o desenvolvimento de novos serviços (inovação radical ou incremental e inovação de processo), o caráter dos serviços (orientados para processos e intangibilidade), integração com o cliente e também com relação aos aspectos organizacionais na coordenação de atividades para desenvolver novos serviços.

Pouco se conhece a respeito da colaboração entre empresas no desenvolvimento de novos produtos comparado com o desenvolvimento de novos serviços, conforme Schleimer e Shulman (2011). Os autores estudaram o tema e compararam 194 alianças colaborativas para verificar como o desenvolvimento de produtos difere do de serviços e qual o impacto no desempenho do processo de desenvolvimento. Os resultados da pesquisa mostraram uma relação de intensidade de união forte e positiva entre as firmas envolvidas no desenvolvimento de produtos mais do que quando um novo serviço é desenvolvido. Mas, a relação de confiança mútua entre as empresas de serviços é mais forte e positiva no desenvolvimento de um novo serviço, quando comparadas com empresas de produtos quando desenvolvem um novo produto.

Nijssen et al (2006) exploraram as similaridades e diferenças entre a inovação de produtos e serviços, por meio da pesquisa dos caminhos da inovação no desenvolvimento de novos produtos (DNP ou NPD em inglês) e no desenvolvimento de novos serviços (DNS ou NSD em inglês). Os autores apontaram que os caminhos para ambos podem ser os mesmos, mas a importância relativa dos caminhos pode ser diferente. Introduzem um modelo básico sobre os distintos efeitos no contexto de novos produtos e novos serviços, por meio da pesquisa empírica. Assim, defendem que o modelo desenvolvido pode ser aplicado igualmente no contexto de inovação de produtos ou serviços, conforme os dados da Figura 13. 


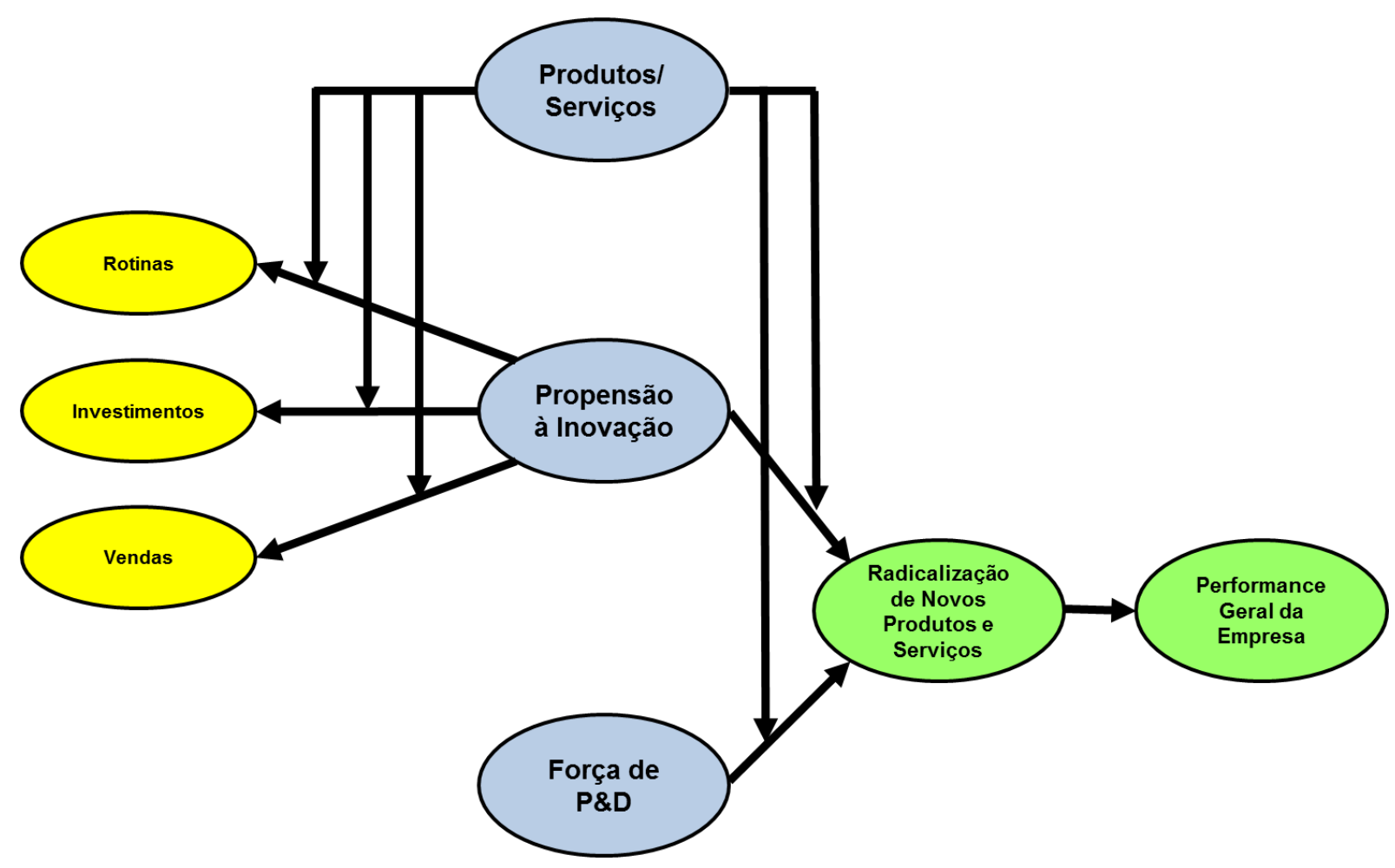

Figura 13: Modelo Conceitual para Inovação de Produtos e Serviços

Fonte: Nijssen et al, (2006, p. 244).

Os resultados obtidos por Nijssen et al (2006) com relação aos pontos abordados na pesquisa de campo (Figura 13) com 217 empresas de serviços e 105 empresas de produtos mostram:

a) A mudança de rotinas organizacionais tem efeito mais forte na propensão para inovação em novos serviços do que em novos produtos;

b) Não há diferença significativa no contexto de investimentos prévios para novos produtos e serviços incrementais, pois, aparentemente, requerem pouca inovação em processo em ambos os casos (produtos e serviços);

c) As vendas correntes podem ou não ser afetadas, tanto por novos produtos como para novos serviços; e 
d) o alto impacto da radicalização das inovações no desempenho das empresas de serviços comparado com as de produtos pode ser explicado pelo fato de inovações em serviços serem mais fáceis de imitar e, consequentemente, empresas de serviços devem inovar de modo mais radical para manter uma vantagem competitiva sustentável no mercado. Esta conclusão deve ser discutida e examinada, levando-se em conta que a percepção de que inovações incrementais contínuas levam a uma vantagem competitiva sustentável no caso dos serviços.

\subsection{Tipologia da Inovação em Serviços e seu Inter-relacionamento}

Em seu texto clássico sobre taxonomia da inovação, Pavitt (1984) dividiu as empresas em três grupos: dominadas por fornecedores, intensivas em produção e baseadas em ciência. $O$ autor afirma que, dentre as empresas dominadas por fornecedores, encontram-se aquelas que prestam serviços comerciais (caso das lavanderias domésticas), profissionais e financeiros, enfatizando que as empresas desse grupo são de pequeno porte, com baixa capacitação em engenharia e pesquisa e desenvolvimento e, portanto, mais dependentes dos fornecedores para inovar em produto ou processo. Por outro lado, Miozzo e Soete (2001) afirmam que as empresas de serviços dominadas pelo fornecedor e usuários de tecnologia, geralmente, são empreendimentos de pequeno porte, com pouca capacitação em pesquisa e desenvolvimento interno, pouca expertise em softwares próprios e encontram-se em setores tradicionais da economia, que incluem os chamados serviços pessoais (onde se encontram as lavanderias, restaurantes e hotéis, serviços de reparos e cabeleireiros) e serviços públicos e sociais (educação, cuidados com a saúde e administração pública).

A influência da composição dos tipos de inovação no desempenho organizacional foi estudada por Damanpour, Walker e Avellaneda (2009). Os autores observaram que a distinção entre os tipos de inovação no setor de serviços pode ser mais problemática que no setor de manufatura, em razão das características de intangibilidade, produção e consumo simultâneos e variabilidade de serviços que se inter-relacionam, dificultando a diferenciação entre eles. 
Zeithaml e Bitner (2011) apresentaram os tipos de inovação em serviços, vinculando-os às alterações ou expansões das ofertas de serviços:

a) Inovações radicais em serviços: novos serviços para mercados ainda indefinidos ou totalmente novos;

b) Inovações com novos serviços em mercados já atendidos por produtos existentes: normalmente, serviços oferecidos por empresas entrantes;

c) Inovações com a disponibilização de novos serviços para clientes que já consomem serviços da própria empresa;

d) Inovações por extensões de linhas de serviço: aumento da linha de serviços existentes;

e) Inovações por melhorias no serviço já oferecidos: maior rapidez, disponibilização do serviço por períodos maiores ou expansão com serviços adicionais; e

f) Inovações por alterações no estilo: vinculadas à mudança na aparência do serviço e não em sua essência.

Paswan; D'Souza e Zolfagharian (2009) desenvolveram uma tipologia da inovação em serviços sob a perspectiva interna (empresa) e externa (clientes) e ancorada em três dimensões: incerteza do meio ambiente, orientação estratégica e orientação ao mercado. Os autores enfatizaram que as várias tipologias oferecidas pela literatura são direcionadas na perspectiva de que os serviços são diferentes de bens por suas características diferenciadas, que incluem intangibilidade, heterogeneidade, inseparabilidade e perecibilidade. Explicam que os bens tornam-se significativos pelo uso ou serviço que eles fornecem, e o valor é definido e cocriado com o consumidor. Com essa perspectiva, os autores desenvolveram um framework de tipologia da inovação em serviços, que não é baseada em produtos versus serviços, mas nas estratégias de liderança de custos (entrega de valor por meio da entrega de serviço eficiente com baixo custo) e diferenciação (aumento do valor percebido pela diferenciação incremental ou marginal). 
Oke, Burke e Myers (2007) estudaram os tipos de inovação presentes em pequenas e médias empresas, mesclando empresas de produtos e serviços. Os autores argumentam que estudos prévios sobre os tipos de inovação e seus impactos no desempenho das empresas estão focados nas grandes empresas e consideram em seu estudo três tipos básicos de inovação: produto, serviço e processo.

Os mesmos autores (2007b) relacionaram os tipos de inovação e práticas de gestão predominantes em empresas de serviços do Reino Unido com o desempenho das empresas, identificando dois tipos de inovação: inovação em produtos de serviços (novos desenvolvimentos nas ofertas principais das empresas de serviços e que criam novas receitas) e inovação de serviços (inovações nos processos e na organização para os produtos de serviços existentes).

Os autores supracitados também identificaram os tipos de inovação predominantes no setor de serviços e como esses tipos estão relacionados com o desempenho inovador e as práticas de gestão na implementação da inovação, concluindo que o foco das atividades de inovação encontrava-se nas inovações incrementais. A relação entre os tipos de inovação e o grau de inovatividade mostrou que tanto as inovações radicais como as inovações incrementais em serviços estão relacionadas de forma significativa com o desempenho inovador. Mas, a relação entre as práticas mais formais de gestão da inovação e a inovação em serviços estão mais relacionadas com as inovações radicais do que com as inovações incrementais.

Em uma abordagem mais abrangente, ao defenderem a necessidade da criação de uma tipologia da inovação para o setor de serviços, Hipp e Grupp (2005) avaliaram as tipologias da inovação versus as características do setor de serviços, como simultaneidade e intangibilidade e indicam: primeiro, que a simultaneidade da produção e consumo impedem a separação entre inovações de produto e processo; segundo, que muitas inovações do setor de serviços usam desenvolvimentos tecnológicos mais como um meio de criar ou melhorar novos serviços e processos do que mostrar o progresso tecnológico; terceiro, que a intangibilidade não permite a visualização de como será um serviço e suas qualidades, assim como é difícil a criação de um monopólio temporário com a ajuda de algum tipo de patente. 
Ao discutirem a aplicabilidade da tipologia de Schumpeter e do Manual de Oslo (2005) para serviços, Vasconcellos e Marx (2011, p.444) afirmaram que "a classificação proposta no Manual de Oslo não parece ser muito precisa quando aplicada a serviços". Nessa linha, os autores discutem os quatro tipos de inovação (produto, processo, marketing e organizacional), exemplificando casos de inovação de empresas de serviços e as dificuldades em classificar a inovação como de produto ou de marketing, de produto ou de processo e a aplicabilidade da classificação da inovação tecnológica. Por outro lado, Hauknes (1998) afirma que, apesar da classificação de serviços implicar uma série de características específicas, estas características permitem o uso da taxonomia tradicional de inovação de produto, processo, organizacional e de marketing.

O Manual de Oslo justifica a inserção das inovações de marketing e organizacional na terceira edição, com base nas considerações sobre a inovação no setor de serviços:

Como existe uma noção crescente de que muita inovação no setor de serviços não é apreendida de maneira adequada pelo conceito TPP, decidiu-se adicionar a questão das inovações não tecnológicas nesta revisão. Dessa forma, o escopo do que é considerado uma inovação foi agora expandido para incluir dois novos tipos: inovação de marketing e inovação organizacional. Esses são certamente conceitos novos, mas eles já foram testados em vários países da OCDE, com resultados promissores (MANUAL DE OSLO, 2005, p.11).

Com relação à adoção de mais de um tipo de inovação pelas empresas de serviços, Tamura et al. (2005) afirmam que poucas empresas adotam somente um tipo de inovação. Para os autores, geralmente, as inovações de produto, processo e organizacional ocorrem juntas. 


\subsubsection{Resumo da Tipologia da Inovação Geral e de Serviços e Escolha dos Tipos de Inovação para a Pesquisa}

A partir dos itens anteriores, podem ser resumidos os autores que estudaram a tipologia da inovação geral (tanto para produtos como para serviços):

- Walker (2007): inovações totais (novos usuários), expandidas (serviços existentes para novos usuários) e evolutivas (novos serviços para usuários existentes).

- Andreassi (2007): inovação de produto (produto ou serviço novo ou já existente), de processo (novos processos produtivos ou alteração dos já existentes), de gestão (modificação de processos administrativos) e de modelo de negócios (modificação na essência do negócio).

- Rowley; Baregheg e Sambrook (2011) (revisão bibliográfica):

- Knight (1967): inovação em estrutura organizacional, processo de produção, pessoas, produto/serviço;

- Trott (2005): inovação em processo, marketing, produto, produção, gestão, organizacional e serviço;

- Oke (2007): inovação em processo (administrativa, serviço, produção), produto (radical e incremental) e serviço;

- Francis e Bessant (2005): inovação de paradigma, processo, posição e produto;

- Manual de Oslo (2005): inovação de produto, processo, organizacional e marketing;

- Damanpour; Walker e Avellaneda (2009): inovação em serviço, processos tecnológicos e administrativos;

- Zmoginski et al (2009): inovação intensiva em conhecimento (clientes, universidades como conhecimento externo), em rede, intensiva em escala e por domínio de fornecedores;

- Gunday et al (2011): inovação em processos, organizacionais, de produto e de marketing; e

- Oke; Burke e Myers (2007): inovação de produto, de serviços, de processo e organizacional.

Os autores que estudaram a tipologia da inovação em serviços nos itens anteriores foram: 
- Zeithaml e Bitner (2011): inovações radicais em serviços, novos serviços para produtos existentes, novos serviços para clientes atuais, extensões de linhas de serviços atuais, melhorias no serviço já oferecido e alterações de estilo (aparência);

- Oke; Burke e Myers (2007): inovação de produtos e serviços (novos desenvolvimentos nas ofertas principais) e inovação de serviços (de processo e organizacional para produtos e serviços existentes);

- Vasconcellos e Marx (2011): inovação de produto, processo, marketing e organizacional; e

- Hauknes (1998): inovação de produto, processo, organizacional e marketing.

Com base nas considerações dos diversos autores citados e pela abrangência da tipologia da inovação do Manual de Oslo (2005), optou-se por utilizar no presente estudo a tipologia da inovação nos quatro macrogrupos do Manual (inovação de produto, inovação de processo, inovação de marketing e inovação organizacional) e os subgrupos contemplam a tipologia relacionada às empresas de serviços pessoais. Como exceção, não será utilizado o grupo inovação de produto, embora esteja relacionado ao desenvolvimento de novos serviços ao mercado consumidor, por sua baixa aplicabilidade no segmento das lavanderias, já que neste segmento a inovação em "novos produtos" está mais relacionada ao tipo de lavagem adotada (à agua, à seco ou wetcleaning) e, portanto, vinculada a inovações de processo. Além da baixa aplicabilidade da inovação de produto no mercado das lavanderias, existe a dificuldade na separação da inovação de processo e produto para o setor de serviços, conforme os autores a seguir.

Hipp e Grupp (2005) analisaram à luz da literatura a questão da simultaneidade da produção e consumo em serviços como um empecilho para a separação das inovações de produto e processo. Os autores afirmam que, para a gestão da inovação, as dimensões de processo e produto devem ser desconsideradas, já que os consumidores aceitam não só um novo produto (serviço), mas também um novo processo de entrega do serviço.

Evangelista e Sirilli (1998) também encontraram dificuldade para separar a inovação de produto e processo, ao estudarem a inovação em empresas de serviços na Itália. 
Os autores constataram que um dos problemas metodológicos foi saber em que extensão a distinção analítica entre produto e processo era aplicada e passível de medições estatísticas no setor de serviços. Em sua pesquisa, verificaram que a maioria das empresas não considerava aplicável a distinção entre produto e processo por acharem difícil separar um do outro. Com base nos dados obtidos na análise estatística, observaram que a maior parte das inovações introduzidas nas empresas de serviços italianas estava relacionada à inovação de processo.

Ao discutir o uso do termo "inovação de produto" para serviços, Gallouj (1998, p.126) afirmou que "em serviços, o produto é um processo", já que é difícil fazer a distinção entre inovação de produto e inovação de processo. Para Gallouj e Weinstein (1997), a distinção entre produto e processo é uma ferramenta analítica importante no caso de bens tangíveis, mas o mesmo não é verdade para serviços. Os autores afirmam que o termo "produto" em serviços, frequentemente, denota "processo", havendo o entendimento que produto é análogo com o ato imediato de entregar um serviço. Argumentam ainda que existe dificuldade em separar as características técnicas das características de processo no caso de serviços.

Ainda na discussão sobre a distinção entre inovação de produto e de processo para serviços, Evangelista (2000) cita que as fases de produção e consumo ocorrem concomitantemente e não podem ser distinguidas na prática. Essa concomitância entre produção e consumo faz a distinção entre inovação de produto e processo, e é mais utilizada na manufatura de bens, tendo pouco significado em serviços. Em sua pesquisa empírica, o autor afirma que somente $25 \%$ das empresas inovadoras no setor de serviços foram capazes de distinguir entre inovações de produto e processo.

Pelo exposto, no presente estudo, optou-se por subdividir cada macrogrupo em grupos menores de inovação que são mais aderentes ao setor de serviços no grupo de serviços pessoais, no qual as lavanderias domésticas estão inseridas:

a) Inovação de Processo (Inovação em Sustentabilidade Ambiental e Inovação Tecnológica em Serviços); 
b) Inovação de Marketing (Inovação de Marketing em Serviços e Inovação de Marketing e Estratégia); e

c) Inovação Organizacional (Inovação de Modelo de Negócio, Inovação no Processo de Entrega (Linha de Frente) e Produção (Linha de Retaguarda)).

\subsubsection{Inovação de Processo}

\subsubsection{Conceito de Inovação de Processo}

Conforme o Manual de Oslo (2005, p.58) "uma inovação de processo é a implementação de um método de produção ou distribuição novo ou significativamente melhorado. Incluem-se mudanças significativas em técnicas, equipamentos e/ou softwares". Os autores do manual, ao diferenciar inovações de produto e processo complementam:

\footnotetext{
Se a inovação envolve características novas ou substancialmente melhoradas do serviço oferecido aos consumidores, trate-se de uma inovação de produto; se a inovação envolve métodos, equipamentos e/ou habilidades para o desempenho dos serviços novos ou substancialmente melhorados, então é uma inovação de processo; se a inovação envolve melhorias substanciais nas características do serviço oferecido e nos métodos, equipamentos e/ou habilidades usados para seu desempenho, ela é uma inovação tanto de produto como de processo (MANUAL DE OSLO, 2005, p.64).
}

As inovações de processo estão voltadas ao ambiente interno das organizações e têm por objetivo aumentar a eficiência e efetividade dos processos organizacionais internos, facilitando a produção e a entrega dos produtos e serviços aos clientes (DAMANPOUR; WALKER; AVELLANEDA, 2009). 


\subsubsection{Inovação em Sustentabilidade Ambiental}

Neste tópico, será abordada a inovação em sustentabilidade, porém com foco ambiental, já que no entendimento dos especialistas e órgãos que apoiam as lavanderias, a preservação do meio ambiente pode ser um canal de diferenciação e ganho de competitividade.

Ao discutir se a inovação em sustentabilidade ambiental estaria inserida, com base na tipologia do Manual de Oslo (2005), como inovação de processo, Rennings (2000) refere que as inovações de produto e de processo no Manual de Oslo (2005) incluem tecnologias ambientais. Ao analisar a inovação sob a ótica do desenvolvimento sustentável, o autor cita que a literatura introduziu o termo inovação ambiental e definiu de forma ampla o termo "ecoinovação":

...todas as medidas de atores relevantes (empresas, políticos, uniões, associações, igrejas e domicílios particulares) que desenvolvem novas ideias, comportamentos, produtos e processos, e os aplicam ou introduzem para contribuir com a redução das cargas ambientais ou direcionam para objetivos ecológicos específicos (RENNINGS, 2000, p.322).

Rennings (2000) estudou ainda os determinantes da ecoinovação em três áreas (tecnológica, regulatória e de mercado), utilizando o que chamou de efeitos "empurrados" e "puxados" na economia da inovação, conforme mostram os dados da Figura 14. O autor afirma que a principal discussão na economia da inovação é saber se a inovação tecnológica vem sendo direcionada pelo desenvolvimento tecnológico (tecnologia "empurrada") ou fatores de demanda ("puxada" pelo mercado). $\mathrm{O}$ aspecto regulatório e, em especial, a política ambiental também tem um grande impacto na ecoinovação. 


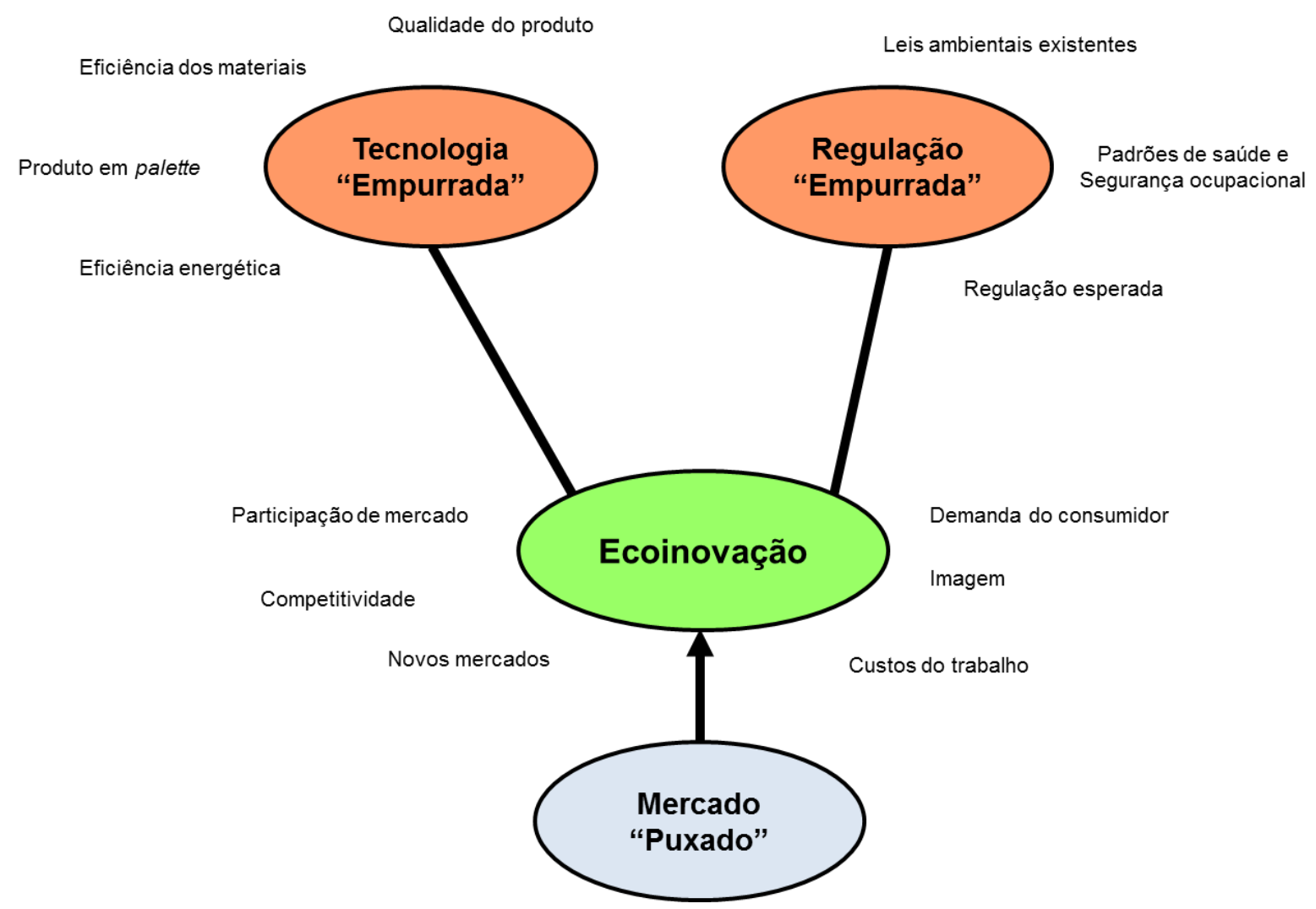

Figura 14: Determinantes da Ecoinovação

Fonte: Rennings, (2000, p. 326).

Tidd, Bessant e Pavitt (2008) ponderam que existem oportunidades para produtos e serviços inovadores com a crescente preocupação com a questão da sustentabilidade. No caso das lavanderias, parte das inovações em sustentabilidade ambiental está vinculada a seu processo produtivo (produtos, efluentes, uso de solventes de baixo impacto, entre outros).

Barbieri et al. (2010) estudaram a relação entre sustentabilidade e inovação, abrangendo as dimensões: social (impactos sociais dentro e fora da empresa), ambiental (impactos pela emissão de poluentes) e econômica (eficiência econômica ou lucro e competitividade). Ao abordar a "ecoinovação", os autores indicam que o termo refere-se à "ecoeficiência" ou à maneira de atuar na intersecção das dimensões econômica (lucro) e ambiental (planeta), por meio do desenvolvimento de serviços ou bens que atendam à sociedade com redução do impacto ambiental, conforme mostram os dados da Figura 15. 


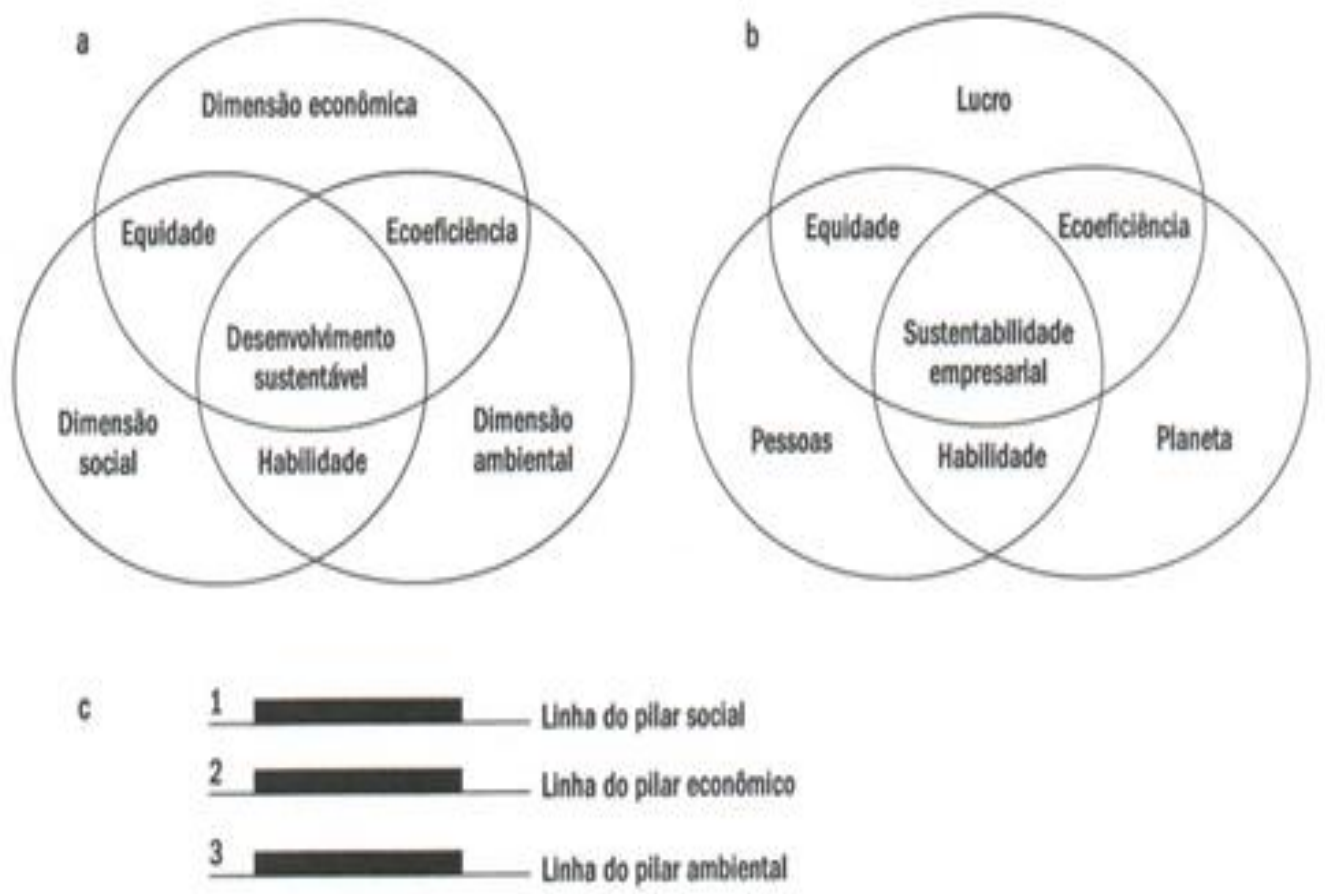

Figura 15: Ecoinovação e as dimensões econômicas e sociais Fonte: Barbieri et al, (2010, p. 152 (Fig. 1a))

Quando se trata de inovação em sustentabilidade ambiental, o termo ecoinovação tem ganhado relevância nos trabalhos acadêmicos sobre o tema. Hellström (2007) define o termo como o processo de desenvolver novas ideias, comportamentos, produtos e processos que contribuam para uma redução no impacto ambiental ou para um objetivo sustentável ecologicamente especificado. $O$ autor aborda a ecoinovação como a inovação em sustentabilidade do meio ambiente e refere que, a exemplo da maior parte das inovações, a ecoinovação é representada na maior parte das vezes por inovações incrementais, enfatizando que a inovação ambiental vem sendo fortemente influenciada pela inovação ecoeficiente, ou seja, a inovação nos processos produtivos que reduzam o impacto ambiental (ex.: limitando o uso de energia, reciclando materiais, entre outros).

As barreiras à ecoinovação foram estudadas por Del Río; Carrilho-Hermosilla e Könnölä (2010), que desenvolveram um diagrama com as políticas que auxiliam na minimização das barreiras à ecoinovação. Os autores exploram a abrangência da 
ecoinovação em processos, produtos, serviços e a mudança organizacional, realizando uma distinção entre ecoinovações incrementais e radicais. Conforme os autores supracitados, no primeiro caso referem-se às mudanças menores nos processos e às últimas a mudanças substanciais (ex.: efluentes que se tornam matérias-primas para novos processos). As barreiras à ecoinovação são agrupadas em três categorias: aquelas relacionadas ao ambiente externo (falta de pressão para ecoinovação por consumidores, organizações não governamentais, entre outros); as relacionadas às condições externas (falta de recursos, baixa competência tecnológica para absorver ou desenvolver ecoinovações e baixa prioridade ao meio ambiente); as relacionadas às características tecnoeconômicas das ecoinovações (quando são muito caras ou incompatíveis com o processo existente).

Estudos sobre a relação entre a ecoinovação e pequenas e médias empresas (PMEs) vêm sendo apresentados por diversos autores:

a) Buttol et al (2012) ponderam que as pequenas e médias empresas representam um vetor chave para a introdução e difusão da ecoinovação, por sua relevância para o meio ambiente e para o produto interno bruto do continente europeu, onde representam 99\% das empresas (cerca de 23 milhões) e 30\% da força de trabalho do setor privado. Conforme os autores, como as PMEs estão direcionadas em inovação contínua e incremental de seus produtos, a otimização dos caminhos para a ecoinovação pode ser considerada relevante a seus negócios;

b) Na Alemanha, Klewitz; Zeyen e Hansen (2012) buscaram identificar as diretrizes e barreiras à ecoinovação em PMEs e mostram os efeitos induzidos pela colaboração entre PMEs, autoridades locais e consultorias. As características das PMEs, como a maneira informal de comunicação, flexibilidade e estrutura enxuta, levam a uma gestão menos burocrática nos assuntos relacionados ao meio ambiente. Para os autores, a inovação ecoeficiente pode ser aplicada a todos os tipos de inovação, tais como: inovação de processo (produção de serviços com menos energia e produção limpa), de produto (produtos mais eficientes) e organizacional (reorganização de estruturas ou implementação de novas ferramentas de gestão). 
Desse modo, os referidos autores concluem que o acesso proativo de uma autoridade pública é fator essencial para acionar as ecoinovações em PMEs com baixa capacidade de absorção, por meio de diferentes tipos de suporte, que variam dos customizados aos mais livres, como por exemplo, redes de contato; e

c) Bos-Brouwers (2010, p.418) afirma que "existem diferenças significativas em processos de inovação entre grandes e pequenas/médias empresas. As políticas, teorias e instrumentos que servem para empresas maiores, não necessariamente leva a resultados positivos no ambiente de pequenas e médias empresas". O autor acrescenta que os dados sobre desempenho em sustentabilidade ambiental de pequenas e médias empresas são escassos, pois não existem relatórios formais nem estratégias para inovação. Parte das pequenas e médias empresas atua em mercados de nicho para manterem-se competitivas e a adoção da inovação é direcionada à inovação incremental e melhoria de processo com introdução de novas tecnologias.

Com relação à implementação de ecoinovações por empresas de serviços, Desmarchelier, Djellal e Gallouj (2012) avaliam a sensibilidade da ecoinovação dessas empresas às políticas publicas ambientais e comparam a efetividade de duas dessas políticas (a taxa ambiental e a informação ao consumidor) no incentivo à inovação.

Os autores supracitados concluem que, no contexto estudado, as politicas ambientais podem encorajar as empresas de serviços a introduzir ecoinovações e que a taxa ambiental (política pública de pagamento de taxa pela empresa de serviços poluidora) é mais efetiva do que a informação ao consumidor (programa de informação que influencia a decisão de compra do consumidor).

\subsubsection{Inovação Tecnológica em Serviços}

Os avanços em tecnologia influenciam diretamente o crescimento e a importância dos serviços, conforme cita Kandampully (2002). O autor afirma que a tecnologia 
facilita a manutenção do relacionamento com os clientes e parceiros dentro e fora da empresa.

A tecnologia como fonte de construção de vantagem competitiva em empresas de serviços é abordada por Kang (2006). O autor afirma que a tecnologia pode ser aplicada em todos os estágios do sistema de produção do serviço e altera radicalmente o ambiente estratégico ao oferecer novas oportunidades e ameaças.

Para Evangelista (2000), a inovação tecnológica é um fenômeno difundido em serviços; desse modo desenvolveu um quadro com quatro diferentes grupos de empresas de serviços que se diferenciam por sua interação com a tecnologia em suas áreas de atuação, de acordo com os dados da Figura 16:

a) Usuários de Tecnologia (caso das lavanderias domésticas, transportes terrestres e marítimos): utilizam tecnologias desenvolvidas por outras empresas, efetuando investimentos em novas máquinas e equipamentos;

b) Baseadas em ciência e tecnologia (caso das empresas de engenharia e computação): são os maiores difusores de conhecimento tecnológico nos setores de serviços e manufatura;

c) Baseadas em tecnologia da informação e interativas (caso de bancos, seguros e hotéis): elevados investimentos em softwares e alta interação com os usuários e clientes; e

d) Consultorias técnicas: têm características comuns das empresas baseadas em ciência e tecnologia e das empresas voltadas à tecnologia da informação. Possuem interação muito próxima com os clientes finais, empresas de consultoria e institutos de pesquisa. 


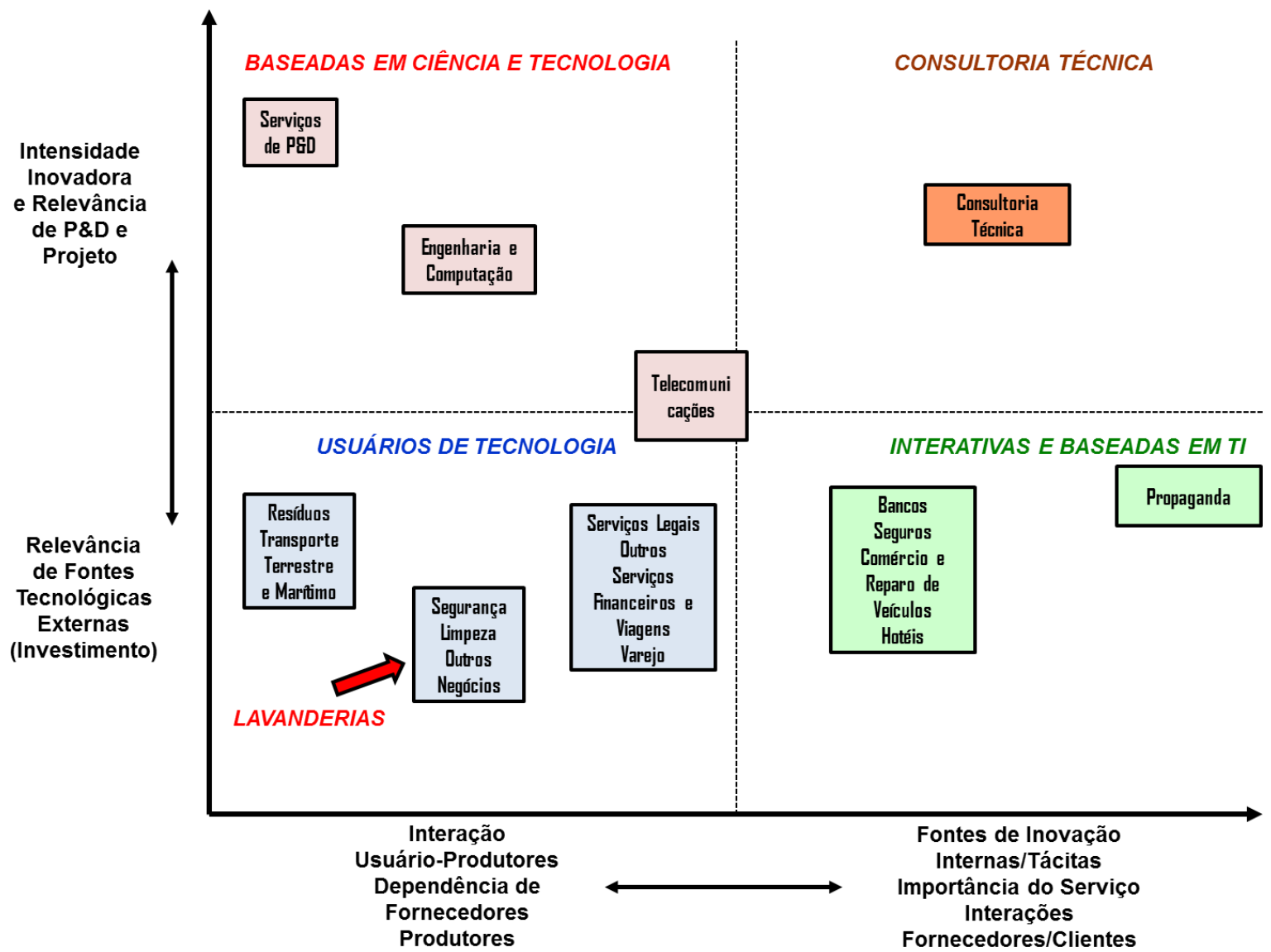

Figura 16: Padrões setoriais de mudança tecnológica em serviços

Fonte: Evangelista; (2000, p. 214 (Fig. 3))

Ao analisar as relações entre inovação tecnológica e inovação em serviços, Gallouj (1997) identificou situações específicas, como:

a) O uso de ferramenta técnica inovadora como um "fornecedor" de serviço existente: por exemplo, em operações da linha de apoio para sistemas de reservas, transações bancárias, máquinas de atendimento automático, entre outros;

b) Uso de ferramenta técnica inovadora, como um "fornecedor de novos serviços": por exemplo, em serviços de telecomunicação (melhora de serviços de telefonia, correio eletrônico, vídeos de alta definição, entre outros); 
c) Uso de ferramenta técnica inovadora, como determinante para inovação em serviços: por exemplo, no fornecimento de bens para empresas de limpeza, manutenção e serviços de locação;

d) Serviços, como difusores da inovação tecnológica: por exemplo, em atividades de consultoria para alta tecnologia;

e) Serviços, como determinantes para a inovação tecnológica: por exemplo, em empresas comerciais na área alimentícia, que pressionam as indústrias alimentícias e outros setores produtivos para melhora da qualidade e condicionamento de produtos, assim como suas características ecológicas; e

f) Serviços, como produtores de ferramentas técnicas inovadoras: por exemplo, fornecedores especializados e empresas de base científica, onde as empresas de serviços atuam na elaboração de ferramentas técnicas para seus setores em parceria com empresas de manufatura.

A relação entre as inovações de processo com inovações tecnológicas é abordada por Damanpour; Walker e Avellaneda (2009, p.654), que definem inovações de processo tecnológicas como "novos elementos introduzidos no sistema de produção da organização ou operação de serviço para produção de seus produtos ou serviços aos clientes". Os autores complementam que os princípios para adoção dessas inovações são, primariamente, a redução no tempo de entrega, o aumento na flexibilidade operacional e a redução de custos de produção do serviço.

Muitos serviços são prestados utilizando a tecnologia como ferramenta para a concretização da entrega a seus clientes finais. Embora não desenvolvam a tecnologia, o uso de máquinas ou softwares inovadores permite que as empresas de serviços desenvolvam inovações nas áreas de processo, controle gerencial diferenciado, sustentabilidade ambiental e processos de produção do serviço.

Rowley; Baregheh e Sambrook (2011) destacaram que inovação técnica é, frequentemente, confundida com inovação tecnológica. Os autores definem inovação tecnológica como a iniciada pelo uso da tecnologia e com as 
oportunidades disponíveis para a organização, como resultado dos avanços tecnológicos. A inovação técnica, por outro lado, descreve genericamente a inovação relacionada com os sistemas técnicos das empresas e suas atividades primárias. O setor de serviços pode utilizar inovação tecnológica como ferramenta de melhora de seu processo produtivo ou para aproveitar oportunidades que signifiquem agregar valor aos serviços entregues a seus clientes.

Ao questionarem as razões pelas quais as empresas de serviços implementam tecnologia, Mc Dermott; Kang e Walsh (2001) apontaram quatro evidências empíricas: melhora no processamento de informações (entre o cliente e o funcionário externo e entre funcionários internos); melhora na flexibilidade em funções de operação; melhora no controle e repetibilidade da oferta de serviços (ex.: lavanderias); melhora no pacote de serviços com relação à qualidade do serviço entregue (ex.: utilização de material adequado ao serviço prestado).

A classificação das inovações tecnológicas e não tecnológicas pode gerar controvérsias quando aplicadas a serviços, conforme citam Vasconcellos e Marx (2011). Os autores abordam algumas referências tipicamente utilizadas para o setor de produtos (como Stage-Gates e a cadeia da inovação de Hansen e Birkinshaw) e argumentam que a própria palavra "tecnologia" transmite a ideia de que a inovação tecnológica ocorre somente com a presença de um componente tecnológico ou o uso de uma nova tecnologia de informação na prestação de serviço, o que pode não ser a realidade para o setor de serviços que, frequentemente, lança mão de inovações não tecnológicas.

Miozzo e Soete (2001) citaram que, com a importância dos serviços, a diferenciação nos padrões de inovações tecnológicas também cresce e um número maior de setores também poderá ser desenvolvido, tais como aqueles intensivos em escala, baseados em ciência, e os que são providos por fornecedores especializados. Os autores abordaram os efeitos das tecnologias da informação e telecomunicações na estrutura e gestão de serviços, que incluem a importância da ligação entre a produção de bens e serviços, a transportabilidade dos serviços e o aumento da intensidade do conhecimento do setor de serviços. 
As implicações da mudança tecnológica na gestão e estrutura dos serviços sugerem que, quanto maior uma economia, mais próxima será a ligação entre a produção de serviços e a demanda na indústria de manufatura (MIOZZO; SOETE, 2001). Fitzsimmons e Fitzsimmons (2010) afirmam que a introdução da tecnologia de produtos tem efeito secundário na inovação de serviços, exemplificando que a introdução de aparelhos de DVD expandiu o negócio de aluguel de vídeos e o lançamento do serviço de entrega de DVD em casa via correio.

Andreassi (2007) relacionou as inovações de produto e processo com inovações tecnológicas ao afirmar que, quando as inovações de produto ou de processo são acompanhadas de inserção de novas tecnologias, tais como emprego de conhecimento científico ou empírico, as inovações tecnológicas ocorrem.

Bessant e Tidd (2009) focaram-se no uso da tecnologia da informação como apoio à inovação em serviços, aumentando a capacidade na concepção de novos tipos de serviços. Os autores citados ressaltam que as inovações em serviços, que se diferenciam na forma como os clientes percebem o serviço prestado, exigirão grandes investimentos em tecnologia e inovação de processo. No caso de prestadores de serviços diretos ao consumidor, a presença de ferramentas associadas ao uso do computador pode favorecer a agilização da contratação de serviços de entrega, automação de processos para produção de um serviço, automação de máquinas com consequente aumento na velocidade das operações individuais e como apoio às áreas de promoção, propaganda e marketing.

Ainda no foco da inovação tecnológica por meio da tecnologia da informação, Kandampully (2002) examinou a inovação como a competência central das organizações de serviços e o papel da tecnologia como um dos recursos que dão base ao crescimento em serviços, facilitando a manutenção das redes de contatos com os clientes e parceiros dentro e fora da empresa. O autor argumenta que a tecnologia, conhecimento e redes de contatos representam um conjunto de fatores único que poderão estimular a inovação em organizações de serviços.

Klement e Yu (2008, p.14) estudaram a inovação tecnológica em uma organização hoteleira e afirmam que "a evolução da inovação em serviços é dinâmica, ou seja, a 
implementação de uma tecnologia que gera inovação na prestação de serviços, mesmo que incremental, pode contribuir para outra inovação a posteriori", ou seja, pode haver a combinação ou sobreposição de inovações tecnológicas.

Em sua pesquisa empírica sobre inovação tecnológica em serviços na Itália, Perani e Del Santo relacionaram inovação tecnológica e inovação de processo e definem:

Um serviço é tecnologicamente inovador se existe uma melhora expressiva
na performance e nas tecnologias utilizadas, oriundas de novos
procedimentos ou procedimentos melhorados. A inovação de processo é a
adoção de novos métodos tecnológicos em produção ou novos métodos
para fornecer serviços. Podem ser necessárias mudanças em
equipamentos ou organização da produção ou ambos (PERANI, DEL
SANTO, 1998, p.4).

Os autores supracitados admitem não ser um objetivo fácil identificar quando as atividades de inovação tecnológica têm lugar e também como efetuar a coleta de informações. O estudo também encontrou dificuldades no entendimento pelas empresas das definições de inovações tecnológicas e na interpretação dos dados sobre inovações tecnológicas em serviços, por serem substancialmente diferentes das empresas de manufatura. Um ponto acentuado por Perani e Del Santo (1998) foi a diferenciação do que seriam inovações tecnológicas e não tecnológicas (foi utilizada a interpretação do Manual de Oslo de 1997). Não foram consideradas inovações tecnológicas: a substituição ordinária de equipamento, a entrega de serviços customizados, somente a diferenciação externa de serviços e qualquer intervenção no contexto onde os serviços são produzidos.

Na mesma linha de estudo, Sirilli e Evangelista (1998) pesquisaram evidências empíricas sobre a inovação tecnológica no setor de serviços, porém, comparando similaridades e diferenças com o setor de manufatura, e ressaltam os pontos importantes:

a) A inovação tecnológica é um fenômeno difuso no mercado de serviços, sendo os setores mais inovadores os da engenharia, consultoria técnica, computação e software; 
b) As estratégias de inovação consistem em melhorar a qualidade do serviço, aumentando a participação de mercado e reduzindo custos de produção;

c) Os maiores obstáculos na introdução da inovação tecnológica em serviços e produtos são de natureza econômica (fontes de financiamento não apropriadas e alto custo da inovação).

Sirilli e Evangelista (1998) pesquisaram empresas de serviços e de manufatura que tivessem introduzido, pelo menos, uma inovação tecnológica no prazo de 3 anos. Entre os setores de serviços, foram pesquisadas empresas de limpeza, com um percentual baixo de inovação $(10,5 \%)$ se comparadas com os bancos $(61,8 \%)$, seguros $(63,1 \%)$ e computação/software $(54,3 \%)$. Utilizando os resultados da mesma pesquisa, Evangelista (2000) acentua que os canais mais importantes que as empresas de serviços utilizaram para inovar foram: inovação em processo, investimentos inovadores (gastos na aquisição de maquinas e equipamentos relacionados à introdução de novos serviços, processos e sistemas de entrega) e aquisição e desenvolvimento interno de software.

A aquisição de equipamentos e máquinas é um complemento relevante na inovação em serviços, já que as empresas de serviços desempenham um papel estratégico importante como usuários de novas tecnologias, assim como também se envolvendo indiretamente pelo fornecimento de informações de campo (ELCHE-HOTELANO, 2011).

\subsubsection{Inovação de Marketing}

\subsubsection{Conceito de Inovação de Marketing}

Conforme o Manual de Oslo, a definição de inovação de marketing é: 
Uma inovação de marketing é a implementação de um novo método de marketing com mudanças significativas na concepção do produto ou em sua embalagem, no posicionamento do produto, em sua promoção ou na fixação de preços. Inovações de marketing são voltadas para melhor atender as necessidades dos consumidores, abrindo novos mercados, ou reposicionando o produto de uma empresa no mercado, com o objetivo de aumentar as vendas. A característica distintiva de uma inovação de marketing comparada com outras mudanças nos instrumentos de marketing de uma empresa é a implementação de um método de marketing que não tenha sido utilizado previamente pela empresa. Isso deve fazer parte de um novo conceito ou estratégia de marketing que representa um distanciamento substancial dos métodos de marketing existentes na empresa. O novo método de marketing pode ser desenvolvido pela empresa inovadora ou adotado de outras empresas ou organizações. Novos métodos de marketing podem ser implementados para produtos novos ou já existentes (MANUAL DE OSLO, p.59).

Yang; Jayashree e Marthandan (2012) incluíram a inovação de marketing como um dos tipos de inovação estratégica, ao lado de inovação de serviços e de produto, aumentando, assim, a abrangência do conceito de inovação estratégica (relacionando-a com as qualificações da empresa e as mudanças ambientais, com base nas ideias, processos, técnicas e serviços).

\subsubsection{Inovação de Marketing em Serviços}

Para que a inovação em serviços possa ocorrer, as empresas devem expandir sua visão para além dos serviços existentes e sua capacidade para executá-lo e abranger também as metas e trabalho de seus clientes, conforme citam Bettencourt; Brown e Sirianni (2012). Os autores enfatizam que a verdadeira inovação em serviços não é perguntar "como estamos fazendo", mas, "como o cliente está fazendo". A visão dos autores é de uma abordagem centrada no trabalho, e o trabalho do consumidor é a unidade de análise: que trabalhos o consumidor está tentando fazer? Estes trabalhos são partes de um processo maior? Quais oportunidades existem para fazer tais trabalhos? Quais recursos precisam ser investidos na criação de valor? 
$\mathrm{Na}$ orientação de mercado em empresas de serviços, a análise do papel da inovação foi explorada por Cheng e Krumwiede (2012). Os autores pesquisaram como cada componente da orientação para o mercado contribui para o desempenho de novos serviços, por meio de vários tipos de inovação. A pesquisa mostrou que a orientação para o cliente estimula a inovação incremental em serviços, e a coordenação interfuncional estimula a inovação radical em serviços e ambos aumentam o desempenho de novos serviços. Outra conclusão do trabalho mostrou que o impacto da orientação para a concorrência no desempenho de novos serviços é mediada pela inovação radical de serviços. Mas, a introdução de inovações no mercado pelas empresas de serviços tem a particularidade de expor a empresa imediatamente ao mercado em caso de falha, já que os serviços são produzidos e consumidos concomitantemente, o que não ocorre com as empresas de bens, que minimizam os riscos de exposição, conduzindo testes em nível piloto fora do mercado (CHANG, 2011).

A geração de novos mercados (com um novo serviço principal) ou a reformulação dos já existentes (novo serviço entregue de forma diferenciada) por meio da inovação em serviços foi estudada por Berry et al. (2006). Os autores desenvolveram uma matriz, conforme os dados da Figura 17, com os tipos de criação de mercados na inovação em serviços: separabilidade (mostra se o serviço precisa ser produzido e consumido simultaneamente ou não) e o tipo de benefício criado (novo benefício principal ou um novo benéfico entregue de maneira diferenciada, como por exemplo, via internet). 


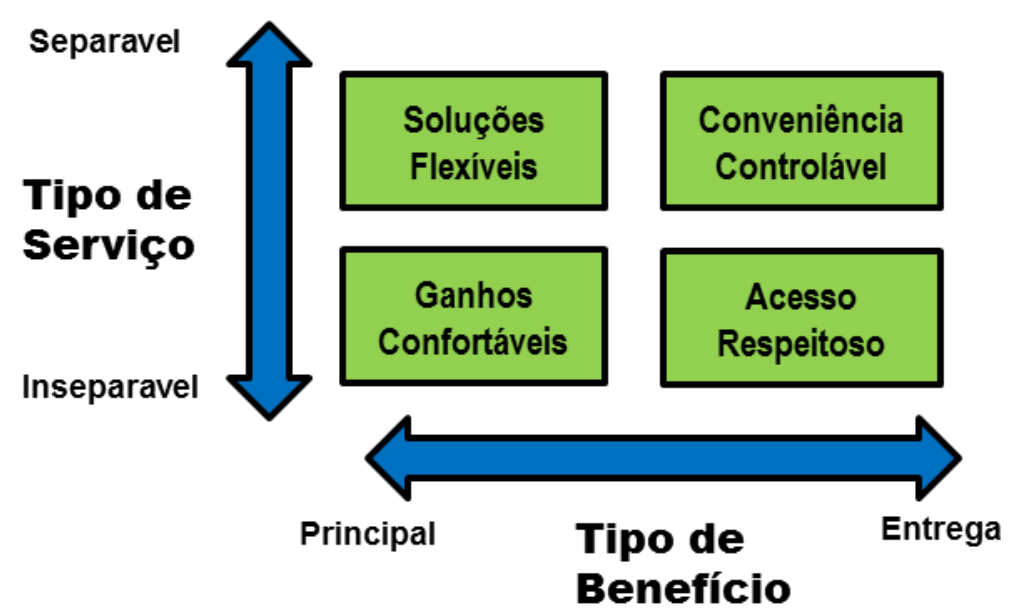

Figura 17: Os quatro tipos de inovações de serviço de criação de mercado

Fonte: Berry et al; 2006, pg. 59

Por outro lado, a relação entre a orientação de mercado e a inovação foi explorada por Atuahene-Gima (1996), que examinou a influência da orientação de mercado sobre as características da inovação e seu desempenho nas empresas de serviços e de manufatura. Os resultados mostraram que a orientação de mercado (conceituada como as atividades que refletem o grau de adoção da filosofia do conceito de marketing) não teve um impacto mais forte no desempenho da inovação das empresas de serviços se comparados com as empresas de bens.

Amaral et al (2013) exploraram a percepção e o discernimento do consumidor de uma inovação em serviços que pode refletir em sua satisfação (sentimento que o consumidor possui quando tem suas necessidades e desejos atendidos) e lealdade (comportamentos e atitudes que indiquem um interesse em conservar o relacionamento com a empresa). Os autores utilizaram as variáveis lealdade e satisfação versus as dimensões "funcionários" (perfil para a atividade; forma como solucionaram problemas), "responsividade" (disponibilidade da empresa para a prestação do serviço; comunicação com o cliente; customização do serviço) e "serviço" (atividades executadas quando o cliente adquire o serviço). A pesquisa gerou uma proposição de modelo que relaciona a inovação com a satisfação e lealdade do consumidor, conforme dos dados da Figura 18, com relações positivas entre as variáveis "funcionários", "responsividade" e "serviço" e a "satisfação" e "lealdade" dos consumidores, ressaltando o papel de mediadora da variável 
"serviços", que leva a "satisfação" e, esta última, como mediadora que leva à "lealdade".

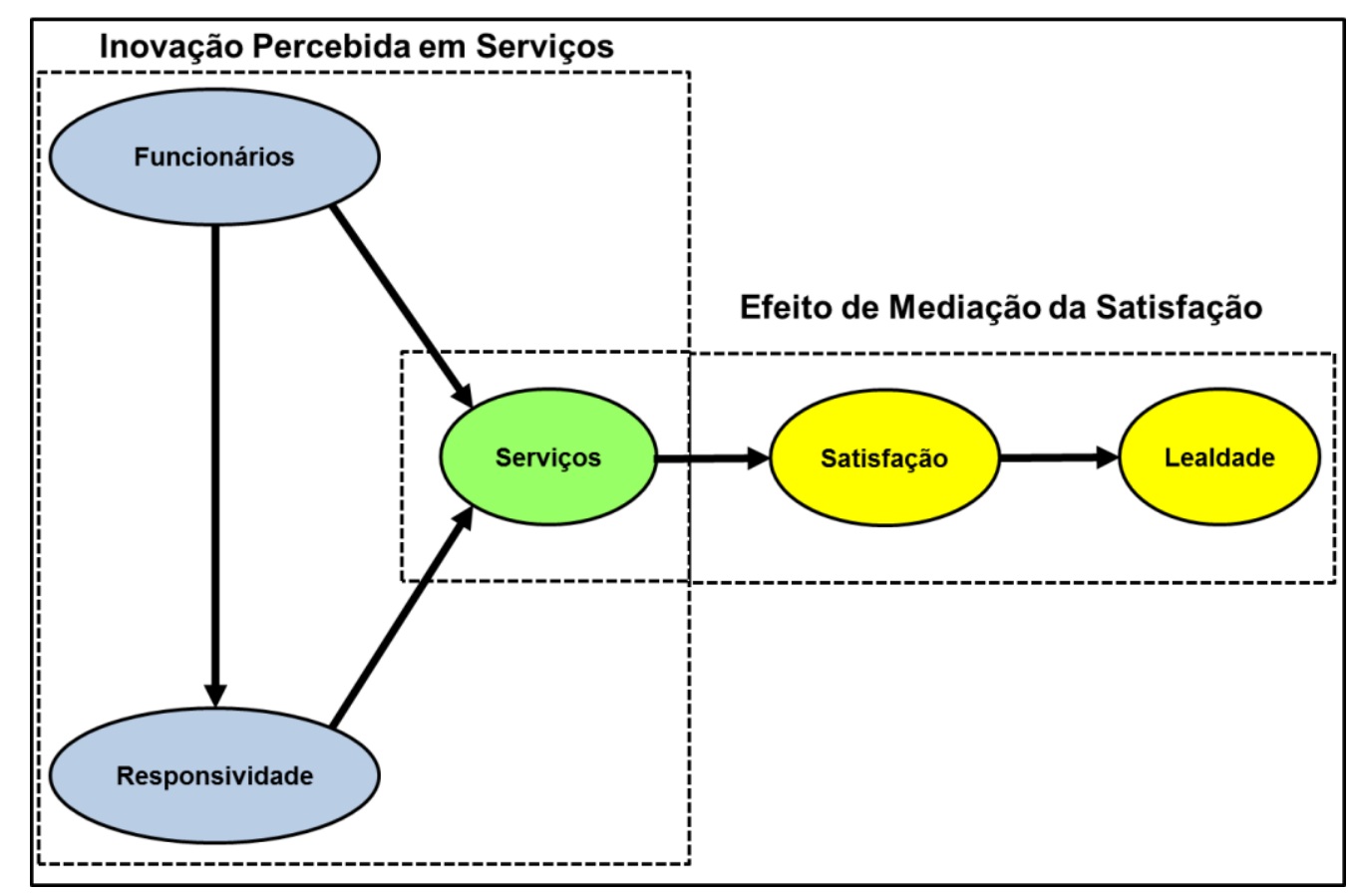

Figura 18: Modelo da influência da inovação na satisfação e lealdade

Fonte: Amaral et al; (2013, p. 41)

\subsubsection{Inovação de Marketing e Estratégia}

Vargas (2007) analisou o processo de inovação em serviços, relacionando-o com a estratégia organizacional. $O$ autor argumenta que o processo de inovação em serviços é endógeno, ou seja, não é identificado pela fonte de tecnologia empregada para ofertar serviços inovadores, mas, pela capacidade de implementar inovações previamente definidas em sua estratégia. $O$ conceito de reflexão estratégica e sua relação com a inovação em serviços foi abordado por Sundbo (2003). Para o autor citado, a reflexão estratégica aplicada à inovação em serviços é um processo social da empresa, no qual os gerentes e funcionários consideram o processo de inovação e estratégia, incluindo padrões organizacionais, interações de papéis e 0 aprendizado organizacional direcionados às condições de mercado. Ou seja, a 
reflexão estratégica indica como a empresa encontra suas estratégias e quando ela deveria reconsiderá-las.

A mudança contínua do mercado consumidor, a presença de processos automatizados, produtos que são inovados continuamente, serviços que são direcionados a públicos específicos, competitividade acirrada na maior parte dos segmentos de consumo, direciona as empresas à tomada de decisões rápidas e à entrega de produtos e serviços com valor e diferenciação.

A relação entre a orientação para a inovação de uma organização (ou seja, como uma organização é inovadora) e os tipos de estratégias competitivas que persegue, foi estudada por Dobni (2010). O autor enfatizou a orientação das empresas para a segmentação de mercado, redução do número de segmentos que as organizações atuam e a customização com a orientação para a estratégia de atuação em nichos de mercado. Apontou para a importância de não confundir inovação e estratégia, já que a primeira diz respeito a uma característica de "ser" da empresa (ser inovadora), ao passo que a segunda diz respeito a um "processo" de fazer. E indicou que a inovação está direcionada positivamente com o desenvolvimento de uma estratégia proativa, e que as organizações inovadoras irão direcionar-se para estratégias com foco no consumidor e baseadas em informação, ao passo que as não inovadoras terão foco interno e serão mais reativas. Os dados da Figura 19 mostram a relação entre a orientação para a inovação e a orientação estratégica (estratégias competitivas) que influenciam o desempenho competitiva das empresas, conforme Dobni.

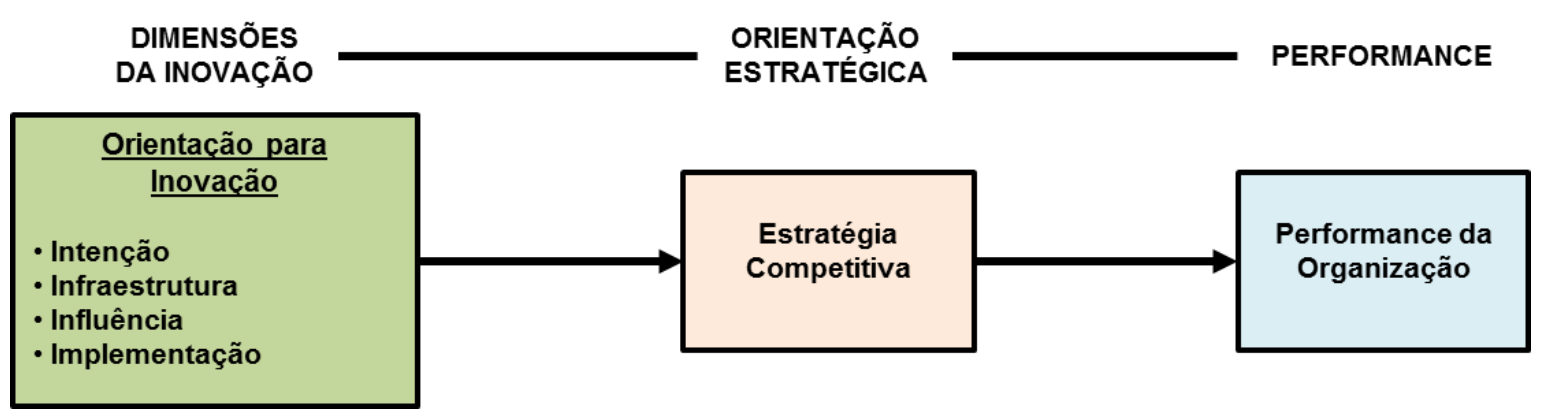

Figura 19: Dimensões da inovação, orientação estratégica e desempenho Fonte: Dobni; (2010, p. 333 (Fig. 1)) 
Na mesma linha da relação entre inovação, orientação estratégica e desempenho das empresas, Grawe; Chen e Daugherty (2009) estudaram as empresas de serviços e discutiram como a orientação estratégica afeta a inovação em serviços e qual o impacto resultante no desempenho da empresa no mercado, conforme mostram os dados da Figura 20.

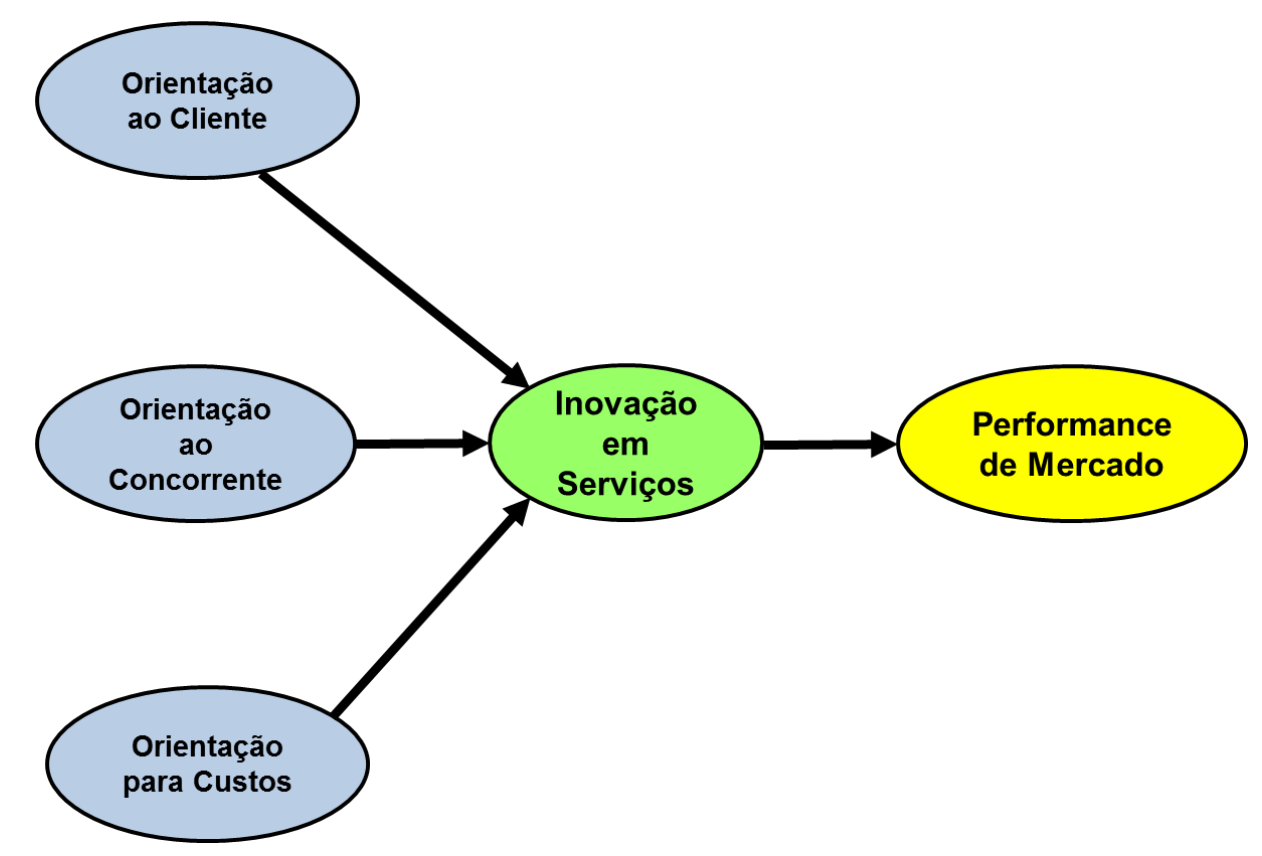

Figura 20: Modelo Conceitual interligando orientação estratégica, inovação em serviços e desempenho de mercado

Fonte: Grawe, Chen e Daugherty; (2009, pg. 293 (Fig. 1))

Os resultados obtidos por Grawe, Chen e Daugherty (2009) mostraram que existe uma relação positiva entre a orientação ao cliente, orientação ao concorrente e inovação em serviços, assim como há uma relação positiva entre inovação em serviços e desempenho de mercado.

Fitzsimmons e Fitzsimmons (2010) abordaram a visão estratégica em serviços e seus elementos (sistema de prestação de serviços, estratégia operacional, conceito do serviço e segmentos do mercado-alvo), partindo do entendimento do ambiente competitivo do setor de serviços: 
a) Poucas barreiras à entrada de concorrentes: inovações em serviços não são patenteáveis em sua maioria, podendo ser facilmente copiadas por concorrentes;

b) Poucas oportunidades para a economia de escala: escoamento do serviço acontece, geralmente, em pequena escala, com o cliente deslocando-se até à empresa ou vice-versa;

c) Flutuações de vendas: dependem da hora e dia da semana ou de maneira sazonal;

d) Pouca vantagem em negociar com compradores e fornecedores em razão do pequeno porte de muitas empresas; e

e) Fidelização de clientes: maior para empresas que prestam serviços personalizados.

Apoiados nas características do ambiente competitivo assinaladas, os autores sugerem três estratégias competitivas em serviços:

a) Liderança global em custos: requer equipamentos de última geração, controle de custos e despesas;

b) Diferenciação: criar lealdade do cliente a serviços percebidos como únicos com custos que o cliente esteja disposto a pagar; e

c) Foco: atendimento a um mercado-alvo restrito de modo mais eficaz que as empresas que servem mercados mais amplos.

Ao estudar as teorias que são apresentadas para formular a inovação em serviços, Sundbo (1997) afirma que o desenvolvimento tecnológico e empreendedorismo não explicam a inovação em serviços de maneira adequada e defende o paradigma da inovação estratégica, como o principal determinante para o tema. Complementa que as empresas líderes em estratégia são caracterizadas por terem a inovação, como uma tarefa estratégica e os funcionários estão envolvidos no processo de inovação. 
Govindarajan e Gupta (2001) e Govindarajan (2006) dedicaram-se a estudar a inovação estratégica e sua metodologia de implementação, fornecendo alguns conceitos básicos:

a) A inovação estratégica envolve novas respostas a questões fundamentais no contexto estratégico: quem é o cliente? Que valor é oferecido ao cliente e como é oferecido?

b) A inovação estratégica pode redefinir clientes potenciais, reformular valor aos clientes e redesenhar a arquitetura da cadeia de valor;

c) A inovação estratégica diferencia-se da inovação na melhoria de processos (que envolvem inovações incrementais sequenciais), na revolução dos processos (que envolvem novas tecnologias) e inovações em produtos e serviços (que não alteram os modelos de negócios tradicionais); e

d) A inovação estratégica envolve modelos de negócios, muitas vezes, sem mudanças nas tecnologias básicas nem nos produtos comercializados.

\subsubsection{Inovação Organizacional}

Para o Manual de Oslo, a definição de inovação organizacional é:

Uma inovação organizacional é a implementação de um novo método organizacional nas práticas de negócios da empresa, na organização do seu local de trabalho ou em suas relações externas. Inovações organizacionais podem visar à melhoria do desempenho de uma empresa por meio da redução de custos administrativos ou de custos de transação, estimulando a satisfação no local de trabalho (e assim a produtividade do trabalho), ganhando acesso a ativos não transacionáveis (como o conhecimento externo não codificado) ou reduzindo os custos de suprimentos (MANUAL DE OSLO, 2005, p.61). 
O Manual ainda expande o conceito de inovação organizacional:

As inovações organizacionais não são apenas um fator de apoio para as inovações de produto e processo; elas mesmas podem ter um impacto importante sobre o desempenho da firma. Inovações organizacionais podem também melhorar a qualidade e a eficiência do trabalho, acentuar a troca de informações e refinar a capacidade empresarial de aprender e utilizar conhecimentos e tecnologias (MANUAL DE OSLO, 2005, p.17).

Os autores do Manual, ao diferenciarem as inovações de processo e a organizacional complementaram que:

\begin{abstract}
Se a inovação envolve métodos de produção ou de abastecimento novos ou significativamente melhorados que visam reduzir custos unitários ou aumentar a qualidade do produto, trata-se de uma inovação de processo; se a inovação compreende 0 primeiro uso de novos métodos organizacionais nas práticas de negócios, na organização do local de trabalho ou nas relações externas da empresa, ela é uma inovação organizacional; se a inovação implica em métodos de produção ou de abastecimento novos ou significativamente melhorados, tem-se uma inovação de processo e organizacional (MANUAL DE OSLO, 2005, p.66).
\end{abstract}

\title{
2.4.4.1 Conceito de Inovação Organizacional
}

As inovações organizacionais estão relacionadas às mudanças nos processos administrativos das empresas, à tomada de decisões, à alocação de recursos, à atribuição de responsabilidades, ao relacionamento com pessoas e outras organizações, aos sistemas de recompensas e punições e outros fatores que estão atrelados à gestão das empresas (BARBIERI, 2003). O autor complementa que inovações organizacionais também incluem: modificações significativas na estrutura da empresa, introdução de técnicas de gestão avançadas e implementação de orientações estratégicas corporativas novas ou modificadas.

Sapprasert e Clausen (2012) estudaram a inter-relação entre inovação organizacional, inovação tecnológica e desempenho do negócio; indicam que a 
combinação entre inovação de produto e de processo com inovações de marketing e organizacional melhoram 0 desempenho em termos de vendas oriundas da inovação, na redução de custos e nas margens de lucros.

Lam (2004) estudou de forma abrangente a inovação organizacional por meio da relação entre a organização e a inovação em três perspectivas: a relação entre as formas de estrutura organizacional e inovatividade; a inovação como um processo de aprendizado organizacional e criação de conhecimento e a capacidade da organização para mudança e adaptação. A autora afirma que, de modo geral, a inovação organizacional é a criação e adoção de uma ideia ou comportamento novo para a organização, mas, conclui que não há consenso na definição do termo pela literatura. Em seu estudo, a análise da relação entre as estruturas organizacionais e inovação indica:

a) Estruturas simples: são mais empreendedoras e, com frequência, altamente inovadoras, atuando em ambiente de alto risco. O julgamento individual e os recursos limitados ao crescimento são os pontos fracos;

b) Estruturas tipo máquina burocrática: projetadas para eficiência e estabilidade e resolução de problemas de rotina, mas, altamente rígidas e com dificuldade em conviver com o novo e com a mudança;

c) Estrutura tipo burocracia profissional: os especialistas individuais podem ser altamente inovadores em seu domínio de atuação, mas, têm dificuldade de coordenação entre funções e áreas diversas, o que impõe limites para a capacidade inovadora da empresa como um todo;

d) Estruturas com formas divisionais definidas: têm habilidade de concentrar competências em nichos específicos. O ponto fraco é a dispersão de um departamento de pesquisa e o desenvolvimento central por meio de esforços locais, com competição entre as divisões, inibindo o compartilhamento do conhecimento; e

e) Estruturas tipo adocracias: capacidade de rápido aprendizado, altamente adaptáveis e inovadoras. O ponto fraco é haver uma vida curta da estrutura instável. 
Elche-Hotelano (2011) analisou as fontes de conhecimento em empresas de serviços espanholas e indica que a interação entre funcionários, fornecedores e consumidores gera uma variedade de processos de aprendizado, salientando que o conhecimento tácito é mais difícil de codificar e comunicar.

\title{
2.4.4.2 Inovação de Modelo de Negócio
}

Em seu clássico artigo, Osterwalder e Pigneur conceituam modelos de negócios:

\begin{abstract}
Um modelo de negócio é uma ferramenta conceitual contendo uma série de elementos e seu inter-relacionamento e permite expressar a lógica de negocio de uma empresa específica. É uma descrição do valor que uma empresa oferece a um ou vários segmentos de consumidores e a arquitetura de uma empresa e sua rede de contatos parceiros para a criação, marketing e entrega desse valor e relacionamento com capital para gerar fluxos de receitas sustentáveis e lucrativas (Osterwalder; Pigneur, 2005, p.10).
\end{abstract}

Ao abordar o conceito de modelo de negocio em nível de empresa, os autores ressaltam seus pontos importantes:

a) Distinção entre estratégia e modelo de negócio: modelo de negócio é um sistema que mostra como as peças de um negócio se ajustam, e a estratégia sempre inclui competição. A estratégia tem execução e implementação, e o modelo de negócio mostra como um negócio trabalha como um sistema;

b) Implementação de um modelo de negócio: inclui traduzir o modelo de negócio em algo mais concreto, como a estrutura de negócio, os processos de negócio, infraestrutura e sistemas. Para implementar um modelo de negócio, é necessário financiamento com fundos internos ou externos;

d) Distinção entre modelos de empresas e modelos de negócios: o termo modelo de empresa é um nome coletivo para o uso de modelos na engenharia e operação da 
empresa (processos e atividades), e os modelos de negócios focam-se em criação de valor e clientes;

e) Tempo: modelos de negócios podem mudar rapidamente, e o termo "modelo de negócio" de uma empresa refere-se à maneira como ela faz negócio em um momento específico de tempo;

f) As partes não são o todo: modelo de negócio é entendido em um conceito mais holístico que envolve elementos, como precificação, relacionamento com o cliente, parceria e compartilhamento de receitas; e

g) Modelo de negócios é composto por quatro pilares que se abrem em nove blocos: produto (proposição de valor), interface com o consumidor (consumidor alvo, canal de distribuição, relacionamento), gestão da infraestrutura (configuração de valor, competência principal, rede de contatos de parceria) e aspectos financeiros (estrutura de custos e modelo de receita).

Davila, Epstein e Shelton (2007, p.51) definem modelos de negócios como "a maneira pela qual a empresa cria, vende e proporciona valor aos seus clientes". Os autores detalham as áreas dos modelos de negócios que podem orientar a inovação, que são:

a) Proposição de valor: relaciona-se ao que é comercializado e lançado no mercado, que pode ser algo novo ou melhoria do que já existe. Os autores enfatizam a mudança de paradigma das empresas de manufatura, que optaram por ter uma proposição de valor baseada em serviços;

b) Cadeia de suprimentos: relaciona-se como o valor é criado e entregue ao mercado, enfatizando que a mudança de modelo de negócio afeta as etapas ao longo da cadeia de valores na produção e entrega do serviço ao cliente final; e

c) Cliente-Alvo: relaciona-se à mudança que envolve ao público a quem se vende, exemplificando que, normalmente, ocorre quando a empresa identifica um segmento onde nunca atuou, mas, que pode enxergar valor nos serviços por ela oferecidos. 
Ainda na linha de definições de modelo de negócio, Johnson, Christensen e Kagermann (2008) têm uma definição que se desmembra em quatro elementos que, juntos, criam e entregam valor:

a) Proposição de valor ao cliente: refere-se à melhor solução ao cliente frente as já existentes, ao menor custo/benefício;

b) Fórmula de lucro: como a empresa cria valor para si mesma, enquanto entrega valor ao cliente;

c) Recursos-chave: pessoas, tecnologia, produtos, facilidades, equipamentos, canais e marca, que são necessários à entrega de proposição de valor ao cliente-alvo; e

d) Processos-chave: processos operacionais e gerenciais que permitem a entrega de valor, de modo a ser possível a repetição e o aumento em escala.

Com base na conceituação de modelo de negócio, a inovação em modelo de negócio está ligada ao fato das empresas comercializarem novas ideias e tecnologias por meio dele. A inovação em modelo de negócio está relacionada à inovação organizacional (ou às novas formas organizacionais) e à mudança nos processos organizacionais. A cultura da empresa deve encontrar formas de aceitar o novo modelo, enquanto mantém a efetividade do modelo atual até que o novo esteja pronto para ser utilizado completamente (CHESBROUGH, 2010).

Ainda na linha da inovação em modelo de negócios estar ligada à inovação organizacional, Zmoginski et al. (2009) afirmaram que os conceitos de inovação organizacional e de modelo de negócios na literatura são, em muitos casos, considerados sinônimos e estão ligados à mudança ou introdução de um novo modelo para melhorar a competitividade. Já Araujo e Zilber (2013) relacionaram a inovação organizacional à inovação de modelo de negócio com base na definição do Manual de Oslo (2005), entendendo a inovação em modelo de negócio, como um "novo método organizacional" que está contido na definição de inovação organizacional. Ades e Plonski (2009) estudaram a inovação em modelo de negócio 
inserida em uma visão integrada com outros tipos de inovação. Analisam a literatura sobre a tipologia de inovações e indicam que, apesar da inovação em modelo de negócio não ser contemplada no Manual de Oslo, está inserida na definição de inovação organizacional.

Ao relacionarem a inovação de modelo de negócio e vantagem sobre a concorrência, Mitchell e Coles (2003) afirmaram que, inovar o modelo de negócios de forma contínua, fornece uma forma paralela de diferenciação da concorrência. Quando uma empresa melhora seu modelo de negócio, redirecionando seu foco, alguns concorrentes continuarão em seu caminho antigo e estarão perdendo a participação de mercado, outros estarão confusos com a nova situação e ficarão inertes. Conforme Govindarajan e Gupta (2001), o modelo de negócios é o resultado da resposta a três questões que operam como um sistema: quem são os clientesalvo? Qual valor queremos Ihes entregar? Como iremos criar esses valores? Os autores afirmam que, pautadas nessas respostas, existem três arenas nas quais as regras da competição podem mudar em regras de sucesso (conforme o ponto de vista do cliente): mudança da arquitetura da cadeia de valor (pesquisa e desenvolvimento, produção, marketing, distribuição e serviço); reinvenção do conceito de valor do cliente e redefinição da base de clientes.

Ao abordar a inovação em modelo de negócio em serviços, Hurmelinna-Laukkanen (2010) estudou a relação entre a colaboração na inovação e a tendência de introduzir novos modelos de negócios que tragam inovações de serviços, como principal oferta. Os resultados apresentados indicam que as inovações em serviços tipicamente incluem atividades colaborativas (compartilhar conhecimento); por outro lado, as empresas precisam proteger o conhecimento (que traz vantagem competitiva). Na gestão dos negócios, as implicações desses fatos demandam uma análise dos modelos de negócios e a verificação se a inovação em serviços é o objetivo principal. Nesse caso, a autora recomenda tomar medidas de proteção com relação ao pessoal de contato direto com o cliente, além de outros atores com interface com clientes e que participam do processo de inovação no modelo de negócio. 


\subsubsection{Inovação no Processo de Recepção e Entrega (Linha de Frente ou Front Office) e Produção (Retaguarda ou Back Office)}

Corrêa e Caon (2002) ponderam que o grau de interação e extensão do contato da empresa com o cliente irá determinar por quanto tempo o contato será estabelecido e os aspectos a serem abordados nesse contato. Os autores definem que as atividades de alto contato com o cliente são chamadas de linha de frente (front office) e as que ocorrem sem contato com o cliente são denominadas de retaguarda (back office). Adicionalmente, ampliam-se algumas características destas duas áreas que se relacionam com o grau de estocabilidade dos elementos do pacote de serviços, da interação e extensão no contato com o cliente e avaliação do desempenho da equipe. Os dados da Figura 21 mostram de forma ampliada as atividades das linhas de frente e de retaguarda.
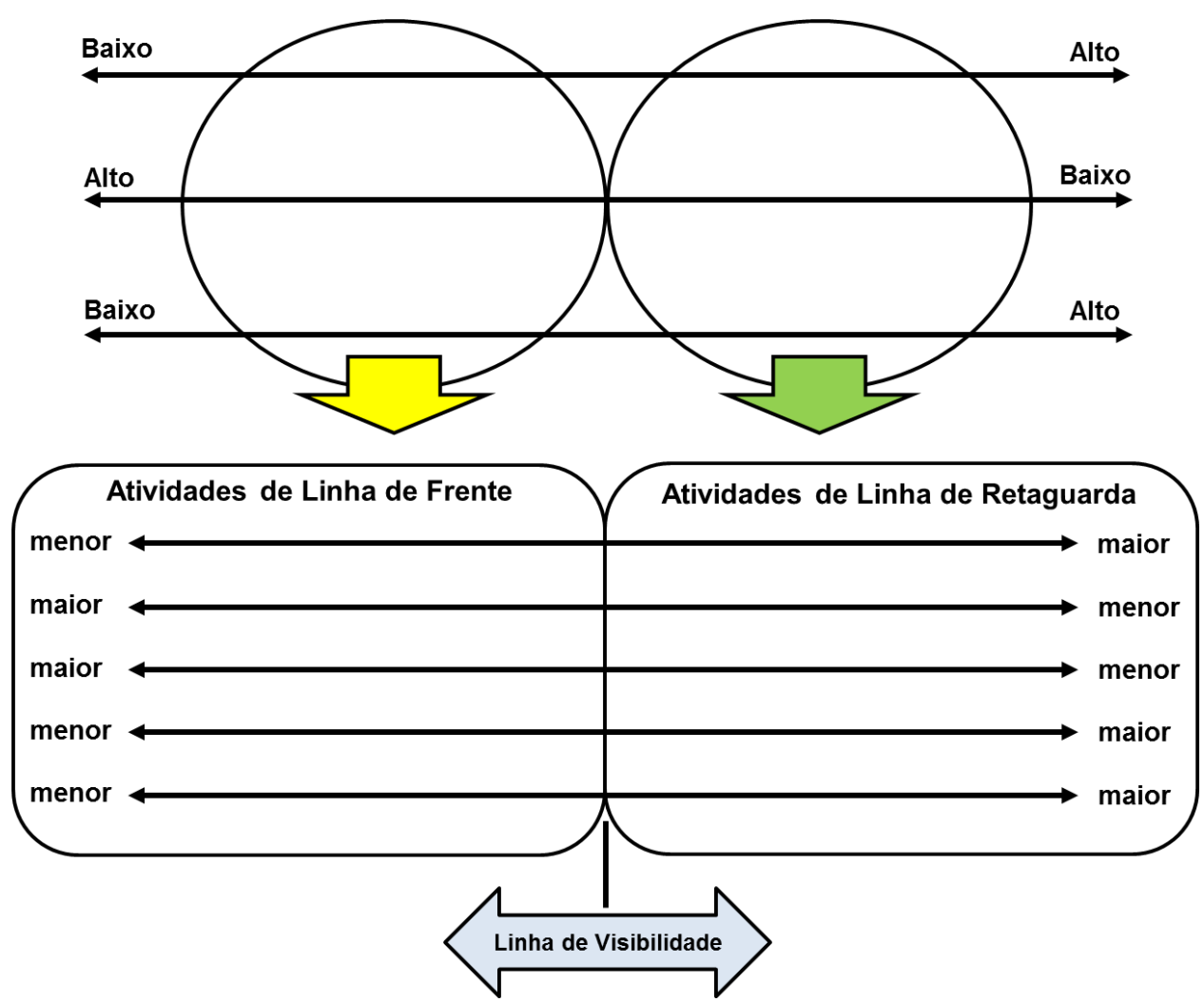

Figura 21: Atividades das linhas de frente e retaguarda Fonte: Corrêa e Caon; (2010, p. 68 (Fig. 2.14))

Assim, a linha de frente tem baixo grau de estocabilidade, alto grau de intensidade, extensão de contato elevada e menor grau de objetivação de desempenho (sendo 
mais ligada à percepção do que à experiência do serviço). Já as atividades da linha de retaguarda têm maior grau de estocabilidade, menor grau de interação/extensão de contato com o cliente e maior grau de objetivação na avaliação do desempenho, por estarem mais ligadas a processos de produção do serviço.

A influência dos funcionários da linha de frente e do consumidor no desempenho do desenvolvimento de novos serviços foi investigada por Melton e Hartline (2010); que afirmam que os resultados de sua pesquisa suportam a hipótese de que a participação dos clientes e funcionários da linha de frente em estágios específicos do processo de desenvolvimento de novos serviços afetam indiretamente 0 desempenho de vendas e os resultados da eficiência no desenvolvimento de projetos.

Assim, os funcionários da linha de frente têm uma posição única na observação das reações dos consumidores às ofertas de serviço e do processo de sua entrega, além de serem fontes para inovações por sua interação constante com os consumidores. A interação com uma grande quantidade de pessoas e os atributos como flexibilidade, facilidade para ajustar o comportamento de acordo com as situações, empatia pelo cliente e habilidade para monitorar o processo de entrega do produto são características da linha de frente e que podem auxiliar na captação das necessidades dos clientes no processo de inovação (FITZSIMMONS; FITZSIMMONS, 2010).

Teboul (2008) discutiu o contraste entre as áreas de frente (front office) e de retaguarda (back office) com foco no cliente, afirmando que o objetivo da área de apoio é zero defeito e da área de frente é zero deserção do cliente. Reforçando a importância da participação de funcionários na inovação em serviços, Fitzsimmons e Fitzsimmons (2010, p.37) destacam que "um novo conceito em serviço geralmente tem origem em um funcionário observador que trabalha com os clientes e identifica uma necessidade que não foi atendida".

Zeithaml e Bitner (2011) citam a importância dos funcionários da linha de frente e enfatizam os efeitos dos comportamentos dos funcionários na qualidade do serviço: 
a) Confiabilidade: a execução de um serviço, muitas vezes, é totalmente controlada pelos funcionários da linha de frente e quando os serviços falham recorrem a julgamento próprio para a recuperação do serviço original;

b) Responsividade: o funcionário da linha de frente está disponível e auxilia de modo rápido ao cliente;

c) Segurança: capacidade dos funcionários em mostrar credibilidade e inspirar confiança; e

d) Empatia: entendimento, atenção e flexibilidade no atendimento às necessidades dos clientes.

A participação e a motivação dos funcionários da linha de frente na implementação da inovação foram estudadas por Cadwallader et al (2010); que afirmam que os funcionários da linha de frente exercem papel crítico na introdução e explanação das inovações de serviços a seus clientes. Por essa razão, as inovações em serviços terão sucesso se esses funcionários as abraçarem, executarem e promoverem, mas, para isso, devem estar motivados a participar. Os funcionários da linha de frente não somente são facilitadores da entrega de serviços de qualidade, mas têm papel importante na construção de relacionamentos com os clientes. Os dados da Figura 22 mostram os níveis hierárquicos da motivação e sua relação com a participação e implementação da inovação, desde a motivação global, passando pela motivação contextual (tecnologia e trabalho) até o sentimento e crenças dos funcionários na inovação e sua decisão em participar da mesma e sua implementação. 


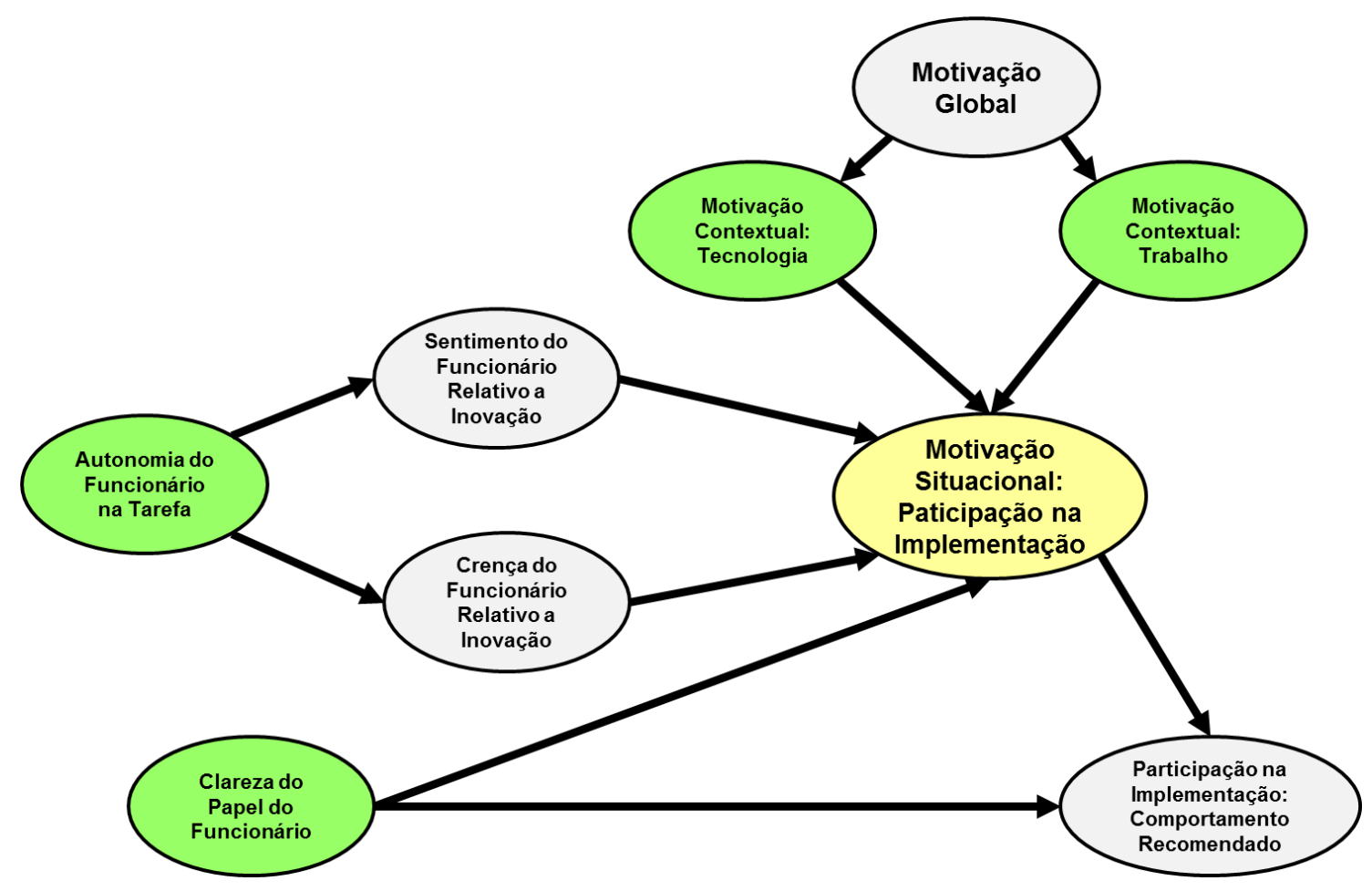

Figura 22: Modelo Conceitual dos Níveis Hierárquicos da Motivação

Fonte: Cadwallader et al.; (2010, p. 224)

Na mesma linha de estudo da motivação dos funcionários para inovar, Fernandez e Pitts (2011) buscaram identificar os fatores que motivam os funcionários da linha de frente em repartições burocráticas para o comprometimento no comportamento inovador. Assim, listam alguns fatores que encorajam a inovação de baixo para cima: expectativa de receber recompensa pela inovação, treinamento e desenvolvimento do funcionário, aumento de poder do funcionário, envolvimento no processo decisório e relação com os supervisores.

A concessão de poder dado a funcionários no processo de inovação foi estudada por Sundbo (1996), que adverte, apesar de importante, o poder dado aos funcionários deve ser controlado e balanceado, devendo as empresas organizar-se para gerenciar esse processo. Os mecanismos de controle listados pelo autor são: controle do tempo durante o processo de inovação, uso de estratégia como mecanismo de controle (evitando o emprego de recursos em inovações não adequadas) e o controle do processo de inovação gerenciados por um departamento de inovação e aprendizado organizacional. 
Coelho e Augusto (2010) investigaram os efeitos principais e interativos das características do trabalho na criatividade dos funcionários de serviços da linha de frente; apontando que a criatividade requer interesse pelo problema e a descoberta de meios para resolvê-lo. Indicam que as características do trabalho (variedade, identidade, retorno e significância) e autonomia influenciam a criatividade do funcionário, conforme os dados da Figura 23.

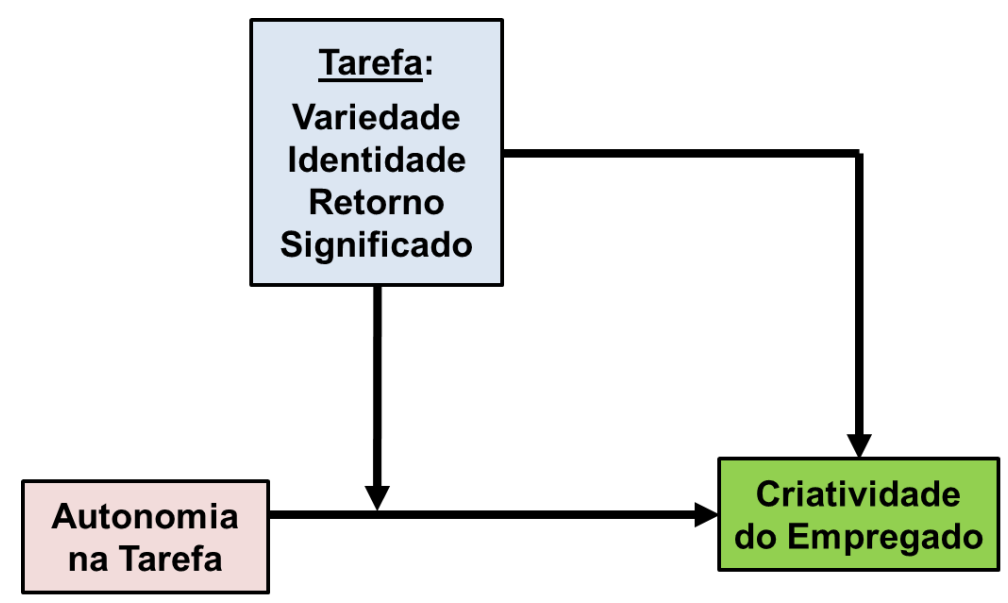

Figura 23: Modelo da Influência das Características do Trabalho na Criatividade do Funcionário

Fonte: Coelho e Augusto; 2010, pg. 428

Os principais impulsionadores para a geração de ideias dos funcionários da linha de frente visando à melhora do serviços aos consumidores foram estudados por Lages e Piercy (2012); que investigaram os caminhos para a geração de ideias rumo à melhora nos serviços dos funcionários da linha de frente, com o objetivo atender às necessidades dos clientes e o fornecimento do exato serviço de que necessitam. A geração de ideias é função do meio ambiente organizacional e das características pessoais do funcionário. Os fatores organizacionais e individuais que influenciam a geração de ideias para a melhora dos serviços são apresentados em um framework conceitual, conforme os dados da Figura 24. 


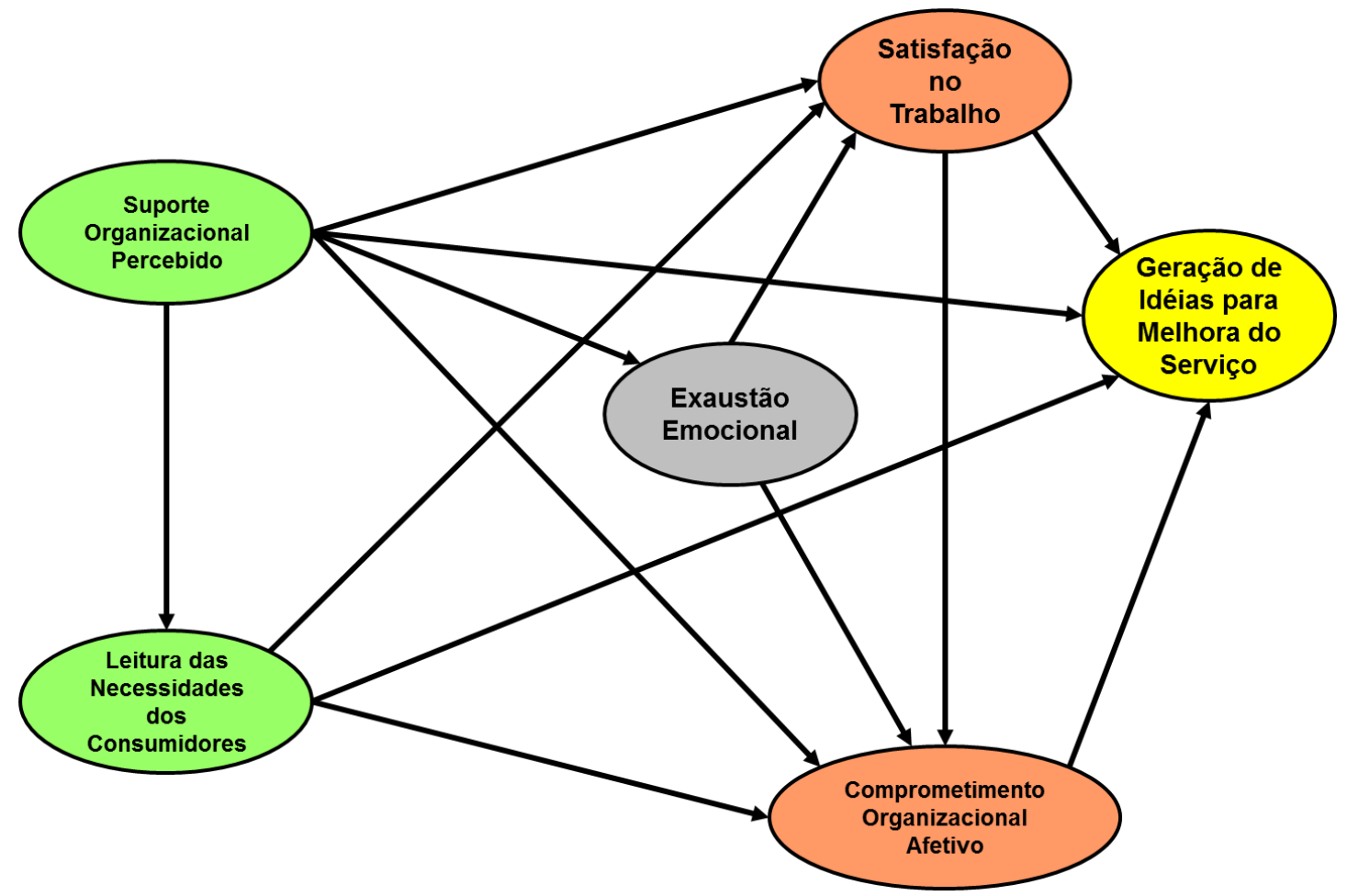

Figura 24: Framework Conceitual: Fatores Organizacionais e Individuais e Geração de Ideias para Melhora do Serviço

Fonte: Lages e Piercy; (2012, p. 217)

\subsection{Inovação em Micro e Pequenas Empresas (MPEs) do Setor de Serviços}

Os obstáculos para inovação no setor de serviços e que afetam diretamente as MPEs incluem as barreiras burocráticas, restrição financeira para investimentos em inovações, problemas técnicos, regulação de mercado e a elevada carga tributária (BATTISTI; VIGORENA; ALVES, 2012).

Vasconcellos e Marx (2011), ao abordarem o avanço das MPEs no valor das inovações no mercado, afirmaram que as MPEs têm uma nova forma adaptativa (já que os recursos são escassos) de lidar com a inovação, utilizando contratos e parcerias externas para auxiliar o processo inovador.

Para Kellog e Nie (1995), as empresas de serviços variam de pequenas organizações a grandes conglomerados, sendo relativamente fácil às pequenas empresas de serviços definir o pacote de serviços, determinar o grau de 
customização, isolar as melhores formas pelas quais os serviços são criados e determinar o grau de influência dos consumidores na entrega do serviço.

Em sua pesquisa sobre a inovação no setor de serviços na Itália em 19 segmentos e comparando as empresas de pequeno e grande portes, Evangelista e Sirilli (1998) constataram que $37,1 \%$ do total de empresas eram inovadoras. As de pequeno porte (29-49 empregados) representavam mais de 50\% do total pesquisado, porém, somente $26,6 \%$ foram consideradas inovadoras, em contraposição às empresas de serviços de grande porte (mais de 500 trabalhadores) com um índice acima de 75\% de empresas inovadoras.

Bos-Brouwers (2010) analisou a capacidade de inovação das pequenas e médias empresas (PMEs) e suas diferenças quando comparadas com as de grande porte. As PMEs têm mais flexibilidade (menor burocracia, resposta mais rápida às mudanças e comunicação interna mais rápida e eficiente); e o proprietário, geralmente, é mais dinâmico e empreendedor, tendo papel direto na geração de ideias para inovação. Mas, essas empresas podem apresentar como desvantagens a baixa habilidade do proprietário com as questões gerenciais (planejamento, delegação inadequada e dependência de pessoas para sobreviver), questões financeiras (dificuldade de atrair capital e investir em tecnologia) e recursos humanos (dificuldade em atrair pessoas habilidosas e com bom conhecimento tecnológico).

\subsubsection{Dados Estatísticos das MPEs do Setor de Serviços}

Os dados da pesquisa SEBRAE (2012a), utilizando informações referentes ao ano de 2009, mostram o perfil das micro e pequenas empresas no Brasil e por região, conforme os dados do Gráfico 1. 


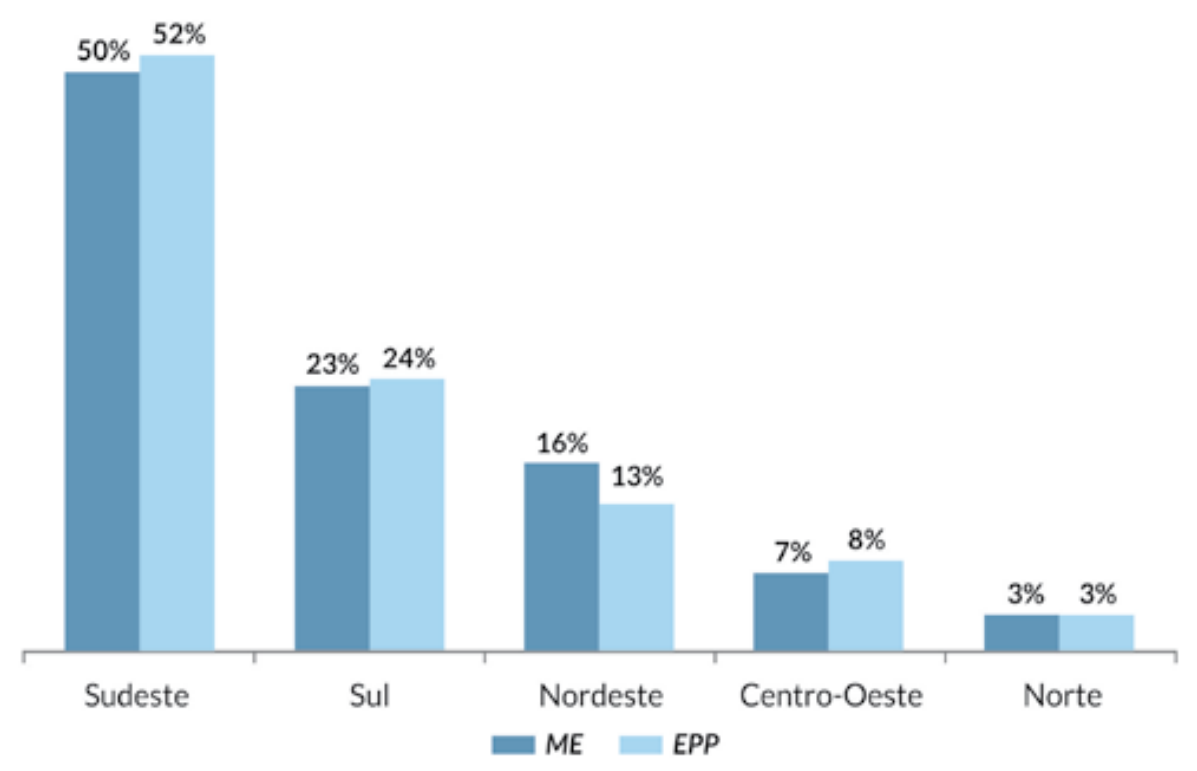

Gráfico 1: Distribuição de ME e EPP por Regiões

Fonte: Sebrae Nacional a partir de dados da Receita Federal do Brasil.

Observa-se que a grande concentração de micro e pequenos empreendimentos, onde a grande maioria das lavanderias domésticas está inserida (item 2.3), encontra-se na Região Sudeste (mais de $50 \%$ do total), à qual pertencem o Estado e a cidade de São Paulo.

Os dados do Gráfico 2 mostram a distribuição das micro e pequenas empresas por setores, mostrando a prevalência das micro e pequenas empresas no setor de comércio ( $59 \%$ do total) e a concentração de microempresas no setor de serviços (27\%). 


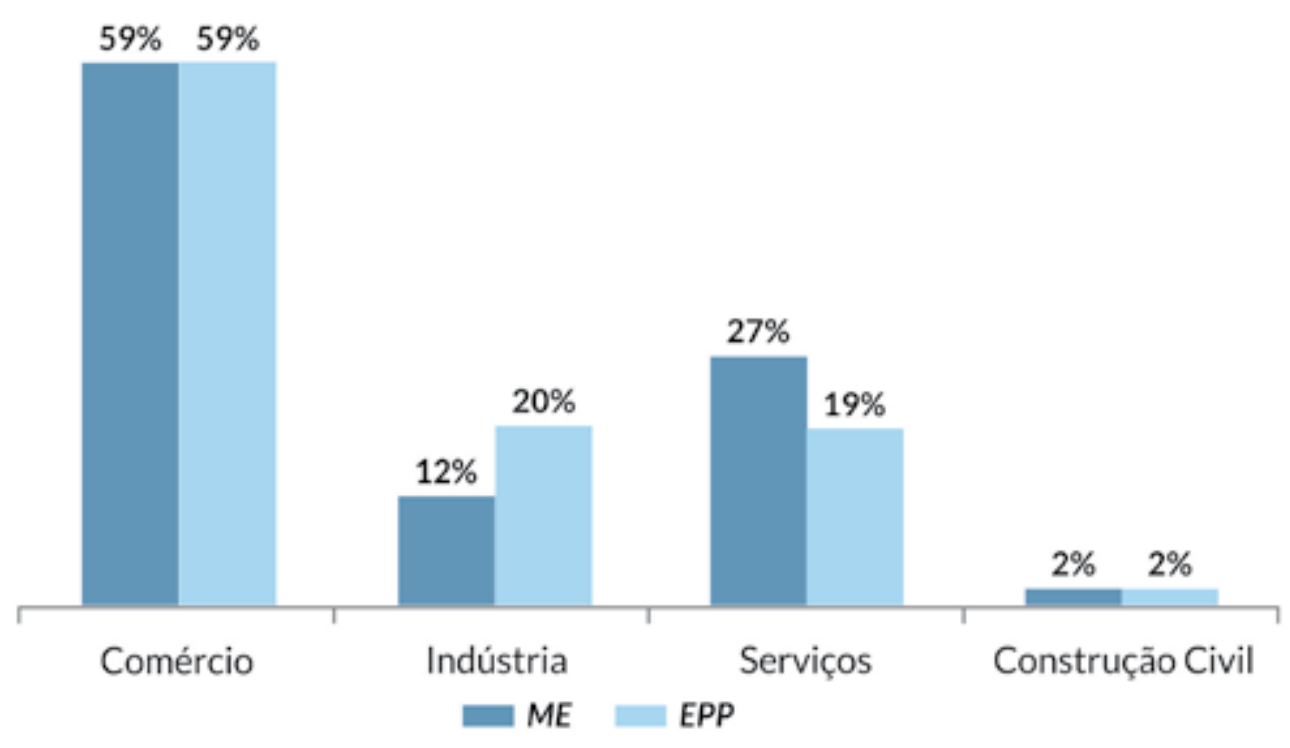

Gráfico 2: Distribuição de ME e EPP por setores

Fonte: Sebrae Nacional a partir de dados da Receita Federal do Brasil.

O estudo do SEBRAE sobre as MPEs do Estado de São Paulo (SEBRAE, 2012b) mostra dados estatísticos importantes sobre o universo de micro e pequenas empresas:

a) $99 \%$ das empresas do Estado de São Paulo são micro e pequenas empresas, gerando $48 \%$ dos empregos e $36 \%$ da folha de salários;

b) 728.077 MPEs do Estado de São Paulo (36\% do total do estado) são empresas de serviços, onde estão incluídas as lavanderias domésticas; e

c) Das 728.077 MPEs de serviços no Estado de São Paulo, 23.270 empresas (3,2\% do total) são dedicadas a serviços pessoais, onde estão incluídas as lavanderias domésticas.

\subsubsection{Inovação em MPEs do Setor de Serviços}

Nos itens anteriores, foram discutidos aspectos relacionados à inovação em empresas e inovação em empresas de serviços. Neste item, será discutida, 
especificamente, a inovação combinada das micro e pequenas empresas no setor de serviços, sendo assim mais pontuais e aproximando-se mais do segmento das lavanderias domésticas, foco do presente estudo.

Estudos sobre inovação em pequenas empresas industriais são mais comuns que as pequenas empresas de serviços, já que as primeiras estão mais ligadas às áreas tecnológicas, e as empresas de serviços são consideradas empresas não tecnológicas ou menos intensivas em pesquisa e desenvolvimento (OCDE, 2005).

Em sua análise sobre os fatores de inovação para a sobrevivência das MPEs brasileiras, Pereira et al. (2009, p.50) citam que os empresários brasileiros "estão inovando no processo de gestão, estando mais atentos para questões como planejamento, análise financeira e qualidade das equipes internas". Por outro lado, o processo decisório aparece, como uma das áreas de conhecimento menos importantes ( $8 \%$ das respostas).

Observou-se uma tendência de maior profissionalização do negócio, mas ainda existe a deficiência tecnológica (ex.: baixo número de patentes das MPEs em relação ao número total de empresas), a presença de membros da família sem capacitação gerencial e certa descontinuidade com a saída do proprietário, comprometendo os resultados e a sobrevivência das empresas. Ao comparar a inovação em empresas de pequeno, médio e grande portes, Elche-Hotelano (2011) pesquisou empresas espanholas e constatou que as empresas de pequeno e grande portes são menos inovadoras, ao passo que as de médio porte mostram alta propensão a inovar (quase 60\%).

Tidd; Bessant e Pavitt (2008) abordaram o posicionamento das pequenas quanto à inovação, ressaltando que as oportunidades para a inovação nas pequenas empresas são fortemente influenciadas pelo sistema de inovação em que se acham inseridas. Os autores indicam que as pequenas empresas utilizam mais pesquisa e desenvolvimento interno do que fontes externas de conhecimento, são altamente influenciadas pelo perfil inovador de seus fornecedores e clientes e fortemente condicionadas ao contexto geográfico e nacional onde estão inseridas. Conforme referem Tamura et al. (2005), existem diferenças significativas no desempenho 
inovador entre os diferentes tamanhos de empresas no setor de serviços. Empresas de maior porte (mais de 250 funcionários), aparentemente, são mais inovadoras que as pequenas (menos que 50 funcionários) e as médias empresas (50-249 funcionários). Os autores constataram também que mais de $80 \%$ das empresas de serviços são pequenas empresas, contra $75 \%$ do setor de manufatura.

A relação entre a atividade inovadora e o porte das empresas foi estudada por Acs e Audretsch (1987), e testada a hipótese de que a relativa vantagem inovadora entre grandes e pequenas empresas é determinada pela concentração de mercado, a extensão das barreiras de entrada, a composição do tamanho da empresa na indústria e a importância geral da atividade de inovação.

Os autores supracitados concluíram que as grandes empresas tendem a ter relativa vantagem inovadora em indústrias intensivas em capital, concentradas e que produzem bens diferenciados. Por outro lado, as pequenas empresas tendem a ter relativa vantagem inovadora em indústrias que têm alto componente de trabalho especializado. A força de trabalho especializada nas MPEs, aparentemente, facilita a entrada em mercados específicos que demandem grau mais elevado de conhecimento técnico e mercadológico.

Os mesmos autores apresentam um modelo sugerindo que os resultados da inovação sejam influenciados por pesquisa e desenvolvimento e características de mercado em grandes e pequenas empresas (ACS; AUDRETSCH, 1988), reforçando a relação entre o número de inovações, o grau de especialização e a força de pesquisa e desenvolvimento, como fatores com efeitos nas grandes e pequenas empresas.

Mc Dermott e Prajogo (2012, p.219) estudaram a inovação em serviços e o desempenho das pequenas e médias empresas de serviços. Discutem a relação entre exploração, definida como "aquela mais frequentemente associada com serviços e produtos novos e globais, criando novos mercados e pela identificação das necessidades de consumidores e mercados emergentes", e explotação, definida como aquela "associada com extensões de linhas de serviços e produtos existentes" na inovação e desempenho do negócio. Os efeitos dessas duas orientações de 
inovação no desempenho do negócio em pequenas e médias empresas é mostrado nos dados da Figura 25.

Os autores supracitados concluíram que a sinergia entre as duas orientações (exploração e explotação) é associada positivamente ao desempenho dos negócios. $O$ trabalho mostra ainda que as inovações em extensões de linha de produtos podem ser potencializadas se combinadas sinergicamente com produtos oriundos da inovação radical das linhas existentes, mais do que se forem aplicadas individualmente. Com relação à comparação entre empresas de produtos e serviços, Mc Dermott e Prajogo (2012) afirmam que o impacto da inovação em serviços é diretamente observável (mais fácil de ser copiada e replicada) e mais rápida de implementar, ao passo que a inovação de produto leva mais tempo para impactar no desempenho do negócio. Os autores citados analisaram também a inovação e o porte das empresas e concluem que as empresas menores são menos propensas à inovação radical por falta de capital e outros recursos, e as empresas maiores beneficiam-se mais da exploração que da explotação. Também observaram que as empresas com menos de 20 funcionários são mais focadas na operação, ao passo que as maiores (200-250 funcionários) são mais direcionadas à estratégia.

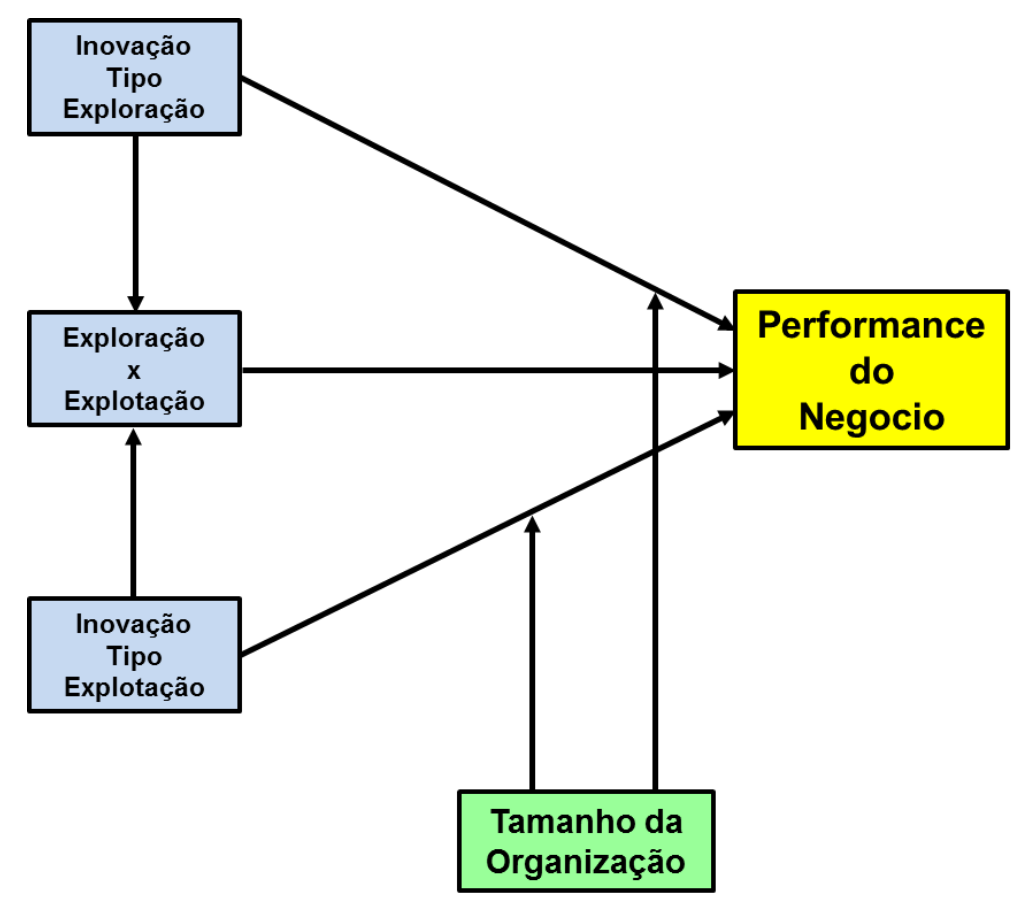

Figura 25: Relação entre exploração, explotação e desempenho do negócio Fonte: Mc Dermott e Prajogo; (2012, p. 228) 
Hine e Ryan (1999) examinaram o aspecto inovador das pequenas empresas de serviços e questionaram as razões de determinados grupos de empresas serem mais inovadores que outros, analisando o impacto da inovação na criação de valor das empresas em seus segmentos. Afirmam que as inovações de processo e inovações não tecnológicas (estas últimas definidas como as que ocorrem dentro das empresas e não estão ligadas a produtos/serviços ou métodos de produção) são mais frequentes e aparentes.

Desse modo, os autores supracitados sugerem que as pequenas empresas de serviços precisam interagir com o ambiente externo (pois são afetadas por ele de alguma forma) por meio do desenvolvimento de uma verdadeira estratégia de inovação. Os resultados do estudo mostram que as empresas, a partir de 20 funcionários, são mais inovadoras (maior índice para empresas entre 50 e 99 funcionários), e empresas de serviços pessoais (onde se incluem as lavanderias) têm seu maior índice para inovações do tipo não tecnológicas, seguidos de inovações tecnológicas (possivelmente pela aquisição de equipamentos com tecnologia mais avançada para a produção de seus serviços).

\subsection{Tipologia da Inovação e as MPEs do Setor de Serviços}

Laforet (2011) estudou como ocorre a inovação organizacional em pequenas e médias empresas (PMEs), desenvolvendo um framework teórico que mostra como a inovação ocorre e seu impacto no desempenho financeiro. Enfatiza a dificuldade em obter os dados financeiros das empresas para análise e afirma que os respondentes de sua pesquisa tinham diferentes percepções e habilidades ao comentar sobre o uso de índices mais sofisticados, como lucratividade e retorno sobre o investimento. No framework proposto, são analisados três aspectos: os vetores da inovação; aspectos positivos e negativos dos resultados da inovação com base no modo interno de trabalhar nas empresas e o impacto da inovação no desempenho financeiro. Os resultados mostraram: 
a) Que a inovação em PMEs é direcionada, entre outros fatores, por margem de lucratividade, modelo de negócio, ganhos de curto prazo, qualidade, fontes externas, força de trabalho qualificada e melhora da condição de trabalho;

b) Os resultados da inovação serão positivos se tiverem impacto no desempenho financeiro, que também auxilia a ter recursos para uma futura inovação;

c) Os resultados da inovação serão negativos se tiverem impacto negativo no desempenho financeiro, levando a uma eventual parada no processo de inovação e sérias consequências para o negócio como um todo.

A inovação em modelos de negócios em microempresas foi estudada por Bourdon e Jaouen (2011), com o objetivo de entender os impactos organizacionais e estratégicos das mudanças criadas pela introdução da tecnologia da informação (TI) em microempresas. Os autores apontam haver uma mudança no modelo de negócio baseada no uso da tecnologia da informação e que a inovação via TI requer a integração dos clientes em todo o processo e também a necessidade de gerir a pressão interna dos funcionários na implementação da inovação.

\subsection{Contextualização do Segmento de Lavanderias Domésticas}

As tipologias do setor de serviços foram resumidas por Kon (2004), apoiadas nos dados da literatura, tomando como base de classificação a produção, função e consumo de serviços. As lavanderias estariam inseridas na função terciária e como serviços pessoais. A inovação em serviços comoditizados foi estudada por Rothkopf e Wald (2011), que mostram algumas características comumente encontradas no segmento das lavanderias domésticas. Em razão da competição por preços baixos, a maioria das empresas trabalha com baixas margens e oferece serviço similar. Os autores sugerem as seguintes características para classificação do grau de comoditização do serviço: 
a) Empresas e marcas estabelecidas perdem a participação de mercado, à medida que novos entrantes competem por preço e ganham participação. Como consequência, margens e lucros são reduzidos;

b) Alta disponibilidade do serviço pela alta demanda e facilidade de entrada no mercado;

c) Alta elasticidade de preços e competição acirrada;

d) Serviços não diferenciados e intercambiáveis; e

e) Redução do poder de precificação do serviço pelo aumento da transparência de preços.

Lovelock (1995) analisou a natureza do ato do serviço, com foco no conceito de processo, afirmando que duas categorias podem ser processadas por serviços: pessoas e objetos. As lavanderias domésticas são caracterizadas por envolver ações tangíveis aos objetos físicos de seus clientes, e o autor as insere no grupo de processamento de posse dos clientes, ao lado de consertos/manutenção, serviços de limpeza, jardinagem, entre outros. Neste enfoque, os serviços de lavanderia são operações assemelhadas à manufatura, com prazos para entrega bem delimitados. $\mathrm{O}$ autor aponta que os clientes envolvem-se menos fisicamente, quando existe 0 processamento de posses que inclui as lavanderias domésticas também nesse conceito:

Os clientes tendem a se envolver menos fisicamente com esse tipo de serviço do que com os serviços de processamento de pessoas, já que geralmente não é necessário entrar na indústria de serviço e acompanhar as posses deles enquanto estão sendo processadas. De fato, o envolvimento do cliente pode ser frequentemente limitado à solicitação do serviço, à explicação do problema e ao pagamento da conta. Se o objeto em questão pode ser transportado, os clientes podem ter a opção entre leva-lo até a indústria de serviço ou (talvez por uma taxa adicional) tê-lo retirado em casa ou no local de trabalho (LOVELOCK, 1995, p.19). 
Lovelock (1995) também indica que o resultado do processo de serviço de uma lavanderia (cita "lavar um vestido a seco"), deve ser uma solução satisfatória para o melhoramento físico do objeto do cliente.

Em outro estudo, Lovelock (1983) propôs uma classificação de serviços que pode afetar a maneira como as empresas desenvolvem e implementam suas estratégias de marketing. Nesta classificação, por suas características, as lavanderias são enquadradas nas seguintes categorias:

a) Com relação à natureza do serviço: serviços direcionados aos bens e outras posses físicas (ao lado de transporte, reparos de equipamentos e cuidados veterinários), com ações tangíveis sobre objetos;

b) Com relação ao relacionamento com consumidores: relação não formal e transações discretas (ao lado de aluguel de carros, transporte público e restaurantes);

c) Com relação à customização e julgamento na entrega do serviço: baixa customização e baixo julgamento de pessoal de contato com o consumidor na busca de necessidades individuais;

d) Com relação à demanda e fornecimento do serviço: baixa extensão de flutuações demanda com o tempo e as demandas de pico podem ser normalmente administradas sem grande demora; $\mathrm{e}$

e) Com relação à entrega do serviço: o consumidor poderá ir até à lavanderia ou poderá optar pelo serviço de entrega.

Kellogg e Nie (1995) desenvolveram um framework que relaciona a estrutura do processo de serviços (influência do consumidor e processo de entrega do serviço) e a estrutura (grau de customização) do pacote de serviços. Utilizam as categorias serviço especializado, loja de serviços e fábrica de serviços em seu estudo. As características da "fábrica de serviços" na estrutura do processo de serviço permite inserir o segmento das lavanderias nessa categoria, a saber: 
a) Baixo nível de influência do consumidor final;

b) Padronização na operação de serviços individuais e sequência ou ordem bem definida de processos; e

c) O consumidor dá o sinal para o início do processamento ou produção do serviço.

Em seu trabalho, os autores supracitados definem as características do pacote de serviços. As lavanderias podem ser classificadas pelo pacote genérico, com baixo grau de customização, elevada padronização e pouca influência do consumidor final em como, o que e onde o serviço é executado. O pacote de serviços entregue ao consumidor final é a roupa processada (o serviço é produzido por meio de um processo definido para aquele artigo têxtil) e com acabamento final (ajustes finais para entrega de acordo com a especificação do cliente ou a qualidade-padrão final com inspeção final antes da entrega).

Ao aplicar as características das operações de serviço apresentadas por Fitzsimmons e Fitzsimmons (2010) ao segmento das lavanderias domésticas, podese pontuar:

a) Participação do cliente: requer atenção ao design das instalações (projeto da loja), e a experiência do cliente ocorre nas instalações (linha de frente ou recepção e entrega de peças) projetadas sob a perspectiva do cliente (estacionamento, espaço para separação das peças a serem lavadas) e participação no processo de análise prévia para a produção do serviço (informação e ajuda na identificação de manchas e histórico de lavagem);

b) Simultaneidade: os serviços não podem ser estocados, mas são criados e consumidos simultaneamente, porém, o problema análogo ao controle de estoques para produtos é a presença de filas de espera para serviços (no caso das lavanderias domésticas, a necessidade da presença de mais de uma recepcionista ou pessoal de apoio para a área burocrática ou exame das peças para confecção do rol). Antes da entrega da roupa lavada e acabada, a exemplo do que ocorre com a 
inspeção de qualidade em produtos, as lavanderias domésticas também têm seu produto final inspecionado pelo consumidor, antes de ser entregue;

c) Perecibilidade: os serviços são mercadorias perecíveis. Nas lavanderias domésticas, também existe um comportamento cíclico da capacidade, nos horários de pico de entrada e saída de trabalho dos clientes e nos períodos de inverno (com maior número de edredons, roupas de inverno e pouca capacidade de secagem ao meio ambiente em apartamentos);

d) Intangibilidade: como os serviços são intangíveis, o cliente não consegue testar seu desempenho antes da compra, como ocorre com produtos. No caso das lavanderias, o cliente deverá confiar que as manchas irão sair, e a roupa estará bem lavada, mantendo as características do tecido antes da lavagem; e

e) Heterogeneidade: a intangibilidade e participação do cliente resulta na variação de serviços. O papel da linha de frente nas lavanderias é importante na interação com o cliente e na verificação de serviços adicionais (ex.: engomagem) e cuidados especiais (ex.: peças de seda, couro e camurça, entre outros).

Fitzsimmons e Fitzsimmons (2010) enfatizam a transformação da economia de serviços de uma natureza transacional para relações baseadas na experiência, que se divide em serviços ao consumidor (B2C ou business-to-consumer) e serviços empresariais (B2B ou business-to-business). De acordo com a tipologia do SINDILAV, as lavanderias domésticas estariam inseridas no primeiro grupo e as industriais no segundo.

Os autores supracitados, ao analisarem os serviços ao consumidor, indicam que 0 valor agregado é criado pelas experiências, ao envolver e estabelecer uma relação com o consumidor de uma maneira pessoal. Com relação aos serviços para empresas, afirmam que "o valor deriva da coprodução e da natureza colaborativa do relacionamento, tal como acontece em consultoria". Com relação às lavanderias de autosserviço, o contato com o consumidor é ainda menor, já que a linha de frente não necessita relacionar e inspecionar a roupa trazida pelo cliente, limitando-se ao fornecimento de insumos e cobrança do serviço. No Brasil, essa modalidade de 
lavanderia é minoria e está restrita a alguns tipos de consumidores no País (estudantes, pessoas solteiras, entre outros).

O segmento das lavanderias domésticas atua entregando serviços diretamente ao consumidor final, atendendo a diferentes classes de consumo, com predominância das classes A e B. Para adaptar-se aos diversos tipos de têxteis atendidos e com mudanças contínuas nos hábitos de consumo, as lavanderias domésticas, normalmente agrupam as peças de acordo com o processo de lavagem:

a) Peças lavadas a água pelo sistema convencional: este grupo congrega o maior volume de peças na maior parte das lavanderias. As máquinas utilizadas podem ser convencionais (alimentação frontal, superior, horizontal ou self-service) ou automáticas (sistema de dosagem automático de produtos, programação do processo de lavagem via automação interna, controle de temperatura do banho, sistema automático de drenagem, alimentação e entrada de água). O sistema de secagem é convencional com controle de temperatura e a passadoria, normalmente, utiliza ferro a vapor e, em algumas lavanderias, sistema de aspiração e suflagem;

b) Peças lavadas a água sistema wetcleaning: este grupo congrega lavagem de peças delicadas e é utilizado como uma alternativa a lavagem a seco e redução na quantidade de água utilizada (apelo ambiental). A característica principal desse processo é utilizar pouca água e lavar peças delicadas que iriam ser lavadas no processo a seco, com produtos de lavagem desenvolvidos, especialmente, para este fim. O sistema também permite a flexibilidade da lavagem convencional por meio de programas específicos. Nesse sistema, as máquinas são todas automáticas com programação de processos de lavagem, dosagem de produtos, controle de entrada e saída de água e de temperatura de lavagem. O sistema de secagem é automatizado para não haver encolhimento das peças, utilizando o controle automático de umidade residual por medida de condutividade. A passadoria das peças utiliza mesas de aspiração e suflagem com ferro a vapor;

c) Peças lavadas a seco: este grupo congrega lavagem de peças delicadas sem utilizar água com o uso de solventes; e os mais usados são o percloroetileno (máquinas fechadas com processo de destilação acoplado, automatizada e com 
controle de emissões), hidrocarboneto (máquinas fechadas e abertas, automatizadas ou não, sem destilação em sua grande maioria) e green earth (solvente siliconado em máquina automatizada, com destilação). A secagem pode ser automática ou ao meio ambiente;

d) Peças de couro e camurça: este grupo congrega lavagem de peças de couro e camurça (couro liso, nobuk, camurça) e utiliza prioritariamente lavagem a água com um processo artesanal e especializado para processamento e retirada de retirada de manchas (pré-lavagem) e hidratação com produtos especializados. A centrifugação é controlada e a secagem é efetuada, na maior parte das vezes, ao meio ambiente;

e) Lavagem de edredons e tapetes: este grupo de peças pode ser lavado na própria lavanderia ou terceirizado com lavanderias industriais, a depender do volume e da análise de custo/benefício. Utiliza lavagem a água com produtos específicos. A secagem pode ser em secadoras de maior porte, estufas ou ao meio ambiente;

f) Retirada de manchas: esta operação é utilizada em todos os processos (lavagem a água, wetcleaning, lavagem a seco, couro e camurça e edredons/tapetes), com produtos especializados por família de manchas. Pode ser realizada em bancadas simples ou máquinas automáticas desenhadas para retirada de manchas.

Nas lavanderias domésticas, o trabalho requer conhecimentos específicos nas seguintes áreas:

a) Área têxtil e atendimento personalizado: pré-seleção das peças por tipo de tecido e verificação de alterações e manchas pela recepção com atendimento personalizado aos clientes, esclarecimento de dúvidas e apresentação dos processos que serão utilizados para o serviço;

b) Área de processamento das peças (linha de retaguarda): processos de lavagem a água, seco, couro e camurça, retirada de manchas, centrifugação e secagem;

c) Área de acabamento das peças (linha de retaguarda): passadoria convencional, especializada e acondicionamento das peças; $\mathrm{e}$ 
d) Área de entrega do serviço (linha de frente): atendimento personalizado, promoção do serviço efetuado e entrega em domićlío.

Farias (2006) pondera pontos importantes na evolução do segmento das lavanderias domésticas:

a) O mercado das lavanderias evolui em busca das tendências da moda, da química fina, da tecnologia dos equipamentos e dos têxteis, com a passagem do sistema convencional (baixa tecnologia) para o científico;

b) A globalização facilitou ações na aplicação dos conceitos modernos de higiene e limpeza; e

c) O processo de lavagem é complexo e precisa ser desmembrado para o entendimento.

A ANEL (Associação Nacional das Empresas de Lavanderias) (ANEL, 2013) foi criada por empresários do setor e tem a função de representar a classe, disseminar o conhecimento técnico e a troca de experiências entre os associados. A associação dedica-se a promover eventos técnicos (cursos, palestras, encontros), congressos e seminários específicos da área, fomentar a qualidade e a sustentabilidade (com um selo de qualidade desenvolvido para o segmento), promover a assessoria jurídica, intercâmbio com instituições do segmento têxtil e órgãos públicos, fomentar a participação em redes de relacionamentos para retirada de dúvidas (Ledface), emitir pareceres técnicos, relatório de indicadores, editar revista especializada (Lavanderia \& Cia) e representar o setor junto à sociedade e órgãos públicos.

Com o objetivo de auxiliar no desenvolvimento de um novo serviço e evitar o método de tentativa e erro para testá-lo, uma ferramenta importante que pode ser utilizada para visualização de um sistema de prestação de serviços é o esboço chamado blueprint de serviços. Shostack (1984) afirma que um blueprint de serviços permite a uma empresa explorar todas as questões inerentes à criação e gestão de um serviço novo, identificando pontos fracos, encorajando a criatividade e aumentando a 
habilidade gerencial de pensar efetivamente a respeito de novos serviços. O blueprint de serviços permite às empresas a visualização do processo de serviço, pontos de contato com o consumidor e evidências associadas ao serviço pela perspectiva do consumidor.

No presente estudo, o autor desenvolveu um blueprint para o segmento de lavanderias domésticas, para melhor visualização do processo de prestação de serviços e interação com o consumidor final, conforme os dados da Figura 26.

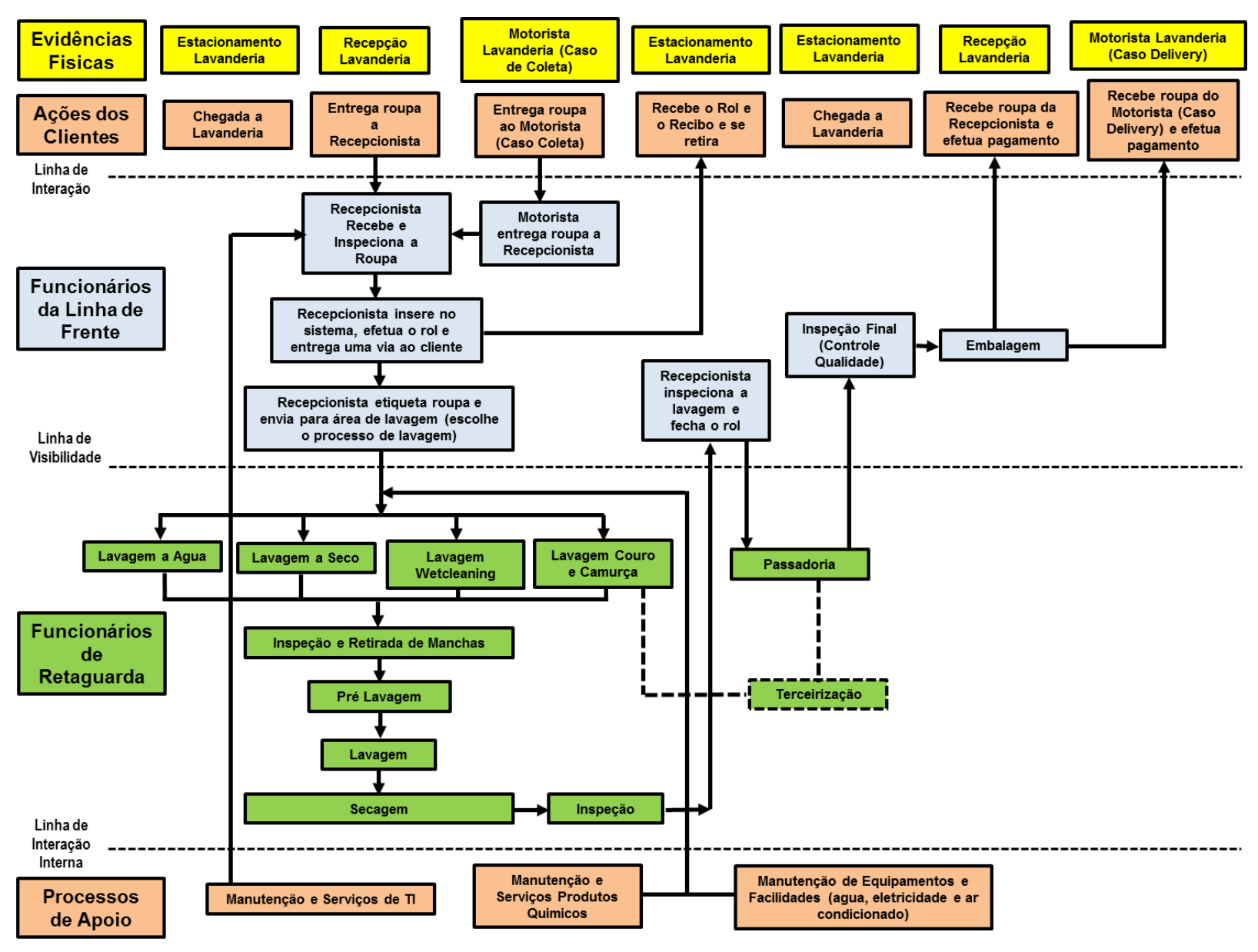

Figura 26: Blueprint para lavanderias domésticas

Elaborado pelo autor (baseado em Fitzsimmons e Fitzsimmons; (2010; Fig. 4.4))

\subsection{A Inovação e o segmento das Lavanderias Domésticas}

As características das lavanderias domésticas e sua contextualização dentro do setor de serviços contribuem para o estudo da adoção da inovação nessas 
empresas. Assim, serão resumidos abaixo os principais pontos levantados nos itens anteriores nessa direção e que caracterizam as lavanderias domésticas:

a) Estão inseridas na função terciária e como serviços pessoais;

b) São caracterizadas por envolverem ações tangíveis aos objetos físicos de seus clientes, inserindo-se no grupo de processamento de posse (roupas ou acessórios) dos clientes;

c) Apresentam baixo nível de influência do consumidor final;

d) Apresentam baixo contato com o cliente final (restrito à operação da linha de frente na recepção e entrega das roupas);

d) Padronização na operação e sequência ou ordem bem definida de processos, com serviços que demandam um espaço de tempo moderado;

e) Podem ser classificadas pelo pacote de serviços genéricos e com baixo grau de customização, já que serviços especiais como lavagem de peças de couro, a seco, peças especiais, entre outros, já estão listados como serviços correntes dos estabelecimentos;

f) O pacote de serviços é entregue por meio de um processo definido, e os ajustes finais para entrega estão de acordo com a especificação do cliente ou a qualidade padrão final;

g) Atuam no mercado de serviços direto ao consumidor final (B2C ou business-toconsumer) e, em sua maioria, seus clientes pertencem às classes A e B.

As grandes cidades concentram o maior número de lavanderias domésticas, facilitando a formação de grupos de empresas com a mesma atividade e beneficiando-se das informações obtidas por fornecedores, favorecendo assim 0 processo de inovação. No Brasil, iniciativas vêm sendo produtivas, como as da Associação Nacional das Empresas de Lavanderias (ANEL) por meio do Leadface 
(site com perguntas e respostas), como uma ferramenta em que é possível tirar dúvidas e responder a perguntas. O Grupo Lua por meio do Yahoo Groups congrega lavanderias de diferentes portes que expõem seus problemas e dúvidas, formando um fórum de opiniões e debates. Gordon e Mc Cann (2005) analisaram a inovação nas pequenas empresas que se beneficiam de alianças e informações mútuas entre empresas por intermédio de trocas formais e informais, trazendo supostas vantagens sobre as empresas de maior porte, onde essa prática é mais limitada. Ainda no enfoque da relação entre inovação e a rede de relacionamentos de pequenas empresas, Partanen; Chetty e Rajala (2011) estudaram as relações entre quatro tipos de inovação (radical, incremental, autônoma e sistêmica) e a rede de relações em empresas de pequeno porte (ex.: fornecedores, distribuidores, clientes e institutos de pesquisa) no ganho de recursos, concluindo que cada tipo de inovação requer certos tipos de relacionamentos e o fortalecimento deles para sua concretização. Massa e Testa (2008) analisaram as relações externas em rede das pequenas empresas e afirmam que os empresários acreditam ter um conhecimento do negócio melhor que os acadêmicos, porém admitem que, sem recursos externos, ficam limitados na implantação da inovação. $O$ tipo de ajuda externa nas pequenas empresas está mais concentrado em seus parceiros, em outros empreendedores e nas redes sociais.

\subsubsection{Inovação de Processo nas Lavanderias Domésticas}

No presente estudo, optou-se por desmembrar a inovação de processo em inovação em sustentabilidade ambiental e inovação tecnológica. No caso das lavanderias domésticas, esta última está relacionada a equipamentos, produtos químicos e tecnologia da informação. A inovação em sustentabilidade ambiental no segmento está intrinsicamente ligada à tecnológica, já que as novas tecnologias em equipamentos e produtos químicos para os processos de lavagem estão de uma forma ou de outra relacionadas à redução de poluentes ambientais (efluentes líquidos, gasosos e sólidos) ou à otimização de insumos, como água de lavagem e energia. Alguns exemplos são: sistema wetcleaning (com redução no consumo de água, energia e produtos químicos), solventes alternativos para lavagem a seco, lavagem com gás carbônico, redução do uso de água em máquinas com automação 
avançada, dosadores de produtos químicos automáticos e ligados à automação das máquinas e sistemas de reuso de águas de lavagem e amaciamento.

Ao abordar a inovação de processo (com foco em inovação tecnológica e sustentabilidade), Gallucci (2013) afirma que o setor de lavanderias vem se atualizando em termos operacionais com relação às recentes tendências tecnológicas. A autora exemplifica citando a introdução da tecnologia wetcleaning no segmento das lavanderias domésticas, como complementar aos processos de lavagem existentes, com benefícios ao meio ambiente (pois utiliza pouca água e detergentes biodegradáveis) e redução de custos variáveis, com apelo para limpeza profunda com riscos menores de danos em roupas delicadas (ex.: peças de seda e lã).

Ao introduzirem o conceito de serviços ecoeficientes, Heiskanen e Jalas (2003) discutem os serviços das lavanderias domésticas com foco na ecoeficiência. Os autores afirmam que os serviços ecoeficientes ou sistemas produto/serviço sustentáveis são identificados como aqueles ligados ao conceito de serviço não material, serviços orientados a resultados, serviços baseados em produtos e projetos ecológicos com serviços acoplados. As lavanderias domésticas estão incluídas nos serviços orientados a resultados, que são conceituados como os que entregam o resultado esperado, evitando que o consumidor adquira um produto (ex.: máquina de lavar e secadora), materiais ou energia (ex.: energia elétrica ou gás natural). Os autores discutem os serviços das lavanderias domésticas com foco na ecoeficiência e os comparam com as lavanderias domiciliares e industriais:

a) As lavanderias domésticas gastam mais água e energia por carga que as lavanderias industriais;

b) Os proprietários das lavanderias investem em máquinas no estado da arte, e os operadores têm mais capacitação que os consumidores finais privados (lavanderias domiciliares); 
c) Em operações profissionais, as variáveis relacionadas à sustentabilidade (como energia, detergente e água) podem ser mais bem controladas do que a operação do consumidor final (lavanderias domiciliares);

d) As lavanderias domésticas com baixa escala de produção poderiam reduzir a carga ambiental de lavagem pelo fator três com a melhora das técnicas de lavagem e reuso de águas;

e) Serviços de lavagem profissional usam $80 \%$ menos água, $66 \%$ menos detergente e $77 \%$ menos energia que as lavanderias de domicílios; e

f) A produtividade de uma lavanderia profissional é 1,9 vezes maior que uma lavanderia domiciliar.

\subsubsection{Inovação em Sustentabilidade Ambiental nas Lavanderias Domésticas}

A inovação em sustentabilidade ambiental vem sendo discutida pelas empresas, como diferencial para melhora de competitividade e imagem da empresa junto ao mercado consumidor. Mas, a sustentabilidade ambiental no setor de serviços tem sido abordada com ações de curto prazo, muitas delas isoladas, mas, que não refletem um planejamento e visão a longo prazo necessários à implementação de estratégias que direcionem a cultura da empresa rumo aos objetivos de sustentabilidade.

O ambiente atual fornece condições mercadológicas mais favoráveis ao tema sustentabilidade se comparado com o passado e pode propiciar uma abordagem de mercado diferenciada, afetando a competitividade das micro e pequenas empresas. Mas, a abrangência a curto prazo, característica dessas empresas, conflita com a visão a longo prazo necessária às ações de inovação em sustentabilidade. Observase, de maneira geral, melhorias incrementais nas pequenas empresas, porém a inovação em sustentabilidade requer usualmente um posicionamento mais radical e de transformação organizacional. O comportamento inovador constante e 
necessário, como o posicionamento destas empresas, e a capacidade de formar redes de relacionamento podem ajudar a superar essas dificuldades.

O conceito de sustentabilidade está atrelado à busca em atender às necessidades da geração atual, sem comprometer a capacidade de futuras gerações em atender suas próprias necessidades (PIEMONTE, 2010). Para Bos-Brouwers (2010), atualmente, a inovação em sustentabilidade está focada em fornecer evidências do envolvimento das empresas no Triplo $\mathrm{P}$ (people, planet and profit ou pessoas, planeta e lucro), basicamente nas grandes empresas, geralmente multinacionais, e negligenciando o importante papel das pequenas e médias empresas.

O autor citado refere que existem diferenças significativas no processo de inovação entre grandes e pequenas/médias empresas. Assim, o conceito de sustentabilidade irá abranger requisitos de viabilidade econômica, ecologia, justiça social e aceitabilidade cultural. Mas, o autor observa que as pequenas empresas praticamente não publicam relatórios de sustentabilidade, inviabilizando a obtenção de dados representativos sobre suas atividades e os resultados obtidos, nem tampouco têm uma estratégia formal e escrita.

Com relação à linha de abertura de novos clientes e mercados, Heiskanen; Kasanen e Timonen (2005) discutem a participação do consumidor na avaliação e desenvolvimento das inovações em sustentabilidade das novas tecnologias e serviços que têm potencial para reduzir o uso de recursos naturais. Os autores exploram o uso compartilhado de produtos (ex.: produtos para lavanderias), como um modo de minimizar os efeitos ambientais ou mudar o foco de produtos para serviços, como por exemplo, o uso de lavanderias em lugar de adquirir produtos de lavagem.

Na mesma linha de lavanderias compartilhadas, Roy (2000) estudou a utilização compartilhada de serviços, exemplificando com o caso das lavanderias centrais para vários consumidores em lugar de maquinas de lavar em casas individuais versus lavanderias comerciais. O estudo considerou a comparação entre um centro de lavagem para residências vizinhas e uma grande lavanderia doméstica comercial, utilizando métricas de energia primária, água e detergente consumido (por quilo de 
roupa lavada). Em razão da eficiência maior em termos de escala e operadores especializados, a lavanderia comercial reduziu em dez vezes o consumo de água e, aproximadamente, 16 vezes o consumo de detergentes em comparação com 0 centro de lavagem. Um fator médio de três vezes em termos de redução do impacto ambiental global (uso de recursos e poluição por quilo de roupa lavada) foi alcançado.

Shove (2002) estudou a sustentabilidade, sistema de inovação e as lavanderias e justifica a escolha das lavanderias domiciliares ${ }^{3}$, como exemplo do elevado consumo de água no oeste da Europa e Estados Unidos da América, chegando a 20\% do total da água doméstica utilizada nos países. O total de uso médio por máquina é de 274 vezes por ano por residência no Reino Unido e 392 vezes nos Estados Unidos da América. A autora cita que as máquinas de lavar são customizadas e os detergentes coloridos para combinar com as tradições e preferências nos diferentes mercados. No Brasil, esses costumes e tradições são trazidos às lavanderias domésticas pelos próprios funcionários, assim como a operação de lavagem prévia (manual) das roupas e a forma de lavar em suas casas (ex.: nível de espuma alto, cheiro nas roupas, viscosidade elevada dos produtos, entre outros).

$\mathrm{Na}$ linha de mudanças de hábito nas lavanderias domiciliares com foco em sustentabilidade, Laitala; Klepp e Boks (2012) estudaram as mudanças de hábito de lavagem na Noruega. Estas mudanças, como já foi referenciado, influenciam diretamente os hábitos dos operadores das lavanderias domésticas, acabando por refletir no modo de lavar e avaliar a qualidade final da roupa lavada.

Os autores supracitados relatam problemas do cotidiano que ocorrem nos lares e também nas lavanderias domésticas comerciais: os tipos de têxteis são separados em lotes diferentes de lavagem, impedindo o enchimento total da máquina e aumentando o consumo; a quantidade utilizada de detergentes é influenciada pela dosagem manual com baixa precisão (o que ocorre também em muitas lavanderias domésticas sem automação na dosagem) e problemas de identificação do tipo de tecido nas etiquetas das peças.

\footnotetext{
${ }^{3}$ Lavanderias domiciliares são as que se encontram dentro dos lares, ao contrário das lavanderias domésticas, que são empresas que prestam serviços de lavagem para consumidores finais.
} 
Os mesmos autores, em outro trabalho sobre o mesmo tema, afirmaram que as práticas de lavagem estão em constante mudança, sendo influenciadas pelas normas sociais, culturais e morais. Observam também que, apesar das tecnologias em lavagem de roupa terem melhorado, o tempo de lavagem não reduziu.

Ao abordarem as lavanderias domiciliares (que operam nas residências das famílias), Heiskanen; Kasanen e Timonen (2005) estudaram o consumo sustentável, como um dos focos das políticas ambientais e das novas inovações tecnológicas que melhoram a ecoeficiência do consumo. Os autores exemplificam que a atitude de consumo sustentável pode levar ao menor uso de produtos e melhora na eficiência energética. Os domicílios do passado mantinham equipamentos antigos, com baixa eficiência. Os autores concluem que, hoje, o volume de roupa a ser lavada é maior, com maior variedade de tecidos e maior frequência no uso de equipamentos de lavagem, pois os equipamentos são menores (para se adaptarem aos espaços dos domicílios atuais).

Com relação aos insumos de lavagem, Laitala; Boks e Klepp (2011) enfatizaram que os detergentes estão tornando-se cada vez mais amigáveis ao meio ambiente em razão sobretudo das mudanças em suas formulações, utilizando matérias-primas mais sustentáveis, proporcionando inclusive processos de lavagem a temperaturas mais baixas com redução da energia.

Gallucci (2012) aponta que, no segmento das lavanderias brasileiro, o termo sustentabilidade ambiental vem sendo tratado com foco no processo produtivo (produtos para lavar e outros procedimentos). Mas a autora alerta sobre a biodegradabilidade das embalagens plásticas utilizadas na entrega das roupas e acrescenta que a tendência é que as lavanderias terão seus processos revistos sob a ótica da sustentabilidade ambiental, desde as fontes de energias utilizadas, passando pela produção limpa e instalações, até a entrega final das peças ao consumidor.

No Brasil, o segmento das lavanderias domésticas vem tendo algumas iniciativas no sentido de amenizar o impacto ambiental da atividade de lavagem de roupas: 
a) A rede nacional de lavandeiras Lavasecco adotou o conceito de sustentabilidade baseado nos três "R" (reduzir, reutilizar e reciclar), utilizando sacolas retornáveis feitas com garrafas PET reutilizadas na entrega e recepção de roupas, portatíquetes em papel reciclado, substituindo o plástico e cabides ecológicos de papelão certificado (VEJA SÃO PAULO, 2010);

b) A Prilav Lavanderia (MT) atuou nos custos da cadeia produtiva, com secagem natural das roupas, com prazo de entrega superior a 24 horas, utiliza energia eólica nos exaustores e reaproveitamento de sacolas plásticas (SEBRAE, 2015).

\subsubsection{Inovação Tecnológica em Lavanderias Domésticas}

Em seu trabalho, Miozzo e Soete (2001) realizaram uma taxonomia do setor de serviços com base na tecnologia, classificando o segmento das lavanderias na categoria de empresas dominadas pelos fornecedores e pertencentes ao setor de serviços pessoais, conforme já referenciado. Os autores afirmam que a principal fonte de tecnologia advém do setor de manufatura, o que pode ser comprovado no segmento das lavanderias: apropriação de avanços tecnológicos no fornecimento de equipamentos de processo (máquinas com diversos tipos de lavagem e automação), de produtos químicos (associados a diversos tipos de lavagem), de automação e controle de processos (máquinas e dosagem automática de produtos químicos) e, finalmente, softwares específicos para a gestão do negócio como um todo, abrangendo as áreas de linha de frente, processamento de roupas e entrega do serviço.

Battisti; Vigorena e Alves (2012) indicam que as inovações tecnológicas no setor de serviços dominados pelos fornecedores (caso das lavanderias), são oriundas de fornecedores de equipamentos (ex.: máquinas para o processo de lavagem) e material (ex.: produtos químicos, insumos de processo, entre outros), visando a redução de custos e a utilização dessas tecnologias, como uma das principais estratégias do setor. 
Gallouj (1997) identifica o uso de ferramentas técnicas (por exemplo, novas tecnologias em equipamentos e acessórios), como determinantes para a inovação em determinados serviços. O autor categoriza as empresas de serviços pessoais (no qual estão inseridas as lavanderias domésticas), como empresas de serviços dominados por equipamentos e fornecedores técnicos.

Ao estudarem a gestão da tecnologia nas empresas de serviços, Mc Dermott; Kang e Walsh (2001) desenvolveram um framework direcionado à geração de valor adicionado aos serviços com foco na tecnologia/sistema/processo (conhecimento dentro da organização) ou no trabalhador (conhecimento básico). As lavanderias domésticas são apontadas pelos autores como serviços de conhecimento básico do trabalhador, cujo maior foco na adoção e implementação da nova tecnologia é a resposta do trabalhador no processo de produção do serviço (como por exemplo, a aquisição de novas máquinas, automação, entre outros). Os operadores interagem e monitoram os equipamentos automáticos e não necessitam de habilidades especiais para desempenhar suas funções.

Na mesma linha, Kang (2006) classificou os serviços de acordo com o valor gerado ao cliente pelo uso do conhecimento:

a) Serviços baseados no conhecimento: a maior parte do valor ao cliente é dada pela pessoa que oferece o serviço (ex.: computação gráfica, salões de beleza, educação, serviços profissionais, serviços legais, cuidados com a saúde, consultores, contadores, entre outros);

b) Serviços que embutem conhecimento: são os que envolvem o valor ao cliente no sistema que fornece o serviço (ex.: lavanderias domésticas, restaurantes tipo fast food, transporte de passageiros, embarque e distribuição, empresas de seguros, teatros e museus, viagens e recreação, entre outros).

As lavanderias, conforme a divisão acima, encontram-se no grupo de serviços que embutem conhecimento. As características desse grupo, de acordo com o autor, são a repetibilidade e melhor conformidade da qualidade, porém o papel do funcionário interagindo com a tecnologia é diferente. Este funcionário é uma extensão da 
tecnologia, que reduz ou substitui a necessidade de certas habilidades. Ou seja, a tecnologia é colocada em funcionamento por meio do funcionário que pressiona botões quando solicitado, escolhe programas, entre outros. Assim, o treinamento da mão de obra é efetuado para capacitação em um processo rotineiro e padronizado e não para que possa interferir no equipamento em si. Nesse tipo de serviço puro, o consumidor interage na seleção das opções de entrega.

O uso de patentes/licenças, universidades e institutos de pesquisa foi considerado de baixa relevância para as empresas de serviços pesquisadas por Evangelista e Sirilli (1998) (somente $25 \%$ das empresas inovadoras consideraram relevantes). No mesmo estudo, os autores pesquisaram as fontes de inovação para as mesmas empresas e constataram que a aquisição e o desenvolvimento de softwares e máquinas/equipamentos foram as principais atividades nas quais as empresas investiram na busca da inovação. No segmento de limpeza, $77 \%$ das empresas investiram em software e $73 \%$, em máquinas e equipamentos. Apesar disso, esse segmento teve o menor custo de investimento de inovação por empregado entre todos os setores pesquisados.

Ao analisarem as características estratégico/operacionais das empresas de serviços do tipo "fábrica de serviços" (onde se incluem as lavanderias domésticas), Kellogg e Nie (1995) consideraram essas empresas, como usuárias do tipo de tecnologia com longa conexão. Esta classificação confere características de racionalização da tecnologia, de modo que o processo de serviço pode ser padronizado e repetitivo, levando assim a uma elevada eficiência, a exemplo do que ocorre nas lavanderias domésticas. Conforme os autores, outras características das "fábricas de serviços" e que têm aderência com o segmento das lavanderias são: o ajuste prévio dos passos do processo (no caso, processos de lavagem e acabamento das roupas); o balanço de tarefas ao longo das estações de trabalho (no caso das lavanderias a recepção, separação, processamento, acabamento, conferência e entrega). Estas tarefas exigem certas habilidades técnicas para aumentar a eficiência e que são conseguidas pelo treinamento no próprio local de trabalho, como realmente ocorre no segmento das lavanderias domésticas. 


\subsection{Equipamentos}

A revista Laundry and Cleaning News (2012) aborda o setor de lavanderias na America Latina e Caribe, analisando as tendências para o mercado brasileiro das lavanderias. $\mathrm{O}$ artigo mostra o crescimento do mercado nacional, porém acentua o elevado custo de importação dos equipamentos de lavagem com tecnologia mais avançada vindos da Europa e Estados Unidos da América, além de barreiras de importação como procedimento para proteger os fabricantes nacionais. $\mathrm{O}$ artigo também evidencia que, no Brasil, o fator econômico é mais importante que o ambiental (sustentabilidade) às lavanderias.

A redução do peso do efluente, visando a um procedimento de lavagem mais sustentável em lavanderias domésticas, foi estudada por Fijan S., Fijan R. e SostarTurk (2008). Os autores abordam a implementação de procedimentos de lavagem sustentável em lavanderias domésticas de modo a reduzir o efluente líquido nos processos, com foco no uso de túneis de lavagem (processo contínuo de lavagem em lugar do convencional por batelada) e o reuso de água de lavagem.

A viabilidade do uso da lavagem wetcleaning como alternativa ao emprego de solventes clorados (especificamente percloroetileno) foi estudada por Sinsheimer e Latif (2007), que afirmam que a tecnologia wetcleaning não foi adotada plenamente, como uma tecnologia substituta ao percloroetileno, mas, sim, uma alternativa, ou seja, as lavanderias manteriam as duas tecnologias ativas no mesmo empreendimento. Os autores explanam a respeito do histórico da regulação da utilização do percloroetileno, intensificada a partir da década de 1990, e o interesse em alternativas com foco ambiental e ocupacional (ex.: solventes isoparafínicos, siliconados e wetcleaning).

A tecnologia wetcleaning demanda, conforme referem Sinsheimer e Latif (2007), agentes de limpeza biodegradáveis, que maximizem a limpeza, minimizem a mudança de cor e o encolhimento. Com relação aos fatores ambientais, o estudo concluiu ser wetcleaning uma alternativa viável ao processo de lavagem a seco tradicional nas áreas de gasto energético, tecnologia com baixas emissões (ar e líquidas), minimização de efluentes perigosos (no caso de percloroetileno, há o 
descarte monitorado da sujidade de fundo que contém solvente) e a minimização da contaminação do solo e água do subsolo. O sistema é constituído por uma máquina de lavar que opera com baixos níveis de água e agitação lenta e controlada. $\mathrm{O}$ sistema de secagem também controla a umidade residual das roupas por meio de um sistema automático, minimizando o encolhimento das peças.

A utilização de gás carbônico $\left(\mathrm{CO}_{2}\right)$ como solvente alternativo também vem sendo estudada pelos fabricantes de máquinas de lavar. Nesse caso, uma máquina especial contém o gás, que é submetido a certa pressão previamente estipulada e torna-se líquido, atuando como solvente. Emprega detergentes especiais na prélavagem e lavagem.

A tecnologia Green Earth utiliza máquinas que lavam utilizando um solvente especial à base de silicone, que permite a lavagem de roupas do cotidiano e peças especiais. Também utiliza detergentes específicos na pré-lavagem e lavagem.

\subsection{Produtos Químicos}

Gallouj e Weinstein (1997) citam que as características técnicas internas dos produtos podem prover um serviço; indicam, como exemplo, que produtos químicos em serviços de limpeza (como os de lavanderias) conferem características técnicas tangíveis usadas para produzir as características do serviço (ex.: roupas mais brancas, com aroma, com detalhes customizados, entre outras). Os autores complementam que a indústria de limpeza desenvolveu uma série de competências, como recrutamento, treinamento de técnicos, uso de produtos químicos e técnicas especiais que apoiam a prestação de serviço.

Palovita e Järvi (2008) estudaram o uso residencial de detergentes para lavagem de roupas, utilizando a Gestão da Cadeia de Valor do Meio Ambiente (EVCM ou Environmental Value Chain Management). A EVCM está ligada às necessidades dos consumidores, valor e informação com respeito a aspectos ambientais e relacionada com o impacto dos produtos de uso corrente dos consumidores, desde a aquisição de matérias-primas e energia, até a gestão de efluentes. 
A EVCM tem como objetivo aumentar a atenção para os aspectos ambientais, por meio de informações sobre o comportamento do consumo para fornecimento de produtos e serviços com menor impacto ambiental. Os autores concluíram que os consumidores atentos ao meio ambiente usam utensílios para medir a dosagem, porém, de maneira geral as pessoas não percebem as residências como possíveis poluidoras, mas, que poderia ser benéfico adotar o pensamento ecoeficiente (melhora do valor econômico e redução do impacto ambiental, simultaneamente) em seu consumo. Apesar das versões concentradas, os fabricantes não tiveram sucesso em reduzir o excesso da dosagem de detergentes pelos consumidores (só a metade dosava corretamente) nem diferenciar produtos concorrentes em termos ambientais.

\subsection{Tecnologia da Informação (TI)}

Com o crescimento e diversificação da indústria de softwares no Brasil, o segmento das lavanderias também buscou agilizar sua operação, tanto na linha de frente (cadastramento de clientes, recebimento e entrega de roupas), como em todo o processamento de seus serviços (etiquetas com codificação e rastreabilidade das peças), que inclui a linha de retaguarda. Com a evolução tecnológica e o aumento da concorrência, muitas lavanderias vêm optando por sistemas informatizados que possam melhor atender às suas demandas, auxiliando na organização do processo produtivo e na recepção e entrega dos serviços prestados.

Algumas empresas de software, como a Equipe Sistemas que iniciou suas atividades em 1996, foram criadas para atender à necessidade do uso de tecnologia da informação visando gerir os negócios das lavanderias. No início, havia poucas lavanderias que vislumbravam uma melhora em sua operação, mas gradativamente os softwares tornaram-se parte integrante do processo de inovação tecnológica. Nessa área, a inovação formalizou-se com o desenvolvimento de softwares customizados para lavanderias, com módulos que vão sendo desenvolvidos à medida que novas necessidades são criadas, desde as áreas financeira, estoque, controle de peças e gerenciamento remoto de todo o processo pelos proprietários. A 
customização dos módulos hoje é efetuada por meio de treinamento e consultoria contínua.

\subsubsection{Inovação de Marketing em Lavanderias Domésticas}

As competências estratégicas em empresas de serviços foram exploradas por Kellogg e Nie (1995). Os autores desenvolveram um framework em que são cruzadas as características da estrutura dos processos de serviços, estrutura de pacote de serviços e a competência estratégica das empresas, conforme os dados da Figura 27. As lavanderias (classificadas como "fábricas de serviços" e empresas com "pacote de serviços genérico") têm as seguintes competências e estratégias na produção e entrega de serviços, conforme os pesquisadores:

a) Utilizam economia de escala para alcançar eficiência e dependem de algumas competências básicas para a entrega do serviço;

b) Os consumidores esperam preços baixos, sendo necessário um controle cuidadoso de custos; e

c) Com customização mínima, a empresa deve saber que está oferecendo um pacote de serviços que será demandado por um número suficiente de clientes necessários à sua operação. 
Estrutura do Pacote de Serviços

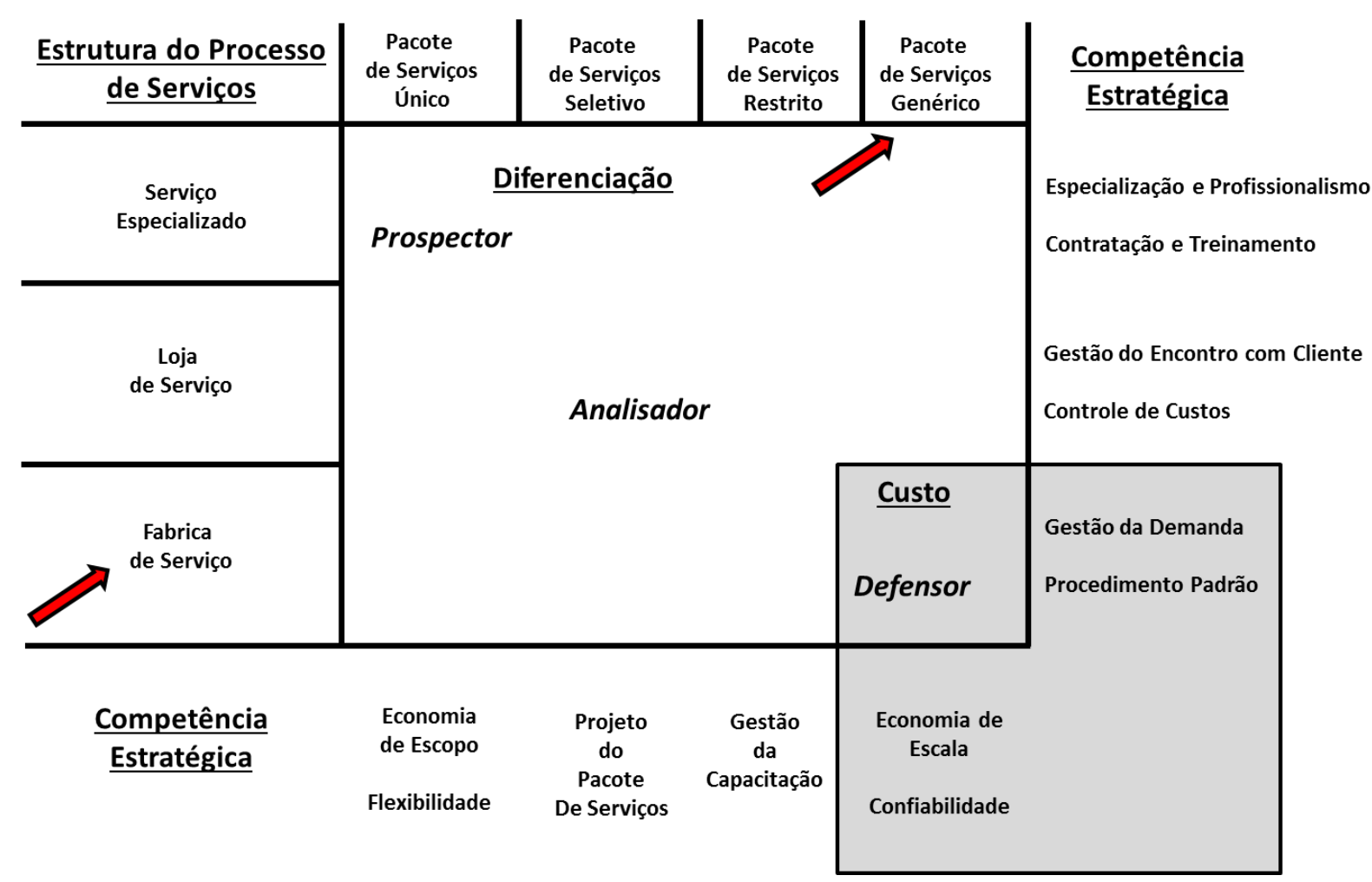

Figura 27: Cruzamento das implicações das estratégias no cruzamento da estrutura de processos e estrutura de pacote de serviços

Fonte: Kellog e Nie; (1995, p.330).

O cenário brasileiro do mercado das lavanderias domésticas mostra fortes perspectivas de crescimento com concorrência forte, já que apenas $4 \%$ da população economicamente ativa utilizam serviços de lavanderias (CAETANO, 2013), revelando um grande mercado potencial para exploração. As perspectivas de crescimento embutem outros fatores, como: aumento da participação da mulher no mercado, crescimento da rede hoteleira, demanda por higienização de roupas industriais e a proposta de emenda à constituição para as empregadas domésticas, com aumento de tributação trabalhista e, consequentemente, os custos para manter esse serviço.

A mudança contínua do mercado consumidor tem direcionado as empresas de serviços a uma adaptação rápida e a adaptações fortes em sua estrutura de atendimento e processamento de serviços, sobretudo aquelas que atendem ao consumidor final, como é o caso das lavanderias domésticas. Gallucci (2013) 
enfatiza o uso de meios de comunicação na divulgação da inovação tecnológica do processo (ex.: wetcleaning) aos consumidores, citando o emprego de folhetos tradicionais sobre o balcão, anúncios em mídias locais do bairro ou cidade, press releases em revistas, jornais e sites que são acessados pelos clientes, divulgação em meios digitais (blogs, sites newsletters) e por meio dos funcionários da linha de frente (que devem ser treinados para divulgação da inovação). Complementa ser preciso traduzir a inovação em linguagem compreensível para os consumidores e comunicar seus benefícios.

Os proprietários das lavanderias domésticas buscam continuamente alternativas diferenciadas para aumentar o faturamento, ganhar competitividade pelo atendimento diferenciado, melhorar as relações com o consumidor final, ter pontos de captação para facilitar o retorno de clientes potenciais e conhecer a concorrência local. A presença de redes de franquias das lavanderias domésticas internacionais, a partir de meados da década de 1990, forçou a profissionalização dos prestadores de serviços locais, pois aumentaram a competitividade do segmento (MENDONÇA, 2003), fazendo com que as lavanderias domésticas tradicionais reformulassem suas operações e sua apresentação ao mercado.

Mas, a inovação estratégica está direcionada não só a uma mudança tecnológica (novas máquinas), inovações de processos (novos processos de lavagem) ou inovações organizacionais (melhora no atendimento de clientes, capacitação), mas a mudanças nos modelos de negócios, identificando o valor oferecido e como é oferecido ao consumidor final, redefinindo a base de clientes e a abordagem de mercado. A pesquisa de mercado "Hábitos dos Usuários de Lavanderia", de novembro de 2009 (SINDILAV, 2009), mostra opiniões dos consumidores e dados mercadológicos importantes do segmento das lavanderias domésticas:

a) Amostra avaliada pela pesquisa SINDILAV (2009):

- Consumidores com idade média de 43 anos ( $1 / 3$ com 51 anos ou mais);

- Sexo: $70 \%$ feminino;

- Classe social: $58 \%$ classe B e $31 \%$ classe A;

- Estado civil: $48 \%$ casado(a) e $37 \%$ solteiro(a); 
- Filhos: 58\% têm filhos;

- Formação: 59\% têm curso superior completo.

b) Lavanderias mais conhecidas: lavanderias de redes de franquias são as mais conhecidas, porém as lavanderias de bairro são as mais utilizadas, com taxa de efetivação (divisão do percentual de lavanderia utilizada pelo percentual de lavanderia conhecida) de 0,96 . As lavanderias de bairro estão em segundo lugar entre as mais preferidas (conveniência);

c) Grau de utilização: $71 \%$ dos entrevistados utilizam a lavanderia uma vez por mês;

d) O principal motivo para a contratação de serviços de lavanderias é a proximidade de casa;

e) Com relação à qualidade e atendimento: 94\% avaliam como "ótimo" ou "bom";

f) Principal maneira de se informar sobre lavanderias: casual em $76 \%$ (passou em frente à loja), seguida por indicação (20\%);

g) $80 \%$ solicitam o serviço pessoalmente com um tempo médio de atendimento de 11 minutos;

h) $63 \%-70 \%$ dos consumidores levam e trazem a roupa pessoalmente e o fazem caminhando na maior parte das vezes (54\%-55\%);

i) A decisão de escolha da lavanderia é do próprio consumidor, sem influência de terceiros em $90 \%$ do total da amostra;

j) As pessoas enviam para a lavanderia todo tipo de roupa, mas algumas peças sempre são enviadas às lavanderias, como terno/paletó (50\%) e edredon/cobertor $(47 \%)$;

k) Para 92\%, o prazo de entrega foi considerado ótimo/bom, e o prazo ideal desejado para a maior parte das peças é de um dia; 
I) $73 \%$ das lavanderias não disponibilizam outros serviços (ex.: costura e tingimento), sendo os serviços adicionais mais desejados os de costura e reparos $(23 \%)$, seguidos de tingimento (5\%). A maior parte do público (63\%) não tem necessidade de serviços suplementares;

m) $73 \%$ gostariam de ter a lavanderia em um hipermercado ou shopping;

n) A forma de pagamento em dinheiro é a mais utilizada (70\%), seguida de cartão de débito (21\%);

o) A maior parte dos entrevistados paga por peça (mais de $85 \%$ ) e não por quilo;

p) $85 \%$ dos consumidores da amostra estão satisfeitos com os preços praticados; e

q) A Lavagem de artigos de decoração (cortinas, capas de sofá e almofadas, entre outros) ainda é baixa (cerca de $20 \%$ do total).

A segunda parte da pesquisa mostra as razões pelas quais parte da população não utiliza os serviços de lavanderias:

a) A maior parte alegou motivos relacionados a preços altos (23\%), porque existem roupas fáceis de lavar (23\%) ou preferem lavar em casa (21\%);

b) A falta de costume/hábito é maior motivo de não utilizar os serviços de lavanderias (53\%), porém parte usaria se o preço baixasse $(24 \%)$.

Gallucci (2011) afirma que a sobrevivência das lavanderias pode passar por uma estratégia de coopetição, definida como aquela que "resulta da soma de competição e cooperação entre empresas que atuam no mesmo setor". No caso das lavanderias, a autora sugere a formação de cooperativas e associações com o uso de ação conjunta das empresas participantes e "complementares" (ex.: produtores de insumos como produtos químicos e fabricantes de máquinas de lavar, secar e passar). 
Shaw (1973) estudou a relação entre investimento e processo competitivo nas lavanderias domésticas, apontando para a presença de pequenas unidades provendo serviço rápido e pessoal em contraposição aos empreendimentos que processam grandes quantidades de roupas com lentidão e sem atendimento diferenciado e personalizado. $O$ autor acentua a mudança no conceito de entrega do serviço de lavanderias, trazendo pequenas unidades para próximo do mercado consumidor, criando valor e fortalecendo o retorno.

\subsubsection{Inovação Organizacional nas Lavanderias Domésticas}

\subsubsection{Inovação de Modelo de Negócios nas Lavanderias Domésticas}

A tendência do mercado imobiliário residencial em atender a um público de classe média, com tempo restrito para atividades nos lares, levou a uma redução das áreas de serviços dos apartamentos, inclusive aquela reservada à lavanderia. Ademais, o custo mais elevado dos serviços domésticos e a relativa redução dos preços de serviços de lavagem e a maior disponibilidade de lavanderias direcionou os consumidores a lavarem parte de suas roupas fora dos domicílios. Também a tendência dos casais trabalharem fora de casa (aumento da participação das mulheres no mercado de trabalho) e os filhos estudarem em colégios em tempo integral, reduziu o tempo disponível para separação e cuidados com a roupa.

Estes fatos levaram algumas lavanderias a implantarem um novo modelo de negócio, aproveitando também a tendência do aumento de serviços digitais: a retirada e devolução de roupas com customização de serviços via internet. Algumas lavanderias domésticas estão vinculadas a sites, como por exemplo, o E-Lave, que reúne cinco lavanderias e presta serviços de retirada e entrega na cidade de São Paulo (VEJA SÃO PAULO; 2014).

Aproveitando a mesma tendência, foi criado o modelo de lavanderia Limelocker, que é uma lavanderia doméstica com serviços totalmente on-line, na qual o consumidor 
deixa suas roupas em armários localizados em edifícios e recebe as mesmas limpas em até 48 horas (LAVANDERIA \& CIA; 2013).

Estes novos modelos de negócio reduzem os custos de atendimento e manutenção de lojas físicas, fazendo com que os investimentos sejam direcionados a uma "fábrica de serviços" (geralmente, localizada em um galpão com menor custo e que é usado para processar as roupas) e a uma logística de entrega mais rápida. Tais práticas permitem a criação de valor pela redução de preços aos clientes finais das lavanderias.

No Brasil, houve uma transformação do setor de lavanderias em meados da década de 1990, com a chegada das grandes redes de franquias internacionais (Ex.: Dryclean USA e 5 a Sec), modificando a forma de administrar e trazendo um novo modelo de negocio (PEQUENAS EMPRESAS, GRANDES NEGÓCIOS, 1999).

No novo modelo surgido, houve a entrada de equipamentos modernos de lavagem a seco, lojas sofisticadas, lay out que expõem o trabalho de processamento das peças pela linha de retaguarda (back office), marketing institucionalizado e padronizado pela matriz e preços mais baixos alicerçados pelos custos menores de processamento e insumos. O movimento provocou também mudanças nas lavanderias já estabelecidas no País, já que houve momentaneamente uma perda de participação de mercado desses estabelecimentos. Apesar da expansão de unidades em bairros mais distantes, os locais com população de maior poder aquisitivo (classes A e B) ainda são os de maior demanda de serviços para as lavanderias domésticas.

Um exemplo de lavanderia que resolveu competir em novas bases com as lavanderias de franquias foi a lavanderia Wash (PEQUENAS EMPRESAS, GRANDES NEGÓCIOS, 1999). A lavanderia mudou a forma de gerir o negócio, utilizando tecnologia da informação, pesquisas de campo, relacionamento com os clientes e remuneração variável dos funcionários por produtividade. Implantou técnicas como 5 S e certificação pela ISO 9000 e ganhou competitividade, inovando em um novo modelo de negócio. 


\subsubsection{Inovação na Linha de Frente (Front Office) e de Retaguarda (Back Office) nas Lavanderias Domésticas}

Lovelock (1996) refere que a gestão da demanda por serviços é o maior desafio às empresas e estuda a natureza da demanda por serviços relacionada à entrega (flutuações). $O$ autor enfatiza que as lavanderias estão inseridas naqueles segmentos com baixa extensão de flutuação de demanda no tempo, o que permite decidir se buscarão continuar crescendo ou se irão manter o padrão atual de demanda. Esta decisão influencia diretamente a capacitação e o treinamento de campo, tanto da equipe de atendimento direto ao cliente ou linha de frente (front office) quanto à linha de retaguarda (back office); esta última atuando na produção do serviço de lavagem.

A integração entre a linha de frente e a de retaguarda é abordada por Nijssen et al (2006), que afirmam que esses dois departamentos precisam operar de forma integrada, tentando reduzir diferenças em objetivos e horizonte de tempo entre eles. A operação da linha de frente é tipicamente designada para satisfazer às necessidades dos consumidores, e a linha de retaguarda enfatiza a maximização operacional e resultados.

O conhecimento e a capacitação nas lavanderias domésticas têm papel importante na adoção da inovação. DeSouza e Amazu (2006) estudaram a gestão do conhecimento em pequenas e médias empresas (PMEs), tendo três lavanderias domésticas entre a população pesquisada. Os autores afirmam que o conhecimento representa especialização, habilidades, ideias, intuições, entre outros, estando, portanto, intimamente ligado à inovação organizacional nas PMEs. No caso de lavanderias domésticas, o conhecimento é transferido pelos proprietários aos funcionários, porém de uma maneira generalizada, e não de forma organizada ou sistemática. A prática do trabalho é passada no dia a dia.

DeSouza e Amazu (2006) afirmam que, nas PMEs, o conhecimento flui menos dos funcionários para o proprietário/gerente, pois os funcionários não estão preocupados 
com os detalhes da gestão do conhecimento, e sim com a operação diária. À medida que a empresa cresce e com o passar do tempo, áreas de especialização emergem, e o conhecimento fica concentrado nessas áreas. Um ponto abordado pelos autores (que é comum nas lavanderias domésticas) diz respeito à perda de conhecimento quando um funcionário especializado desliga-se da empresa e leva o conhecimento consigo, deixando lacunas em sua estrutura. Algumas lavanderias mais maduras têm mecanismos para prevenir a perda do conhecimento comum (dos funcionários), mas a saída dos proprietários (conhecimento principal) pode causar lacunas na operação, que serão difíceis de remediar.

Conforme os autores supracitados, ao pesquisarem as lavanderias domésticas, verificaram que estas contratam pessoas que já trabalharam em lavanderias, conhecem a operação básica do negócio, mas não são especialistas. Quando há uma promoção de cargo, os autores observam que, geralmente, as PMEs (pequenas e médias empresas) promovem um funcionário interno. Também constataram que raramente o gerente deixa uma PME, já que, geralmente, tem uma relação mais estreita com o proprietário. Observam que as PMEs, sabendo ou não, gerenciam o conhecimento da maneira mais adequada, ou seja, via humana (transferindo via pessoas já treinadas).

No caso das lavanderias domésticas, o atendente da linha de frente (front office) é a imagem da empresa, pois tem contato direto com os consumidores finais. Atua, como um "vendedor" da imagem da empresa e dos serviços prestados. Muitas vezes, o retorno do cliente pode não ocorrer pela indiferença ou mau atendimento da linha de frente. $O$ atendente da linha de frente desenvolve seu trabalho por meio de tarefas específicas:

a) Deve conhecer a rotina e funcionamento, sobretudo todo o processo de produção e entrega do serviço pela linha de retaguarda ou back office;

b) Deve conhecer os têxteis e tipos de peças de roupas e, adicionalmente, os processos inerentes à sua lavagem; 
c) Deve obter o máximo de informações do cliente, incluindo suas preferências pessoais;

d) Ofertar um leque de serviços não utilizado pelos clientes (ex.: lavagem de edredons, tapetes, etc.); e

e) Solucionar ou encaminhar reclamações dos clientes com rapidez.

\subsection{Inovação, Competitividade e Produtividade}

Gunday et al. (2011) estudaram os efeitos dos tipos de inovação no desempenho das empresas, explorando inovações organizacionais, de produto e marketing com base no Manual de Oslo (2005). Concluíram que a inovação exerce um papel mediador entre os tipos de inovação e os aspectos de desempenho das empresas. Sugeriram que os gestores coloquem uma ênfase adicional nas inovações, como instrumentos importantes para alcançarem uma força competitiva sustentável. Também afirmaram que pode haver certo período de tempo para observar o reflexo positivo do desempenho inovador no desempenho financeiro, o que pode explicar porque a alta gerência de muitas empresas relata não obter resultados positivos em prazos mais curtos. Por outro lado, os resultados das análises mostraram que as empresas inovadoras têm uma maior participação de mercado, vendas mais elevadas e alcançam uma maior força competitiva sustentável. Nesse aspecto, todos os tipos de inovação têm um papel positivo.

O efeito combinado de diferentes tipos de inovação no tempo melhora o desempenho da organização, de acordo com o estudo de Damanpour; Walker e Avellaneda (2009). Para os autores, as organizações tendem a adotar somente um tipo de inovação, pois possuem conhecimento naquele tipo e podem integrar mais facilmente novos conhecimentos e criar novas oportunidades para melhorar 0 desempenho.

Ao estudarem as organizações de serviços, os autores citados afirmaram que, em lugar de concentrarem-se em um tipo específico de inovação, as empresas deveriam 
introduzir diferentes tipos de inovação de forma balanceada. Essa sinergia entre os distintos tipos afeta a habilidade de introduzir e entregar serviços aos clientes, alcançando múltiplos objetivos, ao contrário da adoção de um único tipo de inovação. Os autores concluíram que, nas organizações de serviços, adotar diferentes tipos de inovação pode oferecer melhores resultados do que continuamente adotar um só tipo.

Ao relacionarem a inovação com o desempenho econômico das empresas de serviços, Cainelli; Evangelista e Savona (2006) utilizaram indicadores de desempenho econômico em serviços, em nível de empresa, para medir o crescimento e a produtividade. Os autores usaram indicadores de competitividade (aumento de vendas) e produtividade (vendas por funcionário), concluindo que a inovação nas empresas de serviços é afetada positivamente pelo desempenho econômico $e$ as atividades de inovação têm efeito positivo no crescimento e produtividade. A produtividade e inovação agem como um mecanismo de autorreforço que melhora o desempenho econômico das empresas. Os autores também apontam que a produtividade não é somente associada à presença da inovação, mas também ao nível de envolvimento financeiro para inovação e pelo tipo de inovação adotada.

\subsubsection{Inovação e Competitividade}

Em seu estudo sobre a atividade inovadora em pequenos negócios, Sebora; Hartman e Tower (1994) concluíram que o contexto de mercado competitivo não afeta as atividades inovadoras, o que contradiz o senso comum de que a inovação ocorre em muitos casos por pressão do mercado e concorrência. Com relação a este último fator, Evangelista e Sirilli (1998) investigaram a importância das fontes externas sobre a inovação em empresas de serviços e constataram que cerca de $62 \%$ das empresas consideraram os concorrentes, como fonte relevante de informação para o desenvolvimento de inovações em suas áreas de atuação.

Riddle (2008, p.2) afirma que o "foco da inovação é competir através da mudança de regras e tornar os concorrentes irrelevantes". Os resultados do sucesso da inovação, 
conforme a autora, aumentam a satisfação dos clientes e sua lealdade, que irá traduzir-se no aumento da recompra, na venda cruzada de serviços relacionados e na recomendação de outros serviços.

Elche-Hotelano (2011, p.221), ao abordar a competitividade nas empresas de serviços, afirmou que "as empresas normalmente tomam decisões sobre inovação baseadas nos recursos disponíveis e capacitações e como podem explotá-las para serem mais competitivas". Complementa que a crescente complexidade do ambiente competitivo demanda uma busca persistente por ideias inovadoras para garantir a sobrevivência da empresa e afirma também que, no setor de serviços, as inovações são, com frequência, pautadas na demanda por novos serviços.

Ao apontarem a relação entre inovação e vantagem competitiva, Tidd; Bessant e Pavitt (2008) enfatizaram a importância da capacidade de prestar melhores serviços (mais rápidos e mais baratos), como uma fonte de vantagem competitiva; acentuando que os serviços podem estar direcionados a um grande mercado, como também a um público restrito e de alto poder aquisitivo, com elevada customização e patamares mais elevados de preço.

A influência da inovação verde (sustentabilidade ambiental) na vantagem competitiva das empresas foi estudada por Radons et al (2012), que analisaram a influência da inovação verde por meio de três construtos (inovação do produto verde, inovação do processo verde e vantagem competitiva). Apesar de direcionarem sua pesquisa ao setor de produção de bens, o estudo concluiu que as empresas concentram seus esforços para potencializar a inovação de processo verde, que foi percebida como a mais influente para alcançar a vantagem competitiva, maximizando resultados e que atua como fator de diferenciação sobre os concorrentes.

Zmoginski et al (2009) apontam a inovação em modelo de negócio, como um meio de criar valor e diferenciar a empresa dos concorrentes e obter vantagem competitiva. Relacionaram a estratégia competitiva com a estratégia de inovação e valor agregado (com base nas oportunidades de mercado), como elementos de 
diferenciação que permitem obter vantagem competitiva, conforme os dados da Figura 28.

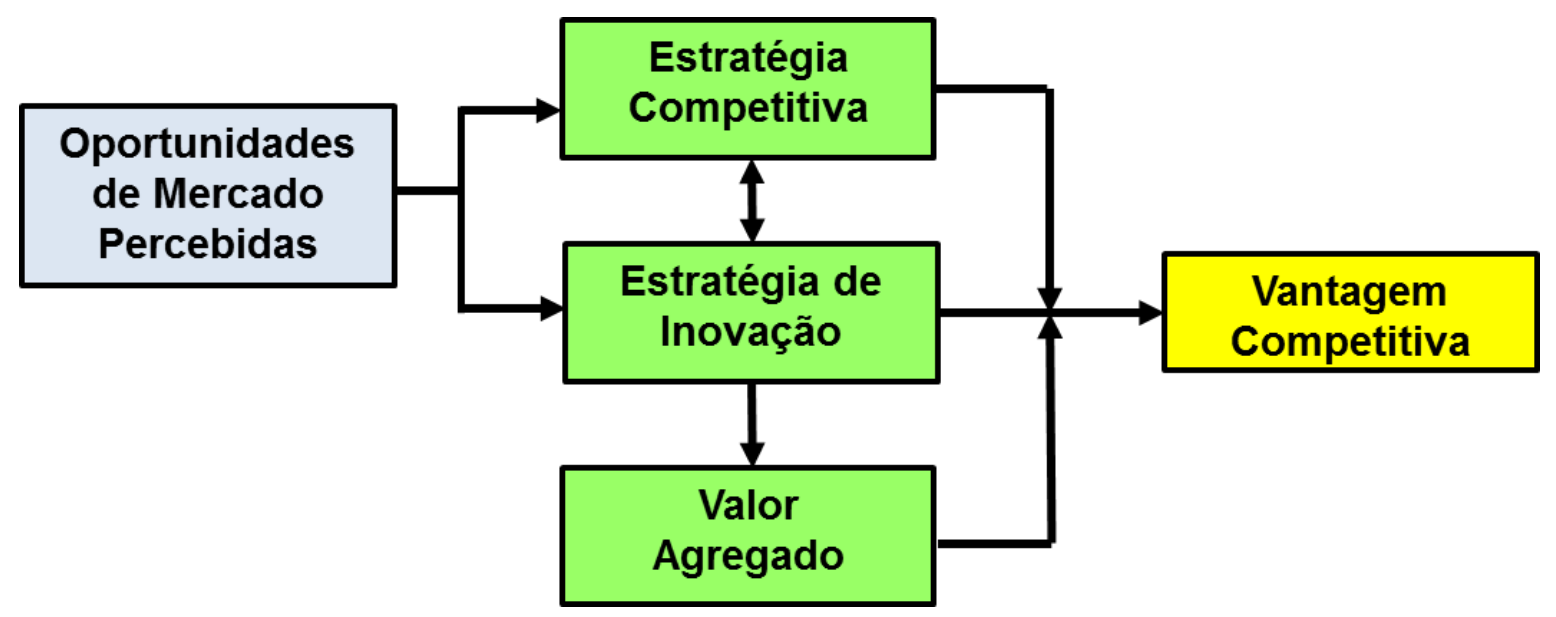

Figura 28: Relação entre estratégia competitiva, estratégia de inovação e valor agregado Fonte: Zmoginski et al.; (2009, p.61).

\subsubsection{Inovação e Produtividade}

A relação entre inovação e produtividade é abordada em estudo do Banco Mundial sobre inovação para a competitividade (BANCO MUNDIAL, 2008). A produtividade foi definida por meio do indicador que considera o valor agregado de cada trabalhador (faturamento líquido (-) custos operacionais (-) valor total dos salários dividido pelo número de trabalhadores). O estudo mostrou que a inovação tem relação direta com o aumento da produtividade da empresa.

Britto $(2009$, p.61) também usou como indicador de produtividade do trabalho a receita líquida de vendas em relação ao número de pessoas ocupadas na empresa. Enfatiza que "a maior parte do crescimento da produtividade do trabalho na economia americana deveu-se ao avanço tecnológico, sendo uma pequena parte deste crescimento atribuído à intensificação do uso de capital" e citou os trabalhos baseados na Pesquisa de Inovação Tecnológica (PINTEC, 2005). A pesquisa concluiu que as empresas inovadoras têm maior produtividade (medida pela relação valor agregado e pessoal ocupado). 
Ao pesquisarem a relação entre inovação e desempenho do negócio em termos de valor das vendas e lucros após taxas em PMEs inglesas (incluindo empresas de serviços profissionais), Oke; Burke e Myers (2007) concluíram que existe uma ligação positiva entre o valor das vendas e a inovação em PMEs, o que confirma a importância de políticas governamentais direcionadas à inovação nesse universo de empresas.

\subsubsection{Competitividade e Produtividade no Setor de Serviços}

Para Porter (1993), a maioria dos estudos sobre vantagem competitiva foi direcionada a bens manufaturados, porém o autor ressalta a importância econômica do setor de serviços e a existência de certa competição internacional na indústria de serviços. Aponta os fatores que aumentam a competitividade e o crescimento de empresas de serviços, como:

a) O crescimento do uso da tecnologia da informação na cadeia de valores das empresas de serviços, otimizando processos e a operação;

b) Automação de máquinas para melhor controle das operações e da produtividade dos funcionários;

c) Crescimento de empresas de unidades múltiplas pela sistematização e padronização de processos; e

d) Especialização nos serviços, com melhora na sistematização e cadeia de valores.

O impacto da inovação no desempenho das empresas de serviços nos Estados Unidos da América foi estudado por Mansury e Love (2008), distinguindo o que é "novo para o mercado" e "novo para a empresa". Desse modo, foram pesquisadas as interações externas em inovação em serviços e seus efeitos no desempenho do negócio e afirmam que os estudos sobre a relação entre inovação e desempenho são relativamente raros na literatura. Atuando de forma particular sobre o universo 
americano das indústrias, os autores afirmam que a presença da inovação em serviços tem efeito positivo consistente no crescimento (em parte, por interações externas mantidas em inovação de processo), mas nenhum efeito na produtividade.

Na mesma linha de ganho de produtividade em empresas de serviços em razão da inovação, Zagler (2002) afirma que o setor de serviços tem um menor ganho de produtividade global que o setor de manufatura, mas os lucros econômicos são mais elevados. A produtividade em termos de empresas individuais reduz, mas ganha-se em importância econômica. Este aumento é em razão da variedade dos serviços fornecidos, ou seja, os consumidores gastam mais com o aumento do leque de serviços oferecidos. Por outro lado, empresas que oferecem novos serviços via inovação têm aumento positivo e crescente de produtividade.

Ao analisar de modo global e por meio de revisão da literatura os efeitos da inovação em serviços em nível de empresa, Aas e Pedersen (2010) constataram que os efeitos da inovação sobre a produtividade e sobre as vendas (competitividade) de novos serviços ou já existentes são positivos para o negócio. Os autores desenvolveram um diagrama, conforme os dados da Figura 29, no qual relacionam o processo de inovação em serviços com os efeitos da inovação em serviços (desempenho do negocio, relacionamento e capacitação), que culminam em efeitos no desempenho financeiro e competitividade (aumento de vendas). 


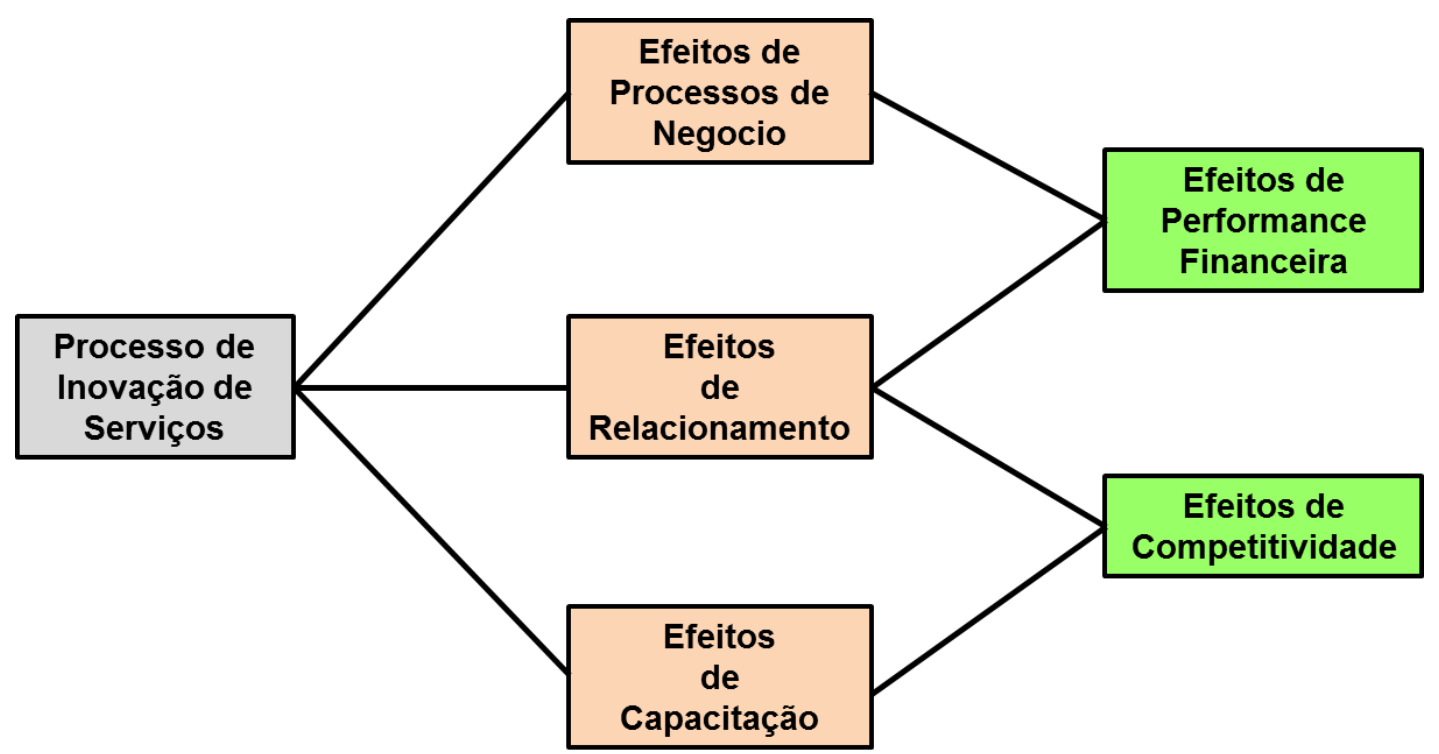

Figura 29: Relações sugeridas entre as categorias de efeitos na inovação em serviços Fonte: Aas e Pedersen; (2010, p.777).

Para Chang (2011), algumas empresas de serviços acreditam que as ideias de serviços e inovações são rapidamente imitadas pelos concorrentes. Outras empresas não conseguem mensurar os efeitos do impacto das inovações em serviços na lucratividade, porque os elementos de serviços inovadores estão no mesmo pacote com outros elementos de serviços quando usados pelos clientes.

\subsubsection{Competitividade e Produtividade em MPEs}

Ao estudarem os benefícios da inovação para as empresas, Rosenbusch; Brinckmann e Bausch (2011) analisaram a relação entre inovação e desempenho nas pequenas e médias empresas. $O$ objetivo foi obter evidências sob quais circunstâncias PMEs com poucos recursos beneficiam-se da inovação. desempenho das empresas pesquisadas foi medido em termos de retorno contábil, crescimento e desempenho no mercado versus maturidade da empresa.

Assim, os autores supracitados indicam que alguns estudos afirmam que a inovação não influencia o desempenho das empresas, porém poucos autores estudaram empresas de pequeno porte, que têm características próprias, tais como: atuam em 
nichos de mercado, têm a vantagem de preços mais reduzidos com produtos inovadores e capacidade de identificar, assimilar e aplicar conhecimento. Afirmam ainda que as pequenas organizações podem lucrar ao ajustar-se ao meio ambiente mais rapidamente que as empresas maiores em razão de pouca hierarquia e decisões rápidas, porém não conseguem absorver os custos de uma falha em novos produtos quando comparadas com empresas maiores. O estudo concluiu que a relação entre inovação e desempenho depende do contexto, ou seja, fatores internos, como idade da empresa, tipo de inovação adotada e contexto cultural afetam grandemente o impacto da inovação no desempenho da empresa. Em geral, pequenas e médias empresas que buscam uma estratégia de inovação parecem ter recursos suficientes e capacidade para se beneficiar da inovação.

O contexto competitivo e a atividade inovadora (definida como qualquer novo produto, serviço ou processo) em pequenos negócios foram estudados por Sebora; Hartmann e Tower (1994). Os autores pesquisaram funcionários de 88 pequenos negócios e investigaram os efeitos do tipo de mercado e da tecnologia na inovação, concluindo que:

a) Ao questionar se o tipo de mercado afeta a inovação em pequenos negócios, o estudo concluiu que organizações de mercado de consumo direto têm mais atividade inovadora inicialmente, mas implementam menos que as atividades industriais;

b) Os funcionários de empresas de serviços evidenciam ter menos atividade inovadora que as empresas de manufatura;

c) Ao discutir se a atividade de inovação é uniforme entre os diferentes níveis hierárquicos das pequenas empresas, foi observado que funcionários do nível operacional têm papel menor no processo de inovação; e

d) Os efeitos do contexto organizacional na atividade inovadora são mais significativos nos níveis estratégico e administrativo que no operacional. 
A competitividade e a gestão estratégica nas pequenas empresas foi estudada por Almeida e Moreira Júnior (2004), que pesquisaram a influência do ambiente organizacional na pequena empresa da cidade de São Paulo. Apontaram a necessidade de agir estrategicamente no mercado competitivo, assegurando sua sustentabilidade nos médio e longo prazos. Afirmam ainda que a inovação (que está inserida na variável ambiental tecnologia) deve ser considerada em uma análise, tanto interna como externa.

A pesquisa mostrou que as pequenas empresas realizam análise do ambiente organizacional de maneira não estruturada quando comparadas com as empresas de grande porte, os autores sugerem uma simplificação dos modelos para se ajustar ao universo das empresas de pequeno porte. A relação entre a inovação nas pequenas e médias empresas, a orientação estratégica e as percepções no meio ambiente foram estudadas por O'Regan e Ghobadian (2005), que categorizaram as pequenas e médias empresas em prospectivas e defensivas (tipologia de Miles e Snow). As primeiras são mais comprometidas com o desenvolvimento de novos produtos, e as defensivas são mais propensas a modificar um produto existente do que introduzir um novo.

Na mesma linha de inovação e estratégia competitiva, Sluismans (2009) identificou três tipos de pequenas e médias empresas (PMEs), de acordo com as necessidades para melhorar sua capacidade de inovação (foram pesquisadas 650 PMEs):

a) PMEs com foco dominante em problemas de otimização interna: clima mediano de inovação e desempenho médio, com problemas relacionados à gestão e organização. Para solucionar esses problemas, as empresas apontaram, preferencialmente, a melhora na organização interna (planejamento, fluxo de comunicação, entre outros);

b) PMEs com foco em marketing/vendas e otimização externa: elevado clima de inovação e alto desempenho, com problemas e oportunidades relacionados a conhecimento e eficiência no serviço a seus clientes; e 
c) PMEs com foco na estratégia antes da otimização interna: baixo clima de inovação e baixo desempenho, com necessidade primária de uma missão clara e planos estratégicos.

\subsubsection{Competitividade e Produtividade nas Lavanderias}

Uma questão importante na competição entre empresas é a utilização de estratégias de inovação, que podem ser concentradas em ações de curto prazo (reativas) ou aquelas que atuam antes das mudanças de mercado (proativas) e mudam as regras de competição. Nas lavanderias domésticas, alguns marcos como: a introdução de lavagem a seco (com economia de água e insumos), o uso de lavadoras extratoras (economia de tempo e espaço com a vantagem de operação única) e o advento de lavagem com pouca água ou wetcleaning (alternativa ecológica a lavagem a seco), trouxeram vantagens pela mudança de paradigma e da imagem do serviço de lavagem, que saiu de uma atividade artesanal para um conceito de especialização, rapidez e melhor custo/benefício.

No caso das lavanderias domésticas no País, existia certa competição dentro das cidades até a década de 1990, sobretudo nas capitais e cidades do interior de maior porte. Mas, a entrada de grandes redes internacionais de franquias de lavanderias mudou este cenário, tornando a competição mais acirrada e disseminada nas cidades de porte médio. A redução de preços, a mudança do lay out das lojas, a introdução de novas tecnologias de lavagem, máquinas automáticas, automação na dosagem de produtos e capacitação de recursos humanos nas lojas influenciou a dinâmica de negócios e da competição.

Porter (1993) ressalta que grandes empresas de serviços de unidades múltiplas, como lavanderia e lavagem a seco, aceleraram a internacionalização da competição em serviços. As vantagens competitivas das empresas de unidades múltiplas em relação às empresas de uma só unidade são: uniformização na capacitação e apoio ao grupo (central de compras única, recrutamento, desenvolvimento de tecnologia, contabilidade, entre outros) e publicidade para todo grupo em nível local e nacional. 
Existe uma relação direta entre a inovação tecnológica e a produtividade nas lavanderias domésticas: a inovação tecnológica é traduzida pelo uso de processos de lavagem mais eficientes e sustentáveis (tecnologia de máquinas, de produtos químicos, processos com menor ou nenhum uso de água e automatizados) e o uso de tecnologia da informação, permitindo melhor controle do processo de entrega do serviço e gestão de informações financeiras e contábeis via programas de gerenciamento específicos para o segmento. Ao relacionar a inovação tecnológica com competitividade, Gallucci afirma:

....aderir a novas tecnologias que melhorem o desempenho da lavanderia "da porta para dentro" é fundamental para que a empresa continue alinhada com as tendências do setor, mas igualmente fundamental é garantir vantagens competitivas para a lavanderia "da porta para fora", ou seja, que gerem mais vendas (GALLUCCI, 2013, p.42).

A produtividade dos trabalhadores da linha de frente (front office) e de retaguarda (back office) nas lavanderias está relacionada à motivação para o cumprimento das tarefas de rotina e controle do processo de produção do serviço, desde a recepção (front office), etapas do processo produtivo (back office) e entrega (front office). Kellog e Nie (1995) analisaram a motivação dos empregados em empresas do tipo "fábrica de serviços" (onde se incluem as lavanderias domésticas) e afirmam que nessas organizações fatores, como sistema de recompensas, políticas de promoção e descrição de cargos são ferramentas importantes para motivação.

\subsubsection{Trabalhos de Helena Forsman (2011) (Inovação, Competitividade e Produtividade em Pequenas Empresas)}

Forsman e Temel (2011) estudaram o tema da presente pesquisa, abordando a inovação e o desempenho de pequenas empresas, em uma pesquisa com 145 empresas, entre 2005 e 2009. Os principais pontos abordados e discutidos foram:

a) Exploração da relação entre inovações desenvolvidas e desempenho do negócio em pequenas empresas (com menos de 50 funcionários); 
b) Mudança do desempenho no tempo durante o período de 5 anos citados;

c) Pesquisa de campo buscando evidência empírica da relação entre inovação e desempenho do negócio; e

d) Análise dos tipos de inovação versus desempenho do negócio.

Para os autores citados, a globalização estimulou a competitividade, e a inovação tornou-se uma ferramenta que impacta na melhora do desempenho de pequenos negócios.

O tipo de inovação, conforme citam os autores, está ligado ao desempenho, exemplificando que as inovações de produto e serviço vêm sendo associadas ao crescimento das vendas, ao passo que as inovações de processo são associadas à produtividade. As inovações radicais representam ofertas inteiramente novas e diferentes quando as empresas querem acessar ou criar novos mercados, sendo consideradas ações de risco que demandam tempo, risco financeiro e conhecimento extenso. As incrementais representam pequenas melhoras em produtos existentes, serviços e processos por meio das quais as empresas melhoram as operações, a qualidade, os processos e reduzem os custos.

Com relação à adoção de diferentes tipos de inovação, Forsman e Temel (2011) afirmam que se deve atentar para a diversidade das inovações em pequenas empresas, já que adotam mais de um tipo de inovação em suas operações, de modo a criar valor a seus clientes. Complementam que a inovação pode resultar em crescimento e eficiência, mas, não imediatamente em altos lucros, estes últimos estão mais ligados à diversidade das inovações.

Com relação à parte metodológica, o trabalho dos autores supracitados explorou as relações entre as inovações desenvolvidas e o desempenho do negócio. As medições foram efetuadas em períodos determinados: no início de 2005; entre 2006 e 2008 (com as inovações desenvolvidas pelas empresas e início da explotação) e 2009 (final das medições). Os autores escolheram uma primeira separação na qual 
pesquisaram as inovações radicais e incrementais e uma segunda entre o produto e o serviço. Posteriormente estudaram a diversidade das inovações e o desempenho do negócio. Afirmaram ainda que a categorização dos diferentes tipos de inovação nem sempre é clara às pequenas empresas. Com relação ao desempenho do negócio, consideraram em sua pesquisa as variáveis lucro, retorno sobre o investimento, crescimento de vendas anuais e vendas por funcionário.

Em seu estudo, Forsman e Temel (2011) concluíram que:

a) Empresas com baixo desempenho em termos de ganhos operacionais e retorno sobre $o$ investimento iniciam o desenvolvimento de inovações radicais e as empresas caracterizadas por alto desempenho continuam a explorar seus produtos/serviços existentes ou desenvolvem pequenas melhorias (estão satisfeitas com seus produtos e serviços atuais). Estes resultados, em parte, conflitam com trabalhos anteriores, que associam empresas de alto desempenho com orientação para inovação, comportamento de risco e proatividade;

b) A inovação em pequenos negócios tende a resultar em crescimento e eficiência, mas não em melhora da lucratividade;

c) A relação entre tipos de inovação e desempenho: o estudo sugere que as inovações incrementais levam a uma pequena melhora no retorno sobre o investimento, ao passo que as inovações radicais levam a uma melhora considerável no crescimento das vendas anuais;

d) As evidências do estudo sugerem que ambas as inovações em produto acompanhadas das inovações de processo produzem melhor desempenho;

e) A diversidade dos tipos de inovação é associada positivamente com o desempenho do negócio, sugerindo que as empresas beneficiam-se por sua capacidade de estarem envolvidas no desenvolvimento de diferentes tipos de inovação; 
f) As condições econômicas têm impacto no desempenho da inovação, sendo as vendas sensíveis às flutuações econômicas, especialmente, aquelas resultantes de inovações radicais em produtos e serviços; e

g) As empresas tendem a manter seus funcionários, mesmo em condições de redução de vendas, levando a um baixo desempenho em termos de lucratividade e vendas por funcionário.

Forsman e Rantanen (2011) exploraram as diferenças na capacidade de inovação e na diversidade das inovações desenvolvidas em empresas de serviços e manufatura. Analisaram o desenvolvimento da inovação em pequenas empresas e afirmaram que a inovação está integrada na rotina dessas empresas, ou seja, não é "visível". Em razão da flexibilidade, alta capacidade de se adaptar e melhorar seus processos, as pequenas empresas são mais rápidas na implementação de mudanças. Com relação à formalização, os autores apontam que pequenas empresas não escrevem um plano de inovação, e só metade reserva recursos para a inovação. Por outro lado, a limitação nas práticas de identificação de oportunidades, capacidade limitada de analisar 0 mercado e tendências tecnológicas, dificuldades para medir o impacto da inovação no negócio, atitudes reativas à inovação e dificuldades em ter uma rede de relacionamentos são desafios apontados pelos autores para as pequenas empresas. Como resultado da pesquisa de campo afirmaram que as empresas de serviços e manufatura têm padrões de inovação similares, porém empresas de serviços têm valores mais altos, tanto para inovações em produto como de serviço em comparação com empresas de manufatura. Os autores atribuem essa diferença ao fato das pequenas empresas não distinguirem esses dois tipos de inovação. Outra conclusão do estudo mostrou que a inovação incremental foi a opção mais comum para ambas as empresas (serviços e produtos).

Forsman (2011) comparou a capacidade e o desenvolvimento da inovação em pequenas empresas de produtos e serviços, concluindo que existe uma rica diversidade de padrões de inovação nessas empresas, porém há pequenas diferenças entre pequenas empresas de manufatura e serviços. Aponta que, em setores dominados por fornecedores, a capacidade de inovação é mais baixa e que 
o desenvolvimento da inovação radical se dá mais no setor de fornecedores especializados, ao passo que os setores dominados por fornecedores são mais propensos à inovação incremental.

\subsection{Resumo do Referencial Teórico}

As referências utilizadas na pesquisa documental teórica encontram-se nos dados do Quadro 1.

Quadro 1: Referências utilizadas na pesquisa documental teórica

\begin{tabular}{|c|c|c|c|}
\hline \multicolumn{3}{|c|}{ TEMA } & REFERÊNCIAS \\
\hline \multirow[b]{2}{*}{2.1 Inovação } & \multicolumn{2}{|c|}{$\begin{array}{l}\text { 2.1.1 Conceito de } \\
\text { Inovação }\end{array}$} & $\begin{array}{l}\text { Schumpeter (1942); Tidd; Bessant e Pavitt (2008); Walker (2007); Manual de } \\
\text { Oslo (2005) }\end{array}$ \\
\hline & \multicolumn{2}{|c|}{$\begin{array}{l}\text { 2.1.2 Tipologia da } \\
\text { Inovação e Seu Inter- } \\
\text { Relacionamento }\end{array}$} & $\begin{array}{c}\text { Walker (2007); Andreassi (2007); Rowley; Baregheh e Sambrook (2011); } \\
\text { Manual de Oslo (2005); Damanpour; Walker e Avellaneda (2009); Zmoginski et } \\
\text { al (2009); Ades e Plonski (2009); Hipp e Grupp (2005); Gunday et al. (2011); } \\
\text { Oke; Burke e Myers (2007) }\end{array}$ \\
\hline \multirow{2}{*}{$\begin{array}{l}\text { 2.2 O Setor de } \\
\text { Serviços }\end{array}$} & \multicolumn{2}{|c|}{$\begin{array}{l}\text { 2.2.1 Definição e } \\
\text { Abrangência do Setor de } \\
\text { Serviços }\end{array}$} & $\begin{array}{c}\text { Kon (2004); Zeithaml e Bitner (2011); Gianesi e Corrêa (1996); Fitzsimmons e } \\
\text { Fitzsimmons (2010); Kandampully (2002) }\end{array}$ \\
\hline & \multicolumn{2}{|c|}{$\begin{array}{l}\text { 2.2.2 Tipologia de } \\
\text { Serviços }\end{array}$} & $\begin{array}{c}\text { Cook; Goh e Chung (1999); Verma (2000); Schmenner (1986); Bessant e Tidd } \\
\text { (2009); Hauknes (1998); Bowen (1990) }\end{array}$ \\
\hline \multirow{4}{*}{$\begin{array}{l}2.3 \text { A Inovação no } \\
\text { Setor de Serviços }\end{array}$} & \multicolumn{2}{|c|}{$\begin{array}{l}\text { 2.3.1 Visão } \\
\text { Schumpeteriana de } \\
\text { Inovação em Serviços }\end{array}$} & Drejer (2004); Schumpeter (1942); Gallouj (1998); Gallouj (1997) \\
\hline & \multicolumn{2}{|c|}{$\begin{array}{l}\text { 2.3.2 Conceito e } \\
\text { Processo de Inovação em } \\
\text { Serviços }\end{array}$} & $\begin{array}{c}\text { Tamura et al. (2005); Gallouj (2002); Barras (1986); Gallouj (1997); Gallouj } \\
\text { (1998); Gallouj e Weinstein (1997); Evangelista (2000); Sundbo (1997); } \\
\text { Fitzsimmons e Fitzsimmons (2010); Guimarães e Resende Júnior (2010); } \\
\text { Damanpour; Walker e Avellaneda (2009); Vasconcellos e Marx (2011); Elche- } \\
\text { Hotelano (2011); Omachonu e Einspruch (2010) }\end{array}$ \\
\hline & \multicolumn{2}{|c|}{$\begin{array}{l}\text { 2.3.3 Desenvolvimento de } \\
\text { Novos Serviços }\end{array}$} & $\begin{array}{c}\text { Mello (2006); Fitzsimmons e Fitzsimmons (2010); Omachonu e Einsprunch } \\
\text { (2010); Schulteß et al. (2010); Scheuning e Johnson (1989); Jong e Vermeulen } \\
\text { (2003); Chen (2011); Hortelano e González-Moreno (2007); Evangelista e Sirilli } \\
\text { (1998); Vargas e Zawislak (2006) }\end{array}$ \\
\hline & \multicolumn{2}{|c|}{$\begin{array}{l}\text { 2.3.4 Inovação em } \\
\text { Serviços x Inovação em } \\
\text { Produtos }\end{array}$} & $\begin{array}{c}\text { Bessant e Tidd (2009); Berry et al. (2006); Dörner, Gassmann e Gebauer } \\
\text { (2011); Cook; Goh e Chung (1999); Drejer (2003); Ettlie e Rosenthal (2011); } \\
\text { Damanpour; Walker e Avellaneda (2009); Hipp e Grupp (2005); Schleimer e } \\
\text { Shulman (2011); Nijssen et al. (2006) }\end{array}$ \\
\hline \multirow{2}{*}{$\begin{array}{c}2.4 \mathrm{Ti}- \\
\text { pologia da } \\
\text { Inovação em } \\
\text { Serviços e seu } \\
\text { Inter- } \\
\text { relacionamento }\end{array}$} & \multicolumn{3}{|c|}{$\begin{array}{l}\text { Pavitt (1984); Miozzo e Soete (2001); Damanpour; Walker e Avellaneda (2009); Zeithaml e Bitner (2011); } \\
\text { Paswan, D'Souza e Zolfagharian (2009); Oke; Burke e Myers (2007); Hipp e Grupp (2005); Manual de Oslo } \\
\text { (2005); Vasconcellos e Marx (2011); Hauknes (1998); Tamura et al. (2005) }\end{array}$} \\
\hline & $\begin{array}{l}2.4 .2 \\
\text { Inovação de } \\
\text { Processo }\end{array}$ & $\begin{array}{l}\text { 2.4.2.1 } \\
\text { Conceito } \\
\text { de } \\
\text { Inovação } \\
\text { de } \\
\text { Processo }\end{array}$ & Manual de Oslo (2005); Damanpour; Walker e Avellaneda (2009) \\
\hline
\end{tabular}




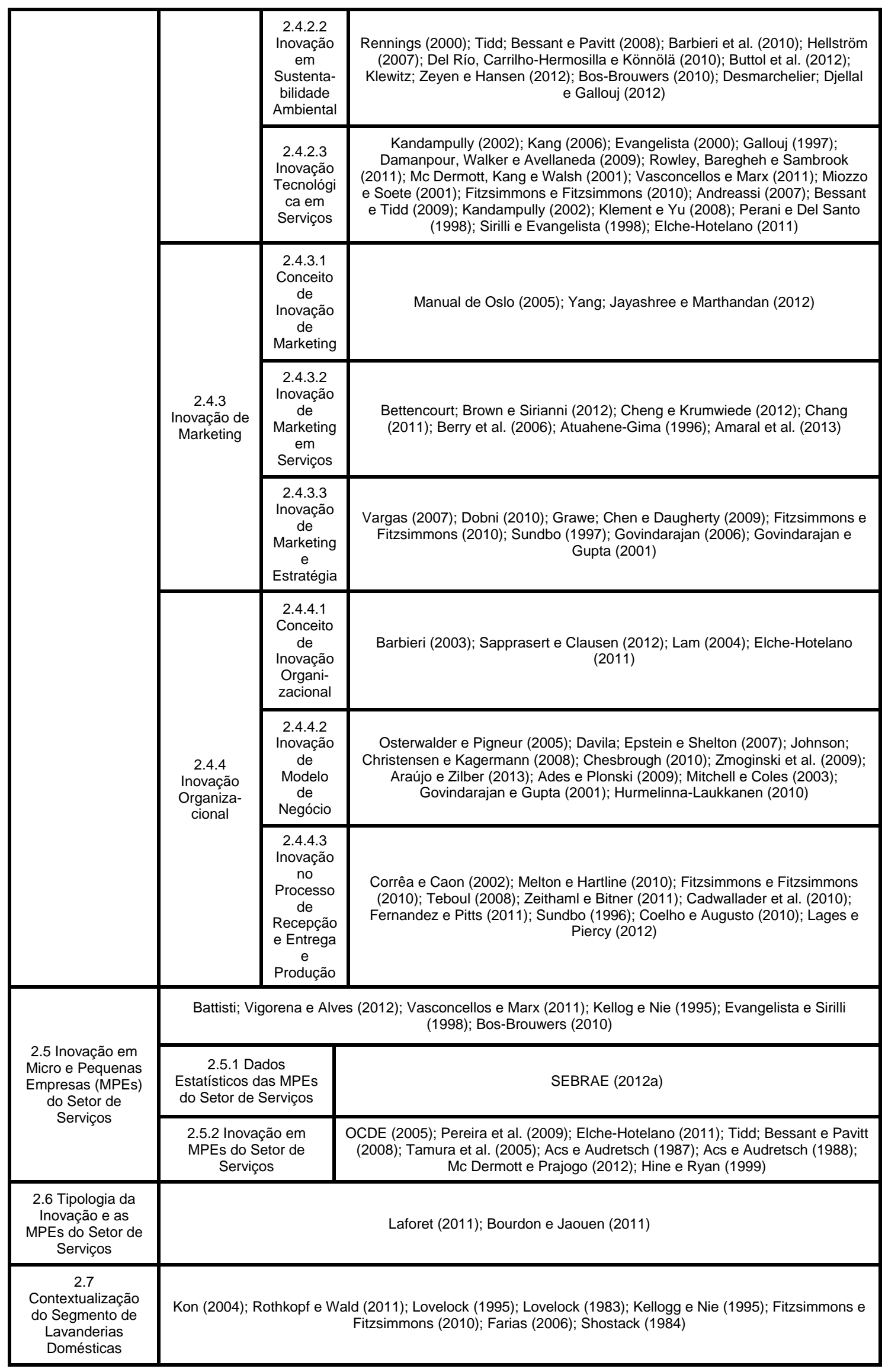




\begin{tabular}{|c|c|c|c|}
\hline \multirow{6}{*}{$\begin{array}{l}\text { 2.8 A Inovação e o } \\
\text { segmento de } \\
\text { Lavanderias } \\
\text { Domésticas }\end{array}$} & \multicolumn{3}{|c|}{ Gordon e Mc Cann (2005); Partanen; Chetty e Rajala (2011); Massa e Testa (2008) } \\
\hline & \multirow{3}{*}{$\begin{array}{c}2.8 .1 \\
\text { Inovação de } \\
\text { Processo } \\
\text { em } \\
\text { Lavande- } \\
\text { rias } \\
\text { Domésti- } \\
\text { cas }\end{array}$} & \multicolumn{2}{|r|}{ Heiskanen e Jalas (2003) } \\
\hline & & $\begin{array}{c}\text { 2.8.1.1 } \\
\text { Inovação } \\
\text { em } \\
\text { Sustentabili } \\
\text { dade } \\
\text { Ambiental } \\
\text { nas } \\
\text { Lavanderias } \\
\text { Domésticas }\end{array}$ & $\begin{array}{c}\text { Piemonte (2010); Bos-Brouwers (2010); Heiskanen; Kasanen e Timonen } \\
\text { (2005); Roy (2000); Shove (2002); Laitala; Klepp e Boks (2012); Laitala; } \\
\text { Boks e Klepp (2011); Gallucci (2012) }\end{array}$ \\
\hline & & $\begin{array}{c}2.8 .1 .2 \\
\text { Inovação } \\
\text { Tecnológica } \\
\text { nas } \\
\text { Lavanderias } \\
\text { Domésticas }\end{array}$ & $\begin{array}{l}\text { Miozzo e Soete (2001); Battisti; Vigorena e Alves (2012); Gallouj (1997); Mc } \\
\text { Dermott; Kang e Walsh (2001); Kang (2006); Evangelista e Sirilli (1998); } \\
\text { Kellogg e Nie (1995) Fijan S.; Fijan R. e Sostar-Turk (2008); Sinsheimer e } \\
\text { Latif (2007); Gallouj e Weinstein (1997); Palovita e Järvi (2008) }\end{array}$ \\
\hline & $\begin{array}{c}2.8 .2 \\
\text { Inovação de } \\
\text { Marketing } \\
\text { nas } \\
\text { Lavande- } \\
\text { rias } \\
\text { Domésti- } \\
\text { cas } \\
\end{array}$ & \multicolumn{2}{|c|}{$\begin{array}{c}\text { Kellogg e Nie (1995); Caetano (2013); Mendonça (2003); Gallucci (2013); Gallucci (2011); } \\
\text { Shaw (1973) }\end{array}$} \\
\hline & $\begin{array}{l}2.8 .3 \\
\text { Inovação } \\
\text { Organiza- } \\
\text { cional nas } \\
\text { Lavande- } \\
\text { rias } \\
\text { Domésti- } \\
\text { cas }\end{array}$ & \multicolumn{2}{|r|}{ Lovelock (1996); Nijssen et al. (2006); DeSouza e Amazu (2006) } \\
\hline \multirow{7}{*}{$\begin{array}{l}2.9 \text { Inovação, } \\
\text { Competitividade e } \\
\text { Produtividade }\end{array}$} & \multicolumn{3}{|c|}{ Gunday et al. (2011); Damanpour; Walker e Avellaneda (2009); Cainelli; Evangelista e Savona (2006) } \\
\hline & \multicolumn{2}{|c|}{\begin{tabular}{c|} 
2.9.1 Trabalhos de \\
Helena Forsman (2011) \\
(Inovação, \\
Competitividade e \\
Produtividade em \\
Pequenas Empresas) \\
\end{tabular}} & Forsman e Temel (2011); Forsman e Rantanen (2011); Forsman (2011) \\
\hline & \multicolumn{2}{|c|}{$\begin{array}{l}2.9 .2 \text { Inovação e } \\
\text { Competitividade }\end{array}$} & $\begin{array}{l}\text { Sebora; Hartman e Tower (1994); Evangelista e Sirilli (1998); Riddle (2008); } \\
\text { Elche-Hotelano (2011); Tidd; Bessant e Pavitt (2008); Radons et al. (2012); } \\
\text { Zmoginski et al. (2009) }\end{array}$ \\
\hline & \multicolumn{2}{|c|}{$\begin{array}{l}\text { 2.9.3 Inovação e } \\
\text { Produtividade }\end{array}$} & Banco Mundial (2008); Britto (2009); Oke; Burke e Myers (2007) \\
\hline & \multicolumn{2}{|c|}{$\begin{array}{l}\text { 2.9.4 Competitividade e } \\
\text { Produtividade no Setor de } \\
\text { Serviços }\end{array}$} & $\begin{array}{l}\text { Porter (1993); Mansury e Love (2008); Zagler (2002); Aas e Pedersen (2010); } \\
\text { Chang (2011) }\end{array}$ \\
\hline & \multicolumn{2}{|c|}{$\begin{array}{l}\text { 2.9.5 Competitividade e } \\
\text { Produtividade em MPEs }\end{array}$} & $\begin{array}{l}\text { Rosenbusch; Brinckmann e Bausch (2011); Sebora; Hartmann e Tower (1994); } \\
\text { Almeida e Moreira Junior (2004); O'Regan e Ghobadian (2005); Sluismans } \\
\text { (2009) }\end{array}$ \\
\hline & \multicolumn{2}{|c|}{$\begin{array}{l}\text { 2.9.6 Competitividade e } \\
\text { Produtividade nas } \\
\text { Lavanderias }\end{array}$} & Porter (1993); Gallucci (2013); Kellog e Nie (1995) \\
\hline
\end{tabular}

Elaborado pelo autor 


\section{METODOLOGIA}

A pesquisa em administração caracteriza-se pela interação entre os conceitos teóricos e as práticas nas empresas e a escolha do método tem como foco responder aos objetivos gerais e específicos da pesquisa. Para Martins (2005), a construção de uma linha de investigação acadêmica supõe a definição de uma metodologia adequada à natureza do objeto de estudo.

No presente estudo, o autor optou por utilizar a seguinte metodologia de pesquisa:

a) Pesquisa bibliográfica teórico-documental sobre o tema escolhido para estudo, que abrange os conceitos de inovação, serviços, micro e pequenas empresas e lavanderias. Estes conceitos foram desmembrados para melhor aprofundamento e abrangência do tema;

b) Pautados nos resultados da revisão bibliográfica teórica, foram delineadas as hipóteses com o objetivo de propor respostas ao problema de pesquisa. As hipóteses forneceram afirmações sobre os parâmetros populacionais escolhidos para serem testadas;

c) Pesquisa de campo, que foi operacionalizada em ações sequenciais objetivando coletar dados e informações que permitissem atender aos objetivos do estudo, a saber:

- Pesquisa prévia inicial qualitativa por meio de entrevistas semiestruturadas e perguntas abertas e fechadas com especialistas e consultores do segmento de lavanderias domésticas que participam e auxiliam na difusão da inovação entre as empresas. O objetivo foi efetuar uma avaliação preliminar para verificar se as premissas sobre os tipos de inovação e sua adoção pelas lavanderias tinham aderência aos objetivos gerais e específicos delineados para 0 estudo. Adicionalmente, o questionário desenvolvido para a pesquisa de campo foi apresentado aos entrevistados para que opinassem, antes do envio do mesmo para a amostra escolhida; 
- Desenvolvimento de um questionário como instrumento de coleta da pesquisa de campo (quantitativa), utilizando perguntas fechadas e, predominantemente, a escala Likert para respostas, em uma amostra aleatória das lavanderias da cidade de São Paulo. As perguntas foram direcionadas de modo a indagar a respeito dos parâmetros populacionais (competitividade e produtividade) e sua relação com a tipologia da inovação, com o objetivo de conseguir resultados quantitativos que permitissem analisar e testar as afirmações formuladas nas hipóteses;

- A população e a amostra das lavanderias domésticas pesquisadas foram delineadas; a amostra da população das lavanderias domésticas da cidade de São Paulo foi escolhida aleatoriamente. A proximidade geográfica permitiu mesclar coleta por envio via eletrônica e por meio de entrevistas pessoais, minimizando o tempo de resposta e aumentando a confiabilidade nos resultados;

- Pautado nas hipóteses delineadas apoiadas na teoria e na revisão do questionário de campo pelos entrevistados na pesquisa prévia, foi efetuada a pesquisa de campo quantitativa com a amostra escolhida aleatoriamente junto à população das lavanderias domésticas da cidade de São Paulo. Todas as lavanderias da amostra foram contatadas via telefone antes do envio dos questionários via eletrônica (email);

- Os dados de campo foram coletados, sendo empregadas técnicas estatísticas para posterior análise dos resultados.

Com relação à mensuração por escala Likert, Günther (2003) afirma que esta mensuração é utilizada sobretudo nas ciências sociais, em levantamentos de opiniões, avaliações e atitudes. O autor afirma que o número de alternativas é uma decisão importante, já que um número ímpar de alternativas permite ao respondente ter a alternativa do meio quando não quer se comprometer na resposta. Na presente pesquisa, por tratar-se de um público (lavanderias) familiarizado com os assuntos abordados nas perguntas (inovação em lavanderias), optou-se por não ter a opção "não sei". 


\subsection{Pesquisa Bibliográfica Teórico-Documental}

A pesquisa bibliográfica documental explica um problema com base nos referenciais teóricos publicados em documentos e busca conhecer e analisar as contribuições culturais ou científicas do passado existentes sobre determinado assunto, tema ou problema. Os conceitos escolhidos para a presente pesquisa (conceitos básicos e conceitos particulares) estão delineados no ítem 2 (Referencial Teórico). Na presente pesquisa, foi utilizado material bibliográfico pautado em periódicos, livros e congressos científicos.

A pesquisa bibliográfica teve como objetivo o melhor entendimento dos conceitos básicos relacionados à inovação, à sua tipologia, ao setor de serviços e às micro e pequenas empresas. Tornou-se necessário também maior aprofundamento nos conceitos particulares diretamente ligados à pesquisa, tais como: o entendimento de como se processa a inovação em micro e pequenas empresas do setor de serviços e os principais tipos de inovação utilizados por estas empresas, além da questão da inovação nas lavanderias domésticas.

\subsection{Pesquisa Qualitativa Prévia (Entrevistas Semiestruturadas)}

Manzini (2004) cita que, por definição, uma entrevista é um processo de interação social (verbal e não verbal), ocorrendo face a face entre o pesquisador (que tem um objetivo predefinido) e o entrevistado (que supostamente possui a informação que permite estudar 0 assunto em pauta). $O$ autor refere que a entrevista semiestruturada é um modo de coletar dados, e a interação ocorre no momento da coleta. Destaca ainda o uso das entrevistas semiestruturadas como instrumento de pesquisa:

A entrevista semiestruturada está focalizada em um assunto sobre o qual confeccionamos um roteiro com perguntas principais, complementadas por outras questões inerentes às circunstâncias momentâneas à entrevista. Esse tipo de entrevista pode fazer emergir informações de forma mais livre e as respostas não estão condicionadas a uma padronização de alternativas (MANZINI, 2004, p.2). 
Em seu estudo sobre os efeitos dos tipos de inovação no desempenho das empresas, Gunday et al. (2011) utilizaram entrevistas prévias com executivos escolhidos, com o objetivo de testar se a abordagem, o formato e a sequência dos questionários estavam apropriados, antes dos mesmos serem enviados para a população escolhida. Oke; Burke e Myers (2007) em seu estudo sobre os tipos de inovação e a inovação em práticas gerenciais, utilizaram uma entrevista prévia com seis executivos escolhidos em empresas líderes para, posteriormente, completar com uma pesquisa via e-mail para 214 gerentes de empresas de serviços.

Ao pesquisar os tipos de inovação e as práticas de gestão da inovação em empresas de serviços, Oke (2007) utilizou duas metodologias principais:

a) Pesquisa qualitativa: entrevistas prévias para esclarecer os conceitos identificados na literatura e utilizar os resultados no desenvolvimento da pesquisa de campo via questionário;

b) Pesquisa quantitativa: questionário enviado via e-mail para gerentes sêniors de empresas de serviços, usando as ideias colhidas nas entrevistas qualitativas e na literatura sobre a gestão da inovação. O autor utilizou a escala Likert (1-5) para medir o grau de inovação, revisando os serviços atuais prestados, as extensões de linhas de serviços, as adaptações de um serviço para suprir as necessidades dos clientes específicos e as adaptações de um serviço, visando a atingir novos mercados. Houve um pré-teste dos questionários com dez funcionários envolvidos em atividades de desenvolvimento dos novos serviços nas empresas.

No presente estudo, utilizando como base e apoio para a revisão do questionário de campo, foi elaborada uma pesquisa prévia qualitativa, não aleatória e não probabilística, usando como ferramenta entrevistas semiestruturadas com especialistas do segmento de lavanderias, oriundos de áreas de atuação diferentes (fornecedores, proprietários de lavanderias, membros da diretoria de sindicatos e associações de classes, consultores, entre outros), que tivessem um histórico de atuação, influência e envolvimento significativo no ambiente do segmento das lavanderias domésticas. $O$ objetivo da pesquisa prévia foi obter informações que 
pudessem ratificar a escolha dos tipos de inovação, seu inter-relacionamento e a relação com a competitividade e produtividade, assim como auxiliar na revisão final do questionário aplicado em campo na amostra escolhida. Um roteiro com questões abertas e fechadas foi usado e permitiu certa liberdade ao entrevistado ao direcionar suas respostas e comparar as opiniões entre os entrevistados. As entrevistas foram realizadas face a face, exceto uma (via e-mail), gravadas com tempo médio de 1 hora e posteriormente transcritas. O Apêndice A mostra a pesquisa prévia utilizada como instrumento de pesquisa e os resultados obtidos com cada especialista.

\subsection{Pesquisa Quantitativa de Campo}

\subsubsection{Bancos de Dados Estatísticos Utilizados para Delimitação da Amostra}

Cinco fontes de dados estatísticos foram usadas para a tomada de informações do segmento de lavanderias, sendo escolhida uma fonte que serviu de base para a escolha da amostra representativa da população das lavanderias domésticas da cidade de São Paulo para a pesquisa quantitativa. Também foram coletados dados secundários do segmento, tais como: níveis de investimentos e resultados financeiros das lavanderias em uma análise global.

\subsubsection{Instituto Brasileiro de Geografia e Estatística (IBGE)}

De acordo com a Classificação Nacional das Atividades Econômicas do IBGE (2007) versão $2.0^{4}$, o segmento de lavanderias está enquadrado na divisão 96 (Outras Atividades de Serviços Pessoais) e classe 96.01-7, compreendendo as seguintes atividades:

\footnotetext{
${ }^{4} \mathrm{Na}$ versão 1.0 (2002), o segmento de lavanderias estava classificado na divisão 93 e classe 93.01-7.
} 
a) Lavar, passar e limpar todo tipo de artigos têxteis e do vestuário, inclusive couro e peles;

b) As atividades de lavanderias de autosserviço;

c) A lavagem de tapetes, carpetes e cortinas, inclusive, na residência do cliente;

d) As atividades de tingimento de todo tipo de artigos têxteis e do vestuário, inclusive, de couro e peles;

e) Os serviços associados de aluguel e lavagem de roupas de cama, mesa e banho, de uniformes de trabalho e artigos relacionados; e

f) Os serviços de postos de coleta e entrega de roupas para lavanderias e tinturarias.

O Cadastro Central de Empresas (CEMPRE) do IBGE abrange o universo das organizações inscritas no Cadastro Nacional da Pessoa Jurídica - CNPJ da Secretaria da Receita Federal, abrangendo entidades empresariais, órgãos da administração pública e instituições privadas sem fins lucrativos. A atualização é anual e as informações são colhidas nas áreas da Indústria, Construção Civil, Comércio e Serviços do IBGE e da Relação Anual de Informações Sociais - RAIS do Ministério do Trabalho e Emprego. O CEMPRE 2011 mostra um universo de 6.107 lavanderias, tinturarias e toalheiros no Brasil, com 64.243 trabalhadores assalariados e um salário médio de 1,6 salários mínimos.

A Pesquisa Anual de Serviços 2010 do IBGE, no grupo de Outros Serviços Pessoais, mostra dados estatísticos do Brasil em uma amostra de 442 lavanderias, tinturarias e toalheiros com 20 funcionários ou mais inseridas na Classificação Nacional de Atividades Econômicas (classificação CNAE 96.01-7):

a) Aquisições de ativo tangível no ano totalizaram $R \$ 88,8$ milhões, sendo $R \$ 37,9$ milhões ( $42,7 \%$ do total) em novas máquinas, equipamentos e instalações; 
b) Os Custos Totais foram de $R \$ 266,7$ milhões no ano, sendo $R \$ 211,0$ milhões ( $79,1 \%$ do total) em mercadorias, materiais de consumo e de reposição;

c) Despesas Operacionais Totais de $R \$ 215,9$ milhões, sendo $R \$ 26,2$ milhões (12,1\% do total) relativos a aluguéis de imóveis, $R \$ 19,1$ milhões em despesas com manutenção e reparos ( $9 \%$ do total) e $R \$ 2,1$ milhões ( $0,9 \%$ do total) em publicidade e propaganda;

d) Despesas financeiras, leasing e participações acionárias, totalizando $R \$ 29,2$ milhões, sendo o item despesas financeiras responsável por $R \$ 24,3$ milhões $(83,2 \%$ do total);

e) Gastos com pessoal totalizando $R \$ 503,9$ milhões, sendo $R \$ 330,7$ milhões ( $65,6 \%$ do total) em salários e outras remunerações, $R \$ 4,5$ milhões $(0,9 \%$ do total) em participações nos lucros e honorários da diretoria e $R \$ 46,6$ milhões $(9,2 \%$ do total) em retiradas pró-labore de proprietários e sócios; e

f) Receita Bruta na prestação de Serviços (99,5\% do total) em $R \$ 1,30$ bilhões e receita operacional líquida em $R \$ 1,18$ bilhões ( $90,5 \%$ da receita bruta).

Embora a Pesquisa Anual de Serviços do IBGE não reflita as empresas com menos de 20 funcionários (que podem representar um número relevante de lavanderias domésticas no País), alguns pontos devem ser salientados:

a) As aquisições de novas máquinas, equipamentos e instalações totalizaram quase metade das aplicações em ativo tangível das lavanderias, apontando para uma tendência em priorizar investimentos na área tecnológica ou ampliação dos negócios;

b) Os custos de materiais de consumo que incluem custos variáveis representados por insumos no processo de produção do serviço (produtos químicos, embalagens, entre outros), representam a maior parte dos custos totais $(79,1 \%)$. Do total de $R \$$ 1,02 bilhões (que incluem despesas operacionais, financeiras e gastos com 
pessoal), os custos de materiais de consumo representam $26,2 \%$ e os gastos com pessoal ocupado $49,6 \%$ do total. Os dados indicam um peso mais elevado dos custos com pessoal em relação aos custos de bens de consumo (incluindo custos que incidem diretamente no processo produtivo) nos custos totais;

c) Com relação às despesas operacionais, verifica-se uma maior participação ( $23,8 \%$ do total) no consumo de energia elétrica (a maior parte como custo variável na operação de máquinas e equipamentos durante o processamento do serviço), seguido da participação de serviços técnicos profissionais $(17,1 \%$ do total) e manutenção (8,9\% do total). Estes dois últimos itens somados contribuem com $26 \%$ das despesas operacionais. As despesas fixas de aluguel contribuem com 12,1\% do total e os serviços de comunicação, que incluem internet, contribuem com $3,6 \%$ do total; e

d) As despesas com publicidade e propaganda representam $0,96 \%$ do total de despesas operacionais. Do total de $\mathrm{R} \$ 1,02$ bilhões (que incluem despesas operacionais, financeiras e gastos com pessoal), as despesas com publicidade e propaganda representam $0,20 \%$.

\subsubsection{Estudo do Ministério do Comércio Exterior da Itália}

O estudo efetuado pelo Ministero Dello Sviluppo Economico/Istituto Nazionale per il Commercio Estero (2011) da Itália teve como objetivo estimar o mercado potencial para comercialização de equipamentos italianos para lavanderias no Brasil. O estudo foi disponibilizado pela ITA (Italian Trade Agency) para esta pesquisa. Conforme os pesquisadores, a metodologia utilizada para obtenção dos dados primários e secundários do segmento baseou-se em entrevistas pessoais com profissionais, fabricantes e distribuidores de acessórios para lavanderias, editores da revista Lavanderia \& Cia., diretores das principais entidades e associações do setor e órgãos governamentais abrangendo toda a cadeia de valores do segmento. 
A análise estimou o número e os tipos de lavanderias no mercado brasileiro, concluindo o seguinte:

a) Existem 8.600 a 9.300 lavanderias profissionais no Brasil (domésticas e industriais, incluindo lavanderias de jeans);

b) Cerca de $87 \%$ são lavanderias domésticas o que equivaleria entre 7.500 e 8.000 lavanderias domésticas no Brasil que lavam cerca de 400 toneladas/dia de roupa;

c) Cerca de $90 \%$ do total de lavanderias são pequenos negócios com menos de dez funcionários, sobretudo as lavanderias domésticas.

\subsubsection{Federação das Indústrias do Estado de São Paulo (FIESP)}

Os dados da Federação das Indústrias do Estado de São Paulo (FIESP) no aplicativo Inteligência de Mercado V.1.0.205 (2010) mostram o universo das lavanderias no Estado de São Paulo e na cidade de São Paulo. O aplicativo foi disponibilizado para esta pesquisa, e o autor pesquisou individualmente cada lavanderia da cidade de São Paulo, verificando quais pertenciam ao grupo lavanderias domésticas e separando-as por porte, de acordo com o critério FIESP. Os resultados obtidos foram:

a) 1.727 lavanderias no Estado de São Paulo;

b) 846 lavanderias na cidade de São Paulo (representando 48,9\% do Estado de São Paulo); e

c) Das 846 lavanderias da cidade de São Paulo, 811 são lavanderias domésticas (representando $47,0 \%$ do total estadual e $95,9 \%$ do total municipal); 


\subsubsection{Ministério do Trabalho e Emprego (MTE) do Brasil}

O Ministério do Trabalho e Emprego (MTE) por meio do PDTE (Programa de Disseminação de Estatísticas do Trabalho) disponibilizou o acesso aos bancos de dados do CAGED (Cadastro Geral de Empregados e Desempregados) e o RAIS (Relação Anual de Informações Sociais) para esta pesquisa, sendo possível o uso das informações referentes às empresas (via CNAE) em nível nacional, estadual e municipal, atualizadas para o ano de 2013:

a) O número total de estabelecimentos de serviços no Brasil é de 3.165.164, sendo 1.035.803 no Estado de São Paulo $(32,7 \%$ do total nacional) e 411.630 estabelecimentos na cidade de São Paulo $(13,0 \%$ do total nacional e $39,7 \%$ do total estadual); e

b) O número total de lavanderias e tinturarias no Brasil é de 8.405 estabelecimentos, sendo 2.590 no Estado de São Paulo $(30,8 \%$ do total nacional) e 1.237 estabelecimentos na cidade de São Paulo $(14,7 \%$ do total nacional e $47,8 \%$ do total estadual).

\subsubsection{SINDILAV (Sindicato Intermunicipal de Lavanderias no Estado de São Paulo)}

O SINDILAV representa a classe empresarial de lavanderias, está presente em 611 cidades do Estado de São Paulo e disponibiliza em seu site as lavanderias a ele afiliadas, distribuídas entre lavanderias domésticas, decoração, EPI, hospitalar, hotéis e restaurantes, jeans e industrial:

a) O SINDILAV tem um total de 504 lavanderias afiliadas no Estado de São Paulo;

b) Do total de 504 lavanderias, 380 são lavanderias domésticas no Estado de São Paulo (75,4\% do total estadual); 
c) Do total de 504 lavanderias, 330 são lavanderias na cidade de São Paulo (65,5\% do total estadual);

d) Do total de 504 lavanderias, 266 são lavanderias domésticas na cidade de São Paulo ( $52,8 \%$ do total estadual e $80,6 \%$ do total municipal); e

e) Com relação aos dados globais, o SINDILAV pontua que no Estado de São Paulo existem, aproximadamente, 5.100 lavanderias, sendo 4.200 domésticas e 900 industriais. Destas, $70 \%$ estão localizadas no Município de São Paulo, $80 \%$ são pequenas empresas e $90 \%$ têm até dez funcionários. No Brasil, estima-se que existam cerca de 8.400 lavanderias, sendo 7.400 domésticas ( $88 \%$ do total) e 1.000 industriais ( $12 \%$ do total).

\subsubsection{Resumo dos Resultados dos Bancos de Dados Estatísticos Utilizados}

O dados do Quadro 2 mostram o resumo dos resultados obtidos nos bancos de dados estatísticos e que serviram como base para a escolha da população e amostra para a pesquisa de campo. 
Quadro 2: Resumo dos Dados Estatísticos como base para a escolha da população e amostra

\begin{tabular}{|c|c|c|c|c|c|c|c|}
\hline \multicolumn{2}{|c|}{ BANCOS DE DADOS } & $\begin{array}{c}N^{0} \text { TOTAL DE } \\
\text { LAVANDERIAS } \\
\text { NO BRASIL } \\
\text { (DOMÉSTICAS } \\
E \\
\text { INDUSTRIAIS) }\end{array}$ & $\begin{array}{c}N^{0} \text { TOTAL DE } \\
\text { LAVANDERIAS } \\
\text { DOMÉSTICAS } \\
\text { NO BRASIL }\end{array}$ & $\begin{array}{l}N^{0} \text { TOTAL DE } \\
\text { LAVANDERIAS } \\
\text { NO ESTADO DE } \\
\text { SÃO PAULO }\end{array}$ & $\begin{array}{c}\mathbf{N}^{0} \text { TOTAL DE } \\
\text { LAVANDERIAS } \\
\text { DOMÉSTICAS } \\
\text { NO ESTADO DE } \\
\text { SÃO PAULO }\end{array}$ & $\begin{array}{l}\mathrm{N}^{0} \text { TOTAL DE } \\
\text { LAVANDERIAS } \\
\text { NA CIDADE DE } \\
\text { SÃO PAULO }\end{array}$ & $\begin{array}{c}\mathbf{N}^{0} \text { TOTAL DE } \\
\text { LAVANDERIAS } \\
\text { DOMÉSTICAS } \\
\text { NA CIDADE DE } \\
\text { SÃO PAULO }\end{array}$ \\
\hline $\begin{array}{c}\text { IBGE } \\
\text { (Instituto } \\
\text { Brasileiro de } \\
\text { Geografia e } \\
\text { Estatística) }\end{array}$ & $\begin{array}{c}\text { CEMPRE } \\
2011\end{array}$ & 6.107 & $\ldots$ & $\ldots$ & 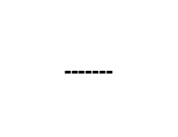 & $-\overline{-o}^{-}$ & -..- \\
\hline $\begin{array}{l}\text { Istituto } \\
\text { Nazionale per } \\
\text { il Commercio } \\
\text { Estero (Itália) }\end{array}$ & 2011 & 8.600 a 9.300 & 7.500 a 8.000 & --o- & - & 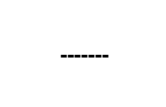 & $\ldots$ \\
\hline $\begin{array}{c}\text { FIESP } \\
\text { (Federação } \\
\text { das } \\
\text { Indústrias do } \\
\text { Estado de } \\
\text { São Paulo) }\end{array}$ & $\begin{array}{c}\text { Inteligência } \\
\text { de Mercado } \\
\text { v.1.0.205 } \\
\text { (2010) }\end{array}$ & -.-- & - & 1.727 & -.-- & 846 & $\begin{array}{l}\text { Total Bruto } \\
=811 \\
\text { Total após } \\
\text { Ajustes } \\
=665\end{array}$ \\
\hline $\begin{array}{c}\text { MTE } \\
\text { (Ministério do } \\
\text { Trabalho e } \\
\text { Emprego) }\end{array}$ & $\begin{array}{c}\text { PDTE } \\
\text { (Programa de } \\
\text { Disseminaçã } \\
\text { o de } \\
\text { Estatísticas } \\
\text { do trabalho) } \\
(2013)\end{array}$ & 8.405 & $\ldots$ & 2.590 & -.-- & 1.237 & $-+-{ }_{-1}$ \\
\hline SINDILAV & $\begin{array}{l}\text { Site Sindilav } \\
\text { (2013) }\end{array}$ & ----- & ..--- & 5.100 (est.) & 4.200 (est.) & 3.570 (est.) & 2.940 (est.) \\
\hline
\end{tabular}

Elaborado pelo autor

\subsubsection{População e Amostra Escolhidas para a Análise Quantitativa}

Stevenson (1981, p.158) refere que "a inferência estatística envolve a formulação de certos julgamentos sobre um todo após examinar apenas uma parte, ou amostra dele". No presente estudo, foram usados bancos de dados estatísticos governamentais e de associações de classe, de modo realizar a delimitação de uma população significativa das lavanderias domésticas. A população escolhida para o presente estudo foi a das lavanderias domésticas da cidade de São Paulo, cujo número corresponde à, aproximadamente, metade do total de lavanderias domésticas do Estado de São Paulo e este, por sua vez, a, quase, um terço do total nacional (Quadro 2).

Anderson, Sweeney e Williams (2011) definem população, amostra e parâmetro populacional: 
a) População é o conjunto de elementos de interesse em um estudo (no caso deste estudo, lavanderias domésticas da cidade de São Paulo); e

b) Amostra é um subconjunto da população (no caso deste estudo, 71 lavanderias domésticas escolhidas aleatoriamente e respondentes à pesquisa de campo);

c) Parâmetro populacional são medidas que referem-se a dados da população (no caso deste estudo, competitividade e produtividade).

A população abrangida por este estudo foi a das lavanderias domésticas na cidade de São Paulo que, conforme dados estatísticos (FIESP, 2010; MINISTERO DELLO SVILUPPO ECONOMICO, 2011; SEBRAE, 2011; SINDILAV, 2013), compõem-se de mais de $90 \%$ por micro e pequenas empresas.

Para a presente pesquisa, foram utilizados os dados estatísticos da FIESP/Inteligência de Mercado (Quadro 2), por ser considerada a base que contém dados completos sobre cada lavanderia da cidade de São Paulo (CNPJ, razão social e dados de localização), permitindo a seleção do tipo de lavanderia pesquisada (doméstica ou industrial), o sorteio probabilístico entre as lavanderias da população escolhida (formatação por planilha Microsoft Excel 2010 que permite a geração de números aleatórios) e a localização para o envio do questionário ou agendamento de entrevista. Os outros bancos de dados pesquisados não permitiram esse nível de detalhamento.

Para o trabalho de verificação do tipo de lavanderia, ou seja, se doméstica, industrial ou doméstica/industrial (quando prestar serviços para ambos os mercados), foram utilizados os bancos de dados das lavanderias associadas ao SINDILAV, bancos de dados oriundos do cadastro de lavanderias de fornecedores de insumos do segmento, banco de dados do próprio autor e checagem diretamente junto às empresas via telefone. Para a amostra, foram escolhidas só as lavanderias domésticas.

O estudo da FIESP mostra um universo de 811 lavanderias domésticas na cidade de São Paulo (48,9\% do total de lavanderias do Estado e 95,9\% do total de lavanderias 
do Municipio). Foram retiradas as lavanderias pertencentes à mesma razão social (filiais), restando 757 lavanderias domésticas. Foram selecionadas as lavanderias pertencentes aos portes 1 e 2 (empresas com até nove empregados) de modo a garantir-se a presença de micro e pequenas empresas, restando 665 lavandeiras domésticas.

Desta forma, para o presente estudo serão consideradas 665 empresas, como população escolhida de lavanderias domésticas na cidade de São Paulo.

Foi tomada uma amostra aleatória simples de população finita (ANDERSON; SWEENEY; WILLIAMS, 2011) ${ }^{5}$ de 71 lavanderias domésticas na cidade de São Paulo (aproximadamente $10,7 \%$ da população de 665 lavanderias domésticas da Cidade de São Paulo, segundo os dados da FIESP - Quadro 2) para a coleta de dados para análise probabilística, cuja operacionalização será discutida nos próximos itens. Para a escolha da amostra foi utilizada a função de gerar números aleatórios da planilha Microsoft Excel 2010.

Assim, para este estudo, as delimitações da população $(\mathrm{N})$ e da amostra (n) foram as seguintes:

$\mathrm{N}=$ população de 665 lavanderias da cidade de São Paulo

$\mathrm{n}=$ amostra de 71 lavanderias da população de lavanderias da cidade de São Paulo (aproximadamente, 10,7\% da população)

A operacionalização e os parâmetros a serem utilizados na pesquisa probabilística e não probabilística serão delineadas a seguir.

\footnotetext{
${ }^{5}$ Anderson; Sweeney e Williams (2011), citam que a amostra aleatória simples (n) de população finita (N) é selecionada de modo que cada amostra possível de tamanho "n" tenha a mesma probabilidade de ser escolhida.
} 


\subsubsection{Estabelecimento das Hipóteses para Análise Quantitativa}

Stevenson (1981, p.166), cita que "os planos de amostragem probabilística são delineados de tal modo que se conhece a probabilidade de todas as combinações amostrais possíveis" e "a amostragem aleatória é um exemplo de amostragem probabilística".

Conforme já referenciado, a pesquisa por amostragem estatística utilizou uma amostra aleatória, em que cada elemento da população (lavanderias domésticas com até nove funcionários da cidade de São Paulo, conforme estudo da FIESP/Inteligência de Mercado) tem a mesma oportunidade de ser incluído na amostra (população discreta). A amostragem aleatória simples foi usada com 0 programa Microsoft Excel 2010 (ANDERSON; SWEENEY; WILLIANS, 2011).

Uma hipótese é uma declaração ou proposição que propõe a solução de um problema de pesquisa (JACOBINI, 2011). Fonseca e Martins (1982, p.176) definem hipótese estatística como "uma suposição quanto ao valor de um parâmetro populacional que será verificada por um teste paramétrico, ou uma afirmação quanto à natureza da população, que será verificada por um teste de aderência".

No presente estudo, as hipóteses foram retiradas do referencial teórico pesquisado e comparadas com os resultados da pesquisa quantitativa de campo, possibilitando a confrontação da teoria com a prática. As hipóteses foram elaboradas de modo a atender aos objetivos específicos deste estudo, conforme item 1.4.2.

Para o teste de hipóteses, foram criadas hipóteses experimentais ou nulas a respeito dos parâmetros de interesse e hipóteses alternativas (opostas às hipóteses nulas), de modo a testar as informações antagônicas (ANDERSON; SWEENEY; WILLIAMS, 2011) e estabelecer uma região de rejeição para a hipótese em estudo.

As hipóteses testadas refletiram a validade das informações sobre inovação, competitividade e produtividade. Anderson; Sweeney e Williams (2011) defendem que, ao testar uma afirmação, presumimos que a afirmação seja verdadeira, portanto a hipótese nula baseia-se nesta afirmação: 
Em situações que envolvem testar a validade de uma afirmação, a hipótese nula geralmente se baseia no pressuposto de que a afirmação é verdadeira. A hipótese alternativa é então formulada a fim de que a rejeição de $\mathrm{H}_{0}$ produza a evidência estatística de que a hipótese declarada é incorreta (ANDERSON; SWEENEY; WILLIAMS, 2011, p.311).

Neste contexto, os parâmetros populacionais escolhidos foram:

a) Competitividade: traduzida pelo aumento de vendas advindo da inovação. Fontes Bibliográficas: Porter (1993); Aas e Pedersen (2010) e Radons et al (2012).

b) Produtividade: traduzida pelo aumento de vendas por funcionário advindo da inovação. Fontes Bibliográficas: PINTEC (2005); Banco Mundial (2008) e Brito (2009).

Os parâmetros escolhidos para a formulação das hipóteses foram organizados de modo a refletirem a tipologia da inovação oriunda da teoria (ex.: inovação em processo/em sustentabilidade ambiental, entre outras) e sua relação com os parâmetros populacionais teóricos (competitividade e produtividade), por meio da pesquisa das práticas mais relevantes do segmento das lavanderias domésticas (ex.: reuso de água, processos sustentáveis, entre outros) relacionadas às tipologias escolhidas de acordo com as informações obtidas na pesquisa qualitativa (entrevistas semiestruturadas).

a) Inovação em Processo

a.1) Inovação em Sustentabilidade Ambiental (Hipóteses $\mathrm{H}_{1}$ e $\mathrm{H}_{2}$ )

Hipótese $\mathrm{H}_{1}$ :

Base Teórica: Rennings (2000); Hellström (2007); Tidd; Bessant e Pavitt (2008); e Barbieri et al. (2010) e Radons et al. (2012)

$\mathrm{H}_{1}$ : "A adoção de produtos e práticas ambientais relacionadas à ecoinovação, como o reuso de águas tem uma relação positiva com o aumento de vendas a clientes que valorizam a proteção ambiental, aumentando a competitividade" 
Parâmetro populacional: competitividade .

Referente a questão 2.1 do questionário de campo (Apêndice B).

Hipótese $\mathrm{H}_{2}$ :

Base Teórica: Rennings (2000); Hellström (2007); Tidd; Bessant e Pavitt (2008);

Barbieri et al. (2010) e Radons et al. (2012)

$\mathrm{H}_{2}$ : "O uso de sistemas de lavagem que reduzem o impacto ambiental e economizam insumos, como wetcleaning, tem uma relação positiva com a melhora da produtividade"

Parâmetro populacional: produtividade.

Referente a questão 2.4 do questionário de campo (Apêndice B).

a.2) Inovação Tecnológica:

Hipótese $\mathrm{H}_{3}$ (Equipamentos):

Base Teórica: Gallouj (1997); Evangelista e Sirilli (1998); Evangelista (2000); Mc

Dermott; Kang e Walsh (2001); Forsman e Temel (2011); Elche-Hotelano (2011);

Battisti; Vigorena e Alves (2012).

$\mathrm{H}_{3}$ : "A adoção da inovação tecnológica em equipamentos tem uma relação positiva com a produtividade do processamento e entrega do serviço "

Parâmetro populacional: produtividade.

Referente a questão 3.2 do questionário de campo (Apêndice B).

Hipóteses $\mathrm{H}_{4}$ (Produtos quimicos):

Base Teórica: Gallouj e Weinstein (1997); Battisti; Vigorena e Alves (2012).

$\mathrm{H}_{4}$ : "A adoção da inovação tecnológica em produtos químicos para o processo tem uma relação positiva com a produtividade na entrega do serviço"

Parâmetro populacional: produtividade.

Referente a questão 3.4 do questionário de campo (Apêndice B). 
b) Inovação de Marketing:

Hipótese $\mathrm{H}_{5}$

Base Teórica: Tidd; Bessant e Pavitt (2008); Grawe; Chen e Daugherty (2010); Fitzsimmons e Fitzsimmons (2010).

$\mathrm{H}_{5}$ : "A promoção e a propaganda aumentam o número de novos clientes e, consequentemente, têm uma relação positiva com a competitividade"

Parâmetro populacional: competitividade.

Referente a questão 4.1 do questionário de campo (Apêndice B).

Hipótese $\mathrm{H}_{6}$

Base Teórica: Tidd; Bessant e Pavitt (2008) e Dobni (2010).

$\mathrm{H}_{6}$ : "A introdução da inovação de marketing de nicho para segmentos específicos aumenta a base de novos clientes e, consequentemente, tem uma relação positiva com a competitividade"

Parâmetro populacional: competitividade.

Referente a questão 4.2 do questionário de campo (Apêndice B).

Hipótese $\mathrm{H}_{7}$

Base Teórica: Elche-Hotelano (2001); Zagler (2002); Berry et al. (2006) e Riddle (2008).

$\mathrm{H}_{7}$ : "O aumento no leque de serviços oferecidos aumenta as vendas e, consequentemente, tem uma relação positiva com a competitividade"

Parâmetro populacional: competitividade.

Referente a questão 4.3 do questionário de campo (Apêndice B).

c) Inovação Organizacional:

Hipótese $\mathrm{H}_{8}$ (Modelo de Negócio)

Base Teórica: Davila; Epstein e Shelton (2007); Johnson; Christensen e Kagermann (2008) e Zmoginski et al. (2009).

$\mathrm{H}_{8}$ : "Uma nova proposição de valor da empresa por meio de um novo modelo de negócio com foco na melhora da conveniência e rapidez na entrega do serviço, tem uma relação positiva com a competitividade" 
Parâmetro populacional: competitividade.

Referente a questão 5.2 do questionário de campo (Apêndice B).

Hipótese $\mathrm{H}_{9}$ (Linha de Frente)

Base Teórica: Melton e Hartline (2010); Fitzsimmons e Fitzsimmons (2010) e Cadwaller et al (2010).

$\mathrm{H}_{9}$ : "A atuação de funcionários da linha de frente comunicando inovações e os diferenciais da empresa tem uma relação positiva com a competitividade"

Parâmetro populacional: competitividade.

Referente a questão 6.1 do questionário de campo (Apêndice B).

d) Inter-relacionamento entre tipos de Inovação:

Hipótese $\mathrm{H}_{10}$

Base Teórica: Forsman e Temel (2011) e Sapprasert e Clausen (2012).

$\mathrm{H}_{10}$ : "A adoção de mais de um tipo de inovação concomitantemente tem uma relação positiva com a competitividade"

Parâmetro populacional: competitividade.

Referente a questão 7.1 do questionário de campo (Apêndice B).

\section{Hipótese $\mathrm{H}_{11}$}

Base Teórica: Damanpour; Walker e Avellaneda (2009) e Forsman e Temel (2011).

$\mathrm{H}_{11}$ : "A adoção de mais de um tipo de inovação concomitantemente, tem uma relação positiva com a produtividade"

Parâmetro populacional: produtividade.

Referente a questão 7.2 do questionário de campo (Apêndice B).

A Figura 30 mostra as variáveis relacionadas a cada uma das hipóteses formuladas. 


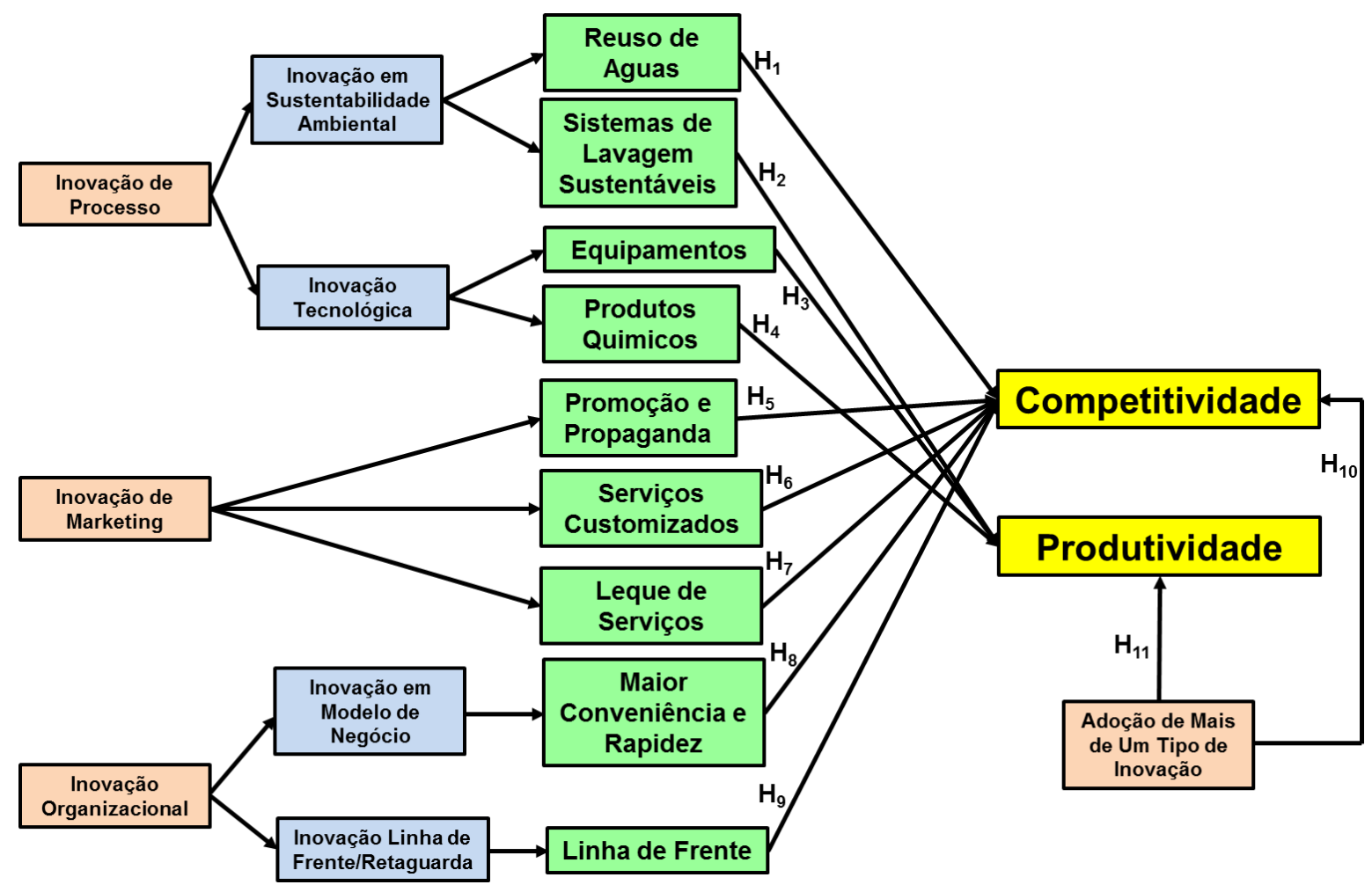

Figura 30: Hipóteses formuladas e variáveis relacionadas na pesquisa Elaborado pelo autor

\subsubsection{Questionário como Instrumento para Pesquisa de Campo Quantitativa}

Em sua análise bibliométrica sobre o tema inovação em serviços, Guimarães e Resende Júnior (2010) ressaltam que as pesquisas utilizando multimétodo (técnicas qualitativas e quantitativas na mesma pesquisa) são raras. Os autores propõem que este seja um dos objetivos da agenda para o desenvolvimento das futuras pesquisas sobre inovação em serviços, já que via de regra existe um direcionamento para pesquisas sobre um método somente (ou total qualitativa ou totalmente quantitativa). O uso de pesquisa multimétodo permite ampliar a abrangência na tomada dos resultados, sobretudo se a pesquisa prévia for qualitativa, visto que permite obter um panorama mais detalhado sobre o tema, em especial, por meio de entrevistas com perguntas fechadas e abertas. 
O questionário deve estabelecer uma ligação com os objetivos e hipóteses da pesquisa, além da população a ser pesquisada, sendo seu desenvolvimento ligado ao problema a ser investigado (CHAGAS, 2000).

Com relação ao uso de perguntas fechadas ou abertas, Günther (2003) afirma que, para uma pesquisa inicial, exploratória, não conhecendo a abrangência ou variabilidade das respostas, a opção é pergunta aberta.

No presente estudo foram elaboradas perguntas abertas para as entrevistas semiestruturadas, para que os entrevistados especialistas pudessem ter a liberdade de discorrer sobre os tipos de inovação e seu inter-relacionamento aplicados às lavanderias domésticas. Por outro lado, a opção para a pesquisa de campo junto às lavanderias foi o uso de questionário com perguntas fechadas, em que foi possível pontuar as opiniões (escala Likert) e utilizar técnicas quantitativas. Anderson; Sweeney e Williams (2011), ao analisarem as escalas de medição, afirmam que os dados de uma escala ordinal também podem ser registrados, usando-se um código numérico (ex.: 1 para "concordo plenamente"; 2 para "concordo em parte" e assim por diante).

Com base nos resultados a serem obtidos na pesquisa prévia e hipóteses delineadas, o instrumento de coleta de dados foi o questionário estruturado para testar as hipóteses, com questões de múltipla escolha, utilizando a escala numérica com notas (1-5) para cada questão, a saber:

$1=$ Concordo Totalmente

2 = Concordo em Parte

$3=$ Indiferente

4 = Discordo em Parte

$5=$ Discordo Totalmente

A escala numérica permitiu a quantificação das tendências apoiada nas respostas obtidas na pesquisa quantitativa. Esta quantificação possibilitou atribuir intervalos de valores para rejeição ou aceitação de cada hipótese delineada. 
O questionário analisou a adoção dos principais tipos de inovação utilizados pelas lavanderias domésticas, os impactos de cada inovação isoladamente e em conjunto sobre a competitividade. O Apêndice B mostra o questionário utilizado como instrumento de pesquisa quantitativa junto à amostra das lavanderias domésticas. $O$ questionário foi criado, enviado e monitorado pelo site Survey Monkey.

A primeira parte do questionário foi elaborada de modo a conseguir informações relevantes que permitiriam obter uma visão geral da utilização de técnicas ou ferramentas ligadas à inovação, tais como: sistemas de reúso de águas, lavagem a seco, wetcleaning, utilização de embalagens recicláveis, energia solar ou eólica, uso de tecnologia para retirada de manchas, uso de propaganda e promoção, delivery e entrega via serviços on line.

Conforme já citado, foram sorteadas aleatoriamente, via programa Microsoft Excel 2010, as lavanderias que fizeram parte da amostra da população das lavanderias domésticas da cidade de São Paulo. A lista não continha telefone para contato, sendo necessário utilizar internet ou bancos de dados disponíveis para localização. Mesmo com essas ferramentas, em muitos casos, não foi possível estabelecer contato.

Todas as lavanderias respondentes e não respondentes foram escolhidas aleatoriamente e, sem exceção, contatadas via telefone. Em muitos casos, não foi possível o contato com o responsável, e o envio da pesquisa por razões diversas (indisponibilidade, recusa em responder ou telefone de contato não atendia ou não foi encontrado). Os objetivos da pesquisa foram esclarecidos ao proprietário ou gerente geral e solicitada autorização para envio via e-mail. Os questionários foram enviados só àquelas empresas que concordaram responder à pesquisa. Günther (2003, p.33) afirma que "do ponto de vista da padronização das perguntas e do potencial para transcrever as respostas, instrumentos distribuidos por meio de e-mail têm grande potencial". O autor destaca que os e-mails são mais rápidos do que a pesquisa via telefone e mais baratos, pois eliminam os custos de papel, impressão, selo, etc. Mas, alerta que a população-alvo a ser atingida é mais restrita, já que a amostra escolhida pode conter respondentes que não têm acesso a essa tecnologia. 
Uma amostra inicial com 115 lavanderias (Lista 1) foi escolhida aleatoriamente. Os resultados obtidos com a Lista 1 foram:

- 33 lavanderias respondentes $(29,2 \%$ do total);

- 18 lavanderias: o segundo contato foi feito após o envio da pesquisa, solicitando a resposta, mas não responderam (15,9\% do total);

- 62 lavanderias: o contato com o respondente ou o envio não foi possível (indisponibilidade, recusa em responder ou telefone de contato não encontrado) ( $54,9 \%$ do total); e

- Total lavanderias pesquisadas na Lista 1: 113.

Como o número de respondentes previamente fixado (70 respondentes) não foi alcançado na primeira lista, foi elaborada uma segunda lista (Lista 2), com as lavanderias constantes nas linhas imediatamente acima e abaixo da amostra inicial (Lista 1) escolhida pelo Excel dentro população de 665 lavanderias. Os resultados obtidos com a Lista 2 foram:

- 23 lavanderias respondentes (22,1\% do total);

- 12 lavanderias: o segundo contato foi feito após o envio da pesquisa, solicitando a resposta, mas não responderam ( $11,5 \%$ do total);

- 69 lavanderias: o contato com o respondente ou o envio não foi possível (indisponibilidade, recusa em responder ou telefone de contato não encontrado) (66,3\% do total); e

- Total lavanderias pesquisadas na Lista 2: 104.

Como o número de respondentes previamente fixado (70 respondentes) não foi alcançado na segunda lista, foi escolhida uma terceira lista (Lista 3), com as lavanderias constantes nas linhas imediatamente acima e abaixo da Lista 2. Os resultados obtidos com a Lista 3 foram:

- 15 lavanderias respondentes (17,4\% do total);

- 12 lavanderias: o segundo contato foi feito após o envio da pesquisa, solicitando a resposta, mas não responderam ( $14,0 \%$ do total); 
- 59 lavanderias o contato com o respondente ou o envio não foi possível (indisponibilidade, recusa em responder ou telefone de contato não encontrado) (68,6\% do total); e

- Total lavanderias pesquisadas na Lista 3: 86.

Resumo dos resultados alcançados na pesquisa quantitativa (somatório das listas 1 , 2 e 3):

- O número total de respondentes foi de 71 lavanderias;

- O número de lavanderias não respondentes foi de 42 lavanderias;

- O número de lavanderias cujo contato ou envio não foi possível foi de 190 lavanderias; e

- O número total de lavanderias pesquisadas foi de 303.

\subsubsection{Uso de Testes Não-Paramétricos com Escala Likert}

Para Curado; Teles e Marôco (2013), a escala Likert usa variáveis ordinais, com escalas de medida que podem apresentar diferentes formas (ex.: 3, 5 ou 10 pontos). Os autores citados discutem a respeito dos testes estatísticos que podem ser usados com a escala Likert e afirmam que as opiniões divergem entre os autores. Alguns consideram que, com variáveis ordinais, só podem ser usados testes não paramétricos; outros entendem que, após a transformação das variáveis em números, devem ser utilizados testes paramétricos.

Alguns artigos estudam a normalidade da distribuição das variáveis e outros verificam a homogeneidade das variâncias, com o objetivo de decidirem se optam por testes paramétricos (p. ex.: "t" de Student) ou não paramétricos. Mas, Curado; Teles e Marôco (2013) também observam que a maioria dos artigos pesquisados em seu estudo não justifica o uso de testes paramétricos ou não paramétricos.

Para Sanches; Meireles e De Sordi (2011), um problema com a aplicação de escala Likert é o modo de analisar os dados, já que estes se encontram na forma ordinal e admitem apenas testes não paramétricos. 
De acordo com Rocha e Delamaro (2011), se os dados forem coletados em escalas discretas ou ordinais, não serão usadas operações matemáticas para tratamento destes, impedindo o uso de técnicas paramétricas. Em seu estudo, os autores usaram a escala Likert, como uma escala indireta e os respondentes não só concordaram ou discordaram das afirmações, mas informaram os graus de concordância/discordância, mensurados por meio de um número. Desta forma, pelo fato de ser usada uma escala ordinal e não haver conhecimento dos parâmetros da população, os autores optaram por métodos não paramétricos.

Os testes paramétricos exigem da amostra uma distribuição normal (que é determinada pela média e desvio-padrão), ao passo que os não paramétricos não exigem requisitos, como a normalidade. Nos testes não paramétricos, as variáveis nominais ou ordinais podem ser usadas, e a média de localização central, normalmente, é a mediana.

Para Vieira e Dalmoro (2008), quando se usa a escala Likert pode existir a chamada tendência central ou ponto neutro, que ocorre quando há relutância dos respondentes no uso de posições extremas. Esta tendência pode ocorrer pelo sentimento de maior conforto dos respondentes ou indiferença, porém, também pode refletir que o respondente não tenha opinião sobre aquele tema, especificamente. Outra tendência que pode verificar-se, conforme os autores, é a decisão dos respondentes em selecionar a opção de resposta que havia sido escolhida no ítem anterior, como uma espécie de resposta-padrão (os respondentes entram na rotina de escolher determinado padrão, por exemplo, a segunda opção).

De acordo com Fonseca e Martins (1982), os testes não paramétricos são os que não dependem de parâmetros populacionais e de suas estimativas. Para os autores, a estatística Qui-Quadrado visa a comprovar ou não a concordância entre os valores observados e esperados de um certo fenômeno e pode ser efetivada por meio de um teste com os seguintes passos: 
a) Enunciar as hipótese $H_{0}$ e $H_{1}: H_{0}$ afirmará não haver discrepância entre as frequências esperadas $\left(E_{1}\right)$ e as observadas $\left(O_{i}\right)$ e $H_{1}$ afirmará que o modelo testado é inadequado para representar a distribuição da população;

b) Fixar o nível de significância e os graus de liberdade ( $\mathrm{gl}$ ), sendo $\mathrm{gl}$ igual ao número de categorias em a amostra $(\mathrm{k})$ menos 1 foi dividida; e

c) Determinar a região crítica ou de aceitação de $\mathrm{H}_{0}$ : com base no nível de significância e dos graus de liberdade. Se as frequências observadas forem bem

próximas das frequências esperadas, o valor de $X_{2}$ será pequeno e levará a aceitação de $\mathrm{H}_{0}$. Caso contrário, será rejeitado.

Para o presente estudo, optou-se pelo uso de testes não paramétricos com amostras independentes, já que os resultados da escala Likert são medidos em escala ordinal (desde "concordo totalmente" até "discordo totalmente"), e a transformação das opiniões em escala numérica também obedece a uma ordem estabelecida ( 1 = "concordo totalmente", etc.). A técnica escolhida foi a estatística do Qui-Quadrado de proporção com uma amostra (71 respondentes) e cinco categorias (opções de resposta da escala Likert).

\subsubsection{Teste de Hipóteses e Técnica Estatística Não Paramétrica Utilizada}

De acordo com Reis e Ribeiro Júnior (2007), ao abordarem as técnicas estatísticas a serem usadas em testes de hipóteses, afirmam:

Os testes de hipóteses se dividem em paramétricos e não paramétricos. Os paramétricos são aqueles que utilizam os parâmetros da distribuição, ou uma estimativa destes, para o cálculo de sua estatística. Normalmente, estes testes são mais rigorosos e possuem mais pressuposições para sua validação. Já os não paramétricos utilizam, para o cálculo de sua estatística, postos atribuídos aos dados ordenados e são livres da distribuição de probabilidades dos dados estudados (REIS; RIBEIRO JÚNIOR, 2007, p.1). 
Para o presente estudo, o teste de hipóteses permitiu analisar a validade das afirmações relacionadas à tipologia da inovação e às variáveis competitividade e produtividade. Para proceder aos testes de hipóteses, optou-se pelo uso de técnica estatística não paramétrica com amostras independentes, levando-se em conta que os resultados da escala Likert são medidos em escala ordinal, conforme discutido nos ítens 3.3.4 e 3.3.5.

Com base nos resultados do questionário, o seguinte critério foi usado para se testar as hipóteses estudadas:

a) Estabeleceu-se que os parâmetros populacionais produtividade (vendas por funcionário) e competitividade (vendas), para terem relação positiva nas hipóteses testadas com as outras variáveis deveriam ter valores menores que 3 na escala numérica de 1 a 5 , considerada para os questionários (ou seja, "concordo totalmente" e "concordo em parte"); e

b) A amostra considerada foi de 71 respondentes em uma população de 665 lavanderias. Quatro lavanderias não responderam a todas as questões, e este fato foi considerado na contagem do número de respondentes da amostra em cada uma das questões.

A hipótese experimental ou nula $\left(\mathrm{H}_{0}\right)$ foi criada apoiada em um parâmetro da população que pressupomos não ser verdadeiro e que foi rejeitado pela hipótese alternativa que entendemos ser verdadeira. Em nosso estudo, as hipóteses alternativas $\left(H_{1}, H_{2}, \ldots\right)$ são opostas às hipóteses nulas $\left(H_{0}\right)$, ou seja, se as hipóteses nulas forem falsas, elas serão rejeitadas e as hipóteses alternativas serão verdadeiras. As hipóteses nulas foram formuladas com base nos resultados negativos da associação entre as variáveis produtividade e competitividade e os diferentes tipos de inovação (tecnológica, sustentabilidade, de marketing, organizacional, entre outras). As hipóteses alternativas $\left(H_{1}, H_{2}, H_{3}, \ldots\right)$ foram formuladas a fim de rejeitar as hipóteses nulas, confirmando, dessa forma, as relações positivas entre as variáveis citadas. 
Conforme discutido no ítem 3.3.5, a técnica escolhida para proceder ao teste de hipóteses foi o método Qui-Quadrado de Proporção para uma amostra (71 lavanderias respondentes), que permitiu estabelecer um percentual de respostas esperadas. Por exemplo, espera-se que cada uma das cinco opções da escala Likert sejam escolhidas por $20 \%$ dos respondentes, estabelecendo uma certa linearidade de escolha. Esta premissa forneceria resultados de somente $40 \%$ na escolha das opções 1 e 2 , o que rejeitaria as hipóteses formuladas $\left(H_{1}, H_{2}, H_{3}, \ldots\right.$, ou seja, todas as relações positivas) e não rejeitaria a hipótese $H_{0}$ (que teria $60 \%$ das opções pelos itens 3, 4 e 5). O confronto dessa situação "ideal" com os resultados obtidos na pesquisa de campo forneceu subsídios para rejeitar ou não a hipótese $\mathrm{H}_{0}$ e aceitar ou não as demais.

A sequência de cálculos usada para obtenção do $X^{2}$ e $X^{2}$ foi a seguinte:

- Estabelecimento da frequência absoluta das categorias 1 e 2 da escala Likert: número de vezes que as categorias "concordo totalmente" e "concordo em parte" foram citadas por cada respondente. As citações nas categorias 1 e 2 remetem a uma relação positiva entre as variáveis (ex:: "reúso de águas tem uma relação positiva com competitividade"), favorecendo a aceitação das hipóteses $H_{1}, H_{2}, H_{3}, \ldots$, etc. e, consequentemente, rejeitando a hipótese $\mathrm{H}_{0}$.

- Estabelecimento da frequência absoluta das categorias 3, 4 e 5 da escala Likert: número de vezes que as categorias "indiferente", "discordo em parte" e "discordo totalmente" foram citadas por respondente. As citações nas categorias 3 , 4 e 5 remetem a uma relação negativa entre as variáveis (ex.: "reúso de águas não tem uma relação positiva com competitividade"), favorecendo a rejeição das hipóteses $\mathrm{H}_{1}, \mathrm{H}_{2}, \mathrm{H}_{3}, \ldots$, etc. e, consequentemente, aceitando a hipótese $\mathrm{H}_{0}$;

- Número de respondentes: é o número total de respondentes para cada questão;

- Nível de significância do teste (a): é a probabilidade de uma hipótese nula ser rejeitada quando verdadeira. As escolhas do nível de significância é arbitrária e habitualmente situam-se entre 0,05 e 0,01 , ou seja, riscos na faixa de $1 \%$ a $5 \%$ da hipótese $\mathrm{H}_{0}$ ser rejeitada quando verdadeira; 
- Número de categorias na escala Likert (k): número de opções de resposta em cada questão baseado na relação ordinal da escala Likert;

- Graus de liberdade ( $\mathrm{gl}$ ): no método Qui-Quadrado representa o número de categorias menos um;

- Frequência observada $\left(\mathrm{O}_{\mathrm{i}}\right)$ das categorias 1 e 2 da escala Likert: calculadas com base nos resultados obtidos em campo. É o número de vezes que as categorias $1 \mathrm{e}$ 2 foram citadas em cada questão (significando relações positivas entre as variáveis), estando, dessa forma, atreladas à aceitação das hipóteses $\mathrm{H}_{1}, \mathrm{H}_{2}, \mathrm{H}_{3}, \ldots$, etc;

- Frequência esperada $\left(\mathrm{E}_{\mathrm{i}}\right)$ das categorias 1 e 2: é o número de vezes que se espera haver escolha das categorias 1 e 2 ;

- Cálculo de $X^{2}$ (Qui-Quadrado obtido das frequências observadas e esperadas): por meio da diferença entre a frequência observada e a esperada elevado ao quadrado, dividido pela frequência esperada, ou seja: $X 2=(\mathrm{Oi}-\mathrm{Ei})^{2} \div \mathrm{Ei}$;

- Cálculo de $X^{2}{ }_{c}$ (valor crítico de $X^{2}$ ): obtido por intermédio do número de graus de liberdade ( $\mathrm{gl}$ ) e nível de significância ( $\alpha$ ) em tabela específica de distribuição do QuiQuadrado. $O$ valor crítico de $X^{2}$ indica o marco de início da área de rejeição da hipótese $H_{0}$ e, consequentemente, a aceitação das hipóteses $H_{1}, H_{2}, H_{3}, \ldots$, etc; e

- Decisão (rejeitar ou não $\mathrm{H}_{0}$ ): comparação entre $X^{2}$ e $X^{2}{ }_{c}$. Se $X^{2}$ for maior que $X^{2}{ }_{c}$, rejeita-se a hipótese $\mathrm{H}_{0}$; caso contrário, aceita-se. 


\section{RESULTADOS OBTIDOS E ANÁLISE}

\subsection{Resultados Obtidos na Pesquisa Qualitativa (Entrevistas Semiestruturadas com Especialistas)}

Os resultados da pesquisa prévia, realizada por meio de entrevistas semiestruturadas com especialistas do segmento de lavanderias domésticas, mostraram importantes pontos que contribuíram para checar a validade da escolha dos tipos de inovação típicos nas lavanderias domésticas, sua adoção e o interrelacionamento entre eles.

É importante frisar que os entrevistados têm interação constante e diária com o segmento das lavanderias domésticas e, em muitos casos, são proprietários de lavanderias. Por sua atuação mais específica com a rotina das lavanderias e por vivenciarem diferentes tipos de empresas em suas atividades, conseguem visualizar o segmento sob uma ótica mais abrangente e balizarem suas opiniões em uma análise ambiental atualizada.

\subsubsection{Entrevistados}

Adriano de Almeida Gonçalves

Presidente da ANEL (Associação Nacional das Empresas de Lavanderias) e SócioProprietário da lavanderia Ecolaundry.

\section{José Carlos Larocca}

Presidente do SINDILAV (Sindicato Intermunicipal de Lavanderias no Estado de São Paulo), Sócio Fundador da ANEL (Associação Nacional das Empresas de Lavanderias), Segundo Secretário da FECOMERCIO (Federação do Comércio de Bens, Serviços e Turismo do Estado de São Paulo), Conselheiro do SENAC (Serviço Nacional de Aprendizagem Comercial) e Sócio-Proprietário da lavanderia Elite. 


\section{Othon Barcellos}

Fundador e Ex-Presidente da ANEL (Associação Nacional das Empresas de Lavanderias) por dois períodos, Ex-Presidente do SINDILAV (Sindicato Intermunicipal de Lavanderias no Estado de São Paulo), Ex-Presidente do Conselho da ANEL, Conselheiro Vitalício da ANEL, Fundador das lavanderias Rotovic e VIP, Engenheiro Mecânico e Técnico em Lavanderia pelo IFI (International Fabricare Institute).

\section{$\underline{\text { Rui Sérgio Torres }}$}

Diretor do SINDILAV (Sindicato Intermunicipal de Lavanderias no Estado de São Paulo), Ex-Diretor do Segmento de Lavanderias Domésticas da ANEL (Associação Nacional das Empresas de Lavanderias), Ex-Diretor Administrativo Financeiro da ANEL e Sócio-Proprietário da Lavasecco Paraiso/Aclimação.

\section{Alaor Chiodin}

Diretor do SINDILAV (Sindicato Intermunicipal de Lavanderias no Estado de São Paulo), Conselheiro da ANEL (Associação Nacional das Empresas de Lavanderias), Ex-Presidente do Conselho da ANEL; Ex-Vice-Presidente do SINDILAV, SócioProprietário da lavanderia Wash.

\section{Cláudia Cristina dos Santos Diniz Meirelles}

Diretora de Vendas/Consultoria Técnica da Planeta Azul ${ }^{6}$ (produtos quimicos para lavanderias), Consultora Autônoma de Lavanderias, Docente dos cursos para lavanderias, Docente convidada dos cursos da ANEL (Ass. Nac. Empr.Lavanderias) e SENAI (Serviço Nacional de Aprendizagem Industrial) Têxtil, Administradora de Empresas.

\section{Maria Ramos Soares}

Coordenadora Técnica da ANEL (Associação Nacional das Empresas de Lavanderias), Professora SENAI (Serviço Nacional de Aprendizagem Industrial) Têxtil e Técnica Têxtil.

\footnotetext{
${ }^{6}$ O autor é socio-proprietário da empresa Planeta Azul.
} 
José Carlos Miranda

Sócio-Proprietário e Diretor Executivo da Startec (equipamentos para lavanderias).

\section{Arnaldo Afonso Moreira}

Sócio-Proprietário Equipe Sistemas (tecnologia da informação para lavanderias).

\section{Ludmila Viana}

Membro do Conselho da ANEL (Associação Nacional das Empresas de Lavanderias) e Sócia-Proprietária da lavanderia E-Lave (pioneira na coleta e delivery on line no País).

\subsubsection{Resumo dos Resultados Obtidos nas Entrevistas Semiestruturadas (Apêndice A)}

As respostas às entrevistas semiestruturadas com os especialistas do segmento de lavanderias (ítem 3.2) encontram-se descritas no Apêndice A.

A análise dos resultados das entrevistas semiestruturadas foi realizada com o objetivo de verificar se os tipos de inovação levantados e escolhidos do referencial teórico estavam condizentes com a prática e reforçar a relação dos tipos adotados com a produtividade (vendas por funcionário) e competitividade (vendas). Adicionalmente, os entrevistados opinaram sobre os questionários que seriam enviados às lavanderias com o objetivo de verificar as opiniões dos empresários sobre esses temas.

A pesquisa qualitativa contribuiu para a validação da tipologia da inovação utilizada na pesquisa quantitativa e permitiu escolher as práticas utilizadas pelas lavanderias domésticas relacionadas a cada tipo de inovação. O resumo das respostas obtidas encontram-se nos itens a sequir. 


\subsubsection{Localização Geográfica das Lavanderias}

O objetivo desta questão foi avaliar se a população escolhida para a pesquisa quantitativa, a saber, a cidade de São Paulo, seria representativa para uma inferência sobre o restante do País.

A análise das respostas indicou:

- O principal consumidor das lavanderias domésticas encontra-se nas classes com maior poder aquisitivo (classes A e B, sobretudo);

- Em cidades acima de 50 mil habitantes a operação começa a viabilizar-se e acima de 100-200 mil habitantes é semelhante às capitais;

- Lavanderias em grandes cidades diversificam mais os serviços e praticam preços mais elevados em comparação com cidades menores;

- Lavanderias em cidades menores têm melhorado em termos tecnológicos, mas tecnologia de ponta (inovação) e o treinamento da mão de obra vêm concentrandose em cidades maiores;

- A competição nas grandes cidades é maior que nas menores; e

- A abrangência geográfica de atendimento nas cidades maiores é menor que nas menores (atendimento em bairro versus atendimento em todo o município).

Conforme os entrevistados, existem importantes diferenças entre as lavanderias de grandes cidades e das menores, tanto em termos tecnológicos, diversificação, competitividade e abrangência geográfica. No presente estudo, optou-se por realizar a pesquisa quantitativa em uma cidade de grande porte (São Paulo). Pelas diferenças assinaladas pelos entrevistados, possivelmente, os resultados obtidos poderiam ser distintos se efetuássemos a mesma pesquisa em cidades de menor porte ou mais distantes dos grandes centros urbanos. 


\subsubsection{Inovação Geral}

O objetivo desta questão foi avaliar de forma abrangente se os tipos de inovação escolhidos da teoria para a pesquisa (ítem 2.4.1) tinham aderência com a prática das lavanderias domésticas e se eram considerados relevantes para o segmento.

A análise das respostas indicou que a tipologia escolhida tem aderência com a prática das lavanderias rumo à melhor competitividade e produtividade:

a) Inovação de processo (sustentabilidade e tecnológica):

- Citação direta de inovação de processo por meio de produtos químicos diferenciados, equipamentos e processos de lavagem inovadores (wetcleaning e lavagem a seco), remoção diferenciada de manchas e automação de máquinas e dosagem de produtos;

- Inovação em sustentabilidade pelo reúso de água de lavagem; e

- Uso de equipamentos modernos que utilizam menos água e permitem lotes maiores que aumentam a produtividade.

b) Inovação de marketing:

- Aumento da lucratividade por melhor qualidade e diferenciação no serviço prestado (melhora da competitividade);

- Ênfase no nível de exigência do mercado brasileiro em relação à qualidade da roupa processada e customização (benefício secundário); e

- Melhora da comunicação entre a lavanderia e o cliente (proximidade) com aumento na agilidade na resolução de problemas.

c) Inovação organizacional (modelo de negócios e linha de frente e retaguarda):

- Ênfase no treinamento da linha de frente (atendimento) para melhora da produção em escala, minimização de riscos de indenização e melhora da competitividade;

- Qualidade do serviço prestado pela linha de retaguarda melhora a competitividade; 
- Melhoria nos aspectos comerciais com novos modelos de negócios (ex.: serviços on line, retirada e entrega diferenciada, como por exemplo, armários em condomínios).

\subsubsection{Tipologia da Inovação}

O objetivo desta questão foi investigar os exemplos práticos de cada um dos tipos de inovação e suas contribuições para a melhora da competitividade e produtividade das lavanderias.

A análise das respostas identificou os pontos que as lavanderias entendem que podem melhorar seus processos pela adoção da inovação e que têm aderência com a teoria (tipologia escolhida para a pesquisa):

a) Inovação de processo (sustentabilidade e tecnológica):

- Citação direta de inovação de processo por meio de produtos químicos diferenciados (eficácia e proteção ao meio ambiente), equipamentos e processos de lavagem inovadores (com grande ênfase em wetcleaning, seguida de lavagem a seco com hidrocarbonetos), remoção diferenciada de manchas e automação de máquinas e dosagem de produtos, trazendo redução de custos de processo e mão de obra e melhorando a produtividade e competitividade (menores custos de processamento permitem melhor controle de preços e aumento das vendas);

- Inovação em sustentabilidade pelo reúso de águas de lavagem, economia de energia (ex.: secagem automatizada), máquinas com filtros e barreiras de proteção com melhora da produtividade, produtos químicos mais sustentáveis e cabides/sacolas reciclaveis ou que são devolvidos pelos clientes. A melhora da competitividade pelo aumento da base de clientes que valorizam ações de proteção ambiental ainda não é considerado fator importante para aumento de competitividade;

- Uso de programas de controle gerencial que melhoram o manejo de informações (balcão e processamento das roupas), reduzem a mão de obra, gerenciam peças, melhoram o fluxo de trabalho, aumentando a produtividade global do processo; 
- Uso de equipamentos modernos que utilizam menos água, são automatizados e processam lotes maiores, aumentando a produtividade;

- Adoção do selo de qualidade e sustentabilidade (SQS) em lavanderias para práticas relacionadas à entrega final e sustentabilidade ambiental; $\mathrm{e}$

- Lavanderias aproveitam para inovar por meio de seus fornecedores de tecnologia (máquinas, tecnologia da informação, produtos químicos) e sustentabilidade (máquinas e produtos químicos).

b) Inovação de marketing:

- Aumento da lucratividade por melhor qualidade e diferenciação no serviço prestado (melhora da competitividade);

- Ênfase no nível de exigência do mercado brasileiro em relação à qualidade da roupa processada e customização (benefício secundário);

- Melhora da comunicação entre a lavanderia e o cliente (proximidade) com aumento na agilidade na resolução de problemas;

- Melhora na "fachada" das lojas, uso de redes sociais, site bem elaborado e diferenciado, aplicativos para celulares, campanhas pela midia escrita e apresentação diferenciada da peça (acabamento e embalagem) superam as expectativas do cliente final, aumentam as vendas e melhoram a competitividade;

- Melhora da conveniência para o cliente pelo uso da internet ou delivery, aumentando a rapidez e comodidade no atendimento; e

- Oferta de um leque maior de serviços e serviços customizados/diferenciados para os diferentes públicos (ex.: delivery para executivos, lavagem de peças dentro das residências, serviços de costura diferenciados).

c) Inovação organizacional (modelo de negócios e linha de frente e retaguarda):

- Ênfase no treinamento da linha de frente (atendimento) para melhora da produção em escala (melhora da produtividade), "venda" de serviços de valor agregado, minimização de riscos de indenização e melhora da competitividade;

- Treinamento da linha de retaguarda em processos controlados e automatizados, auxiliados pelas novas tecnologias em equipamentos e produtos químicos; 
- Interligação entre as equipes da linha de frente e retaguarda com processos de integração inovadores, aumentando a produtividade e o retorno dos clientes à loja (aumento da competitividade);

- Uso de funcionários polivalentes, que podem atuar na linha de frente e retaguarda com capacitação diferenciada;

- Qualidade do serviço prestado pela linha de retaguarda melhora a competitividade;

- Melhoria nos aspectos comerciais com novos modelos de negócios (ex.: serviços on-line, retirada e entrega diferenciada, como por exemplo, armários em condomínios) com aumento da competitividade;

- Ênfase no uso de tecnologia da informação (site, aplicativos, redes de relacionamento, entre outros) para os novos modelos de negócios, aumentando a conveniência, rapidez e atendimento a necessidades específicas; e

- Franquias internacionais trouxeram novos modelos de negócios, com descentralização e nova formatação das lojas.

d) Adoção de mais de um tipo de inovação e inter-relacionamento entre eles:

- As inovações estão inter-relacionadas (tecnológica, sustentabilidade, marketing e organizacional) e uma acaba ajudando a outra, gerando melhora de produtividade; e - Os diferentes tipos de inovações devem ser implantados no negócio em um modelo integrado, com melhor resultado em vendas e produtividade do que a adoção de um só tipo de inovação, que devem ser implantadas gradativamente.

Resumindo, as seguintes evidências surgiram com base na pesquisa qualitativa:

a) Inovação de Processo: um nítido direcionamento à inovação tecnológica pelo uso de novas tecnologias em máquinas (wetcleaning e lavagem a seco) e de produtos quimicos diferenciados foi constatado. Estas tecnologias foram relacionadas com o aumento da produtividade e, da mesma forma, com a inovação em sustentabilidade ambiental, representada sobretudo pelo menor consumo de água em sistemas wetcleaning (com uso de pouca água) e lavagem com solventes que substituem a água; 
b) Inovação de Marketing: as respostas foram direcionadas à diferenciação pela qualidade dos serviços prestados, já que o consumidor brasileiro tem um nível de exigência maior com limpeza, acabamento e, em alguns casos, exige certa customização. A comunicação com o cliente final foi direcionada à maior proximidade da linha de frente na resolução de problemas de forma rápida; e

c) Inovação Organizacional: a maior ênfase foi na linha de frente, fato este também observado nas fontes bibliográficas pesquisadas. Os pontos críticos dizem respeito à melhora da produção em escala (interação entre linhas de frente e retaguarda). A exemplo da inovação de marketing, houve ênfase na qualidade do serviço final entregue (roupa processada), vinculando essa responsabilidade à linha de retaguarda. A citação da existência de novos modelos de negócios, como lavanderias com serviços on-line e retirada/entrega em condomínios, foi vinculada à diferenciação via conveniência ao cliente final e melhoria dos aspectos comerciais.

Ao aprofundar cada um dos tipos de inovação e suas relações com a competitividade e produtividade (conforme o objetivo específico deste estudo), os entrevistados citaram exemplos práticos de inovação que impactaram nessas duas variáveis:

a) Ênfase em processos que economizam água (redução de custo variável), remoção de manchas (melhora da qualidade e baixo retorno para reprocessamento), a adoção de produtos químicos mais eficientes (melhor custo/benefício) e automação de processos. Tais fatores foram vinculados à melhora da competitividade traduzida em aumento do faturamento, da lucratividade e da produtividade, esta última direcionada à redução da mão de obra operacional;

b) A inovação em sustentabilidade ambiental foi vinculada à inovação tecnológica, com poucas citações sobre o uso de embalagens recicláveis e economia de energia. A percepção do cliente final sobre ecoinovação como diferenciação ainda é baixa, suplantada pelos fatores custo e qualidade do serviço final entregue (indicados, como aqueles que aumentam a competitividade); 
c) O uso de tecnologia da informação foi vinculado ao aumento da produtividade (agilidade no processo, redução da mão de obra e melhor gerenciamento interno), mas houve poucas citações do uso da informação como ferramenta para o aumento da participação de mercado, ou seja, o uso estratégico para melhora da competitividade;

d) A citação de adoção das inovações pelas lavanderias por meio de parcerias, sobretudo inovações tecnológicas, confirma a teoria no que diz respeito à apropriação das tecnologias desenvolvidas por fornecedores para melhoria dos processos internos, que impactam diretamente no aumento da produtividade e competitividade;

e) A diferenciação pela qualidade, agilidade, comunicação e conveniência foram fatores citados que estão vinculados às inovações de marketing e a novos modelos de negócios. Observa-se certa ênfase, ao aspecto visual das lojas, padronização visual da empresa (sobretudo logomarca), investimento em mídia digital (sites e serviços on-line), como fatores importantes para atrair clientes com potencial de tornarem-se usuários de lavanderias (classes A e B), aumentando a competitividade;

f) A oferta de serviços diferenciados foi associada a serviços customizados ou a atuação em nichos de mercado. Poucas lavanderias ainda vinculam suas abordagens unicamente à diferenciação por segmentação (ex.: armários em condomínios, lavagem a custos mais baixos para estudantes ou serviços on-line sem loja física). Aquelas que utilizam essas práticas, como parte de seu negócio, fazem-no com o objetivo de aumentar a lucratividade e não como aumento relevante da demanda, já que, geralmente, o volume de clientes de nicho é menor (ex.: estudantes, terceira idade, entre outros);

g) Com relação à inovação organizacional na linha de frente e retaguarda, houve ênfase à atuação da linha de frente, como agente coordenador do processo como um todo (incluindo a linha de retaguarda) na ausência do proprietário, ajustando os fluxos de demanda e produção, como uma espécie de responsável pelo planejamento e controle da produção. Nos processos, a melhora da produtividade foi 
vinculada à essa atuação integrada entre as duas linhas (coordenada pela linha de frente);

h) Existe a tendência de uso de funcionários polivalentes, porém foi constatado certo cuidado na atuação da linha de retaguarda no contato direto com o cliente. Os funcionários desse setor devem receber treinamento adequado para atuarem na linha de frente, para que não haja prejuízo do retorno do cliente à loja e, consequentemente, da competitividade;

i) A linha de frente foi considerada aquela que "vende" a imagem da empresa ao cliente final, apresenta serviços complementares, elucida os processos que serão utilizados e cuida da garantia da qualidade final do serviço. Verificou-se uma certa ênfase no treinamento diferenciado contínuo dessa equipe, como ação inovadora, com vista ao aumento da competitividade. Com a automação dos processos e novas tecnologias "mais amigáveis" operacionalmente, a inovação da linha de retaguarda tende a estar cada vez mais vinculada a aumentar a abrangência do conhecimento tecnológico. Este expertise é necessário à operação dos novos equipamentos, assim como o aprofundamento em conhecimentos na área têxtil, em razão do aumento da diversidade de tecidos em peças confeccionadas;

j) A inovação em novos modelos de negócios foi direcionada à conveniência do consumidor final, como ferramenta de aumento da competitividade. Fatores como ampliação dos direitos dos empregados domésticos, atuação feminina crescente no mercado de trabalho e problemas de locomoção foram motivadores para a mudança de foco das lavanderias domésticas na disponibilização de serviços que trouxessem conveniência; e

k) A adoção de mais de um tipo de inovação concomitantemente e o interrelacionamento entre os diversos tipos de inovação foram considerados fatores importantes no ganho de competitividade e produtividade. $\mathrm{Na}$ opinião dos entrevistados, uma inovação "ajuda" a outra, porém a organização da adoção de todos os tipos concomitantemente foi considerado fator relevante. Alguns entrevistados acreditam que a adoção de vários tipos de inovação deve ser 
escalonada (uma de cada vez), já que o tempo dispendido para a administração das inovações pode concorrer com as atividades diárias do empreendedor.

\subsection{Pesquisa Quantitativa}

\subsubsection{Resultados Obtidos e Análise das Respostas do Questionário Enviado}

\subsubsection{Resultados a Respeito das Características e Práticas das Lavanderias da Amostra (Apêndice B: Questionário - Dados Preliminares)}

Os 73 respondentes que representaram as lavanderias escolhidas aleatoriamente tinham as seguintes características e práticas:

a) $36,99 \%$ da amostra pertenciam a redes de franquias nacionais e internacionais e $63,01 \%$ eram lavanderias autônomas, o que permitiu uma razoável representatividade da população das lavanderias domésticas da cidade de São Paulo (Figura 31);

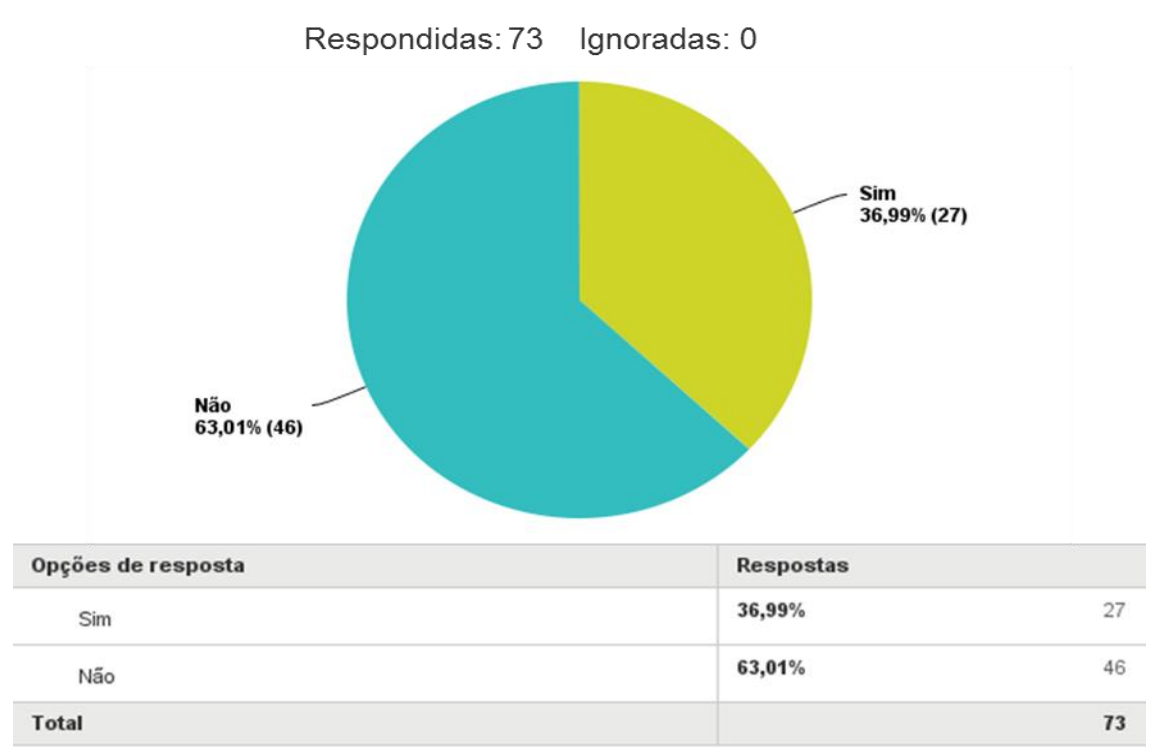

Figura 31: Questão DP 3 Questionário 
b) $97,26 \%$ das lavanderias da amostra eram micro e pequenas empresas, conforme o enfoque do tema da pesquisa (Figura 32);

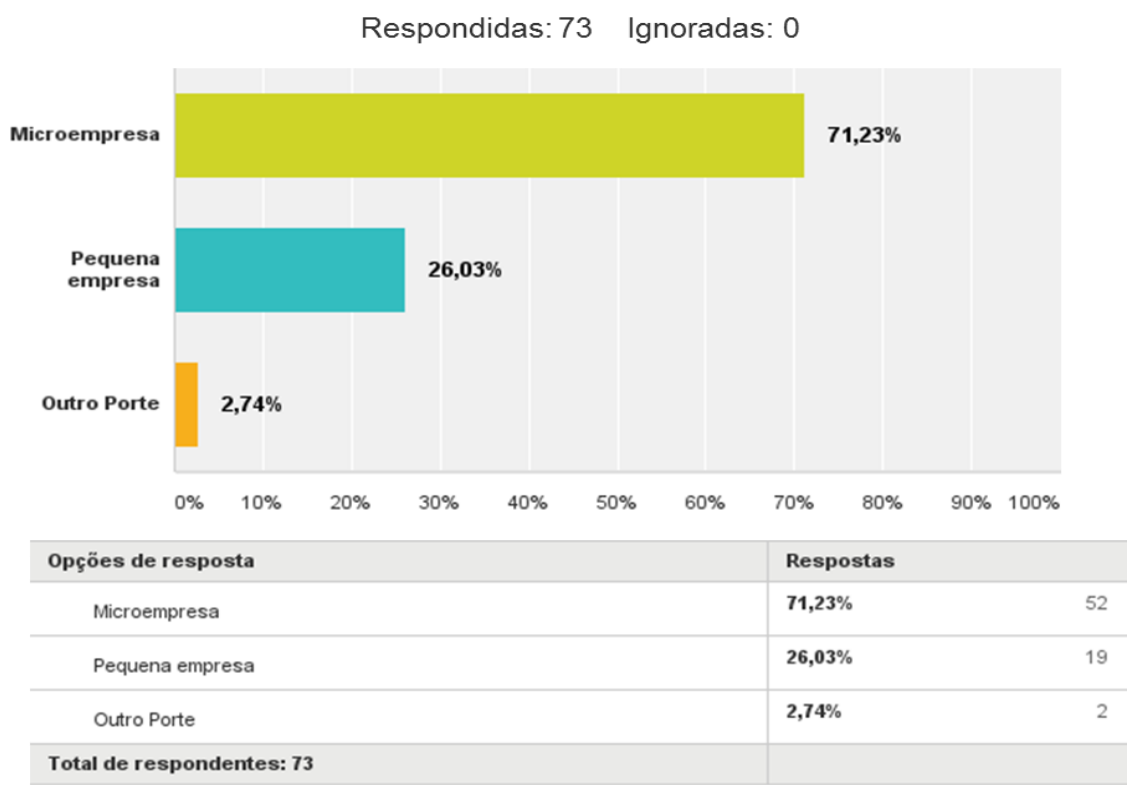

Figura 32: Questão DP 6 Questionário

c) $79,45 \%$ dos respondentes eram proprietários e $16,44 \%$ gerentes ou supervisores, ou seja, pessoas que comandavam e tinham conhecimento e poder de decisão em seus negócios. Em nosso contato telefônico, constatamos que os gerentes e supervisores respondentes iriam consultar os proprietários sobre as perguntas do questionário (Figura 33); 


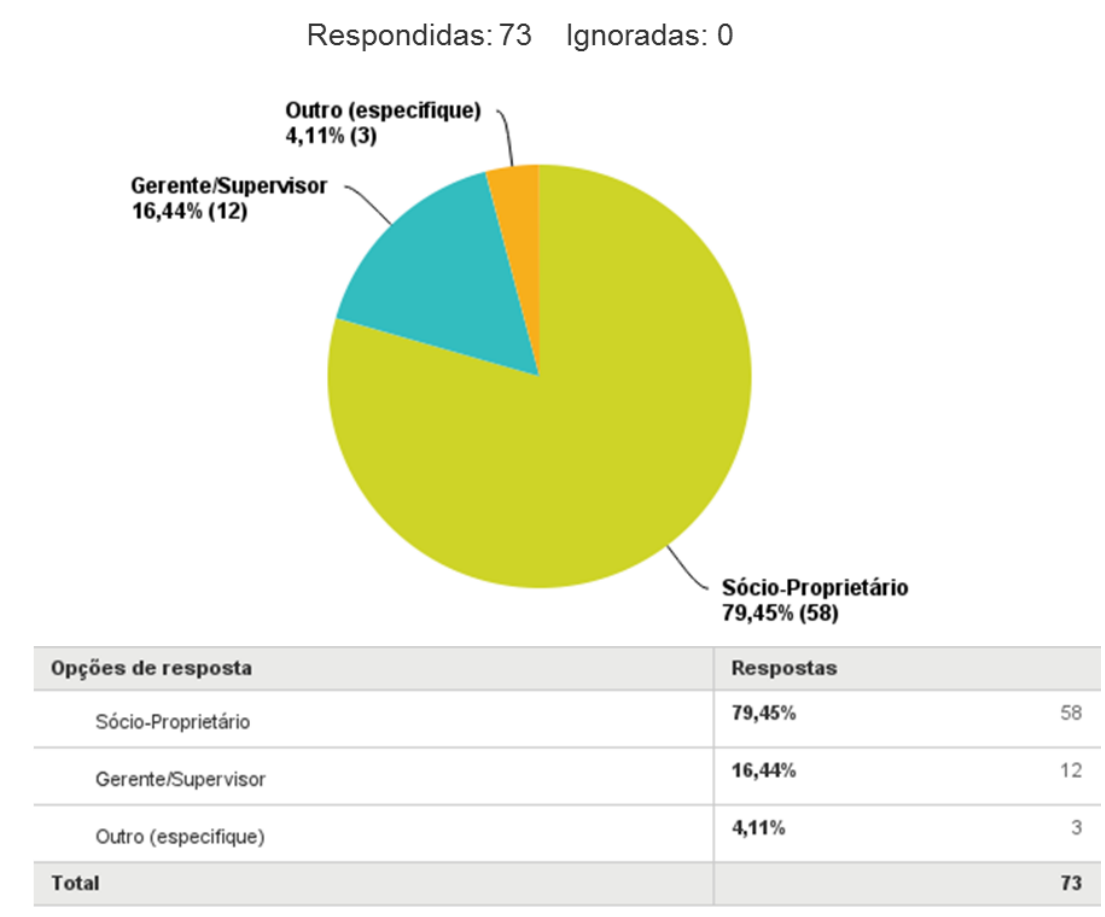

Figura 33: Questão DP 7 Questionário

d) Com relação às práticas voltadas à sustentabilidade ambiental, só 15,07\% das empresas possuíam sistema de reúso de águas (Figura 34) e 8,22\% utilizavam energia solar ou eólica (Figura 35). Por outro lado, 57,53\% usavam embalagens recicláveis (Figura 36 ) e $41,10 \%$ possuíam máquinas com a tecnologia de lavagem com pouca água (wetcleaning) (Figura 37);

Respondidas: 73 Ignoradas: 0

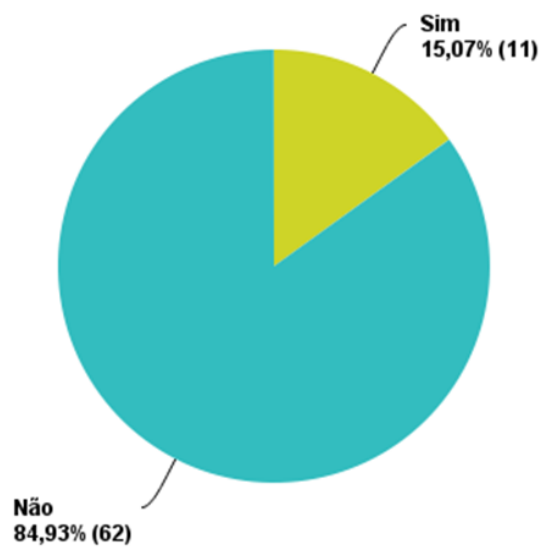

\begin{tabular}{|c|lc|}
\hline Op̧̧öes de resposta & Respostas & \\
\hline Sim & $\mathbf{1 5 , 0 7 \%}$ & 11 \\
\hline Nå̊ & $\mathbf{8 4 , 9 3 \%}$ & 62 \\
\hline Total & & $\mathbf{7 3}$ \\
\hline
\end{tabular}

Figura 34: Questão 1.1 Questionário 
Respondidas:73 Ignoradas: 0

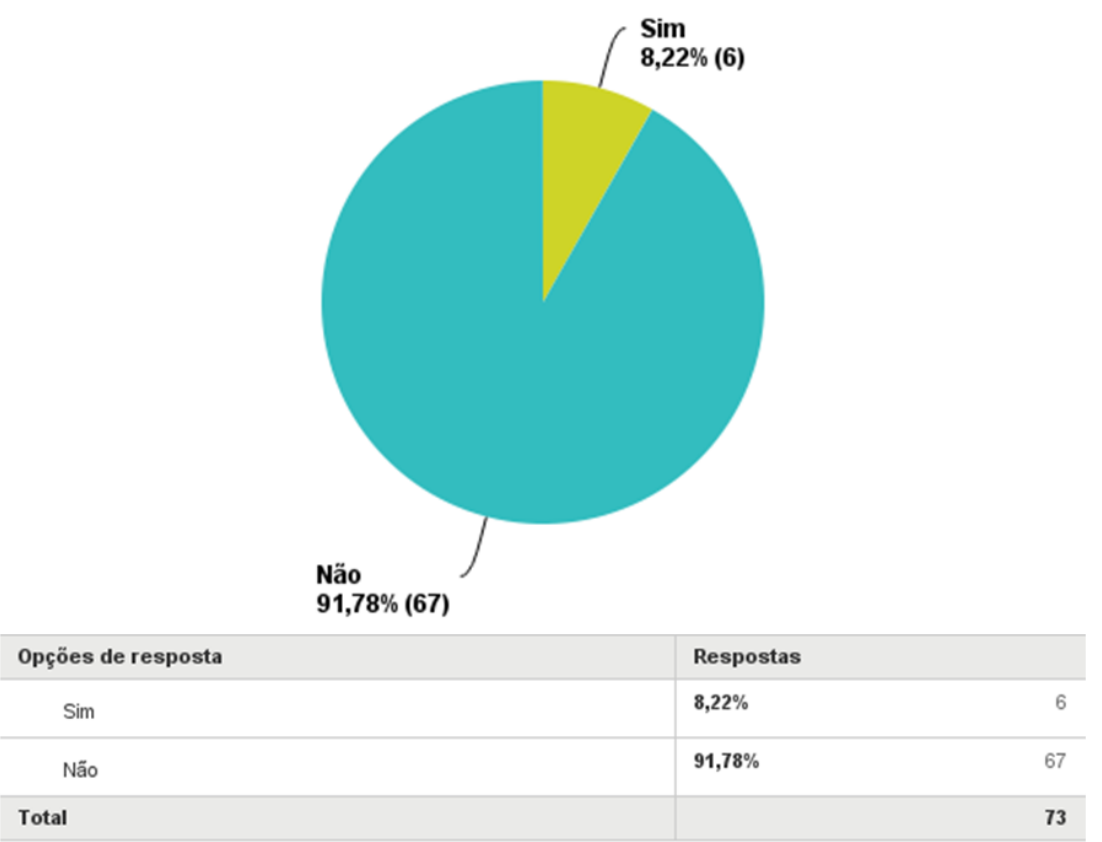

Figura 35: Questão 1.5 Questionário

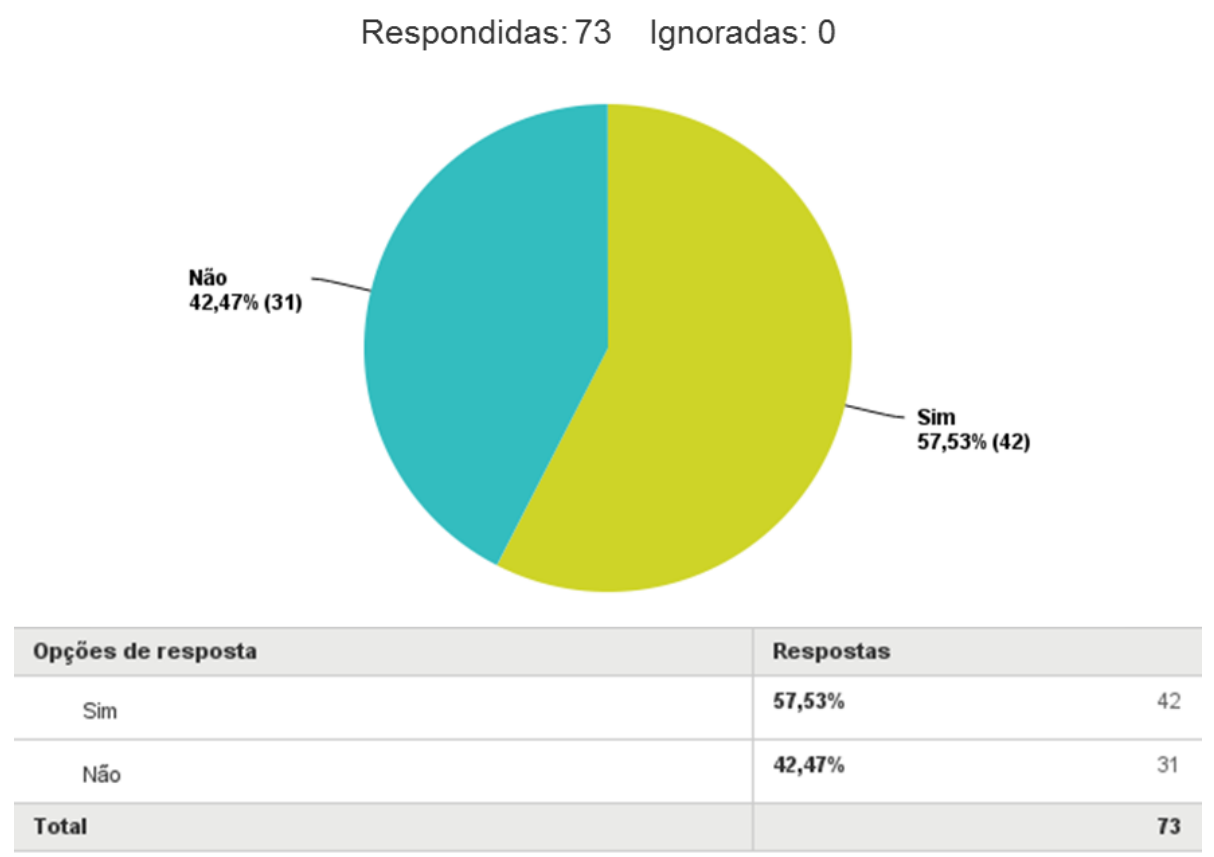

Figura 36: Questão 1.4 Questionário 


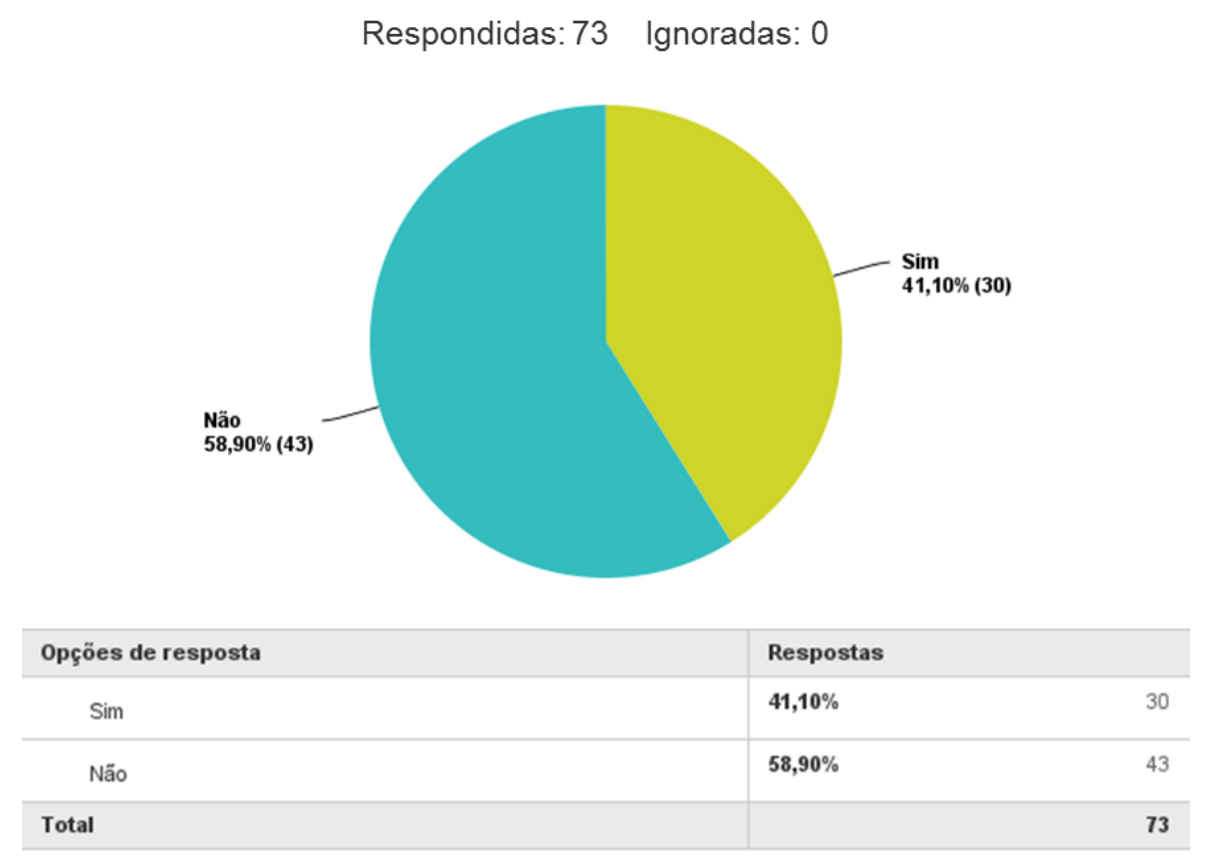

Figura 37: Questão 1.3 Questionário

e) Com relação à diversificação tecnológica no processo de lavagem de roupas delicadas, 58,90\% possuíam lavagem a seco (Figura 38), 41,10\% sistema wetcleaning (Figura 37) que, embora recente, vem sendo rapidamente implantado nas lavanderias domésticas, e $82,19 \%$ utilizavam linha de produtos tira-manchas (Figura 39). Estas práticas demonstram a preocupação na qualidade final da roupa lavada e melhora na produtividade do processo de lavagem e acabamento; 


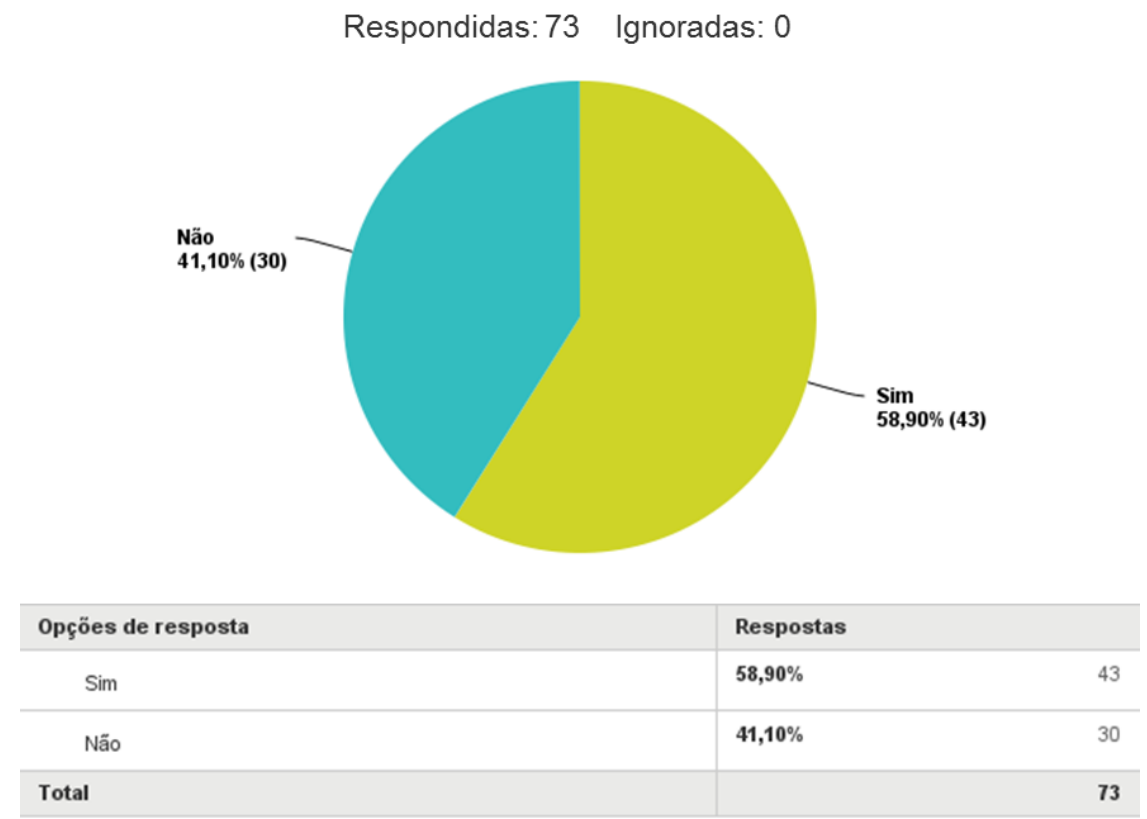

Figura 38: Questão 1.2 Questionário

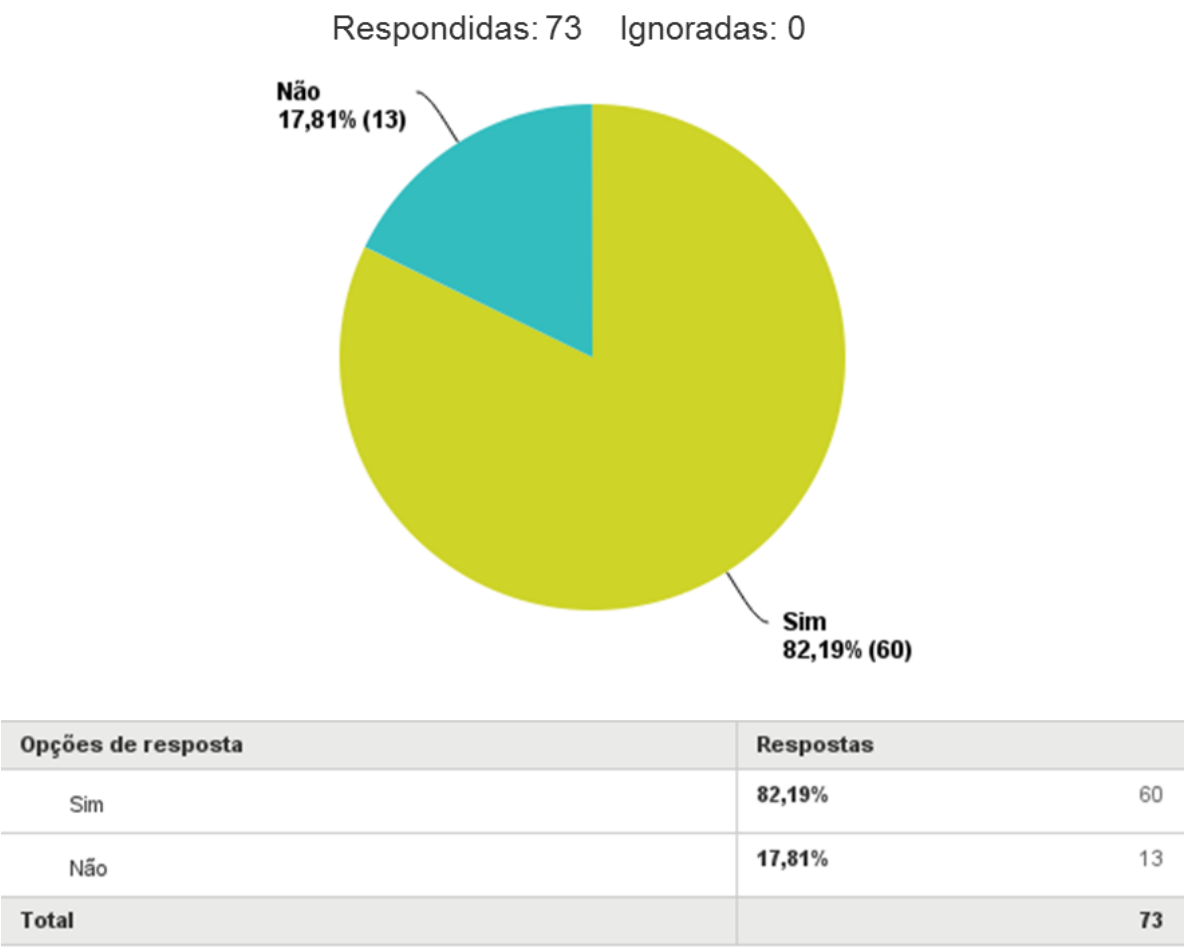

Figura 39: Questão 1.6 Questionário

f) O uso de promoção e propaganda pela maior parte das empresas $(76,71 \%)$ mostra a preocupação em comunicar seus diferenciais ao mercado consumidor, buscando maior competitividade (Figura 40); 


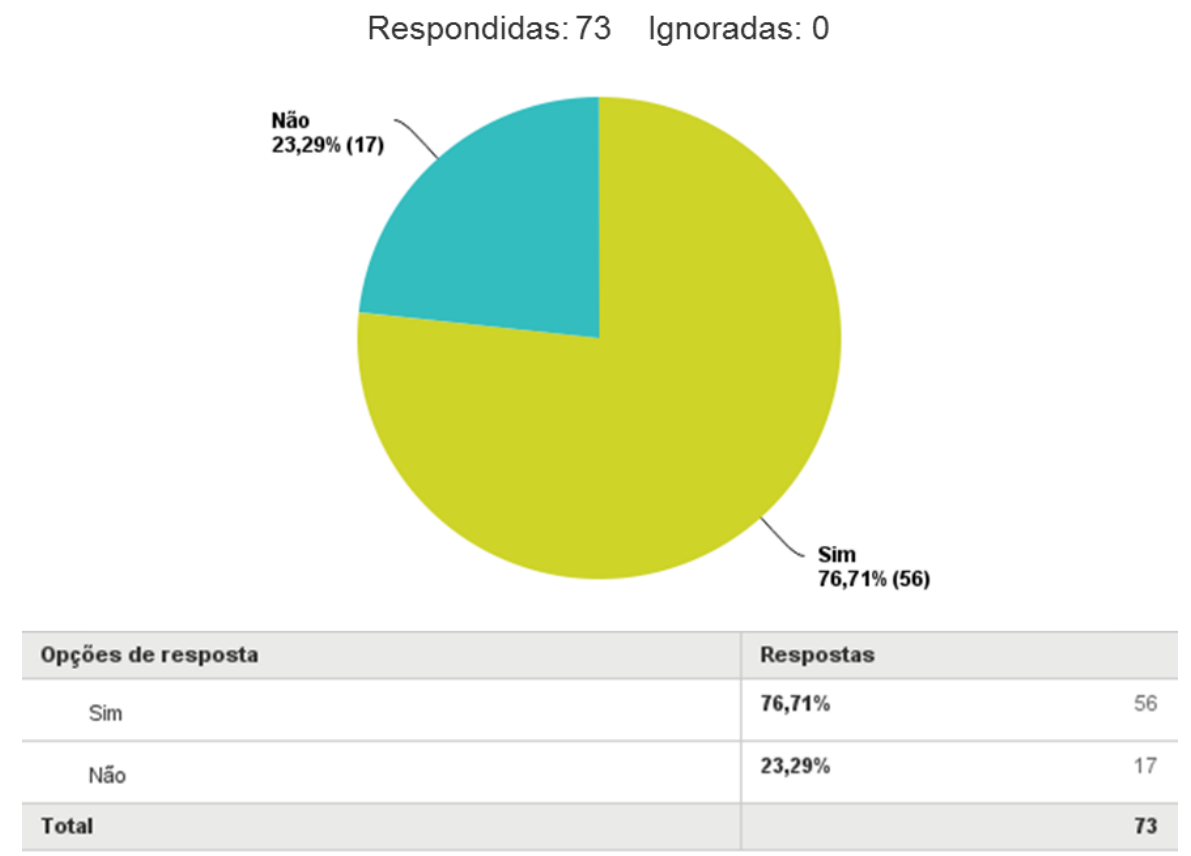

Figura 40: Questão 1.7 Questionário

g) A conveniência para o consumidor final foi o alvo de $90,41 \%$ das lavanderias que coletavam e entregavam as roupas processadas (delivery) (Figura 41). Mas, o uso de tecnologia da informação para melhorar a conveniência (serviços on-line) era usada por só $21,92 \%$ da amostra (Figura 42 ).

Respondidas: 73 Ignoradas: 0

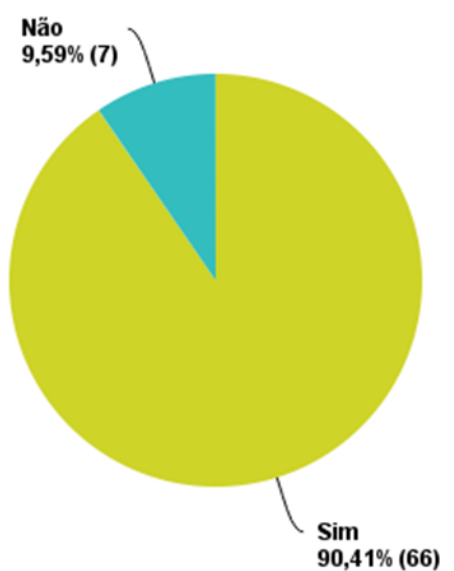

\begin{tabular}{|c|lc|}
\hline Opçöes de resposta & Respostas & \\
\hline Sim & $90,41 \%$ & 66 \\
\hline Nẵ & $9,59 \%$ & 7 \\
\hline Total & & 73 \\
\hline
\end{tabular}

Figura 41: Questão 1.8 Questionário 


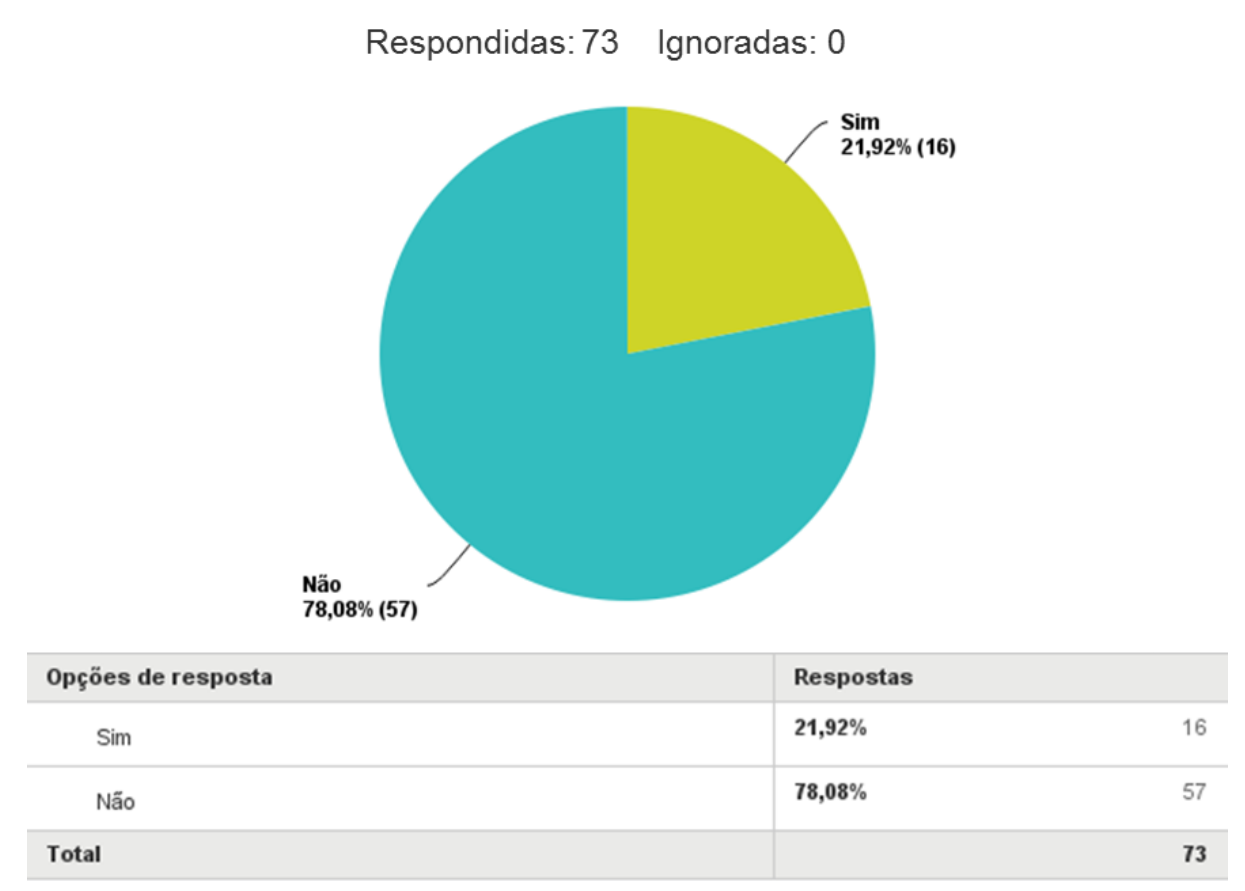

Figura 42: Questão 1.9 Questionário

A pesquisa quantitativa foi planejada de modo a obter resultados de uma amostra heterogênea de lavanderias domésticas e que pudesse ser representativa da população escolhida. As perguntas iniciais (questões 1 a 17) mostraram que tal objetivo foi alcançado:

a) Pertence ou não a uma rede de franquias:

Cerca de $63 \%$ das lavanderias entrevistadas não pertenciam a uma rede de franquias (eram lavanderias independentes), o que tornou a amostra mais heterogênea. As lavanderias vinculadas a redes recebem assessoria técnicocomercial, além de um pacote de promoção e propaganda do franqueador master e contribuem com uma taxa de comunicação, além do pagamento de royalties. Os treinamentos da linha de frente são efetuados de modo a transmitirem a visão e os diferenciais da rede na abordagem de mercado. O visual das lojas é padronizado e, geralmente, a rede de fornecedores é homologada pelo franqueador master. As inovações pelo franqueado estão vinculadas, na maior parte das vezes, às inovações da rede. Mas, o tratamento diferenciado a clientes, a qualidade do produto final, o controle financeiro e o fluxo de processo das lavanderias são 
individuais de cada unidade. Já as lavanderias independentes inovam por meio de fornecedores diretos de tecnologia, atendimento personalizado, organização e administração de processos internos, de acordo com o ganho de experiência ou por treinamentos externos em orgãos, como a ANEL, SEBRAE e fornecedores. A inovação de marketing, no caso de lavanderias independentes, utiliza recursos próprios e demanda estudos de mercado que, geralmente, são efetuados pelo próprio empreendedor e sua equipe, no raio de atuação do empreendimento. A comunicação utiliza mídia escrita, o visual das lojas (que, inicialmente, foi em parte influenciado pelas lavanderias de rede) e, mais recentemente, a atuação em mídias digitais e redes sociais. Nas lavanderias independentes, observa-se uma certa tendência em atender de forma mais segmentada e personalizada, muitas vezes, utilizando estratégia de nicho de mercado. A diferença básica entre as empresas independentes e as redes de franquias é a existência, nas últimas, de uma equipe na franquia master, que é responsável pela comunicação, tecnologia e pacotes promocionais, liberando o franqueado para atuar no aumento de produção e ganho de mercado. Por outro lado, as lavanderias independentes têm mais liberdade na aquisição de tecnologia mais adequada a seu negócio, planejamento e controle de custos de comunicação, gestão de despesas, de acordo com a demanda e livre escolha de fornecedores, levando-se em conta a estrutura de seu negócio e os segmentos específicos em que irá atuar, além dos consumidores regulares.

b) Enquadramento de porte:

A amostra pesquisada refletiu a tendência de porte do segmento das lavanderias domésticas, ou seja, praticamente a totalidade (mais de $97 \%$ ) foi composta por micro e pequenas empresas, com predominância de micro empresas (acima de 71\%). 0 menor faturamento de empresas de pequeno porte é compensado pela menor tributação pelo regime com alíquotas mais baixas. A velocidade de mudança em empresas menores para adoção de inovações tecnológicas, geralmente, depende de recursos externos a juros moderados. As maiores despesas são as fixas, sobretudo a mão de obra. 
c) Cargo dos respondentes

Quase $80 \%$ dos respondentes eram proprietários da lavanderia avaliada (ratificando a premissa do objetivo geral deste estudo) e cerca de $16 \%$ eram supervisores e gerentes que, normalmente, estão envolvidos em todas as operações da lavanderia e no planejamento das atividades de inovação junto aos proprietários. Dessa forma, o público entrevistado espelhou as pessoas de comando e poder de decisão das empresas .

d) Empresas entrevistadas e a sustentabilidade ambiental (ecoinovação)

As práticas voltadas à ecoinovação aparentemente ainda não estão nas prioridades de investimento da maior parte das lavanderias entrevistadas (só 15\% têm reúso de águas e $8 \%$ utilizam energia solar ou eólica). Mas, observa-se que existe uma tendência à mudança para processos de lavagem que utilizem pouca água e que possam substituir a lavagem a seco com solventes $(41 \%$ dos entrevistados já possuem wetcleaning). A prática de uso de embalagens recicláveis, que demanda menor investimento, era utilizada por $57 \%$ dos entrevistados.

e) Uso de novas tecnologias

A diversificação no uso de tecnologias de lavagem, como lavagem a seco (cerca de $59 \%$ possuíam) e produtos químicos para retirada de manchas específicas (cerca de $82 \%$ possuíam), indicou a prioridade dos proprietários em investir nas inovações de processo. Pode-se inferir que, parte dos que utilizavam lavagem a seco, passou a investir na lavagem substituta desse processo, ou seja, wetcleaning.

f) Práticas de inovação de marketing

O uso de propaganda e promoção, além da divulgação do sistema de delivery foi o alvo da maior parte dos entrevistados. Geralmente, as lavanderias utilizam mídia escrita (ex.: folhetos) que exige baixo investimento. A inovação via mídias digitais, que, da mesma forma, são ferramentas de baixo custo de manutenção, era utilizada 
somente por $22 \%$ dos entrevistados, mostrando que esses recursos ainda não estão na pauta de prioridades das lavanderias domésticas.

\subsubsection{Resultados Questões via Escala Likert}

Os resultados dos questionários via escala Likert enviados às lavanderias (ítem 3.3.4) encontram-se nas figuras abaixo (Figura 43 a 62) e correspondem aos itens 2 a 7 do questionário do Apêndice B. Conforme estabelecido no ítem 3.3.4, a escala Likert de 5 pontos foi quantificada $(1=$ Concordo Totalmente; $2=$ Concordo em Parte; 3 = Indiferente; 4 = Discordo em Parte; 5 = Discordo Totalmente), possibilitando obter relações positivas e negativas por meio da média ponderada entre a porcentagem de respondentes no ponto, multiplicado por seu valor.

Conforme explicitado no ítem 3.3.5, foi estabelecido que os resultados com valores menores que 3 na escala Likert de 5 pontos (concordância total ou parcial com as afirmações positivas na relação entre as variáveis) indicam uma relação positiva entre as variáveis utilizadas. Assim, valores com média ponderada entre os percentuais de cada ponto e o número de respondentes mais próximos de 1 ("concordo totalmente") têm maior relação positiva.

Os resultados percentuais e as médias ponderadas mostraram as seguintes relações:

a) Questão 2.1 (relação entre o reúso de águas e competitividade): 80,28\% dos entrevistados concordaram na relação positiva entre as duas variáveis, com uma média ponderada nas respostas de 1,79 (Figura 43).

A Hipótese $\mathrm{H}_{1}$ foi formulada com base nesta questão. 
Respondidas: 71 Ignoradas: 2

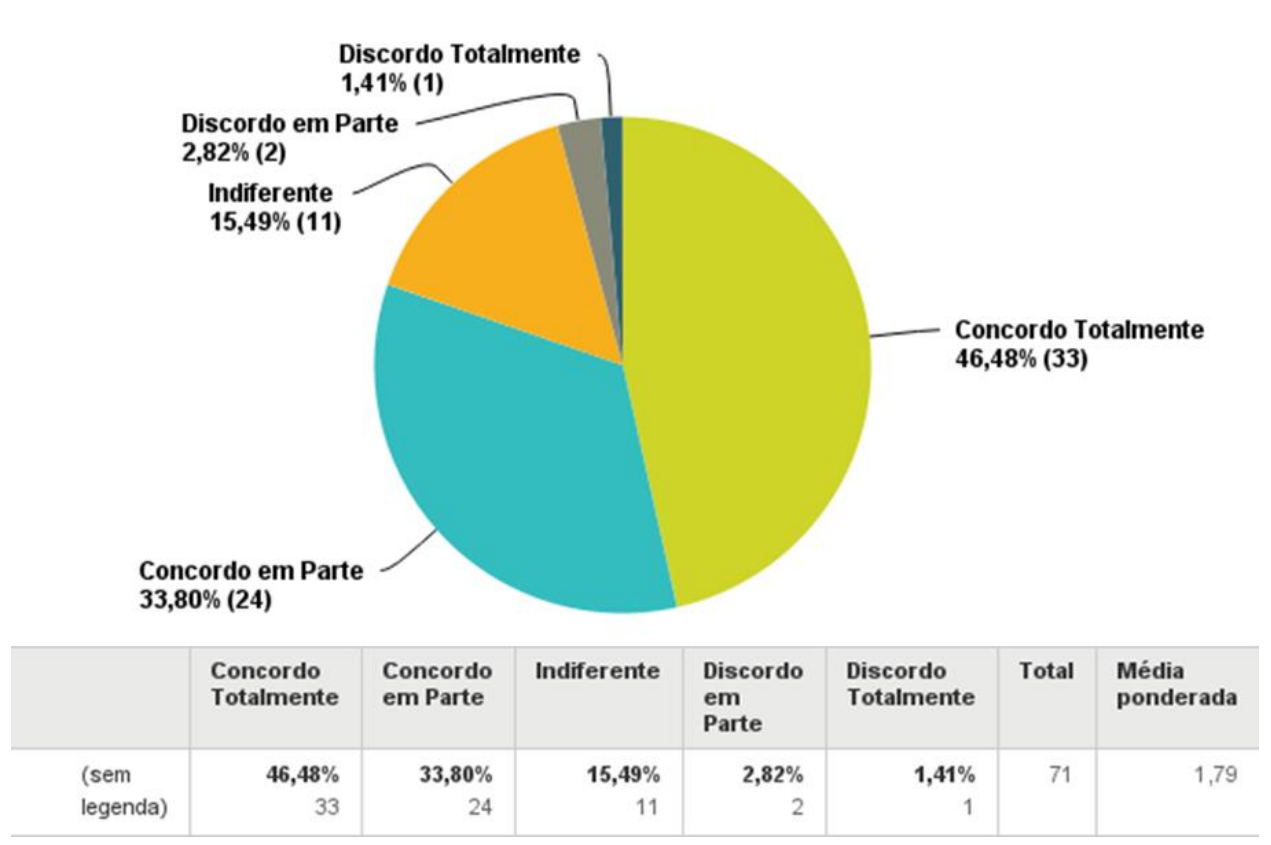

Figura 43: Questão 2.1 Questionário

b) Questão 2.2 (relação entre o reúso de águas e produtividade): 46,47\% dos entrevistados concordaram com uma relação positiva entre as duas variáveis, mas, $14,08 \%$ não concordaram e grande parte (39,44\%) considerou indiferente, resultando uma média ponderada nas respostas de 2,62 (mais próxima de 3) (Figura 44).

Respondidas: 71 Ignoradas: 2

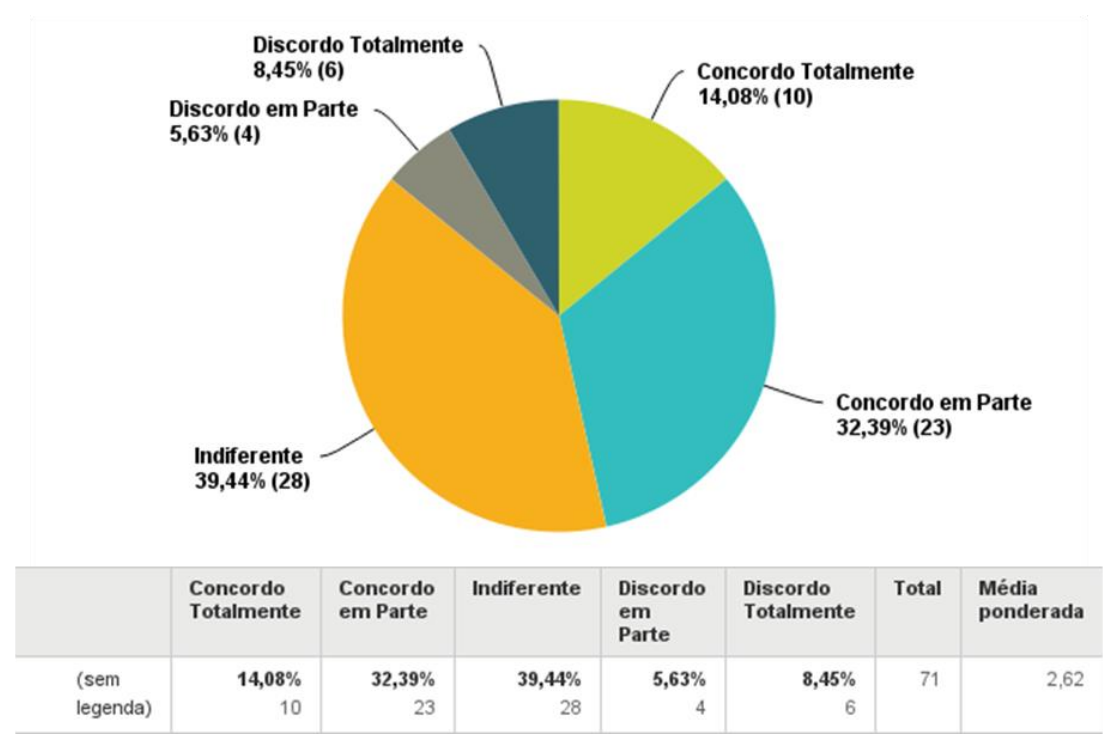

Figura 44: Questão 2.2 Questionário 
c) Questão 2.3 (relação entre sistemas de lavagem sustentáveis e competitividade): $61,97 \%$ dos entrevistados concordaram com uma relação positiva entre as duas variáveis, mas, 29,58\% consideraram indiferente, resultando uma média ponderada nas respostas de 2,25 (Figura 45).

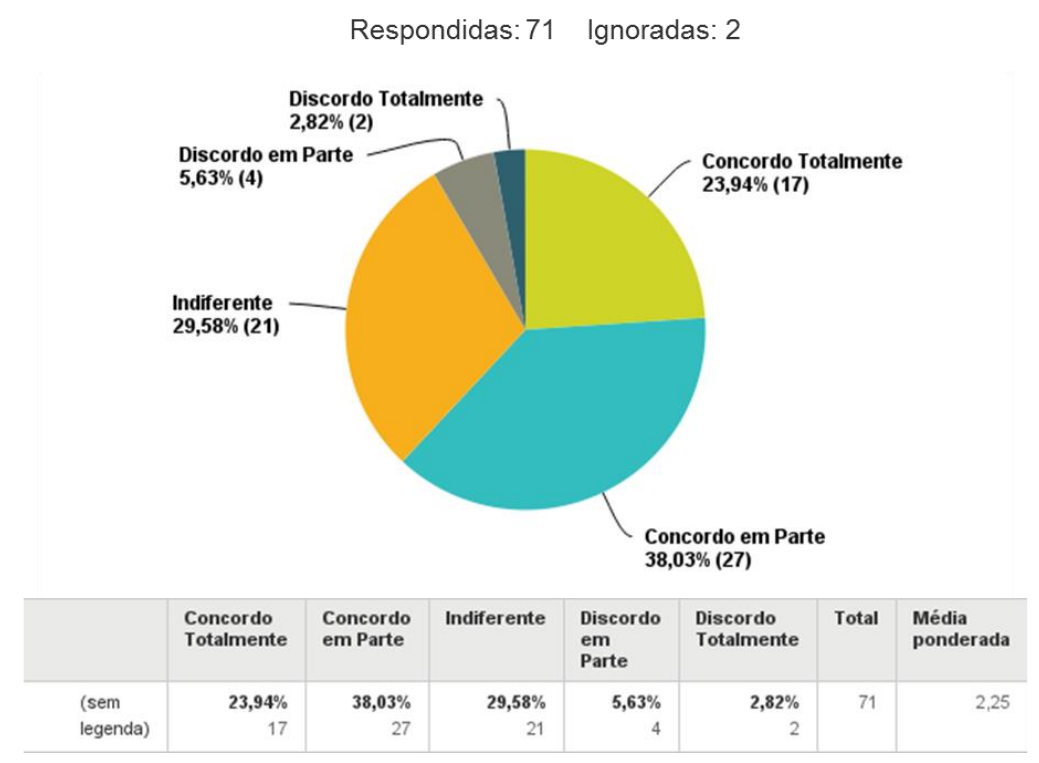

Figura 45: Questão 2.3 Questionário

d) Questão 2.4 (relação entre os sistemas de lavagem sustentáveis e produtividade): $45,07 \%$ dos entrevistados concordaram com uma relação positiva entre as duas variáveis, mas, $42,25 \%$ consideraram indiferente, resultando uma média ponderada nas respostas de 2,59 (mais próxima de 3) (Figura 46).

A Hipótese $\mathrm{H}_{2}$ foi formulada com base nesta questão. 
Respondidas: 71 Ignoradas: 2

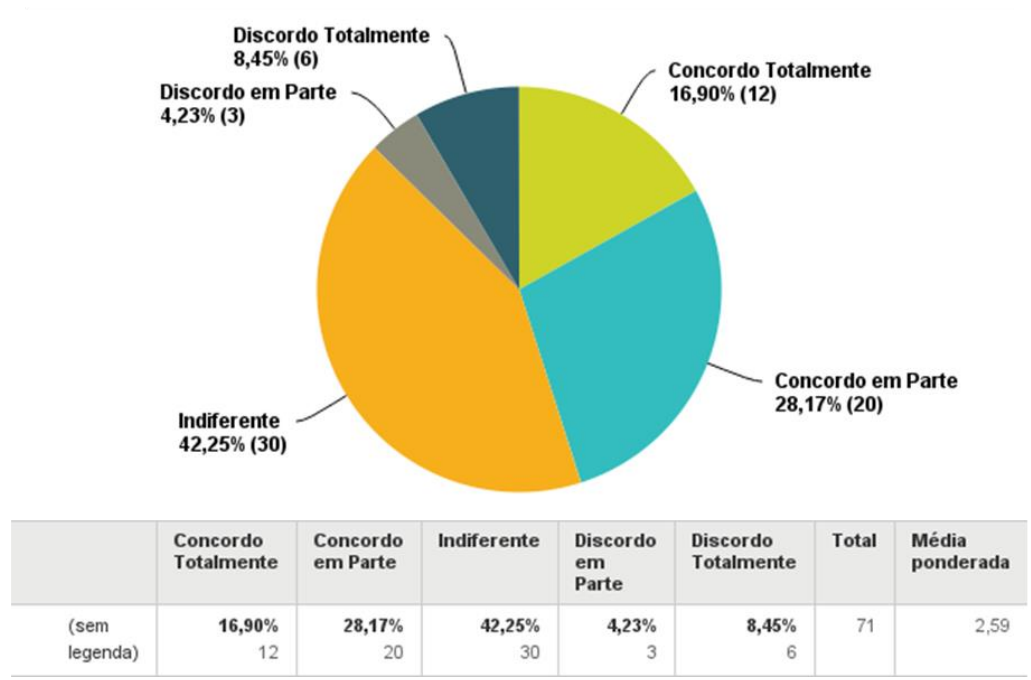

Figura 46: Questão 2.4 Questionário

e) Questão 2.5: (relação entre o uso de embalagens recicláveis e competitividade): $52,12 \%$ dos entrevistados concordaram com uma relação positiva entre as duas variáveis, mas, 18,31\% não; e 29,58\% consideraram indiferente, resultando em média ponderada nas respostas de 2,55 (Figura 47).

Respondidas: 71 Ignoradas: 2

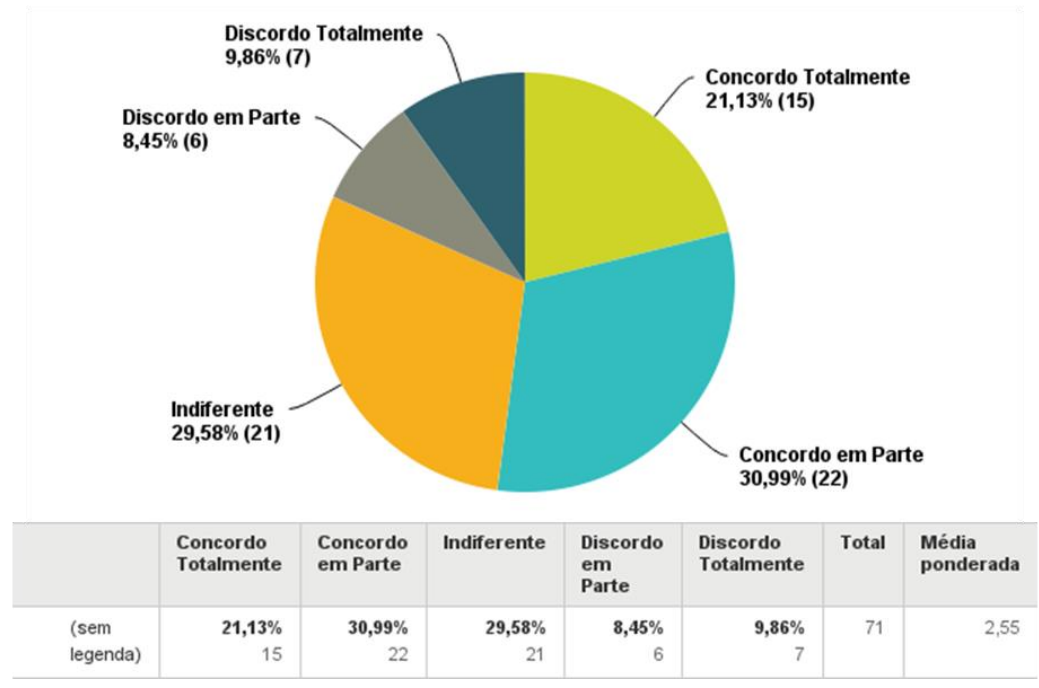

Figura 47: Questão 2.5 Questionário

f) Questão 2.6 (relação entre o uso de embalagens recicláveis e produtividade): só $36,62 \%$ dos entrevistados concordaram com uma relação positiva entre as duas variáveis, $18,31 \%$ não; e a maior parte dos entrevistados $(45,07 \%)$ considerou 
indiferente, resultando em uma média ponderada nas respostas de 2,85 (mais próxima de 3) (Figura 48).

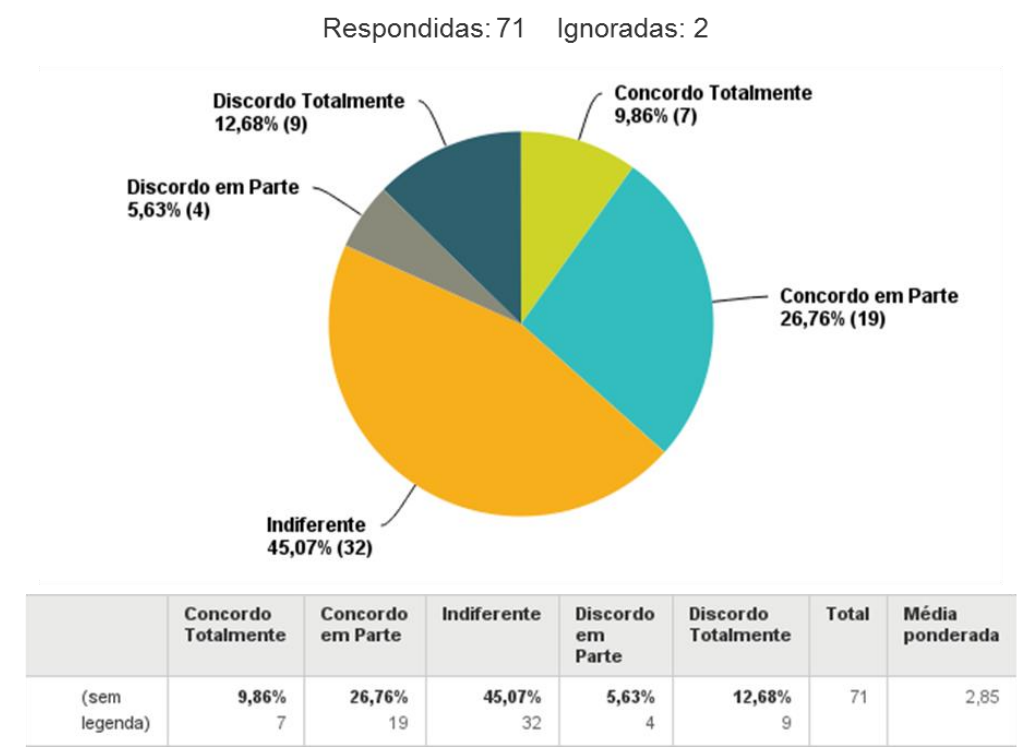

Figura 48: Questão 2.6 Questionário

g) Questão 2.7 (relação entre o uso de energias alternativas e competitividade): $64,79 \%$ dos entrevistados concordaram com uma relação positiva entre as duas variáveis, mas, $22,54 \%$ consideraram indiferente, resultando em média ponderada nas respostas de 2,21 (Figura 49). 


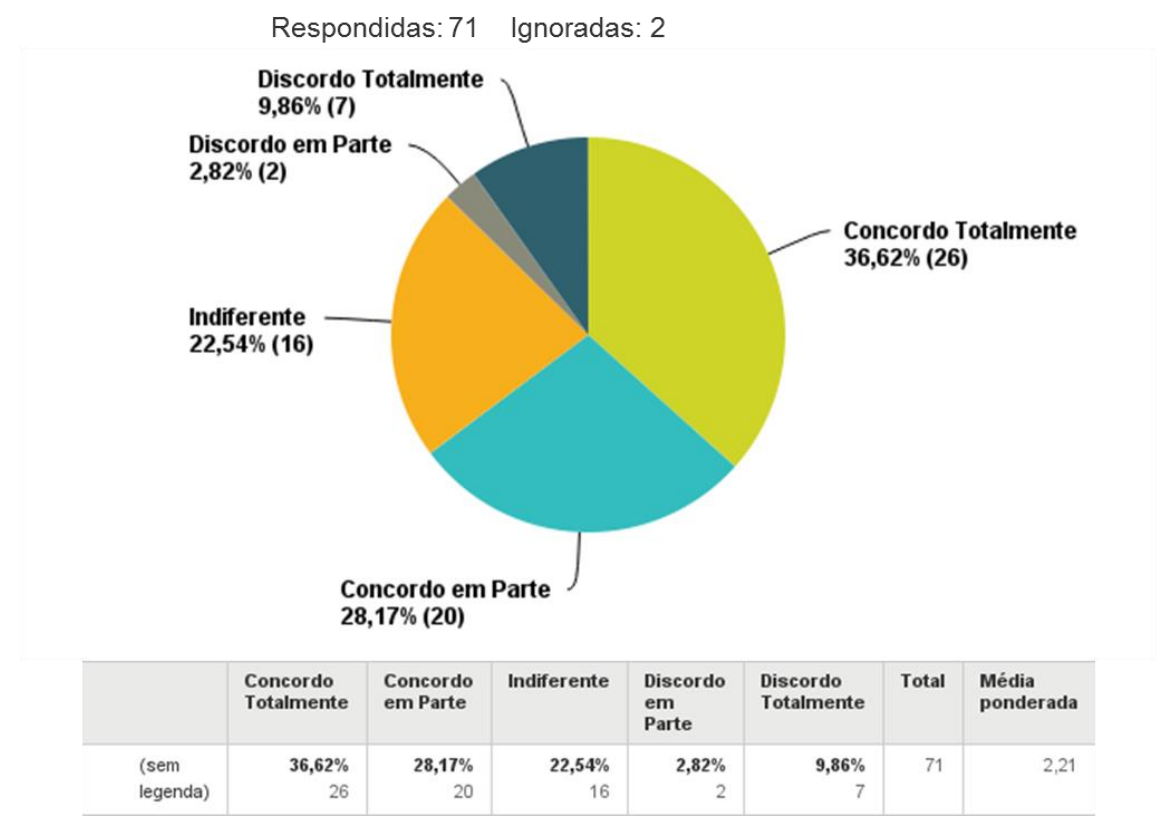

Figura 49: Questão 2.7 Questionário

h) Questão 3.1 (relação entre o uso de equipamentos modernos e competitividade): $86,77 \%$ dos entrevistados concordaram em uma relação positiva entre as duas variáveis, resultando em média ponderada nas respostas de 1,79 (Figura 50).

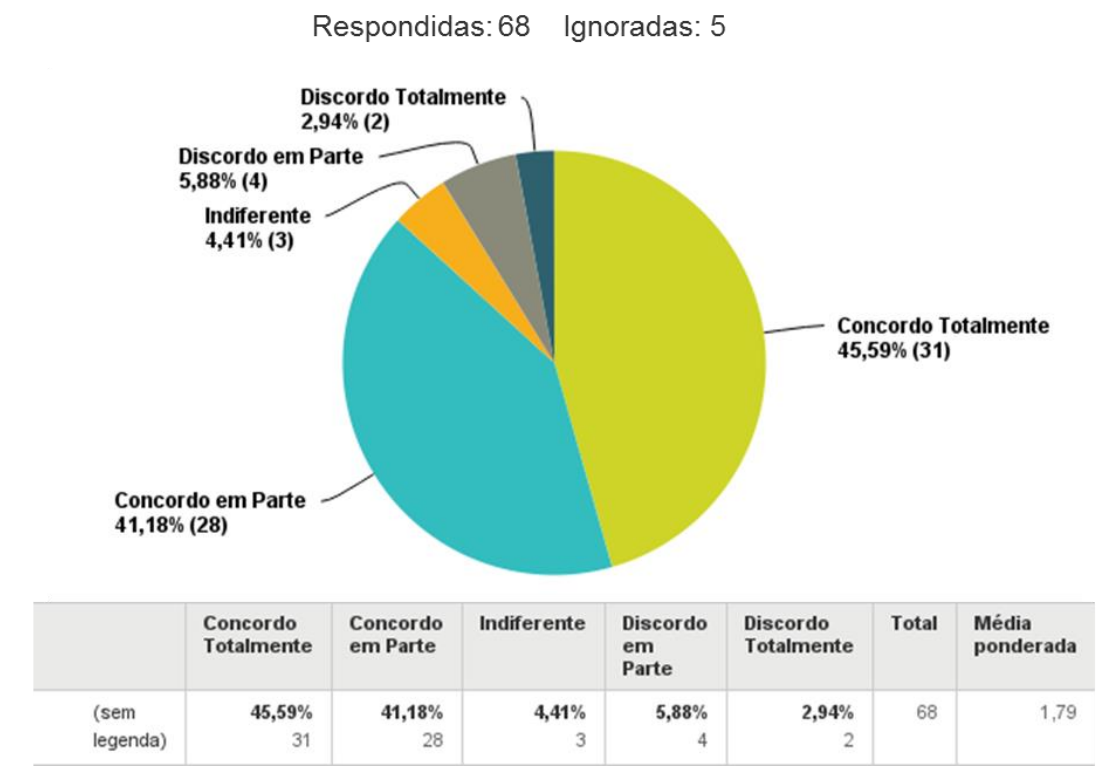

Figura 50: Questão 3.1 Questionário 
i) Questão 3.2 (relação entre o uso de equipamentos modernos e produtividade): $86,77 \%$ dos entrevistados concordaram em uma relação positiva entre as duas variáveis, resultando em média ponderada nas respostas de 1,75 (Figura 51). A Hipótese $\mathrm{H}_{3}$ foi formulada com base nesta questão.

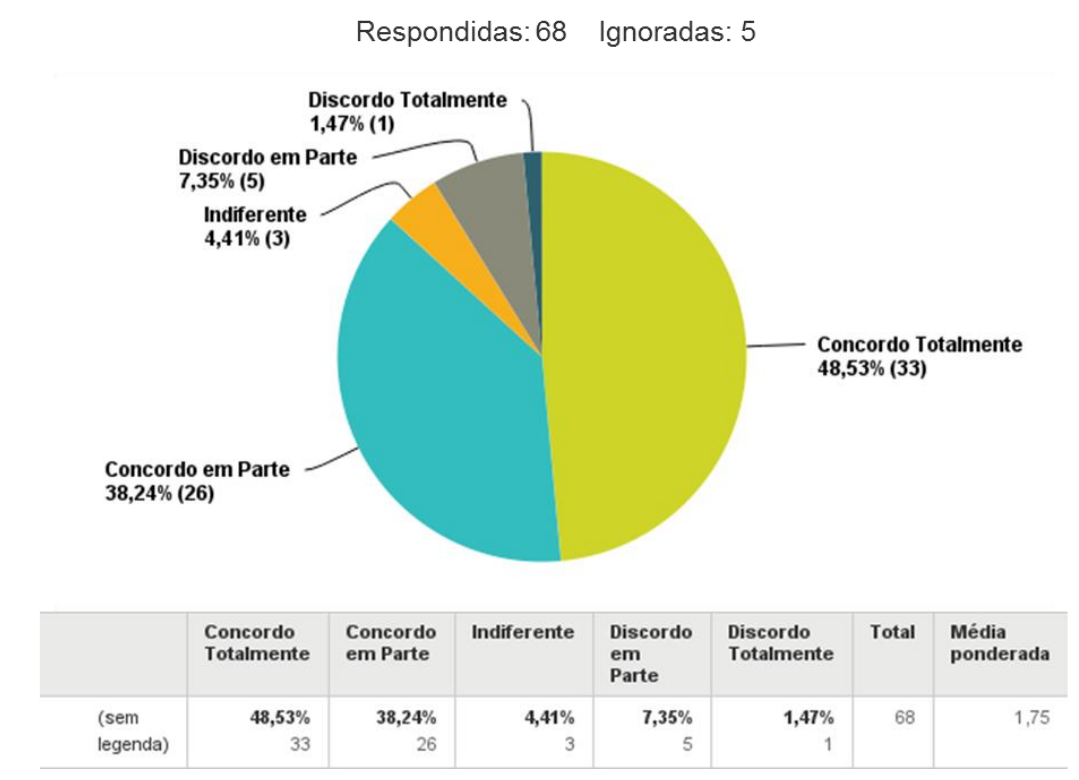

Figura 51: Questão 3.2 Questionário

j) Questão 3.3 (relação entre 0 uso de produtos químicos melhores tecnologicamente e competitividade): $92,65 \%$ dos entrevistados concordaram em uma relação positiva entre as duas variáveis, resultando em média ponderada nas respostas de 1,47 (Figura 52). 


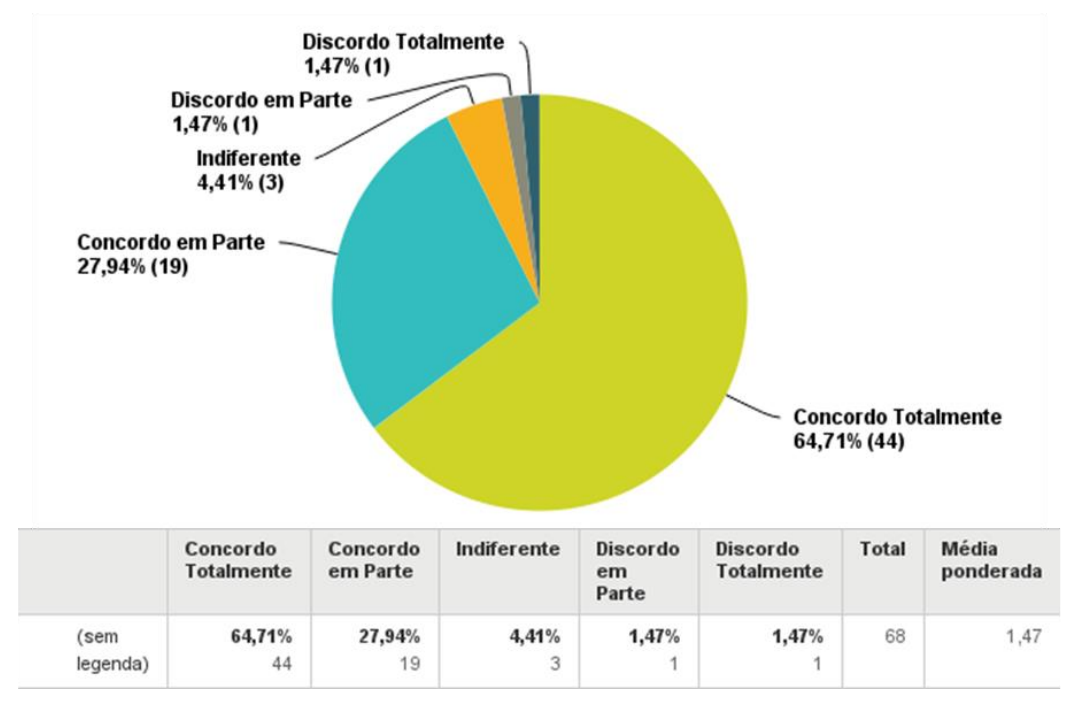

Figura 52: Questão 3.3 Questionário

k) Questão 3.4 (relação entre o uso de produtos químicos melhores tecnologicamente e produtividade): $82,36 \%$ dos entrevistados concordaram em uma relação positiva entre as duas variáveis, resultando uma média ponderada nas respostas de 1,87 (Figura 53).

A Hipótese $\mathrm{H}_{4}$ foi formulada com base nesta questão.

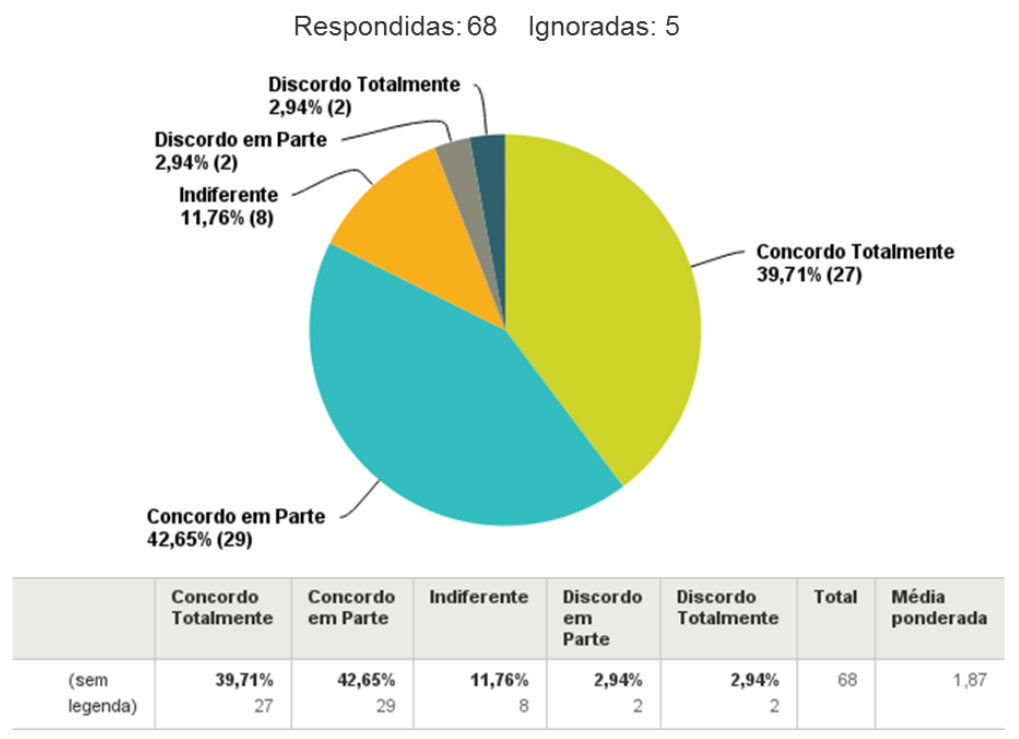

Figura 53: Questão 3.4 Questionário

l) Questão 4.1 (relação entre uso de promoção e propaganda e competitividade): 97,01\% dos entrevistados concordaram em uma relação positiva entre as duas variáveis, resultando uma média ponderada nas respostas de 1,39 (Figura 54). 
A Hipótese $\mathrm{H}_{5}$ foi formulada com base nesta questão.

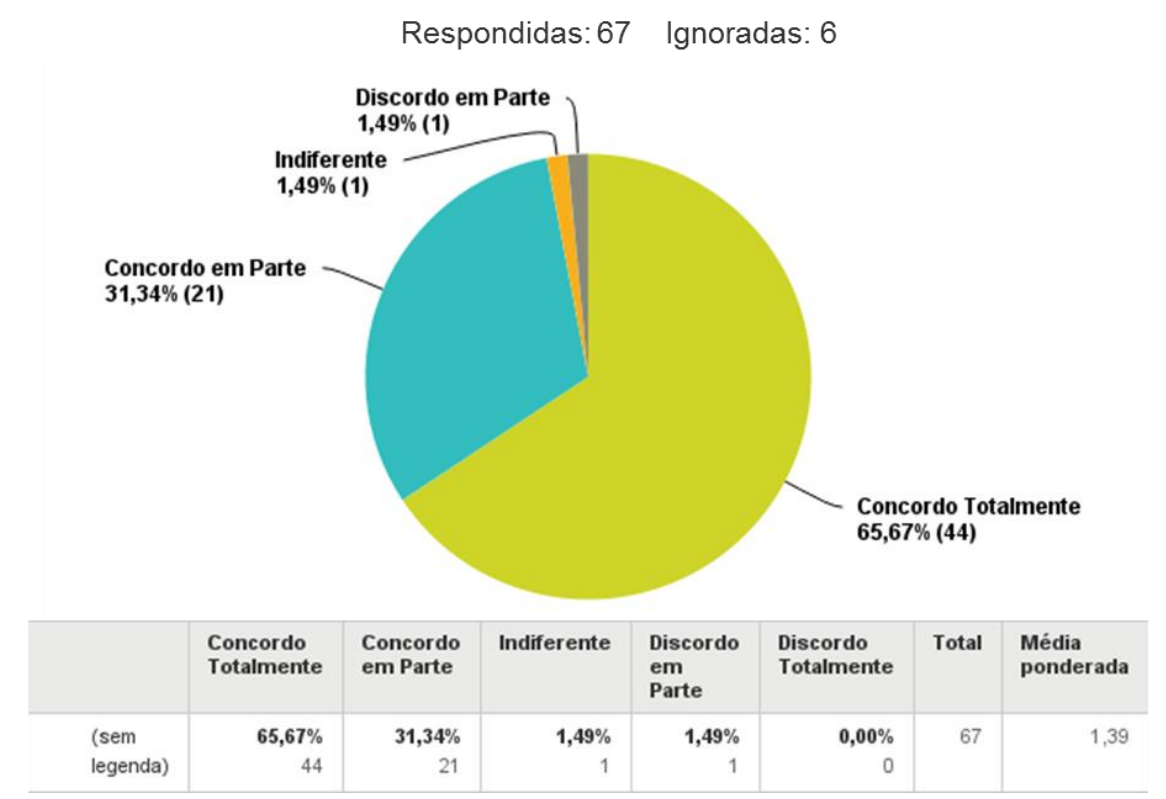

Figura 54: Questão 4.1 Questionário

m) Questão 4.2 (relação entre a prestação de serviços customizados e competitividade): 92,54\% dos entrevistados concordaram em uma relação positiva entre as duas variáveis, resultando uma média ponderada nas respostas de 1,63 (Figura 55).

A Hipótese $\mathrm{H}_{6}$ foi formulada com base nesta questão.

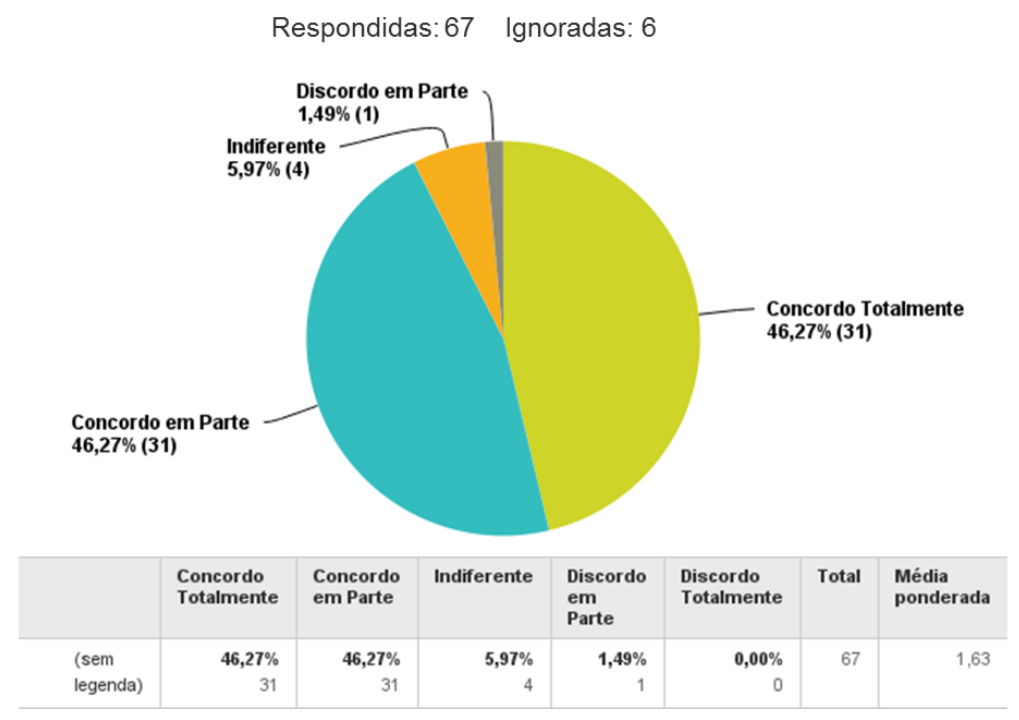

Figura 55: Questão 4.2 Questionário 
n) Questão 4.3 (relação entre o aumento do leque de serviços e a competitividade): $97,01 \%$ dos entrevistados concordaram em uma relação positiva entre as duas variáveis, resultando uma média ponderada nas respostas de 1,51 (Figura 56). A Hipótese $\mathrm{H}_{7}$ foi formulada com base nesta questão.

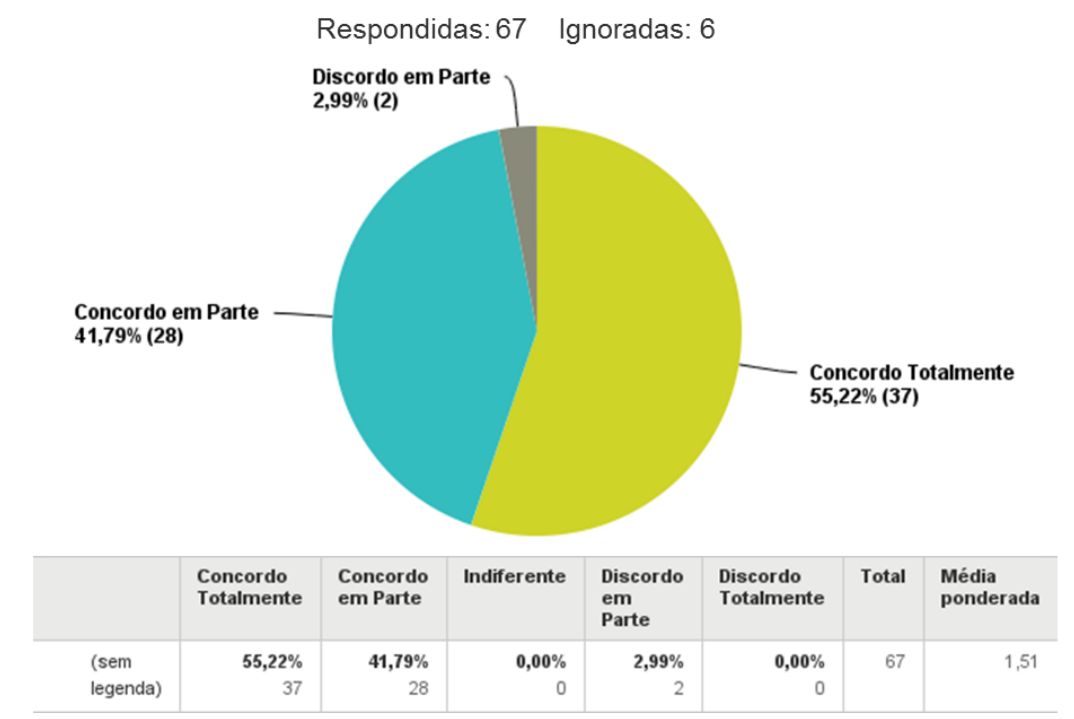

Figura 56: Questão 4.3 Questionário

o) Questão 5.1 (relação entre uma nova logística de entrega do serviço e a competitividade): $91,05 \%$ dos entrevistados concordaram em uma relação positiva entre as duas variáveis, resultando em média ponderada nas respostas de 1,67 (Figura 57).

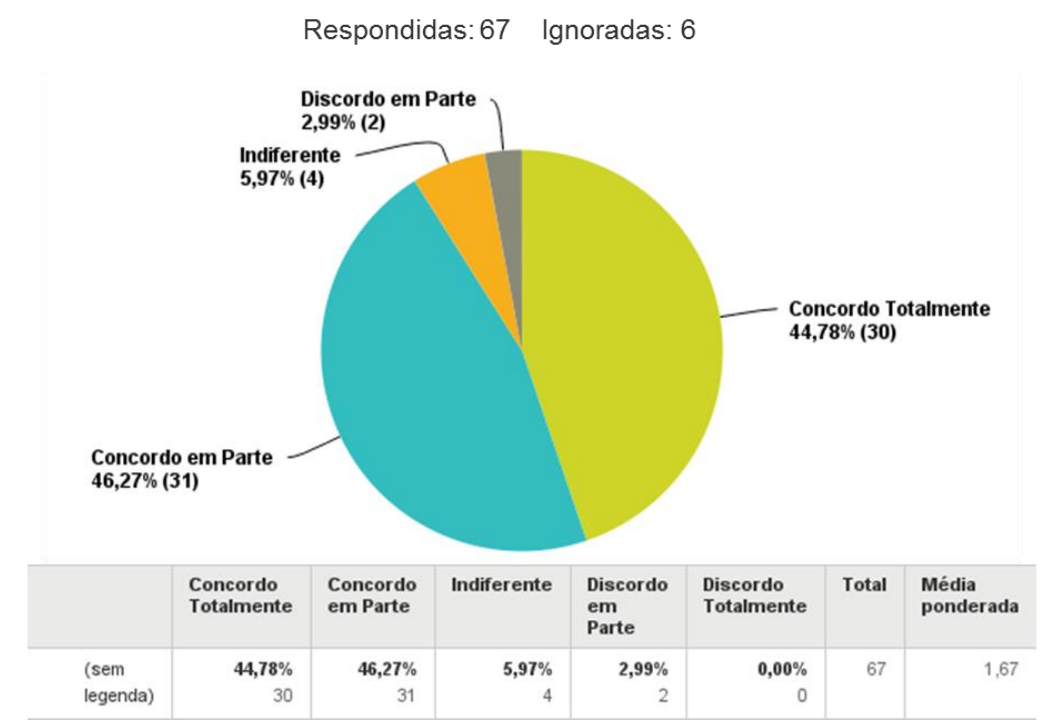

Figura 57: Questão 5.1 Questionário 
p) Questão 5.2 (relação entre um serviço mais rápido e com melhor conveniência e a competitividade): 94,03\% dos entrevistados concordaram em uma relação positiva entre as duas variáveis, resultando em média ponderada nas respostas de 1,48 (Figura 58).

A Hipótese $\mathrm{H}_{8}$ foi formulada com base nesta questão.

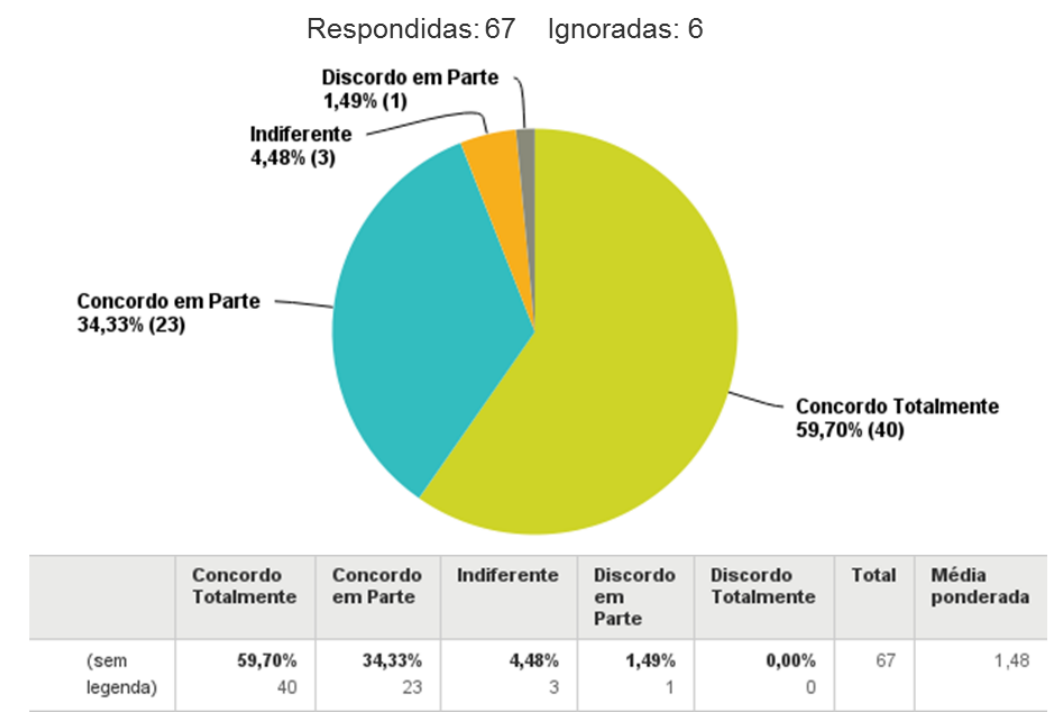

Figura 58: Questão 5.2 Questionário

q) Questão 6.1 (relação entre o desenvolvimento da linha de frente e a competitividade): 95,52\% dos entrevistados concordaram em uma relação positiva entre as duas variáveis, resultando em média ponderada nas respostas de 1,36 (Figura 59).

A Hipótese $\mathrm{H}_{9}$ foi formulada com base nesta questão. 


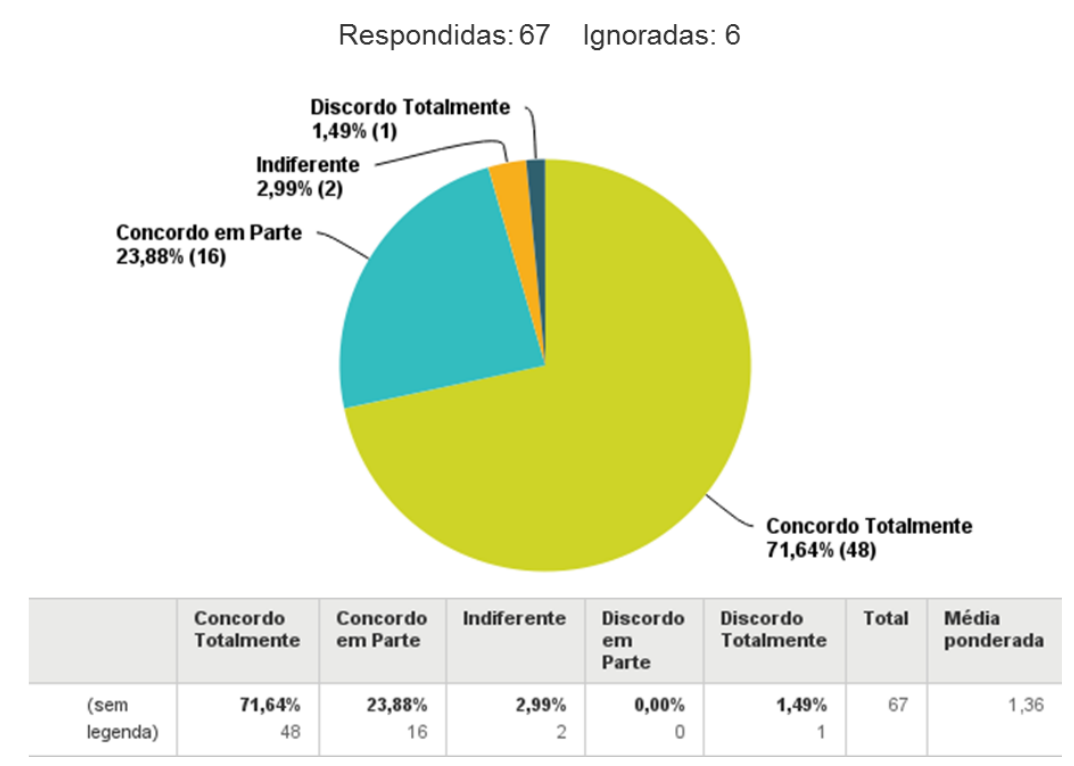

Figura 59: Questão 6.1 Questionário

r) Questão 6.2 (relação entre a desempenho da linha de retaguarda e a produtividade): 97,01\% dos entrevistados concordaram em uma relação positiva entre as duas variáveis, resultando em média ponderada nas respostas de 1,33 (Figura 60). 


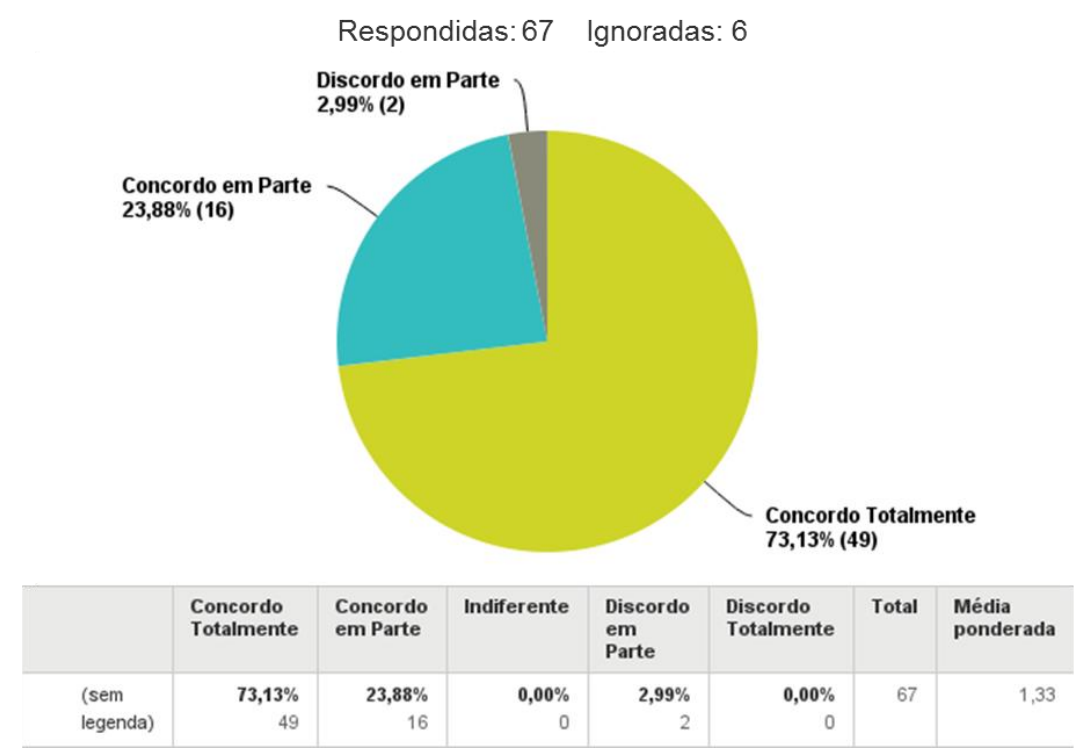

Figura 60: Questão 6.2 Questionário

s) Questão 7.1 (relação entre a adoção de mais de um tipo de inovação concomitantemente e a competitividade): 92,50\% dos entrevistados concordaram em uma relação positiva entre as duas variáveis, resultando em média ponderada nas respostas de 1,60 (Figura 61).

A Hipótese $\mathrm{H}_{10}$ foi formulada com base nesta questão.

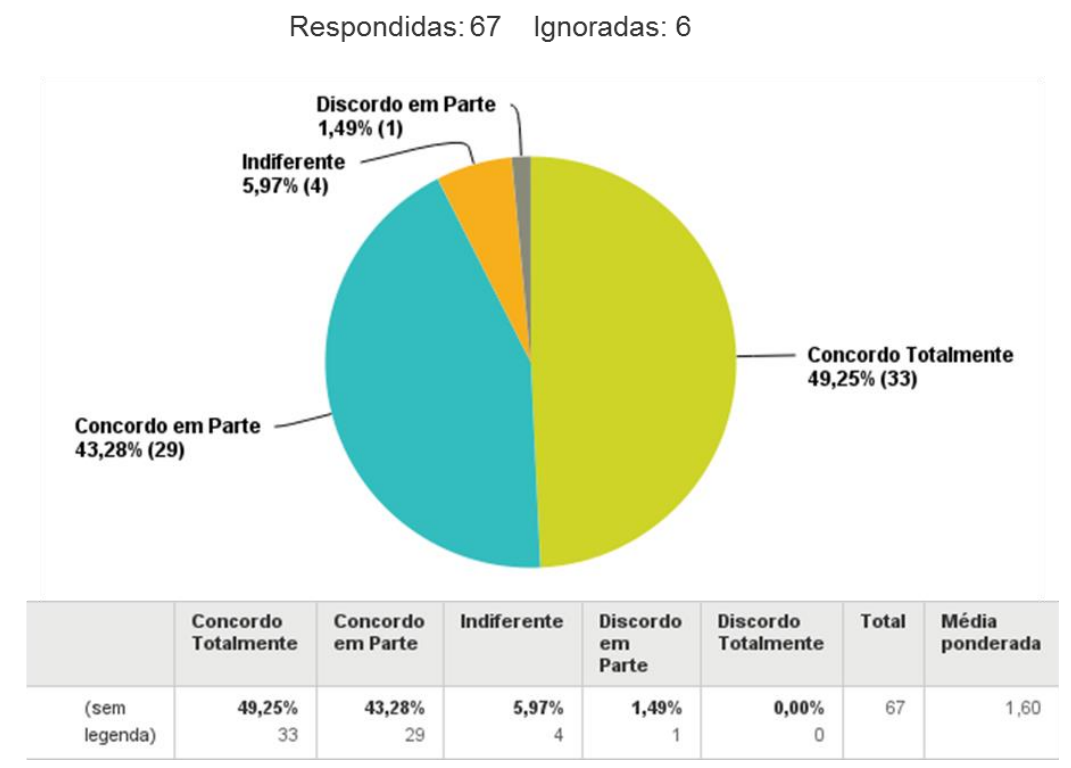

Figura 61: Questão 7.1 Questionário

t) Questão 7.2 (relação entre a adoção de mais de um tipo de inovação concomitantemente e a produtividade): $92,53 \%$ dos entrevistados concordaram em 
uma relação positiva entre as duas variáveis, resultando uma média ponderada nas respostas de 1,64 (Figura 62).

A Hipótese $\mathrm{H}_{11}$ foi formulada com base nesta questão.

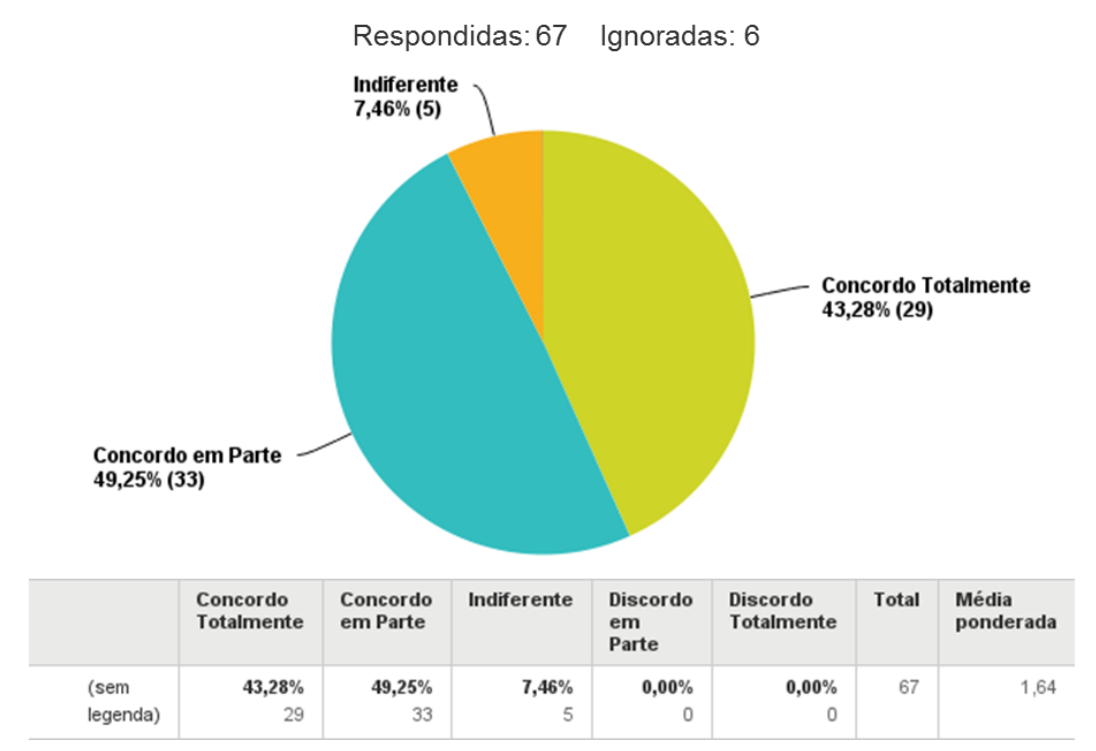

Figura 62: Questão 7.2 Questionário

O resultado da pesquisa quantitativa via escala Likert possibilitou a formulação das hipóteses, que, diretamente relacionaram os tipos de inovação às variáveis competitividade e produtividade. Algumas questões não geraram hipóteses, porém forneceram informações relevantes sobre as referidas relações.

\subsubsection{Resultados dos Testes de Hipóteses a partir da Técnica Qui-Quadrado}

A Figura 63 mostra as variáveis relacionadas a cada uma das hipóteses formuladas. 


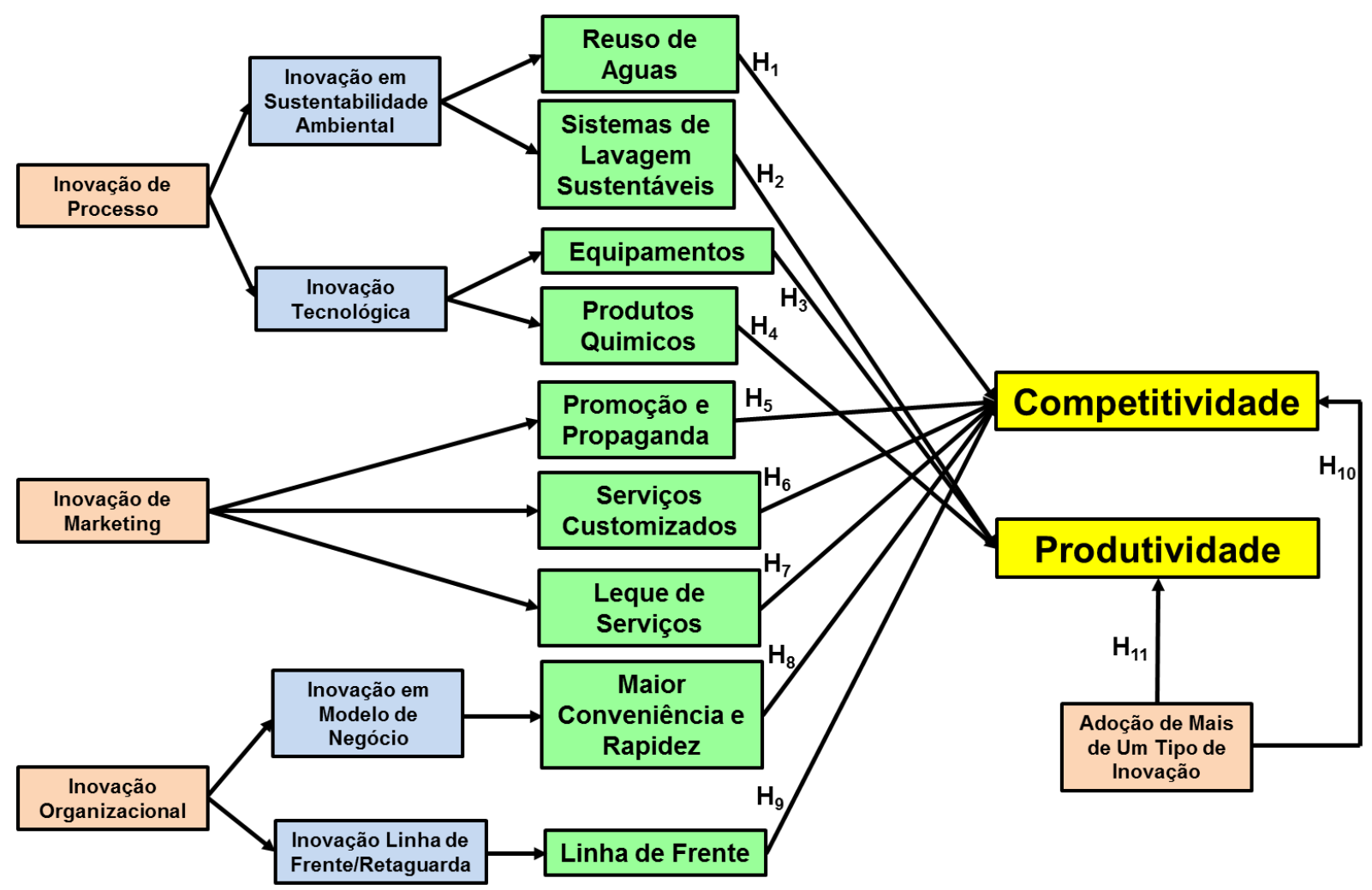

Figura 63: Hipóteses formuladas e variáveis relacionadas na pesquisa Elaborado pelo autor

As hipóteses formuladas no ítem 3.3.3 foram testadas com a metodologia delineada no ítem 3.3.6, por meio da inserção de fórmulas da técnica estatística Qui-Quadrado em planilha do programa Microsoft Excel 2010.

O Apêndice $C$ mostra os resultados obtidos junto às lavanderias (escala Likert: 1, 2, 3,4 e 5) nas questões que geraram as hipóteses. Os resultados foram usados para os cálculos por meio do método Qui-Quadrado de Proporção, que se encontram nos dados do Quadro 3. 
Quadro 3: Resultados Obtidos nos Testes de Hipóteses

\begin{tabular}{|c|c|c|c|c|c|c|c|c|c|c|c|}
\hline Parâmetros & $\begin{array}{c}\text { H1 } \\
\text { Q } 2.1 \\
\end{array}$ & $\begin{array}{c}\mathrm{H} 2 \\
\mathrm{Q} 2.4 \\
\end{array}$ & $\begin{array}{c}\mathrm{H} 3 \\
\mathrm{Q} 3.2 \\
\end{array}$ & $\begin{array}{c}\mathrm{H} 4 \\
\mathrm{Q} 3.4 \\
\end{array}$ & $\begin{array}{c}\mathrm{H} 5 \\
\mathrm{Q} 4.1 \\
\end{array}$ & $\begin{array}{c}\mathrm{H} 6 \\
\mathrm{Q} 4.2 \\
\end{array}$ & $\begin{array}{c}\mathrm{H} 7 \\
\mathrm{Q} 4.3 \\
\end{array}$ & $\begin{array}{c}\mathrm{H} 8 \\
\mathrm{Q} 5.2 \\
\end{array}$ & $\begin{array}{c}\mathrm{H} 9 \\
\mathrm{Q} 6.1 \\
\end{array}$ & $\begin{array}{l}\mathrm{H} 10 \\
\mathrm{Q} 7.1 \\
\end{array}$ & $\begin{array}{c}H 11 \\
Q 7.2 \\
\end{array}$ \\
\hline $\begin{array}{c}\text { Frequência Absoluta } \\
\text { das Categorias } 1 \text { e } 2 \\
\text { "concordo totalmente" } \\
\text { e "concordo em parte" } \\
\text { (Referentes a } \mathrm{H}_{1}, \mathrm{H}_{2} \\
\left.\mathrm{H}_{3}, \ldots\right)\end{array}$ & 57 & 32 & 59 & 56 & 65 & 62 & 65 & 63 & 64 & 62 & 62 \\
\hline $\begin{array}{c}\text { Frequência Absoluta } \\
\text { das Categorias } 3,4 \text { e } 5 \\
\text { "indiferente", } \\
\text { "discordo em parte" e } \\
\text { "discordo totalmente" } \\
\text { (Referentes a HO) }\end{array}$ & 14 & 39 & 9 & 12 & 2 & 5 & 2 & 4 & 3 & 5 & 5 \\
\hline $\begin{array}{c}\text { Número de } \\
\text { Respondentes }\end{array}$ & 71 & 71 & 68 & 68 & 67 & 67 & 67 & 67 & 67 & 67 & 67 \\
\hline Nível de Significância & 0,05 & 0,05 & 0,05 & 0,05 & 0,05 & 0,05 & 0,05 & 0,05 & 0,05 & 0,05 & 0,05 \\
\hline $\begin{array}{c}\text { Número de Categorias } \\
\text { na Es cala Likert (k) }\end{array}$ & 5 & 5 & 5 & 5 & 5 & 5 & 5 & 5 & 5 & 5 & 5 \\
\hline $\begin{array}{c}\text { Graus de Liberdade } \\
(\mathrm{gl}=\mathrm{k}-1)\end{array}$ & 4 & 4 & 4 & 4 & 4 & 4 & 4 & 4 & 4 & 4 & 4 \\
\hline $\begin{array}{l}\text { Frequência Observada } \\
\qquad \begin{array}{l}\left(\mathrm{O}_{\mathrm{i}}\right) \text { Cat. } 1 \text { e } 2 \\
\text { (Ref. a } \mathrm{H}_{1}, \mathrm{H}_{2}, \mathrm{H}_{3} \text {, etc...) }\end{array}\end{array}$ & 57,00 & 32,00 & 59,00 & 56,00 & 65,00 & 62,00 & 65,00 & 63,00 & 64,00 & 62,00 & 62,00 \\
\hline $\begin{array}{c}\text { Frequência Esperada } \\
\text { (E) Cat. } 1 \text { e } 2 \text { ( } 40 \% \text { ou } \\
2 / 5 \text { do Total) } \\
\text { (Ref. a H1, H2, H3, etc...) }\end{array}$ & 28,40 & 28,40 & 27,20 & 27,20 & 26,80 & 26,80 & 26,80 & 26,80 & 26,80 & 26,80 & 26,80 \\
\hline$\left(O_{i}\right)-\left(E_{i}\right)$ & 28,60 & 3,60 & 31,80 & 28,80 & 38,20 & 35,20 & 38,20 & 36,20 & 37,20 & 35,20 & 35,20 \\
\hline$x^{2}=\left(O_{i}-E_{i}\right)^{2} \div E_{i}$ & 28,80 & 0,46 & 37,18 & 30,49 & 54,45 & 46,23 & 54,45 & 48,90 & 51,64 & 46,23 & 46,23 \\
\hline $\begin{array}{c}\mathrm{X}_{\mathrm{c}}^{2} \text { (Valor Critico de } X^{2,} \\
\text { obtido na tabela } \\
\text { utilizando graus de } \\
\text { liberdade e nível de } \\
\text { significância) }\end{array}$ & 9,49 & 9,49 & 9,49 & 9,49 & 9,49 & 9,49 & 9,49 & 9,49 & 9,49 & 9,49 & 9,49 \\
\hline $\begin{array}{l}\text { Decisão sobre Rejeição de } \\
\qquad H_{0} \\
\text { (rejeitar se } X^{2}>X^{2} \text {; caso } \\
\text { contrário, não rejeitar) }\end{array}$ & $\begin{array}{c}\text { Rejeitar } \\
\text { HO }\end{array}$ & $\begin{array}{c}\text { Não } \\
\text { rejeitar } \\
\text { HO }\end{array}$ & $\begin{array}{c}\text { Rejeitar } \\
\text { HO }\end{array}$ & $\begin{array}{c}\text { Rejeitar } \\
\text { HO }\end{array}$ & $\left|\begin{array}{c}\text { Rejeitar } \\
\text { HO }\end{array}\right|$ & $\left|\begin{array}{c}\text { Rejeitar } \\
\text { HO }\end{array}\right|$ & $\begin{array}{c}\text { Rejeitar } \\
\text { HO }\end{array}$ & $\begin{array}{c}\text { Rejeitar } \\
\text { HO }\end{array}$ & $\left|\begin{array}{c}\text { Re jeitar } \\
\text { HO }\end{array}\right|$ & $\left|\begin{array}{c}\text { Rejeitar } \\
\text { HO }\end{array}\right|$ & $\begin{array}{c}\text { Rejeitar } \\
\text { HO }\end{array}$ \\
\hline Resultado Final & $\begin{array}{c}\text { Aceitar } \\
\text { H1 }\end{array}$ & $\begin{array}{c}\text { Não } \\
\text { Aceitar } \\
\text { H2 }\end{array}$ & $\begin{array}{c}\text { Aceitar } \\
\text { H3 }\end{array}$ & $\begin{array}{c}\text { Aceitar } \\
\text { H4 }\end{array}$ & $\begin{array}{c}\text { Aceitar } \\
\text { H5 }\end{array}$ & $\begin{array}{c}\text { Aceitar } \\
\text { H6 }\end{array}$ & $\begin{array}{c}\text { Aceitar } \\
\text { H7 }\end{array}$ & $\begin{array}{c}\text { Aceitar } \\
\text { H8 }\end{array}$ & $\begin{array}{c}\text { Aceitar } \\
\text { H9 }\end{array}$ & $\begin{array}{c}\text { Aceitar } \\
\text { H10 }\end{array}$ & $\begin{array}{c}\text { Aceitar } \\
\text { H11 }\end{array}$ \\
\hline
\end{tabular}

Elaborado pelo autor

A primeira coluna do Quadro 3 mostra a sequência de passos (dados e cálculos) até o resultado final da decisão sobre a rejeição ou não de $\mathrm{H}_{0}$ (as definições sobre os dados da primeira coluna encontram-se no ítem 3.3.6). Podemos discutir os seguintes aspectos em cada passo: 
- Frequência absoluta das categorias 1 e 2 : em todas as questões, esta frequência esteve acima de $80 \%$ do número de respondentes, exceto na questão 2 , cujo percentual foi de $45 \%$;

- Frequência absoluta das categorias 3, 4 e 5: em todas as questões esta frequência esteve abaixo de $20 \%$ do número de respondentes, exceto na questão 2 , cujo percentual foi de $55 \%$;

- Número de respondentes: algumas questões não foram respondidas por algumas lavanderias, porém, esse grupo representou só quatro lavanderias da amostra de 71 respondentes. Em cada questão, o número real de respondentes foi considerado;

- Nível de significância (a): foi escolhido em $5 \%$ para todos os cálculos;

- Número de categorias ou pontos na escala Likert (k): cinco;

- Graus de liberdade (gl): número de categorias menos 1, ou seja, quatro;

- Frequência observada $\left(\mathrm{O}_{\mathrm{i}}\right)$ das categorias 1 e 2: com base nos resultados do Apêndice $C$, que representou o número de vezes que as categorias 1 e 2 foram citadas em cada questão;

- Frequência esperada $\left(E_{i}\right)$ das categorias 1 e 2: foi considerado que a probabilidade esperada de resposta para cada uma das cinco categorias na escala Likert seria igual para todas. Portanto, $20 \%$ para cada categoria. Deste modo, a frequência esperada para as categorias 1 e 2 totalizaram $40 \%$ em cada questão;

- Cálculo de $X^{2}$ : em todas as questões o valor de $X^{2}$ esteve acima de 28 , exceto na questão 2 , cujo valor foi de 0,46 ;

- Cálculo de $X_{c}^{2}$ : em todos os casos, foi de 9,49, pois dependia de dois valores fixos (gle $\alpha)$; e

- Decisão (rejeitar ou não $\mathrm{H}_{0}$ ): em todos os casos $\mathrm{H}_{0}$ foi rejeitada, exceto na hipótese 2 (questão 21), em que foi aceita.

- Decisão final: aceitar ou não as hipóteses $H_{1}$ até $H_{11}$. 
O Gráfico 3 elucida as regiões de rejeição e não rejeição, com base nos resultados do Quadro 3. Dessa forma, os valores de $X^{2}$ que estiverem acima do valor $X^{2}{ }_{c}$ estarão na região de rejeição de $\mathrm{H}_{0}$ e os que estiverem abaixo na região de não rejeição.

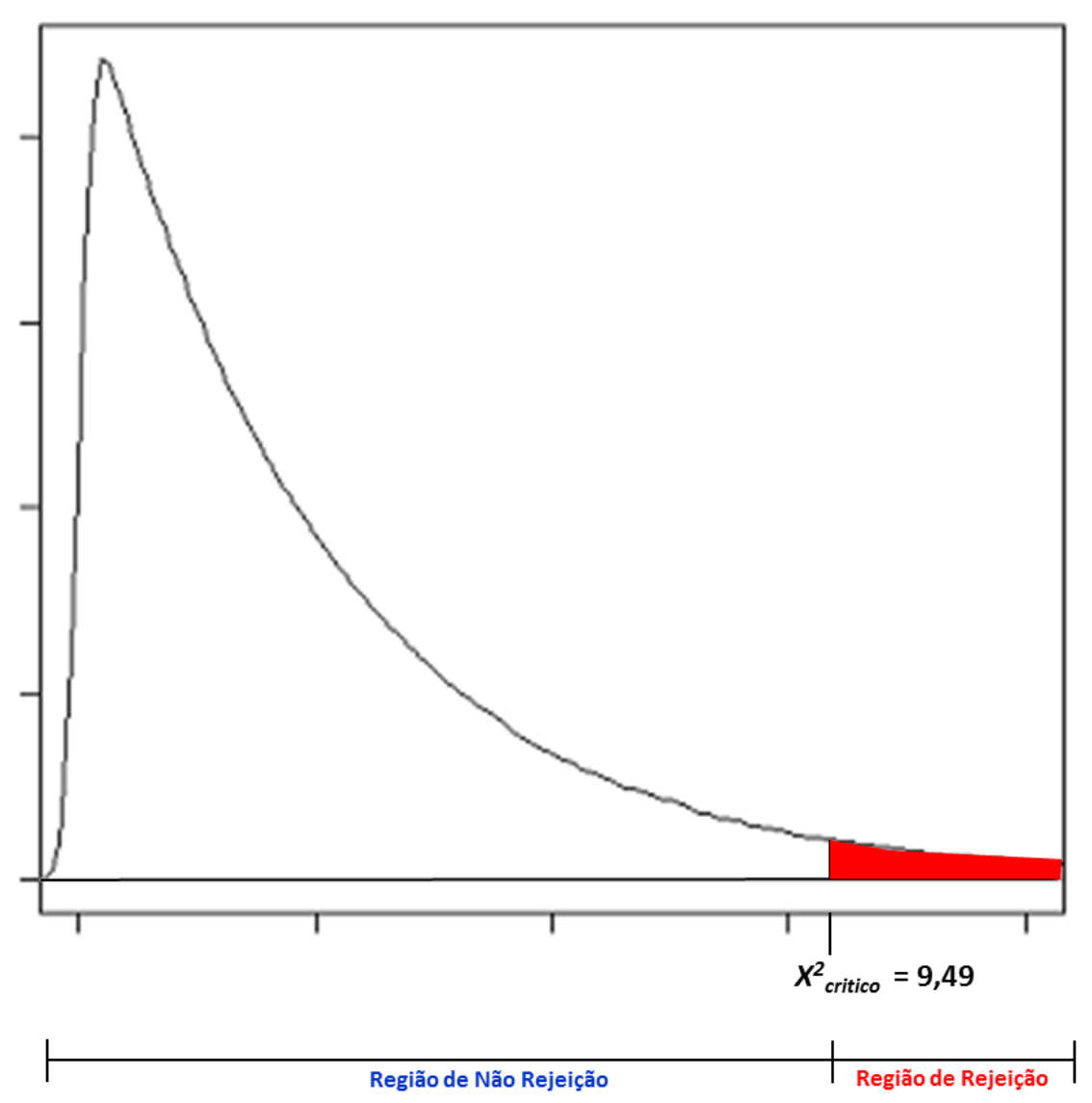

Gráfico 3: Regiões de Rejeição e Não Rejeição Elaborado pelo Autor

Os resultados do Quadro 3 indicaram que todos os tipos de inovação estudados nos testes das hipóteses $H_{1}$ até $H_{9}$ mostram evidências de haver uma relação positiva com a competitividade e produtividade nas lavanderias domésticas, exceto a hipótese 2 (Questão 21), em que não houve rejeição da hipótese $H_{0}$. A adoção de mais de um tipo de inovação nas empresas também indicou haver uma relação positiva com a competitividade e produtividade (hipóteses $\mathrm{H}_{10}$ até $\mathrm{H}_{11}$ ). 
Dessa forma, os resultados evidenciam as seguintes relações entre os tipos de inovação estudados, a competitividade e a produtividade em lavanderias domésticas, a saber:

a) Hipótese 1 (questão 2.1): aceita.

Indica que a adoção de práticas ambientais relacionadas à ecoinovação (inovação em sustentabilidade ambiental) tem uma relação positiva com o aumento das vendas a clientes que valorizam a questão ambiental, com aumento da competitividade.

Embora a prática de reúso de águas (ecoinovação) não esteja concretizada na maior parte das lavanderias da amostra, existe uma conscientização de que esta prática poderá trazer aumento na competitividade.

Por outro lado, a questão 2.2 (que não gerou hipótese) mostra que pouco menos da metade dos entrevistados, considerou que o reúso de águas pode melhorar a produtividade. Pode-se inferir que a busca dessa prática está mais vinculada à redução de custos variáveis (água) e à divulgação ao público, como estratégia de diferenciação.

b) Hipótese 2 (questão 2.4): rejeitada.

Indica que o uso de sistemas de lavagem que reduz o impacto ambiental e economiza insumos (inovação em sustentabilidade ambiental), não tem uma relação positiva com a melhora da produtividade. As respostas indicam que práticas ambientais podem melhorar o ganho de mercado (hipótese 1 aceita), mas não há evidências de que possam melhorar a produtividade nos processos. Um detalhe importante a ser avaliado é o elevado percentual da categoria "indiferente", podendo indicar desconhecimento ou o não comprometimento do respondente em firmar uma opinião nas demais categorias.

A rejeição da hipótese $\mathrm{H} 2$ indica que os empresários ainda não consideram os sistemas de lavagem sustentáveis (ex.: wetcleaning), como instrumentos de melhora 
da produtividade. Mas, acima de 60\% dos entrevistados consideram como uma prática que aumenta o faturamento da lavanderia (questão 2.3). Pode-se inferir, que, sendo produtividade definida como vendas por funcionário, e o sistema wetcleaning demanda mão de obra especializada no processo (apesar de automatizado), os empresários entendem que, apesar do aumento das vendas, há um certo investimento em funcionários para a operação do sistema.

c) Hipótese 3 (questão 3.2): aceita.

Indica que a adoção da inovação nas novas tecnologias em equipamentos (inovação tecnológica) tem uma relação positiva com a produtividade.

Conforme já comentado, há uma tendência na valorização das inovações tecnológicas em máquinas, como fator de aumento da produtividade no processamento de roupas. A hipótese $\mathrm{H} 3$ estabelece uma relação positiva, que foi aderida por $86 \%$ dos entrevistados. A questão 3.1, da mesma forma, reforça a priorização das inovações tecnológicas, observando-se que os empresários enxergam uma relação positiva dessas inovações com a redução de custos e melhora da lucratividade (mais de $87 \%$ concordaram).

d) Hipótese 4 (questão 3.4): aceita.

Indica que a adoção da inovação nas novas tecnologias de produtos químicos para o processo (inovação tecnológica) tem uma relação positiva com a produtividade.

A aceitação da hipótese $\mathrm{H} 4$ indica a relação positiva entre o uso de novos produtos químicos e a produtividade (concordância de mais de $82 \%$ dos entrevistados). Um fato relevante observado é que essa relação positiva também se estende à competitividade, porém com uma concordância maior ainda (questão 3.3: concordância de mais de 92\%), talvez influenciada pela melhor qualidade do serviço final prestado com o uso de produtos químicos mais eficazes. 
e) Hipótese 5 (questão 4.1): aceita.

Indica que o uso da promoção e da propaganda (inovação de marketing) aumenta o número de novos clientes e tem uma relação positiva com a competitividade (ganho de mercado).

f) Hipótese 6 (questão 4.2): aceita.

Indica que a atuação em nichos de mercado (inovação de marketing) aumenta a base de novos clientes e tem uma relação positiva com a competitividade (ganho de mercado).

g) Hipótese 7 (questão 4.3): aceita.

Indica que o aumento no leque de serviços oferecidos (inovação de marketing) aumenta a diversificação, as vendas e tem uma relação positiva com a competitividade.

As hipóteses $\mathrm{H} 5, \mathrm{H} 6$ e $\mathrm{H} 7$ foram formuladas com o objetivo de entender as relações entre as inovações de marketing para as lavanderias (uso de propaganda e promoção, customização de serviços/atuação em nichos de mercado e maior diversificação de serviços) com a variável competitividade. Todas as relações foram consideradas positivas, indicando a tendência das empresas atuarem lançando mão de estratégias de diversificação, além de comunicarem seus diferenciais ao mercado, usando mídias que demandem baixo investimento (exceto as redes de franquias, que já têm essa comunicação padronizada para todo o grupo).

h) Hipótese 8 (questão 5.2): aceita.

Indica que a adoção de novos modelos de negócio (inovação em modelo de negócio) com foco na melhora da conveniência e rapidez na entrega do serviço tem uma relação positiva com a competitividade.

A aceitação da hipótese $\mathrm{H} 8$ indica a adaptação das lavanderias às mudanças no perfil do consumidor atual, que demanda inovações que tragam conveniência, 
sobretudo as relacionadas à logística de coleta e entrega das roupas processadas. No entendimento dos entrevistados, as citadas inovações estão relacionadas ao aumento do faturamento das lavanderias. Esta constatação é reforçada pela concordância de uma relação positiva entre a logística de entrega e competitividade (questão 5.1 com mais de $91 \%$ de concordância).

i) Hipótese 9 (questão 6.1): aceita.

Indica que a atuação dos funcionários da linha de frente na comunicação das inovações e dos diferenciais da empresa (inovação da linha de frente) tem uma relação positiva com a competitividade.

O investimento na capacitação e treinamento da linha de frente foi considerado, pela maior parte dos empresários (questão 6.1 com mais de 95\% de concordância) como diretamente relacionado à competitividade do negócio. Conforme já comentado, existe uma tendência ratificada pela pesquisa qualitativa da concepção da linha de frente, como coordenadora dos processos internos da lavanderia na ausência do proprietário, provavelmente, porque atua nas pontas da recepção e entrega do serviço prestado ao cliente final.

j) Hipótese 10 (questão 7.1): aceita.

Indica que a adoção de mais de um tipo de inovação, concomitantemente, tem uma relação positiva com a competitividade.

k) Hipótese 11 (questão 7.2): aceita.

Indica que a adoção de mais de um tipo de inovação, concomitantemente, tem uma relação positiva com a produtividade.

A existência de relações positivas entre a adoção de mais de um tipo de inovação, ao mesmo tempo, a competitividade e a produtividade (concordância de mais de $92 \%$ dos entrevistados nas questões 7.1 e 7.2), mostra a tendência dos proprietários 
de lavanderias à valorização da adoção das inovações dos diversos setores das empresas concomitantemente (hipóteses $\mathrm{H} 10$ e H11). Esta constatação pode indicar o direcionamento a uma distribuição dos investimentos em inovação nas diversas frentes, talvez de forma mais moderada em cada uma individualmente, exceto no caso de aquisição de novas máquinas, em que, geralmente, existe certa priorização.

I) Outros resultados relevantes.

As questões 2.5 a 2.7 estão relacionadas às outras práticas de sustentabilidade ambiental (ecoinovação) não abordadas pelas questões 2.1 a 2.4. Os entrevistados opinaram que o uso de embalagens recicláveis não é fator relevante para a melhora da competitividade e produtividade (questões 2.5 e 2.6: concordância de, aproximadamente, $51 \%$ e $36 \%$, respectivamente). Por outro lado, o uso de energias alternativas, como a solar e a eólica (questão 2.7), tem relação positiva com a competitividade do negócio para $64 \%$ dos entrevistados. Esta aprovação pode estar associada à divulgação das práticas aos clientes (com ganho de competitividade) ou à melhora da lucratividade pela redução de custos de energia. Com relação à associação positiva entre a linha de retaguarda e produtividade, os resultados da questão 6.2 (com mais de 96\% de concordância) mostram a aceitação dessa associação. Este resultado indica o direcionamento das ações relacionadas à produtividade a um melhor controle do processamento das roupas, no qual a linha de retaguarda tem papel relevante.

\subsection{Estrutura Conceitual (Framework) Relacionando os Tipos de Inovação, Competitividade e Produtividade}

Atendendo ao terceiro objetivo específico (ítem 1.4.2), que preconiza a evidência do inter-relacionamento entre os tipos de inovação adotados (quando da adoção de mais de um tipo de inovação), entre esses e as variáveis produtividade e competitividade, foi desenvolvida uma estrutura conceitual (framework), cujo objetivo foi explicar essas relações. 
As pesquisas qualitativas (entrevistas semiestruturadas) e quantitativas (respostas às perguntas do ítem 7, do Apêndice B) mostraram as referidas inter-relações e sua importância para o segmento das lavanderias domésticas.

\subsubsection{Evidências do Inter-Relacionamento Com Base na Pesquisa Qualitativa (Entrevistas Semiestruturadas)}

A análise das respostas nas entrevistas semiestruturadas mostrou os seguintes resultados relativos às evidências do inter-relacionamento entre os tipos de inovação adotados e entre estes e as variáveis produtividade e competitividade:

a) Inter-relacionamento entre a inovação de processo (tecnológica e sustentabilidade ambiental) e a inovação de marketing:

- A melhora da qualidade final do serviço prestado, com base nas inovações tecnológicas atinge maior número de clientes sensíveis à qualidade final do serviço prestado;

- Os resultados mais rápidos, oriundos da tecnologia, qualidade e eficácia nos processos, melhoram a diferenciação das empresas no mercado;

- O nível de exigência do consumidor brasileiro é alto em termos de qualidade, mas também exige rapidez, ambos conseguidos por meio de equipamentos mais produtivos e eficazes;

- A inovação em sustentabilidade ambiental ainda não é fator que sensibiliza o consumidor final como uma diferenciação;

- O uso de cabides com material reciclável em lugar de plástico sensibiliza o segmento de clientes preocupados com a sustentabilidade;

- A comunicação adequada ao cliente final sobre as práticas de sustentabilidade das lavanderias aumenta a base de clientes;

- Quando ocorre uma comunicação adequada das práticas de sustentabilidade, existe uma crescente participação dos clientes por meio da devolução de todo material que pode ser reciclado (ex.: plásticos que embalam as roupas); 
- O uso de novas tecnologias de informação é uma forma barata de obter dados e, sobretudo, informações de mercado (segmentação de clientes, vendas e informações pontuais);

- A tecnologia da informação permite a interligação de equipamentos e melhora da comunicação com o cliente final, aumentando a competitividade; e

- A redução do custo de lavagem pela implantação do sistema wetcleaning alcança a parcela de clientes do mercado sensível a preço.

b) Inter-relacionamento entre a inovação de processo (tecnológica e sustentabilidade ambiental) e a inovação organizacional (de modelo de negócios e linha de frente/retaguarda):

- O uso de novas tecnologias em passadoria de roupas aumenta o nível de novos conhecimentos da linha de retaguarda na área de acabamento;

- O treinamento da linha de retaguarda em novos conceitos relacionados a produtos químicos diferenciados para a retirada de manchas, melhora a qualidade do serviço final prestado;

- A organização da força de trabalho (linha de frente e retaguarda) dentro de novos fluxos de processo oriundos de novas tecnologias de lavagem e acabamento, melhora o resultado como um todo;

- Uso de novas tecnologias que melhoram o ambiente de trabalho (ex.: filtros em máquinas de lavagem a seco e máquinas com barreiras de proteção) melhoram a produtividade da linha de retaguarda;

- As inovações tecnológicas, tais como, máquinas com dosadores automáticos, softwares de gestão de entradas/saídas/resultados reduzem a quantidade de mão de obra e melhoram a especialização;

- O uso de tecnologia da informação no balcão melhora o controle nas lavanderias e aumenta a especialização dos funcionários da linha de frente;

- A criação de mão de obra especializada para operar os novos equipamentos de lavagem, passadoria e manuseio de produtos químicos especializados aumenta a produtividade (ex.: wetcleaning);

c) Inter-relacionamento entre a inovação de marketing e a inovação organizacional (de modelo de negócio e linha de frente/retaguarda): 
- Novas técnicas de tratamento das peças individualmente pela linha de retaguarda aumentam a fidelização do cliente final;

- O atendimento diferenciado da linha de frente e delivery (pós-venda) aumenta a fidelização do cliente final;

- A inovação da linha de frente por meio de técnicas que melhorem a relação com o cliente final, pelo atendimento personalizado, aumenta o retorno financeiro da lavanderia;

- A divulgação via site do novo modelo de negócio com assinatura mensal de serviços reduz o custo ao cliente final (gerando valor) e traz maior fidelização, se comparada com a prestação de serviços esporádicos;

- O atendimento on-line do novo modelo de entrega do serviço via sacola-padrão com determinado volume de roupas melhora a conveniência ao cliente final, que não necessita locomover-se até a lavanderia;

- A atuação por meio de modelos de negócios que utilizem a internet para comunicação com clientes heavy user em compras e interação via navegação, aumenta a base de clientes;

- A divulgação por meio da mídia escrita (ex.: folhetos), empregando a linha de frente treinada para fornecer maior personalização ao serviço oferecido, aumenta a competitividade;

- A especialização da linha de frente na checagem de possíveis danos nas peças, antes do processamento, evita possíveis problemas de relacionamento com os clientes na entrega final do serviço processado;

- O treinamento diferenciado da linha de frente para "vender" serviços agregados, como lavagem de peças especiais (por exemplo, couro, vestidos de noiva, dentre outros) aumenta o tíquete médio por cliente;

- Ampliação do universo de conhecimento da linha de frente, que deve prestar informações técnicas corretas sobre têxteis e lavagem, mostrar os diferenciais da lavanderia, assessorar, sugerir, tirar dúvidas, oferecer um leque maior de serviços e manter um bom relacionamento com a linha de retaguarda, de modo a garantir que 0 que foi ajustado com o cliente será cumprido no processamento da roupa;

- A retirada e entrega de roupas em armários no condomínio do cliente é um novo modelo de negócio que gera valor ao cliente pela melhor conveniência, minimizando 
seu custo de deslocamento e otimizando o tempo. Esse modelo aumenta a competitividade em públicos específicos que valorizam essas características;

- Lavanderias que utilizam aplicativos específicos para celulares, inovando na conveniência para clientes que utilizam esse meio de comunicação, aumentando a base de clientes e melhorando a competitividade;

- Modelos de negócios que privilegiem clientes que valorizam o chamado "mundo touch" (site, aplicativos, skype, WhatsApp e Facebook) são mais rápidos e permitem adaptar as ofertas das lavanderias a esse público, facilitando o delivery e aumentando a base de clientes;

d) Inter-relacionamento entre a inovação de processo (tecnológica e sustentabilidade ambiental) e a produtividade:

- O uso de equipamentos de ponta no processo de lavagem e acabamento melhora a produtividade;

- Por meio da implementação das novas tecnologias em equipamentos, automação, softwares e produtos químicos, a lavanderia aproximou-se de um processo industrial (fábrica de serviços) em escala;

- As inovações e softwares de gestão e equipamentos para acabamento (ex.: manequins de passadoria) melhoram a velocidade no processamento e entrega do serviço ao cliente final;

- O uso de novas tecnologias de produtos químicos reduz o número de etapas, o tempo de processamento das roupas e economiza água;

- O uso de tecnologias mais sustentáveis com menor uso de água, como as lavadoras/extratoras e o sistema wetcleaning (que têm a flexibilidade de também lavar de modo convencional), inova em relação ao meio ambiente e melhora a produtividade do processo de lavagem;

- O uso de produtos químicos menos agressivos ao meio ambiente e às roupas auxilia no processamento, reduz o retorno de roupas e aumenta a produtividade;

- A inovação em tecnologia da informação (desde o atendimento, catalogação, automação do processo de produção, controle do fluxo e tipo de clientes e a identificação das peças por códigos de barra) aumenta a produtividade;

- Quando comparados com produtos de uso doméstico (adquiridos em supermercados), o uso de produtos químicos profissionais melhora a vida útil das 
peças e economiza água (menor número de enxágues), aumentando a produtividade;

- A implantação gradativa de produtos químicos que consumam menos água, eliminem etapas do processo, gerem efluentes de maior impacto e reduzam o consumo de energia, melhora a produtividade;

- O uso de equipamentos de wetcleaning permite uma redução no custo de energia por meio da melhor identificação do nível de umidade das peças, reduzindo tempo gasto de energia na secadora e passadoria, aumentando a produtividade;

e) Inter-relacionamento entre a inovação de processo (tecnológica e sustentabilidade ambiental) e a competitividade:

- As novas tecnologias de processamento do serviço trazem melhor qualidade e melhoram a competitividade (maior retorno do cliente final);

- Os clientes estão gradativamente reconhecendo e escolhendo seus fornecedores de serviços de lavanderia pelo compromisso com a sustentabilidade ambiental, mas ainda não é fator relevante no mercado para a escolha entre as diversas lavanderias (custo, rapidez e qualidade são mais relevantes);

- O processo de lavagem wetcleaning e o reúso de águas ainda não refletem no aumento significativo da base de clientes;

- O uso de produtos químicos profissionais, em lugar de produtos comercializados em supermercados, melhora a percepção do consumidor, que passa a diferenciar a lavanderia comercial da lavanderia de sua residência;

- A inovação dos fornecedores de tecnologias de lavagem e da tecnologia da informação é repassada às lavanderias, que as adotam, criam maior valor ao cliente final, aumentando a competitividade e a produtividade dos processos;

f) Inter-relacionamento entre a inovação de marketing e a competitividade:

- A adoção do Selo de Qualidade e Sustentabilidade (SQS) pelas lavanderias, visando à sensibilização do mercado, aumenta a competitividade;

- O uso de novas ferramentas de relacionamento com os clientes por meio de softwares e outras técnicas de gestão de relacionamento, melhora a competitividade; 
- A adoção do delivery, como ferramenta de melhora da conveniência aos clientes finais com menos tempo disponível para ir às lavanderias, aumenta a base de clientes;

- A inovação de marketing por meio de uma melhor comunicação com o cliente via internet (ferramentas de busca e aplicativos específicos), melhora a competitividade das lavanderias;

- A comunicação visual aplicada à mudança na fachada das lojas aumenta as vendas;

- As práticas de inovação por meio da atuação em nichos de mercado aumentam a competitividade;

- A escolha de uma boa localização (ponto), conveniente ao consumidor final, melhora a competitividade;

- As campanhas de comunicação locais no bairro ou região, onde se encontra a lavanderia, aumentam a competitividade;

- A divulgação de um leque maior de serviços (ex.: couro e camurça) aumenta a competitividade;

- O uso de diversas mídias (rádios, revistas, panfletos e e-mail marketing) atinge o público consumidor de forma mais abrangente;

- A apresentação diferenciada do serviço final pode seduzir o cliente que tem uma relação afetiva com suas roupas, gerando a diferenciação da lavanderia; e

- A inovação na iluminação, logomarca e a forma de comunicação podem superar as expectativas do cliente final.

g) O inter-relacionamento entre a inovação organizacional (de modelo de negócio e linha de frente/retaguarda) e a produtividade:

- O treinamento específico da linha de retaguarda para novas tecnologias em passadoria de roupas (aumenta a rapidez na entrega do serviço);

- O investimento em programas de capacitação contínua da linha de retaguarda responsável pelo acabamento das peças (que é um dos gargalos de processo), melhora a produtividade;

- Lavanderias que inovam por meio de novos modelos na logística de entrega, como em horários fora do horário comercial (com menor trânsito de veículos) ou via "caixas automáticos de entrega" (a exemplo dos bancos 24 horas), podem melhorar 
a distribuição da produção durante o dia (evitando horários ociosos), melhorando a produtividade;

- A interação entre as linhas de frente e retaguarda melhora a comunicação com o cliente final (ex.: problemas de processamento de determinada peça dependem da autorização do cliente), aumentando a produtividade;

- O conceito de funcionários polivalentes (que atuam na linha de frente e retaguarda) trouxe melhora à produtividade do processo como um todo e redução de custos quando ocorre a ausência de funcionários; $\mathrm{e}$

- O treinamento específico da linha de frente para o reconhecimento de problemas nas peças antes do processamento, assim como a avaliação do tipo de tecido envolvido, facilitando a classificação, minimiza indenizações e custos de reprocessamento, aumentando a produtividade;

h) O inter-relacionamento entre a inovação organizacional (de modelo de negócio e linha de frente/retaguarda) e a competitividade:

- A implantação de programas de capacitação dos funcionários das linhas de frente e retaguarda gera estímulo e competitividade entre as equipes, aumentando a competitividade da lavanderia em relação à concorrência;

- Utilização de conceito "uma lavanderia dentro da outra", ou seja, como se houvesse uma filial com atendimento via telefone, internet, WhatsApp, dentre outros, aumentando o valor ao cliente final e melhorando a competitividade;

- Investimento no treinamento da linha de frente na melhora da interação no balcão (a lavanderia é um negócio de baixo a médio contato com o cliente), aumentando a empatia e fidelizando o cliente final;

- Instalação de filiais de lavanderias em condomínios, como um novo modelo de negócio para um público específico e concentrado, melhora a competitividade;

- A vinda de franquias internacionais de lavanderias trouxe um novo modelo de descentralização (cada lavanderia é um centro de serviços), aumentando o volume processado e as vendas;

- A adoção de modelos de negócios que ofereça um leque maior de serviços ao cliente (ex.: costura e reforma de roupas sob medida), em um só local, melhora a competitividade das lavanderias; 
- A organização diferenciada da linha de retaguarda, que deverá receber informações da linha de frente sobre as peças que serão processadas, melhorando a qualidade da lavagem com programas adequados e, consequentemente, aumentando a fidelização e ampliando o volume de peças por cliente;

- O modelo de especialização de serviços (por exemplo, lavagem de roupas finas) traz diferenciação e permite a prática de preços mais elevados, aumentando o faturamento e a lucratividade;

- A diferenciação da lavanderia começa na recepção do cliente pela linha de frente e termina na entrega do serviço finalizado (manuseio da roupa pelo delivery). Estas áreas são consideradas áreas-chave para o retorno do cliente e indicação a outros de seu relacionamento; $\mathrm{e}$

- A inovação por meio de delivery com horário pré-fixado (dia ou noite) e a adequação da dobra da roupa para viagens, além dos serviços dentro da residência (higienização de sofás e cortinas no local), melhoram a conveniência e aumentam a base de clientes e a competitividade;

i) O inter-relacionamento entre a adoção de mais de um tipo de inovação e a competitividade/produtividade:

- A adoção de vários tipos de inovação (processo, organizacional e marketing) traduz-se em serviço de melhor qualidade, aumentando o faturamento, a lucratividade e agregando valor ao cliente final;

- A adoção de vários tipos de inovação melhora a competitividade e produtividade, pois as lavanderias comunicam-se mais rapidamente com os clientes (aumentando a proximidade), e as falhas são corrigidas também mais rápido com as inovações adotadas, melhorando a produtividade;

- A adoção de inovações do "lado de dentro" da lavanderia (inovações de processo, marketing e organizacional) e do "lado de fora" (novos modelos de negócios gerando valor ao cliente) melhoram a produtividade e a competitividade;

- A inter-relação entre os diversos tipos de inovação no circuito da roupa dentro da lavanderia (catalogação, classificação e direcionamento ao processo de lavagem mais adequado) melhora a produtividade; 
- A adoção de mais de um tipo de inovação aumenta o valor agregado ao serviço final e reduz o custo de processamento e entrega, aumentando a lucratividade e a produtividade;

- Quanto mais as inovações interagem mais positivamente favorecem as lavanderias, porém devem ser implantadas passo a passo e nunca parar de inovar; - Quando ocorre o inter-relacionamento, uma inovação ajuda a outra, porém deve haver a preocupação de manter um ritmo contínuo de melhorias, gerando uma proposta de valor (qualidade, eficiência e credibilidade) mais clara ao cliente;

- Uma "mistura" entre os diversos tipos de inovação (tecnologia de máquinas, informática, modelo de negócio, sustentabilidade, processos mais rápidos, linha de frente mais preparada) gera crescimento do negócio (aumenta as vendas);

- O inter-relacionamento entre as inovações aumenta a produtividade e as vendas, já que existe um mix de novos conhecimentos que interagem entre si. Quanto maior o número de frentes inovadoras, melhores serão os resultados para o negócio;

- Nas diversas áreas, a pulverização das inovações permite atuar em várias frentes (uma inovação puxa a outra) e melhorar os resultados, pois, em alguns casos, a inovação única pode demorar.

\subsubsection{Evidências do Inter-Relacionamento a partir da Pesquisa Quantitativa (Respostas Ítem 7 do Questionário do Apêndice B)}

As respostas às questões do questionário de campo (Apêndice B) do ítem 7 referiam-se à adoção de mais de um tipo de inovação concomitantemente e sua relação com a competitividade e produtividade nas lavanderias domésticas.

A grande maioria dos respondentes (acima de 90\%) concordou com a existência de uma relação positiva entre a adoção de mais de um tipo de inovação (tecnológica, sustentabilidade, tecnologia da informação, de marketing, de modelo de negócio e da linha de frente/retaguarda) e a variáveis competitividade (vendas) e produtividade (vendas por funcionário). As opiniões dividiram-se entre "concordo totalmente" e "concordo em parte" e a média ponderada das respostas acima de 1,60 mostrou a tendência de escolha da maioria para essas duas tendências. 


\subsubsection{Desenvolvimento da Estrutura Conceitual (framework)}

Com base nas evidências de inter-relacionamento entre a adoção de mais de um tipo de inovação e as variáveis competitividade e produtividade a partir das pesquisas qualitativa e quantitativa (itens 4.3 .1 e 4.3.2) e também dos resultados dos testes das hipóteses $H_{1}$ a $H_{11}$, foi desenvolvida a estrutura conceitual (framework), conforme dados da Figura 64.

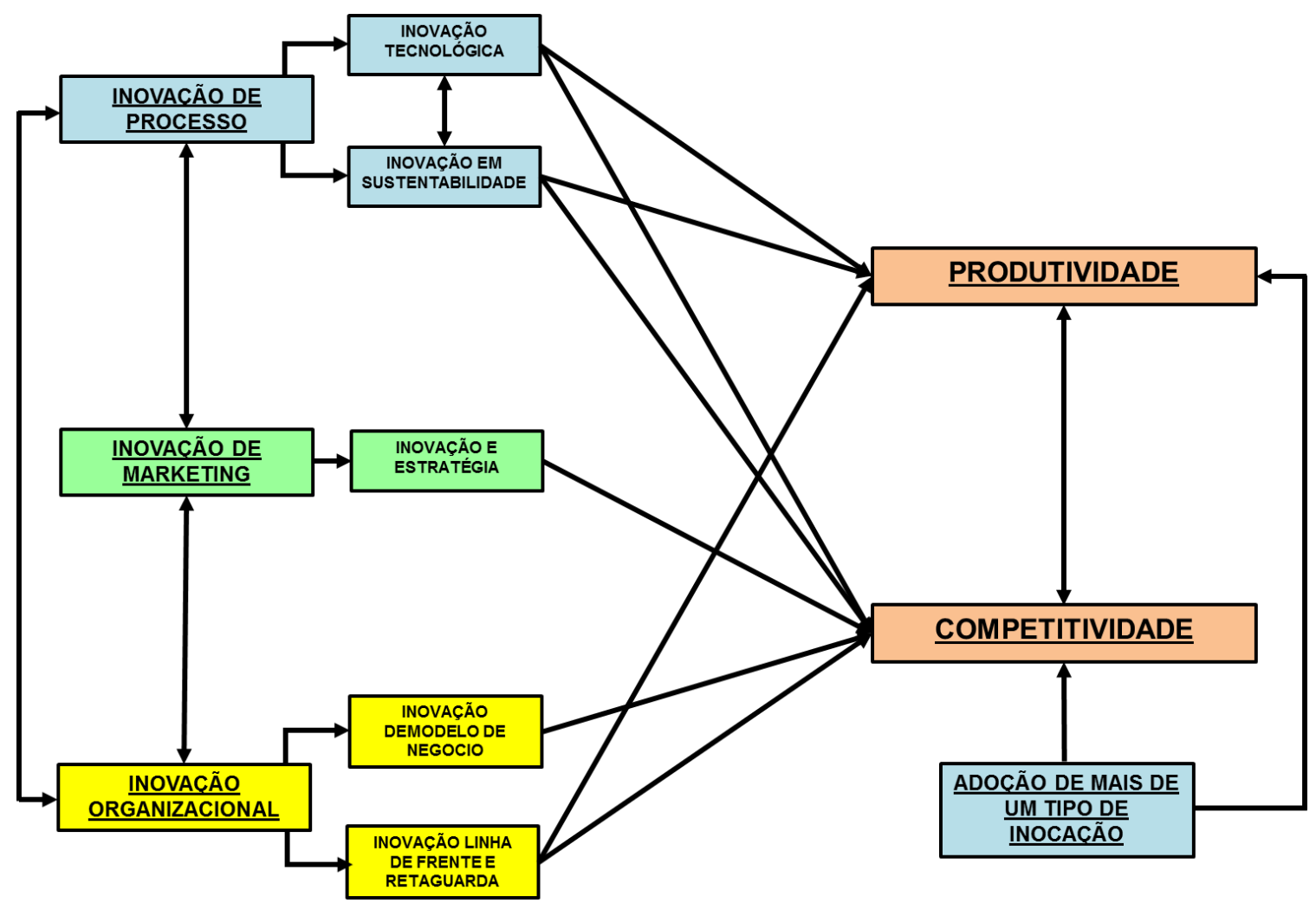

Figura 64: Framework proposto: interelacionamento entre os tipos de inovação e produtividade/competitividade em lavanderias domésticas

Elaborado pelo autor 


\section{CONCLUSÕES}

No presente estudo, o problema de pesquisa buscou entender, por meio do objetivo geral e três específicos, como ocorre a inovação no segmento de lavanderias domésticas, qual a tipologia típica de inovação adotada por essas empresas, se existe a adoção concomitante de vários tipos de inovação, como as inovações se inter-relacionam e, finalmente, qual a percepção dos proprietários de lavanderias sobre a relação entre os tipos de inovação, a competitividade (aumento de vendas) e a produtividade (vendas por funcionário) das empresas.

A contribuição da tese para a administração está ligada ao estímulo do estudo das micro e pequenas empresas de serviços e, de forma mais pontual, ao estudo dos pequenos negócios que prestam serviços pessoais a população. A pesquisa da percepção de valor pela adoção da inovação dos proprietários desse universo de empresas permite contribuir para desenvolvimento de futuros programas de fomento a inovação e entendimento dos tipos de inovação relevantes que contribuam para a melhora da competitividade e produtividade desses empreendimentos.

As conclusões quanto aos objetivos específicos delineados no ítem 1.4.2 e que sustentam as premissas básicas da tese, estão alicerçadas em:

a) Objetivo 1: constatar que existe a adoção de inovações de processo, marketing e organizacional no segmento das lavanderias domésticas e como essas inovações são manifestadas no ambiente na qual estão inseridas essas empresas;

b) Objetivo 2: verificar se existe influência das inovações citadas nos resultados das empresas, sendo escolhidas as variáveis competitividade (vendas) e produtividade (vendas por funcionário), como parâmetros para a análise dos referidos resultados; e

c) Objetivo 3: identificar se existe a adoção concomitante entre os tipos de inovação referenciados e as variáveis competitividade e produtividade. Se essas relações ocorrerem, demonstrar graficamente por intermédio de uma estrutura conceitual (framework). 


\subsection{Atendimento ao Objetivo Específico 1}

Constatou-se que a tipologia escolhida, oriunda da teoria, mostrou-se aderente às práticas de inovação das lavanderias domésticas, sendo necessário, no entanto, subdividir dois tipos de inovação escolhidos, adequando-se à realidade do segmento. A inovação de processo foi abordada por meio da inovação tecnológica (máquinas, produtos químicos e tecnologia da informação) e da inovação em sustentabilidade ambiental (ecoinovação). A inovação organizacional foi abordada pela inovação em modelo de negócio e na inovação da linha de frente e retaguarda.

A escolha dos tipos de inovação escolhidos da teoria, o inter-relacionamento dessas inovações e a relação com a competitividade e produtividade são aderentes às inovações adotadas pelas lavanderias domésticas em suas práticas. Da mesma forma, o estudo mostrou que a escolha de uma cidade de maior porte para a pesquisa quantitativa não permite que as conclusões possam ser estendidas às cidades menores (abaixo de 50 mil habitantes), pelas diferenças no acesso à tecnologia (maior em grandes cidades), pela precificação do serviço (maior em grandes cidades), pela abrangência geográfica (maior em cidades menores) e pela competição (maior em grandes cidades).

As práticas das lavanderias ratificam a escolha da tipologia estudada, com as seguintes particularidades:

a) Na inovação de processo existe um direcionamento quase unânime à inovação tecnológica pelo uso de novas tecnologias em máquinas e de produtos químicos diferenciados;

b) Na inovação de marketing, há um direcionamento à diferenciação pela qualidade dos serviços prestados e certa customização; e

c) Na inovação organizacional, o papel da linha de frente foi ressaltado, como conhecedora do fluxo dos processos internos e destacada a necessidade de inovar por meio da capacitação diferenciada dos funcionários (fornecendo maior abrangência no conhecimento do negócio). Da mesma forma, na linha de 
retaguarda, a inovação foi vinculada à capacitação, visando a melhorar a operação das novas tecnologias (automação e equipamentos de processo). A ênfase na produção em escala preconiza a boa interação entre as linhas de frente e de retaguarda. A citação da existência de novos modelos de negócios, como lavanderias com serviços on-line e retirada/entrega em condomínios, foi vinculada à diferenciação via conveniência ao cliente final e melhoria dos aspectos comerciais.

\subsection{Atendimento ao Objetivo Específico 2}

A escolha do valor das vendas (faturamento) e quanto representa o custo de um funcionário pelo volume de vendas foram indicadores, respectivamente, da competitividade e produtividade, adaptando-se à linguagem do segmento na expressão de seus resultados financeiros. As hipóteses formuladas relacionaram os tipos de inovação às variáveis competitividade e produtividade, assim como o resultado da pesquisa qualitativa (entrevistas semiestruturadas).

A premissa do objetivo 2, buscar como as inovações influenciam na competitividade e produtividade, foi atendida, porém, com ressalvas:

a) Os processos vinculados às inovações de processo (tecnológica e sustentabilidade ambiental) foram relacionados à melhora da competitividade (traduzida em aumento do faturamento), da lucratividade e da produtividade, esta última direcionada à redução da mão de obra operacional. Mas, houve poucas citações sobre o uso de embalagens recicláveis e economia de energia, indicando que a percepção do cliente final sobre algumas práticas relacionadas à ecoinovação como uma diferenciação, ainda é baixa. A maior ênfase é dada a fatores como custo e qualidade do serviço final entregue (indicados como aqueles que aumentam a competitividade);

b) O uso de tecnologia da informação foi vinculado ao aumento da produtividade (agilidade no processo, redução da mão de obra e melhor gerenciamento interno), mas houve poucas citações de uso da informação como ferramenta para o aumento 
da participação de mercado, ou seja, o uso estratégico para melhora da competitividade;

c) A adoção das inovações por meio de parcerias, sobretudo as inovações tecnológicas, confirma a teoria no que diz respeito à apropriação das tecnologias desenvolvidas por fornecedores para a melhoria dos processos internos, que impactam no aumento da competitividade e produtividade;

d) A prática de oferecer serviços diferenciados (inovação de marketing) por meio de customização ou atuação em nichos de mercado, foi relacionada a um aumento de lucratividade. Não foi possível verificar se esse aumento na lucratividade pela atuação em nichos impactou de modo relevante no faturamento global da empresa, já que, geralmente, a quantidade de clientes em nichos tem baixa participação em relação ao total de clientes;

e) A relação positiva entre a capacitação (como prática de inovação organizacional) da linha de frente e a produtividade foi constatada, visto que esse setor pode atuar como coodenador dos processos internos e como agente da integração com a linha de retaguarda;

h) A relação entre o uso de funcionários polivalentes (como prática de inovação organizacional) e a produtividade foi evidenciada. Mas, verificou-se certa preocupação pela atuação da linha de retaguarda no contato direto com o cliente, observando-se ser necessário treinamento específico para que não haja prejuízo do retorno do cliente à loja e, consequentemente, piora da competitividade;

i) A inovação na linha de retaguarda, por meio de treinamento direcionado a novas tecnologias ou ao aperfeiçoamento do fluxo de processo, foi relacionada ao aumento da produtividade. A formação desse expertise foi considerada necessária à operação dos novos equipamentos, assim como 0 aprofundamento de conhecimentos na área têxtil, em razão do aumento da diversidade de tecidos nas peças confeccionadas; 
j) $O$ aumento da competitividade, por meio da inovação em novos modelos de negócios, foi direcionado às mudanças organizacionais que levassem a uma melhor conveniência ao consumidor final, relacionada sobretudo à logistica de coleta, entrega e agilidade no processamento do serviço; e

k) A adoção de mais de um tipo de inovação concomitantemente e o interrelacionamento entre os diversos tipos de inovação foram considerados fatores importantes no ganho de competitividade e produtividade. Mas, não houve evidências de como seria a gestão de todos os tipos de inovação ao mesmo tempo, além do fato de que o tempo dispendido para a administração das inovações pode concorrer com as atividades diárias do empreendedor;

\subsection{Atendimento ao Objetivo Específico 3}

A existência de relações positivas entre a adoção de mais de um tipo de inovação ao mesmo tempo e a inter-relação entre os diferentes tipos com as variáveis competitividade e produtividade mostram a tendência dos proprietários de lavanderias à valorização da adoção das inovações, concomitantemente, nos diversos setores da empresa. Esta constatação pode indicar o direcionamento a uma distribuição dos investimentos em inovação nas diversas frentes, talvez de forma mais moderada em cada uma individualmente, exceto no caso de aquisição de novas máquinas, em que, geralmente, existe certa priorização no dispêndio de recursos.

O inter-relacionamento das inovações em lavanderias pode ser constatado não só entre as inovações que oferecem vantagens tecnológicas (ex.: tecnologia em máquinas e sustentabilidade), como, da mesma forma, entre inovações que promovem a mudança do modelo de negócios e o atingimento de uma vantagem mercadológica para um público específico (ex: atendimento com serviços on-line ou a estudantes universitários).

A força das ligações entre os diferentes tipos de inovações e entre estes e as variáveis competitividade e produtividade, dependerá, da mesma forma, da 
experiência que cada proprietário tenha nas diversas áreas abordadas. Empreendedores com histórico na área financeira preocupam-se de forma especial com resultados e competitividade (direcionamento às inovações de marketing e organizacional), ao passo que aqueles mais ligados à operação terão foco maior na produtividade (direcionamento às inovações tecnológicas).

O inter-relacionamento entre as inovações aumenta a produtividade e a competitividade, por gerar novos conhecimentos que interagem entre si, e quanto maior o número de inovações geradas melhores serão os resultados para o negócio. A adoção de inovações nas diversas áreas das empresas permite atuar diversificando as frentes de atuação e potencializando os resultados, o que poderia não ocorrer na adoção de uma só inovação.

O framework conceitual desenvolvido aponta as interações evidenciadas no presente estudo. Mas, deverá ser revisado à medida que outras relações forem observadas e novas pesquisas indicarem tipologias distintas. 


\section{LIMITAÇÕES DO ESTUDO}

A pesquisa quantitativa por meio de questionários pode levar consigo a incerteza de uma resposta condizente com a realidade vivida pelos empresários, em especial, pela falta de tempo para uma reflexão mais profunda. No presente estudo, observouse que o envolvimento dos empresários entrevistados nas questões operacionais do cotidiano (sobretudo os relacionados à logistica de entrega), pode ter levado a um afunilamento das respostas, direcionando-as à resolução dos problemas mais imediatos e prejudicando a visão dos benefícios da inovação no médio e longo prazos.

De forma geral, notou-se pouca disposição da maior parte dos entrevistados procurados em responder às questões, embora todos os contatos tenham sido efetuados via telefone, com explanação dos objetivos da pesquisa. Pouco mais de $23 \%$ dos entrevistados selecionados responderam à pesquisa quantitativa.

As entrevistas semiestruturadas indicaram que as respostas obtidas para a cidade de São Paulo podem ser influenciadas pelo ambiente competitivo entre as lavanderias do Município, e os resultados não necessariamente poderão ser considerados, como uma realidade para outras regiões do País, sobretudo quando relacionados ao tipo de público final atendido, à mão de obra disponível e à expectativa de valor.

Embora tenham experiência nacional no segmento de lavanderias, a contínua troca de informações entre os especialistas entrevistados na pesquisa qualitativa pode ter um viés de formação de uma opinião coletiva a respeito de alguns assuntos questionados. 


\section{RECOMENDAÇÕES PARA ESTUDOS FUTUROS}

O presente estudo teve por objetivo obter informações sobre a adoção da inovação em lavanderias domésticas, tomando-se uma amostra de lavanderias sem diferenciar se pertenciam ou não a uma rede de franquias internacional. Seria relevante investigar se as opiniões divergem entre os dois grupos, levando-se em conta que as redes internacionais poderiam ter, em alguns momentos, o privilégio de acesso às novas tecnologias que estão sendo introduzidas em nível mundial, antes das lavanderias independentes. Estas considerações devem ser contrabalançadas com o fato de que os fabricantes nacionais de equipamentos e produtos químicos estão respondendo rapidamente à introdução de novas tecnologias, por intermédio do desenvolvimento de equipamentos e produtos nacionais concorrentes.

Conforme já discutido, de acordo com as opiniões dos especialistas na pesquisa qualitativa, a localização da lavanderia em cidades de maior ou menor porte poderia mudar os resultados da pesquisa de campo. Dessa forma, seria relevante investigar os dois grupos, verificando se existem diferenças significativas entre regiões distintas.

Levando-se em conta o fato de existir atualmente baixo número de artigos que enfoquem serviços pessoais, seria importante pesquisar outros segmentos relacionados a esse tipo de serviço, de modo a ampliar a abrangência do modelo conceitual e validar as inter-relações e tipologias descritas no presente estudo.

A pesquisa bibliográfica evidenciou raros trabalhos acadêmicos que incluíam estudos relacionados à inovação nas micro e pequenas empresas que atuam em serviços pessoais. Quando existiam, foram citados somente como exemplos para classificação de serviços. Os fatos favorecem a ampliação do campo para aprofundamento do tema em trabalhos futuros.

Nem todos os resultados das questões formuladas na pesquisa quantitativa geraram hipóteses. Como aqueles que não geraram atingem áreas que podem ser relevantes ao entendimento da inovação como um todo nas lavanderias, seria importante revisitá-los e analisar, por exemplo, se existem relações positivas entre a adoção de 
energias alternativas (eólica e solar) e a redução de resíduos sólidos (ex.: embalagens) com a competitividade e produtividade dos negócios. 


\section{REFERÊNCIAS}

AAS, T.H.; PEDERSEN, P. E. The firm-level effects of service innovation: a literature review. International Journal of Innovation Management, v. 14, n. 5, p. 759-794, Oct. 2010.

ACS, Z. J.; AUDRETSCH, D. B. Innovation, market structure, and firm size. The Review of Economics and Statistics, v. 69, n. 4, p. 567-574, Nov. 1987.

Innovation in large and small firms: an empirical analysis. The American Economic Review, v. 78, n. 4, p. 678-690, Sep 1988.

ADAMS, R.; TRANFIELD, D.; DENYER, D. A taxonomy of innovation: configurations of attributes in healthcare innovations. International Journal of Innovation Management, v. 15, n .2, p. 359-392, April 2011.

ADES, C.; PLONSKI, G. A. Inovação em modelo de negócio e a visão integrada do portfólio de inovações. In: XII SEMEAD - Seminários em Administração, Ago. 2009, São Paulo. Anais... São Paulo: USP, 2009.

ALMEIDA, M. I. R.; MOREIRA JÚNIOR, A. L. A análise do ambiente organizacional na pequena empresa: um estudo em PME'S na cidade de São Paulo. In: Congresso Latino Americano de Estratégia, 2004, Itapema (SC). Anais... Itapema: SLADE, 2004.

AMARAL, V. W. et al. A percepção da inovação no contexto de serviços e sua influência na satisfação e lealdade do cliente. Revista Brasileira de Marketing REMark, v. 12, n. 1, p. 26-50, jan./mar. 2013.

ANDERSON, D. R; SWEENEY, D. J.; WILLIAMS, T. A. Estatística aplicada à administração e economia. São Paulo: Cengage Learning, 2011.

ANDREASSI, T. Gestão da Inovação Tecnológica. São Paulo: Thomson Learning, 2007.

ANEL (Associação Nacional das Empresas de Lavanderia). Disponível em: <http://www.anel.com.br/>. Acesso em: 01/08/2013.

ARAUJO, J. B.; ZILBER, S. N. Adoção de e-business e mudanças no modelo de negocio: inovação organizacional em pequenas empresas dos setores de comercio e serviços. Gestão \& Produção, v. 20, n. 1, p. 147-161, 2013.

ATUAHENE-GIMA, K. Market orientation and innovation. Journal of Business Research, v. 35, p. 93-103, 1996.

BANCO MUNDIAL. Conhecimento e inovação para a competitividade. Brasilia: CNI, 2008.

BARBIERI, J. C. et. al. Inovação e sustentabilidade: novos modelos e proposições. Revista de Administração de Empresas, São Paulo, v. 50, n. 2, p. 146-154, abr./jun. 2010. 
J. C. Organizações inovadoras: textos e casos brasileiros. Rio de Janeiro: Editora FGV, 2003.

BARRAS, R. Towards a theory of innovation in services. Research Policy, v. 15, p. 161-173, 1986.

BATTISTI, P. S.; VIGORENA, D. A. L.; ALVES, J. K. D. Análise dos obstáculos enfrentados pelo setor de serviços para a implementação da inovação segundo a Pintec (2008). In: XV SEMEAD - Seminários em Administração, Out. 2012, São Paulo. Anais... São Paulo: USP, 2012.

BERRY, L. L. et. al. Creating new markets through service innovation. MIT Sloan Management Review, reprint 47213, v. 47, n. 2, 2006.

BESSANT, J.; TIDD, J. Inovação e empreendedorismo. Porto Alegre: Bookman, 2009.

BETTENCOURT, L. A; BROWN, S. W.; SIRIANNI, N.J. The secret to true service innovation. Business Horizons, v. 56, p. 13-22, Jan-Febr 2013.

BOS-BROUWERS, H. E.; HILKE, E. J. Corporate Sustainability and Innovation in SMEs: Evidence of Themes and Activities in Practice. Business Strategy and the Environment, v.19, p.417-435, 2010.

BOURDON, I.; JAOUEN, A. Strategic innovation and information technology in microfirms. In: 56e Annual ICSB World Conference (International Council for Small Business), Jun 15-18, 2011, Stockholm, Sweden. Anais... Stockholm: ICSB.

BOWEN, J. Development of a taxonomy of services to gain strategic marketing insights. Journal of the Academy of Marketing Science, v. 18, n. 1, p. 43-49,1990.

BRITTO, J. Produtividade, Competitividade e Inovação na Indústria. Rio de Janeiro: UFRJ, Instituto de Economia, 2009.

BUTTOL, P. et al. Integrating services and tools in an ICT platform to support ecoinnovation in SMEs. Clean Techn Environ Policy, v. 14, p. 211-221, 2012.

CADWALLADER, S. et. al. Frontline employee motivation to participate in service innovation implementation. Journal of the Academy of Marketing Science, v. 38, n. 2, p. 219-239, 2010.

CAETANO, B. Oportunidades em meio à concorrência. Lavanderia \& Cia., n. 208, p. 44, jan/fev 2013.

CAINELLI, G.; EVANGELISTA, R.; SAVONA, M. Innovation and economic performance in services: a firm-level analysis. Cambridge Journal of Economics, v. 30, p. 435-458, 2006.

CHAGAS, A. T. T. O questionário na pesquisa científica. Administração On Line, v. 1, n. 1, Jan/Mar 2000. Disponível em: <http://www.fecap.br/adm_online/art11/ anival.htm>. Acesso em 28/09/2013. 
CHANG, C. M. The creation of novel and marketable service ideas. International Journal of Innovation and Technology Management, v. 8, n. 1, p. 113-133, 2011.

CHEN, W. Innovation in hotel services: culture and personality. International Journal of Hospitality Management, v. 30, p. 64-72, 2011.

CHENG, C. C. The role of service innovation in the market orientation - new service performance linkage. Technovation, v. 32, p. 487-497, 2012.

CHESBROUGH, H. Business model innovation: opportunities and barriers. Long Range Planning, N. 43, p. 354-356, 2010.

CHRISTENSEN, C. M.; ANTHONY, S. D.; ROTH, E. A. O futuro da inovação: usando as teorias da inovação para prever mudanças no mercado. Rio de Janeiro: Elsevier, 2007.

COELHO, F.; AUGUSTO, M. Job characteristics and the creativity of frontline service employees. Journal of Service Research, v. 13, n. 4, p. 426-438, 2010.

COOK, D. P.; GOH, C.; CHUNG, C. H. Service typologies: a state of the art survey. Production and Operations Management, vol. 8, n. 3, 1999.

CORRÊA, H. L.; CAON, M. Gestão de Serviços: lucratividade por meio de operações e de satisfação dos clientes. São Paulo: Atlas, 2002.

CURADO, M. A. S.; TELES, J. M. V.; MARÔCO, J. Análise estatística de escalas ordinais: aplicações na área de saúde infantil e pediatria. Enfermería Global, n. 30, Abril 2013.

DAMANPOUR, F.; WALKER, R. M.; AVELLANEDA, C. N. Combinative effects of innovation types and organizational performance: a longitudinal study of service organizations. Journal of Management Studies, v. 46, p. 650-675, June 2009.

DAVILA, T.; EPSTEIN, M. J.; SHELTON, R. As Regras da Inovação. Porto Alegre: Bookman, 2007.

DEL RÍO, P.; CARRILLO-HERMOSILLA, J.; KÖNNÖLA, T. Policy strategies to promote eco-innovation. Journal of Industrial Ecology, v. 14, n. 4, 2010.

DESMARCHELIER, B.; DJELLAL, F.; GALLOUJ, F. Environmental policies and ecoinnovations by service firms: an agent-based model, Technological Forecasting \& Social Change, 2012.

DESOUZA, K. C.; AMAZU, Y. Knowledge management at SMEs: five peculiarities. Journal of Knowledge Management, v. 10, n. 1, p. 32-43, 2006.

DOBNI, C. B. The relationship between an innovation orientation and competitive strategy. International Journal of Innovation Management, v. 14, n. 2, p. 331-357, 2010.

DÖRNER, N.; GASSMANN, O.; GEBAUER, H. Service innovation: why is so difficult to accomplish ? Journal of Business Strategy, v. 32, n. 3, p. 37-46, 2011. 
DREJER, I. Identifying innovation in surveys of services: a Schumpeterian perspective. Research Policy, v. 33, p. 551-562, 2004.

ELCHE-HOTELANO, M. D. E. Sources of knowledge, investments and appropriability as determinants of innovation: An empirical study in service firms. Innovation: Management, Policy \& Practice, v. 13, p. 220-235, 2011.

ETTLIE, J. E.; ROSENTHAL, S. R. Service versus Manufacturing Innovation. Journal of Product Innovation Management, v. 28, p. 285-299, Mar 2011.

EVANGELISTA, R. Sectoral patterns of technological change in services. Economics of Innovation and New Technology, 2000, v. 9, p. 183-221, 2000.

; SIRILLI, G. Innovation in the service sector: results from the italian statistical survey. Technological Forecasting and Social Change, n. 58, p. 251-269, 1998.

EUROPEAN COMISSION. Definition of micro, small and medium-sized enterprises. Disponível em: <http: //eur-lex.europa.eu/legal-content/EN/TXT/?qid= 1415127480435\&uri=URISERV:n26026>. Acesso em: 04/11/2014a.

Community Innovation Survey (CIS3). Disponível em: <http://epp.eurostat.ec.europa.eu/portal/page/portal/science_technology_innovation/ data/database>. Acesso em: 06/06/2014b.

FARIAS, R. M. Manual para lavanderias: a revolução na arte de lavar. Caixias do Sul, RS: Educs, 2006.

FERNANDEZ, S; PITTS, D. W. Understanding employee motivation to innovate: evidence from front line employees in United States Federal Agencies. The Australian Journal of Public Administration, v. 70, n. 2, p. 202-222, 2011.

FIESP (Federação das Indústrias do Estado de São Paulo). Inteligência de Mercado da Indústria / Canais de Comercialização. São Paulo: FIESP, 2010.

FIJAN, S.; FIJAN, R.; SOSTAR-TURK, S. Implementing sustainable laundering procedures for textiles in a commercial laundry and thus decreasing wastewater burden. Journal of Cleaner Production, n. 16, p. 1258-1263, 2008.

FITZSIMMONS, J.A; FITZSIMMONS, M.J. Administração de serviços: operações, estratégia e tecnologia da informação. 6 ed. Porto Alegre: Artmed, 2010.

FONSECA, J. S.; MARTINS, G. A. Curso de Estatística. 3 ed. São Paulo: Atlas, 1982.

FORSMAN, H. Innovation capacity and innovation development in small enterprises. A comparison between the manufacturing and service sectors. Research Policy, v. 40 p. 739-750, 2011.

; RANTANEN, H. Small manufacturing and service enterprises as innovators: a comparison by size. European Journal of Innovation Management, v. 14, n. 1, p. 27-50, 2011. 
; TEMEL, S. Innovation and Business performance in small enterprises: an enterprise-level analysis. International Journal of Innovation Management, v. 15, n. 3 p. 641-665, Jun 2011.

GALLOUJ, F. Towards a neo-Schumpeterian theory of innovation in services? Science and Public Policy, v. 24, n. 6, p. 405-420, Dec 1997.

Innovating in reverse: services and the reverse product cycle. European Journal of Innovation Management, v. 1, n. 3, p. 123-138, 1998.

Innovation in services and the attendant old and new myths. Journal of Socio-Economics, v. 31, p. 137-154, 2002.

GALLOUJ, F.; WEINSTEIN, O. Innovation in services. Research Policy, v. 26, p. 537-556, 1997.

GALLUCCI, L. A estratégia de coopetição como alternativa de sobrevivência ao crescimento das micro, pequenas e médias empresas do setor de lavanderia no Brasil. Lavanderia \& Cia, n.198, p. 32, mar/abr 2011.

Sustentabilidade ambiental: o que isso tem a ver com seu negócio. Lavanderia \& Cia, ano 33, n. 203, mar/abr 2012.

Buscar a Inovação Tecnológica é Fundamental. Lavanderia \& Cia, ano 34, n.209, mar/abr 2013.

GIANESI, I. G. N., CORRÊA, H. L. Administração estratégica de serviços: operações para a satisfação do cliente. São Paulo: Atlas, 1996.

GORDON, I. R.; MC CANN, P. Innovation, agglomeration, and regional development. Journal of Economic Geography, v. 5, p. 523-543, 2005.

GOVINDARAJAN, V. Os dez mandamentos da inovação estratégica: do conceito à implementação. Rio de Janeiro: Elsevier, 2006.

; GUPTA, A. K. Strategic innovation: a conceptual road map. Business Horizons, v. 44, p.3-12, Jul-Aug 2001.

GRAWE, S. J.; CHEN, H.; DAUGHERTY, P. J. The relationship between strategic orientation, service innovation, and performance. International Journal of Physical Distribution \& Logistics Management, v. 39, n. 4, p. 282-300, 2009.

GUIMARÃES, T. A.; RESENDE JUNIOR, P. C. Inovação em serviços: o estado da arte e uma proposta de agenda de pesquisa. In.: XXVI Simpósio de Gestão da Inovação Tecnológica, Nov. 2010, Vitória (ES). Anais... Vitoria: ANPAD, 2010.

GUNDAY G. et al. Effects of innovation types on firm performance. International Journal of Production Economics, v. 133, p. 662-676, 2011.

GÜNTHER, H. Como elaborar um questionário. Planejamento de Pesquisa nas Ciências Sociais (série n. 1). Brasilia: UnB, 2003. 
HAUKNES, J. Services Innovation, innovation in services. European Commission, through the Targeted Socio-Economic Research Programme (TSER), Services in European Innovation Systems (SI4S Final Report), August 1998.

HEISKANEN, E.; KASANEN, P.; TIMONEN, P. Consumer participation in sustainable technology development. International Journal of Consumer Studies, v. 29, n. 2, p.98-107, 2005.

; JALAS, M. Can services lead to radical eco-efficiency improvements?: a review of the debate and evidence. Corporate Social-Responsibility and Environmental Management, v. 10, n. 4, 2003.

HELLSTRÖM, T. Dimensions of environmentally sustainable innovation: the structure of eco-innovation concepts. Sustainable Development, v.15, p. 148-159, 2007.

HINE, D.; RYAN, N. Small service firms: creating value through innovation. Managing Service Quality, v. 9, n. 6, p. 411-422, 1999.

HIPP, C.; GRUPP H. Innovation in the service sector: The demand for servicespecific innovation measurement concepts and typologies. Research Policy, v. 34, p. 517-535, 2005.

HORTELANO, M. D. E; GONZÁLEZ-MORENO, A. Innovation in service firms: exploratory analysis of innovation patterns. Management Research, v. 5, n. 2 , p. 113-126, 2007.

HURMELINNA-LAUKKANEN, P.; RITALA, P. Protection for profiting from collaborative service innovation. Journal of Service Management, v. 21, n. 1, p. 624, 2010.

IBGE (INSTITUTO BRASILEIRO DE GEOGRAFIA E ESTATÍSTICA). As Micro e Pequenas Empresas Comerciais e de Serviços no Brasil 2001. Rio de Janeiro: IBGE, 2003. IBGE, 2007.

Classificação Nacional de Atividades Econômicas v.2.0. Rio de Janeiro: Pesquisa Anual de Serviços. Rio de Janeiro: IBGE, 2010. Anual.

2011.

. Estatísticas do Cadastro Central de Empresas. Rio de Janeiro: IBGE,

IPEA (INSTITUTO DE PESQUISA ECONÔMICA E APLICADA). Estrutura e Dinâmica do Setor de Serviços no Brasil. Org.: João Alberto De Negri, Luis Claudio Kubota. 502 p. Brasília: IPEA, 2006.

JACOBINI, M. L. P. Metodologia do trabalho acadêmico. 4 ed. Campinas (SP): Alínea, 2011.

JOHNSON, M. W.; CHRISTENSEN, C. M.; KAGERMANN, H. Reinventing your business model. Harvard Business Review, Dec. 2008. 
JONG, J. P. J. et. al. Innovation in service firms explored: what, how and why ? Literature review. EIM Business and Policy Research, Strategic Study B200205, Zoetermeer, Jan 2003.

JONG, J. P. J.; VERMEULEN, P. A. M. Organizing successful new service development: a literature review. Management Decision, 41/9, p. 844-858, 2003.

KANDAMPULLY, J. Innovation as the core competency of a service organisation: the role of technology, knowledge and networks. European Journal of Innovation Management, v. 5, n. 1, p. 18-26, 2002.

KANG, $\mathrm{H}$. Technology management in services: knowledge-based vs. knowledgeembedded services. Strategic Change, v. 15, p. 67-74, 2006.

KELLOGG, D. L.; NIE. W. A framework for strategic service management. Journal of Operations Management, v. 13, p. 323-337, 1995.

KLEMENT, C. F. F.; YU, A. S. O. Inovação em serviços: estudo de casos de inovação tecnológica em uma organização hoteleira. In: XXXII Encontro da ANPAD. Rio de Janeiro. Anais... Rio de Janeiro (RJ): ANPAD, 2008.

KLEWITZ, J.; ZEYEN, A.; HANSEN, E. G. Intermediaries driving eco-innovation in SMEs: a qualitative investigation. European Journal of Innovation Management, $v$. 15, n. 4, p. 442-467, 2012.

KON, A. Economia de serviços: teoria e evolução no Brasil. Rio de Janeiro: Elsevier, 2004.

LAFORET, S. A framework of organisational innovation and outcomes in SMEs. International Journal of Entrepreneurial Behaviour \& Research, v. 17, n. 4, p. 380-408, 2011.

LAGES, C. R.; PIERCY, N. F. Key Drivers of Frontline Employee Generation of ideas for customer service improvement. Journal of Service Research, v. 15, n. 2, p. 215230, 2012.

LAITALA, K.; KLEPP, I. G.; BOKS, C. Changing laundry habits in Norway. International Journal of Consumer Studies, v. 36, p. 228-237, 2012.

; BOKS, C.; KLEPP, I. G. Potential for environmental improvements in laundering. International Journal of Consumer Studies, v. 35, p. 254-264, 2011.

LAM, A. Organizational Innovation. Munich Personal Repec Archive, N. 11539, April 2004.

LAUNDRY AND CLEANING NEWS INTERNATIONAL. Finding plenty of positives for the textile care sector. Spotlight on Latin America Section. Foots Cray (United Kingdom), v.34, n.11, p.9, Nov 2012.

LAVANDERIA \& CIA. Empresarios apostam em novo modelo de lavanderia, a Limelocker. São Paulo: Editora Hermano, v. 212, p. 18, set/out 2013. 
LOVELOCK, C. H. Classifying services to gain strategic marketing insights. Journal of Marketing, v. 47, p. 9-20, 1983.

. Product plus: produto + serviço = vantagem competitiva. São Paulo: Makron Books, 1995.

. Services marketing. 3 ed. New Jersey: Prentice Hall, 1996.

MANSURY, M. A.; LOVE, J. H. Innovation, productivity and growth in US business services: a firm-level analysis. Technovation, v. 28, p. 52-62, 2008.

MANZINI, E. J. Entrevista semi-estruturada: análise de objetivos e de roteiros. In: Seminário Internacional sobre Pesquisas e Estudos Qualitativos, 2, 2004, Bauru. A pesquisa qualitativa em debate. Anais... Bauru, USC, 2004.

MARTÍNEZ-ROMÁN, J. A.; GAMERO, J.; TAMAYO, J. A. Analysis of innovation in SMEs using an innovative capability-based non-linear model: a study in the province of Seville (Spain), Technovation, v. 31 p. 459-475, 2011.

MARTINS, P. E. M. Administração brasileira: uma disciplina em construção. Vieira, M. M. F.; Zouain, D. M (Org.). Pesquisa qualitativa em administração: teoria e prática. Rio de Janeiro: Editora FGV, 2005.

MASSA, S.; TESTA, S. Innovation and SMEs: misaligned perspectives and goals among entrepreneurs, academics, and policy makers. Technovation, v. 28, p. 393407, 2008.

MC DERMOTT, C. M.; PRAJOGO, D. Service innovation and performance in SMEs. International Journal of Operations \& Production Management, v. 32, n. 2, p. 216-237, 2012.

; KANG, H.; WALSH, S. A framework for technology management in services. IEEE Transactions on Engineering Management, v. 48, n. 3, Aug 2001.

MELLO, C. H. P.; CHIMENDES, V. C. G. Análise de três modelos de referência para o projeto e desenvolvimento de serviços. In: XXVI ENEGEP Encontro Nacional de Engenharia de Produção, 2006, Fortaleza (CE). Anais... Fortaleza: ENEGEP, 2006.

MELTON, H. L.; HARTLINE, M. D. Customer and frontline employee influence on new service development performance. Journal of Service Research, v. 13, n. 4, p. 411-425, 2010.

MENDONÇA, E. Concorrência vem de Fora. Revista H\&C. São Paulo (SP). Ano IV, n. 18, p. 79-80, Jan/Fev 2003.

. Balanço: De Volta às Compras. Revista H\&C, São Paulo (SP), v. 11, n. 61, p. 60-62, Mai/Jun 2010.

MINISTERO DELLO SVILUPPO ECONOMICO/ISTITUTO NAZIONALE PER IL COMMERCIO ESTERO. Brasile: II mercato di macchine per lavanderia e stireria. Italia: 2011. 
MIOZZO, M., SOETE, L. Internationalization of services: a technological perspective. Technological Forecasting and Social Change, n. 67, p. 159-185, 2001.

MITCHELL, D.; COLES, C. The ultimate competitive advantage of continuing business model innovation. Journal of Business Strategy, v. 24, n. 5, p. 15-21, 2003.

MTE (Ministério do Trabalho e Emprego). PDTE (Programa de Disseminação de Estatísticas do Trabalho). Brasília: MTE/PDTE, 2013.

NIJSSEN, E. et. al. Exploring product and service innovation similarities and differences. International Journal of Research in Marketing, v. 23, p. 241-251, 2006.

MANUAL DE OSLO. Manual de Oslo: diretrizes para coleta e interpretação de dados sobre inovação. 3a․ ed. Trad.: FINEP, 2005. Disponível em www.finep.org.br.

OCDE (ORGANIZAÇÃO PARA COOPERAÇÃO E DESENVOLVIMENTO ECONÔMICO). Promoting Innovation in Services. Paris: OECD Publishing, 2005.

OKE, A. Innovation types and innovation management practices in service companies. International Journal of Operations \& Production Management, v. 27, n. 6, p. 564-587, 2007.

OKE, A.; BURKE G.; MYERS A. Innovation types and performance in growing UK SMEs. International Journal of Operations \& Production Management, v. 27, n. 7, p. 735-753, 2007.

OMACHONU, V. K.; EINSPRUCH, N. B. Innovation: implications for goods and services. International Journal of Innovation and Technology Management, v. 7, n. 2 p. $109-127,2010$.

O'REGAN, N.; GHOBADIAN, A. Innovation in SMEs: the impact of strategic orientation and environmental perceptions. International Journal of Productivity and Performance Management, v. 54, n. 2, p. 81-97, 2005.

OSTERWALDER, A.; PIGNEUR, Y. Clarifying business models: origins, present and future of the concept. Communications of the Association for Information Systems, v. 16, p. 1-25, 2005.

PALOVITA, A.; JÄRVI, P. Environmental value chain management of laundry detergents in the use phase. International Journal of Consumer Studies, v. 32, p. 607-612, 2008.

PARTANEN, J.; CHETTY, S. K.; RAJALA, A. Innovation types and network relationships. Entrepreneurship Theory and Practice, May 2011.

PASWAN, A.; D'SOUZA, D.; ZOLFAGHARIAN, M.A. Toward a contextually anchored service innovation typology. Decision Sciences, v. 40, n. 3, August 2009.

PAVITT, K. Sectoral patterns of technical change: towards a taxonomy and a theory. Research Policy, v. 13, n. 6, p. 343-373, 1984. 
PEQUENAS EMPRESAS, GRANDES NEGÓCIOS. Agua, sabão e lucros. São Paulo: Ed. Globo, n. 128, Ano XI, p.26-33, setembro/1999.

PERANI, G.; DEL SANTO, A. Statistical surveying of scientific research and technological innovation in services: methodological problems from ISTAT surveys. In: 13th Voorburg Group Meeting on Service Statistics, 21-24 Sep.1998, Rome. Anais... Rome: ISTAT, 1998.

PEREIRA, M. F. et. al. Fatores de inovação para a sobrevivência das micro e pequenas empresas no Brasil. Revista de Administração e Inovação, v. 6, n. 1, p. 50-65, 2009.

PIEMONTE, L. A. Gestão para Inovar: Como Integrar a Gestão Convencional, orientada ao Desempenho, com os Novos Requisitos de Inovação e Foco no Cliente. São Paulo: Portal Editora, 2010.

PINTEC (Pesquisa Industrial de Inovação Tecnológica) 2005. Disponível em: <http://www.pintec.ibge.gov.br>. Acesso em: 27/07/2014.

PORTER, M. E. A vantagem competitiva das nações. Rio de Janeiro: Campus, 1993.

RADONS, D. L. et al. Vantagem competitiva das empresas: qual a influência da inovação verde ? In: XV SEMEAD - Seminários em Administração, Out. 2012, São Paulo. Anais... São Paulo: USP, 2012.

REIS, G. M.; RIBEIRO JÚNIOR, J. I. Comparação de testes paramétricos e nãoparamétricos aplicados em delineamentos experimentais. In: Simpósio Acadêmico de Engenharia de Produção, Nov. 2007, Viçosa (MG). Anais... Viçosa: III SAEPRO, 2007.

RENNINGS, K. Redefining innovation: eco-innovation research and the contribution from ecological economics. Ecological Economics, v. 32, p. 319-332, 2000.

RIDDLE, D. I. Service innovation: questions and answers. Service Growth Consultants Inc., p.1-7, 2008.

ROCHA, H.M; DELAMARO; M.C. Abordagem metodológica na análise de dados de estudos não-paramétricos, com base em respostas em escalas ordinais. Gestão da Produção, Operações e Sistemas, ano 6, ํำ 3, p.77-91, Jul-Set/2011.

ROSENBUSCH, N.; BRINCKMANN, J.; BAUSCH, A. Is innovation always beneficial? A meta-analysis of the relationship between innovation and performance in SMEs. Journal of Business Venturing, v. 26, p. 441-457, 2011.

ROTHKOPF, M. WALD, A. Innovation in commoditized services: a study in the passenger airline industry. International Journal of Innovation Management, v. 15, n. 4, p. 731-753, Aug 2011.

ROWLEY, J.; BAREGHEH A.; SAMBROOK S. Towards an innovation-type mapping tool. Management Decision, v. 49, n. 1, p. 73-86, 2011. 
ROY, R. Sustainable product-service systems. Futures, v. 32, p. 289-299, 2000.

SANCHES, C.; MEIRELES, M.; DE SORDI, J. O. Análise qualitativa por meio da lógica paraconsistente: método de interpretação e síntese de informação obtida por escalas Likert. In: III Encontro de Ensino e Pesquisa em Administração e Contabilidade. João Pessoa:. Anais... João Pessoa: EnEPQ, 20-22/Nov2011.

SAPPRASERT, K.; CLAUSEN, T. H. Organizational innovation and its effects. Industrial and Corporate Change, v. 21, n. 5, pp. 1283-1305, 2012.

SCHEUING, E. E; JOHNSON, E. M. A proposed model for new service development. The Journal of Services Marketing, vol. 3, n. 2, 1989.

SCHLEIMER, S. C.; SHULMAN, A. D. A Comparison of new service versus new product development: configurations of collaborative intensity as predictors of performance. Journal of Product Innovation Management, v. 28, p. 521-535, 2011.

SCHMENNER, R. W. How can service businesses survive an prosper ? Sloan Management Review, 27:3, p. 21, 1986.

SCHULTE $\beta$, P. et. al. Innovating for and with your service customers: An assessment of the current practice of collaborative service innovation in Germany. Procedia Social and Behavioral Sciences, v. 2, p. 6503-6515, 2010.

SCHUMPETER, J. A. Capitalism, socialism and democracy. New York: Harper and Brothers, 1942.

SEADE (FUNDAÇÃO SISTEMA ESTADUAL DE ANÁLISE DE DADOS). Pesquisa da Atividade Econômica Paulista (Paep). Org.: Silvia Anette Kneip. Brasília: SEADE, 2001.

SEBORA, T. C.; HARTMAN, E. A.; TOWER, C. B. Innovative activity in small businesses: competitive context and organization level. Journal of Engineering and Technology Management, v. 11, p. 253-272, 1994.

SEBRAE (SERVIÇO BRASILEIRO DE APOIO ÀS MICRO E PEQUENAS EMPRESAS). Disponível em: sustentabilidade.sebrae.com.br/Sustentabilidade/Neg\%C3\%B3cios-desucesso/Lavanderia-Prillav. Acesso em: 07/03/2015.

=4154. Acesso em: 04/11/2014.

Anuário das Pesquisas sobre as Micro e Pequenas Empresas (2011). Brasilia: SEBRAE, 2012a.

Book de Pesquisas sobre MPEs Paulistas. São Paulo: SEBRAE, 2012b.

O que pensam as micro e pequenas empresas sobre sustentabilidade.

Brasilia: SEBRAE, 2012c. 
As Pequenas Empresas do Simples Nacional. Brasilia: SEBRAE, 2011.

SHAW, S. W. Investment and competition from boom to recession: a case study in the processes of competition: the drycleaning industry. The Journal of Industrial Economics, v. 21, n. 3, p. 308-324, Jul., 1973.

SHOSTACK, G. L. Designing services that deliver. Harvard Business Review, $p$. 133-139, january-february 1984.

SHOVE, E. Sustainability, system innovation and the laundry. Department of Sociology, Lancaster University, p.1-12, May 2002.

SINDILAV (Sindicato Intermunicipal de Lavanderias no Estado de São Paulo). Disponível em: <http://www.sindilav.com.br/>. Acesso em: 09/07/2013. nov. 2009.

Pesquisa Habitos dos usuários de lavanderias. GS \& MD Gouvêa de Souza,

SINSHEIMER, P; LATIF, A. The viability of professional wet cleaning as a pollution prevention alternative to perchloroethylene dry cleaning. Journal of the Air \& Waste Management Association, v. 57, n. 2, p. 172-178, Feb 2007.

SIRILLI, G.; EVANGELISTA, R. Technological innovation in services and manufacturing: results from Italian surveys. Research Policy, v. 27, p. 881-899, 1998.

SLUISMANS et. al. Strategy and innovation in SMEs: three profiles of innovating SMEs. In: Industrial Engineering Research Conference. 2009. Anais... Miami: 30 May-3 June.

STEVENSON, W. J. Estatística aplicada à administração. São Paulo: Harper \& Row do Brasil, 1981.

SUNDBO, J. The balancing of empowerment: a strategic resource based model of organizing innovation activities in service and low-tech firms. Technovation, v. 16, n. 8, p. 397-409, 1996.

. Management of innovation in services. The Service Industries Journal, v.

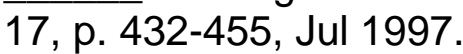

Innovation and strategic reflexivity: an evolutionary approach applied to services. In: SHAVININA, L. V (editor). The International Handbook on Innovation. Oxford: Elsevier, 2003.

TAMURA, S. et. al. Enhancing the performance of the services sector. OECD Publishing, Chapter 6, p. 133-175, 2005.

TEBOUL, J. Serviços em cena: o diferencial que agrega valor ao seu negócio. Brasilia: IEL/NC, 2008.

TIDD, J.; BESSANT, J.; PAVITT, K. Gestão da Inovação. 3 ed. Porto Alegre: Bookman, 2008. 
VARGAS, E. R.; Relação entre estratégia e Inovação em serviços: análise de casos no setor hospitalar. Revista O\&S, v. 14, n. 40, 2007.

; ZAWISLAK, P. A. Inovação em serviços no paradigma da economia do aprendizado: a pertinência de uma dimensão espacial na abordagem dos sistemas de inovação. Revista de Administração Contemporânea (RAC), v. 10, n. 1, Jan./Mar. 2006.

VASCONCELLOS, L. H. R.; MARX, R. Como ocorrem as inovações em serviços? Um estudo exploratório de empresas no Brasil. Gestão \& Produção, São Carlos, v. 18, n. 3, p. 443-460, 2011.

VEJA SÃO PAULO. Lavanderia Ecológica: com ações sustentáveis, rede ganha prêmio da Fundação Getulio Vargas. São Paulo: Ed. Abril, ed. 2195, ano 43, n. 50, p. $77,15 / 12 / 2010$.

Limpeza moderna: lavanderias investem em self service e agendamento por internet. São Paulo: Ed. Abril, n. 2391, p.60, 17/09/2014.

VERMA, R. An empirical analysis of management challenges in service factories, service shops, mass services and professional services. International Journal of Service Industry Management, v. 11, n. 1, p. 8-25, 2000.

VIEIRA, K. M.; DALMORO, M. Dilemas na construção de escalas tipo Likert: o número de itens e a disposição influenciam nos resultados? In: XXXII Encontro da ANPAD, Set. 2008, Rio de Janeiro (RJ). Anais... Rio de Janeiro: ANPAD, 2008.

WALKER, R. M. An empirical evaluation of innovation types and organizational and environmental characteristics: towards a configuration framework. Journal of Public Administration Research and Theory, v. 18, p. 591-615, 2007.

YANG, X.; JAYASHREEL; MARTHANDAN, J. Ideal types of strategic innovation: an exploratory study of chinese cosmetic industry. International Journal of Business and Management, v. 7, n. 17; 2012.

ZAGLER, M. Services, innovation and the new economy. Structural Change and Economic Dynamics, v. 13, p. 337-355, 2002.

ZEITHAML, V; Bitner, M. Marketing de serviços: a empresa com foco no cliente. 5 ed. Porto Alegre: Bookman, 2011.

ZMOGINSKI, A. S. et al. Co-criação de valor: inovação no modelo de negócio obtendo vantagem competitiva. Revista Jovens Pesquisadores, ano VI, n. 10,. jan./jul. 2009.

ZOLFAGHARIAN, M.; PASWAN, A. Do consumers discern innovations in service elements? Journal of Services Marketing, v. 22, n. 5, p. 338-352, 2008. 


\section{APÊNDICES}

\section{APÊNDICE A - Instrumento de Pesquisa - Questionário para a pesquisa prévia por meio de entrevistas semiestruturadas com especialistas e consultores do segmento de lavanderias (perguntas abertas e fechadas) e resultados obtidos com cada entrevistado}

\section{Questionário Pesquisa Prévia (Entrevistas Semiestruturadas)}

Nome:

Entidade/Empresa:

Cargos ocupados:

1) Diferenças da Localização Geográfica entre Lavanderias Domésticas (tamanho das cidades)

1.1) Existem diferenças entre lavanderias instaladas em grandes centros urbanos/capitais e as demais cidades? Quais são?

2) Inovação Geral

Definições gerais a serem usadas:

Definição de Inovação (Manual de Oslo, 2005): "Uma inovação é a implementação de um produto (bem ou serviço) novo ou significativamente melhorado, ou um processo, ou um novo método de marketing, ou um novo método organizacional nas práticas de negócios, na organização do local de trabalho ou nas relações externas".

Medida de produtividade: vendas por funcionário

Medida de competitividade: vendas

2.1) Em sua opinião, quais são as áreas onde uma lavanderia pode inovar?

2.2) Estas inovações trouxeram melhora na produtividade e competitividade das lavanderias domésticas?

3) Inovação de Processo

Definição de Inovação de Processo (Manual de Oslo, 2005): "...envolve métodos, equipamentos e/ou habilidades para o desempenho dos serviços novos ou substancialmente melhorados...".

3.1) Quais foram as inovações no processamento das roupas e entrega do serviço final em lavanderias domésticas mais expressivos nos últimos 10 anos?

Inovação em Sustentabilidade Ambiental

Definição de Sustentabilidade do Meio Ambiente ou Ecoinovação (RENNINGS, 2000): "todas as medidas de atores relevantes que desenvolvem novas ideias, comportamentos, produtos e processos, e os aplicam ou introduzem para contribuir com a redução das cargas ambientais ou direcionam para objetivos ecológicos específicos".

3.2) Quais as inovações em sustentabilidade ambiental ou ecoinovação dos últimos $\mathbf{1 0}$ anos? Estas inovações trouxeram melhora à produtividade para as lavanderias? 
3.3) As práticas relacionadas à sustentabilidade ambiental (ecoinovação), como reúso de águas, uso de produtos quimicos biodegradáveis, uso de embalagens sustentáveis e processos de lavagem menos agressivos (p.ex.: wetcleaning, hidrocarbonetos) podem aumentar a base de clientes ou propiciar maior retorno de clientes atuais?

Inovação Tecnológica em Serviços

Definição de Inovação Tecnológica (DAMANPOUR, WALKER; AVELLANEDA, 2009): "novos elementos introduzidos no sistema de produção da organização ou operação de serviço para produção de seus serviços aos clientes".

3.4) Quais tipos de inovações tecnológicas são utilizados pelas lavanderias domésticas?

3.5) Quais são as vantagens de se utilizar inovações tecnológicas (equipamentos, produtos quimicos e tecnologia da informação) para as lavanderias domésticas?

4) Inovação de Marketing

Definição de Inovação de Marketing (Manual de Oslo, 2005): "...é a implementação de um novo método de marketing com mudanças significativas na concepção do produto ou em sua embalagem, no posicionamento do produto, em sua promoção ou na fixação de preços"

4.1) Como a inovação de marketing pode aumentar a competitividade?

5) Inovação Organizacional

Definição de Inovação Organizacional (Manual de Oslo, 2005): "...é a implementação de um novo método organizacional nas práticas de negócios da empresa, na organização do seu local de trabalho ou em suas relações externas". Inclui a redução de custos administrativos, satisfação e produtividade no trabalho.

Inovação de Modelo de Negócio

Definição de Inovação de Modelo de Negócio (DAVILA, EPSTEIN E SHELTON, 2007): "a maneira pela qual a empresa cria, vende e proporciona valor a seus clientes"

5.1) Como as lavanderias podem aumentar suas vendas por meio de novas maneiras de gerar valor a seus clientes (novos modelos de negócio)?

Inovação no Processo de Recepção e Entrega do Serviço (Linha de Frente e de Retaguarda)

5.2) Qual a participação das linhas de frente e de retaguarda na inovação em lavanderias domésticas?

5.3) E no aumento de vendas?

5.4) E na produtividade?

6) Adoção de mais de um Tipo de Inovação e o Inter-relacionamento entre eles

6.1) Existe diferença entre lavanderias que adotam mais de um tipo de inovação ao mesmo tempo daquelas que adotam um só tipo de inovação?

6.2) As inovações inter-relacionam-se para melhorar a produtividade e o aumento das vendas (inovação em sustentabilidade, tecnológica, de marketing, de modelo de negócio e nas linhas de frente e de retaguarda)? 


\section{Resultados Obtidos com Cada Entrevistado}

\section{Localização Geográfica das Lavanderias}

\section{Adriano de Almeida Gonçalves}

- Sim, existem diferenças entre lavanderias de grandes centros urbanos e demais cidades. Pelas características de ritmo de vida, temos os serviços de delivery (entrega no domicílio) mais difundidos e profissionalizados, com softwares de gestão e formas de pagamento mais convenientes; $\mathrm{e}$

- Outra diferença é a maior presença em grandes cidades de novas tecnologias como lavagem a seco com diversos tipos de solventes e o wet cleaning (tecnologia que usa pouca água e aditivos), haja vista que esse tipo de serviço precisa de maquinas com manutenção exclusivas, mais presentes em grandes centros urbanos, sobretudo, São Paulo.

\section{José Carlos Larocca}

- Lavanderia no Brasil está atrelada à capacidade econômica do usuário (somente $4 \%$ da população acessam a lavanderias e com poder aquisitivo mais elevado); e

- Lavanderia doméstica funciona bem com cidades de, no mínimo, 50 mil habitantes.

\section{Othon Barcellos}

- Cidades acima de 200 mil habitantes são muito semelhantes a capitais (lojas operam de maneira semelhante); e

- Nas cidades menores, ainda existem lavanderias mais simples, que vão se modernizando paulatinamente.

\section{$\underline{\text { Rui Sérgio Torres }}$}

- A principal diferença é a verticalização na prestação do serviço. Lavanderias em grandes centros conseguem terceirizar vários serviços (ex.: lavagem de tapetes, edredons, couro). As lavanderias do interior devem ser especializados também nesses serviços, adquirindo, muitas vezes, um grau de conhecimento maior que as lavanderias nos grandes centros e, geralmente, têm uma área menor para essa 
verticalização. Nos grandes centros, as lavanderias estão ficando cada vez menores;

- Com relação a fornecedores, os mesmos atendem a todo o País; e

- Com relação à política de preços, nos grandes centros, os preços tendem a ser mais elevados que no interior.

\section{Alaor Chiodin}

- A diferença básica entre lavanderias dos grandes centros e do interior é o público que pretende atender. Lavanderias dos grandes centros e cidades maiores tem faturamento maior (maior número de peças e melhor nível de preço), e as lojas normalmente são mais elaboradas;

\section{Cláudia Cristina dos Santos Diniz Meirelles}

- Sim, no passado havia diferenças entre as lavanderias a depender do tamanho da cidade, mas hoje foram reduzidas (influência das franquias que foram para o interior dos Estados);

- Número de lavanderias em cidades do interior aumentou em número e algumas unidades (poucas) com melhor tecnologia de equipamentos, porém a tecnologia de ponta ainda está concentrada nas grandes cidades; e

- Quem está nas grandes cidades ou capitais está melhor assistido tecnicamente, pois o treinamento e fornecedores estão mais próximos.

\section{Maria Ramos Soares}

- As lavanderias em grandes centros têm mais acesso a novidades, atualizações, novos equipamentos e custos menores (menor despesa com transportes e no recebimento de produtos e equipamentos).

\section{José Carlos Miranda}

- Por exemplo no Estado de São Paulo, existem três grandes polos além da cidade de São Paulo: São José dos Campos, Campinas, Sorocaba e região. Depende da cidade que estiver fora dos polos, pois podem ser cidades ainda grandes que comportam lavanderias com boa localização, perto das classes A, B e C (público alvo das lavanderias domésticas). Cidades com 100 mil habitantes já comportam 
uma lavanderia com características parecidas com os grandes centros, mas algumas cidades específicas ainda menores têm boas lavanderias.

\section{Arnaldo Afonso Moreira}

- Deveria haver diferença pela localização geográfica, mas hoje não existe tanta diferença como no passado. Os recursos chegam mais rápido até às lavanderias fora dos grandes centros, as franquias têm conseguido atingir uma fatia grande desse mercado e a tecnologia tem estado mais próxima a essas regiões (a internet ajudou a aproximar). Hoje, existem lavanderias que faturam bem nessas cidades, porque não existe a mesma concorrência que as grandes cidades.

\section{Ludmila Viana}

- A diferença entre lavanderias de grandes cidades e as outras é que, nas grandes cidades, é preciso focar nos bairros próximos da sua unidade e também optar por alguns bairros. Lavanderias em cidades pequenas podem atender à cidade inteira.

\section{Inovação Geral}

\section{Adriano de Almeida Gonçalves}

- As lavanderias podem inovar em tecnologia de lavagem, tal a profusão de formas que usam pouca água ou mesmo nenhuma. Existem ainda máquinas que reciclam a própria água de enxague num sistema interno;

- Pequenas centrais de tratamento de água para reuso que podem fazer a diferença em casos de falta de abastecimento das concessionárias.

-A passadoria de roupas é outro segmento que se desenvolve muito rápido cada vez com menor uso de mão de obra e ferros de passar; e

- Não há dúvidas que essas inovações trouxeram melhora na produtividade e competitividade, mas há que se ter um estudo prévio se a massa crítica envolvida compensa a migração para as novas tecnologias, que exigem investimento inicial alto e uma manutenção mais cara. 
José Carlos Larocca

- A lavanderia pode inovar básicamente em atendimento, pois o cliente se propõe a pagar mais por qualidade, atendimento e um bom pós-venda (ex.: retirada de manchas);

- Lavanderia doméstica não é produção em série, e sim peça a peça e muitas delicadas. Nem sempre é possível mensurar a produtividade, pois é necessário a qualidade; e

- A melhor competitividade se consegue pela qualidade do serviço prestado.

\section{Othon Barcellos}

- Lavanderias podem inovar na área de processo (ex.: produtos químicos);

- Reuso de águas é uma inovação. As lavanderias fazem pouco, mas podem fazer mais;

- Lavagem a seco e wetcleaning são dois outros exemplos; e

- Equipamentos mais automatizados (dosadores de produtos e secadores). Secadores do futuro vão parar de secar na hora certa (a exemplo do secador do wetcleaning).

\section{$\underline{\text { Rui Sérgio Torres }}$}

- As lavanderias podem e devem inovar através dos processos, como o processo de lavagem, reuso, produtos para remoção de manchas (aumento de produtividade), aspectos comerciais (conceito de retirada e entrega em armários, atendimento ao cliente, etc.); e

- Em relação à produtividade sim, com equipamentos mais modernos com lavagem com menor quantidade de água e lotes maiores (menor número de funcionários para processar mais roupas).

\section{Alaor Chiodin}

- A lavanderia pode inovar no processo (máquinas mais modernas, produtos quimicos melhor elaborados que atendam a variedade de têxteis), reuso de águas, dosadores e máquinas automatizadas (economia de produto e mão de obra); 
- Treinamento da mão de obra é outra maneira de inovar (recepção, limpeza e passadoria). Deve ter habilidade para desempenhar sua função sem colocar em risco a peça de roupa e limpeza com qualidade; e

- A inovação melhora a empresa como um todo e se traduz no serviço prestado de melhor qualidade. A clientela está disposta a pagar mais (melhor faturamento), e a inovação aumenta a produtividade como um todo da lavanderia.

\section{Claudia Cristina dos Santos Diniz Meirelles}

- Pode inovar na área tecnológica, recursos humanos e marketing;

- Grande melhora com equipamentos de ponta que promovem melhor produtividade;

- Capacitação dos funcionários trazendo estímulo e gerando competitividade entre as equipes; $\mathrm{e}$

- Inovação melhorou a competitividade, pois as lavanderias estão mais preparadas para competirem entre si (resultados mais rápidos pela tecnologia, qualidade e eficácia).

\section{Maria Ramos Soares}

- O Brasil é bem atualizado com relação às novidades que estão surgindo, mas ainda há o que fazer (produtos novos que estão surgindo, execução da limpeza e entrega do serviço);

- Inovações podem trazer melhorias, mas estamos limitados, pois o nível de exigência do brasileiro com a roupa é grande e também o empresário estar mais ligado a equipamentos mais produtivos. Porém, a lavanderia pode esbarrar entre 0 que o cliente está acostumado e um benefício secundário (ajustando o custo com o que o cliente quer); e

- O acabamento é um gargalo se você não tiver profissionais adequados.

\section{José Carlos Miranda}

- A inovação em equipamentos é um desenvolvimento constante na busca pela melhor produtividade (saltos históricos da humanidade) com métodos, acessórios e fluxos;

- Inovação no treinamento e fluxograma de atuação da força de trabalho são fundamentais. No passado, valorizava-se a forma artesanal de lavagem (antigos 
tintureiros) e, hoje, o processo tem escala com aumento da produtividade e rentabilidade do negócio; e

- As inovações trouxeram novos equipamentos, produtos quimicos, marketing, fluxo de trabalho com profissionalização do serviço das lavanderias. Apesar de prestar serviço, lavanderia é um processo industrial cada vez mais automatizado. Por isso, o investimento em lavanderias em equipamentos e tecnologia da informação, como fábrica de serviços é importante.

\section{Arnaldo Afonso Moreira}

- Essas inovações trouxeram melhora na produtividade e competitividade das lavanderias, pois você está se comunicando mais rapidamente com o cliente (que se sente mais próximo da lavanderia), e as falhas são reconhecidas e corrigidas também mais rapidamente. Isso reflete no faturamento (é uma relação direta).

\section{Ludmila Viana}

- Existem duas formas de inovar: do lado de dentro da lavanderia, tais como melhora na produtividade no processo e do lado de fora, como novos modelos de negócio (serviços on line, delivery e self service); e

- Basicamente as inovações em nosso caso trouxeram competitividade (aumento de vendas), já que a nossa produtividade é muito próxima das outras lavanderias (não é o diferencial).

\section{Inovação de Processo (Sustentabilidade e Tecnológica)}

\section{Adriano de Almeida Gonçalves}

- As inovações no processamento das roupas e entrega do serviço final em lavanderias domésticas mais expressivos nos últimos 10 anos foram wetcleaning, softwares de gestão e manequins de passadoria;

- As principais inovações em sustentabilidade ambiental ou ecoinovação dos últimos 10 anos foram a tecnologia wetcleaning, que usa pouca água e as estações compactas de tratamento e reuso de água, dentre outras; e 
- Com relação ao aumento da base de clientes, o consumidor cada vez mais reconhece os esforços dos fornecedores nesse sentido e fazem suas escolhas não somente no preço mas também no compromisso de sustentabilidade.

\section{José Carlos Larocca}

- A última inovação de maior importância é wetcleaning (entre a lavagem a água e a seco);

- Máquinas mais modernas com filtros e barreiras de proteção são importantes;

- Em sustentabilidade, o tratamento de efluentes em lavanderias domésticas é restrito pelo custo. Em lavagem a seco, temos a colocação de filtros para evitar a saída de vapores (que protege o funcionário e o meio ambiente). Com a melhora do ambiente de trabalho, há melhora na produtividade;

- Como o cliente no Brasil está mais atrelado à qualidade e preço, sustentabilidade, hoje, ainda não aumenta o consumo em lavanderias domésticas; e

- Básicamente as inovações tecnológicas são: máquinas com dosadores automáticos (menos produto e tempo), em tecnologia da informação as entradas mais rápidas e a confecção do rol via software. As vantagens são redução da mão de obra e um melhor controle do serviço e escoamento da produção.

\section{Othon Barcellos}

- Na área de processo, um exemplo é o produto químico que lava e amacia ao mesmo tempo, com economia de água e tempo de processo;

- Inovações mais expressivas nos últimos 10 anos foram: wetcleaning, lavagem a seco com hidrocarbono (mais ambientalmente aceito e de menor risco), dosagem automática e reúso de águas (ainda incipiente);

- Inovação em sustentabilidade: wetcleaning, reúso de aguas, lavadoras extratoras (usam menos água). Inovam em relação ao meio ambiente que acabam redundando em melhora da produtividade. É um pouco controvertido que possam aumentar a base de clientes e as vendas, talvez a longo prazo, mas não se pode dizer que sustentabilidade aumente imediatamente a base, talvez, gradativamente; $\mathrm{e}$

- Inovações tecnológicas: já referenciadas e também a tecnologia da informação no balcão, que auxilia muito os controles da lavanderias. 


\section{$\underline{\text { Rui Sérgio Torres }}$}

- As inovações mais importantes dizem respeito ao processamento da roupa dentro da lavanderia ou circuito (maneira como as roupas são catalogadas, classificadas e triadas para serem direcionadas ao processo mais adequado de lavagem);

- A inovação mais importante foi a adoção pelas entidades associativas e sindicatos do Selo de Qualidade e Sustentabilidade (SQS) para sensibilizar o mercado sobre essas questões;

- Inovação pela regulação do uso do solvente clorado percloroetileno (Resolução 61 da ANVISA para manuseio e destino dos resíduos);

- Inovação no desenvolvimento de novos produtos quimicos que ajudam no processo, principalmente, os biodegradáveis.

- O reúso da água para lavanderias domésticas ainda não é uma realidade economicamente viável. Nesse momento, ainda a inovação em sustentabilidade não reflete em aumento da base de clientes e novos clientes. Ainda não há sensibilidade do usuário final com relação à lavanderia ser um aliado na economia de água;

- O processo wetcleaning traz uma economia de água significativa e aumenta a produtividade, mas ainda não trouxe um ganho comercial para as lavanderias;

- A inovação em tecnologia da informação inicia-se pelo atendimento, com sistemas informatizados que fazem a catalogação adequada das peças, no processo de produção indicando os gargalos em função da variação de entrada, clientes do delivery, identificação da peça por códigos de barra;

- Inovação em equipamentos mais modernos, como na finalização (passadoria), que gera maior produtividade em um local que é um dos grandes gargalos. Inovação mais recente em equipamentos de lavagem, permitindo processar quantidades maiores em tempos menores, com menor custo de água e energia; e

- As vantagens de se inovar tecnologicamente: melhor CRM (relacionamento com o cliente), rastreabilidade das peças com melhor controle de produção e entrega, o uso de equipamentos que reduzem custos diretos e indiretos (p.ex.: pessoal) e o uso de produtos quimicos menos agressivos que se adequam a novos tecidos e fibras permitindo um resultado muito bom no processo de lavagem.

\section{Alaor Chiodin}

- A competitividade com a vinda das redes internacionais aumentou; 
- Máquinas mais modernas, quantidade de produtos e agua automatizados com menor dependência da mão de obra (redução de erros) aumenta a produtividade e melhora a qualidade percebida pelo cliente;

- Na lavagem a seco, o percloro tem um cuidado maior, mas a reutilização da água é um fator importante na sustentabilidade (reduz o custo e melhora a utilização do insumo) e melhora a produtividade;

- Existe hoje uma conscientização gradativa maior do cliente com relação à preservação do meio ambiente (a empresa que preserva é mais valorizada), melhorando a imagem e, consequentemente, o cliente passa a ser mais fiel e aumenta as vendas; e

- A inovação tecnológica começou a ocorrer, a partir de 1992/93, com a liberação da importação de máquinas a custos mais baixos. Com a chegada das franquias que trouxeram melhores equipamentos, o mercado começou a mudar (lavadoras extratoras, máquinas a seco, bancas de passar melhores). Tais mudanças melhoram o serviço final ao cliente, com aumento de vendas e também da produtividade.

\section{Cláudia Cristina dos Santos Diniz Meirelles}

- Investimento em treinamento de funcionários para melhorar a produtividade;

- Foco no que o cliente quer, com inovação no processo em retirada de manchas, rapidez no processamento;

- Delivery aumentou a velocidade de entrega para um público com menos tempo de ir à lavandeira;

- Inovação em processo de lavagem: wetcleaning (sustentabilidade com redução de água), lavagem a seco remodelado (pré-tratamento de manchas seguido de lavagem), acabamento com melhores equipamentos;

- Inovação em sustentabilidade: cabides recicláveis no lugar do plástico com inovação em marketing, auxiliando no retorno dos cabides plásticos e trocando com recicláveis. Existe a busca de produtos químicos mais sustentáveis ao meio ambiente. Há a preocupação com a água que está sendo descartada no esgoto (volume e a qualidade da água de saída), ligada também a produtos mais biodegradáveis. Lavanderias estão se preparando para reúso de águas como economia, mas também com preocupação com o meio ambiente; 
- Inovação em sustentabilidade pode aumentar a base de clientes atuais pela melhor consciência ambiental das pessoas, que têm escolhido lavanderias que entregam o serviço com qualidade, mas que respeitam o meio ambiente;

- Inovações tecnológicas: balcão no atendimento tem softwares específicos com informações sobre a peça, rol e como será entregue. Melhor tecnologia de máquinas de passadoria e de lavar com aumento de produtitividade (ex.: manequins; máquinas de alimentação frontal lavadoras/centrífugas; prensas para passar peças maiores). Automação na dosagem de produtos quimicos e controle das operações das máquinas;

- Informatização com informações mais precisas sobre a dosagem de produtos, número de peças lavadas e custo por peça; e

- Vantagens da adoção de inovação tecnológica: melhora da competitividade, estimula os funcionários a serem mais estáveis, redução de custo e tempo com aumento da produtividade (menor tempo de entrega).

\section{Maria Ramos Soares}

- A grande inovação foi o wetcleaning, provocando grandes mudanças no processamento, modalidade do serviço e redução no uso de solventes, além de ter a versatilidade de ser usado também para lavagem a água convencional, melhorando a produtividade;

- O uso de hidrocarbonetos também é visto com bons olhos, mas ainda estamos defasados em relação ao número de equipamentos fechados, utilizando esses solventes no Brasil (custo elevado). Equipamentos abertos têm problemas de descarte de resíduos;

- Nos químicos para lavagem a água, existem pequenas mudanças, mas o empresário que vai ao supermercado ainda não percebe essas mudanças e não enxerga valor nessas tecnologias. O uso de produtos não profissionais traz problemas de produtividade (mais enxágues, perda de vida útil das peças);

- O Brasil explora pouco o uso de sacolas de papel (ao invés de plástico), que talvez possam ser melhores e mais econômicas;

- Inovações em sustentabilidade têm ainda pouca relação com a produtividade, mas ainda existe pouca disposição da maioria no tema e mudará se realmente afetar o negócio diretamente. Ainda existe muito desperdício, mas algum movimento na 
busca de produtos que consumam menos água, eliminem etapas do processo e gerem efluente de menor impacto. Com relação à redução no consumo de energia, a preocupação é menor que a preocupação com efluentes;

- Muitas lavanderias domésticas ainda utilizam produtos de prateleiras de supermercados, fazendo com que o consumidor questione se vale a pena lavar em lavanderias ou em casa, já que os produtos são iguais;

- Inovações em sustentabilidade podem aumentar a base de clientes e a geração de negócios, já que existe hoje uma melhor percepção dos clientes para negócios mais sustentáveis; e

- A operação envolve equipamentos, tecnologia de químicos e treinamento de pessoal.

\section{José Carlos Miranda}

- Um grande passo foi a lavagem a seco com máquinas fechadas;

- Outro passo foi o fluxo de trabalho incluindo o tira-manchas (recepção, triagem, lavagem ou tira-manchas, acabamento e entrega);

- O avanço tecnológico levou a uma mão de obra especializada nos equipamentos, amparados por uma rede de fornecedores que apoia a lavanderia (químicos, equipamentos e software);

- O desafio da modernização levou ao wetcleaning, que profissionaliza o conhecimento que algumas pessoas tinham de lavar qualquer roupa. O processo é automatizado, tem quimicos, lava, seca e finaliza com menos químicos, economia de água e menos especialização do operador;

- Estamos no meio da revolução da passadoria. Hoje, ainda o operador é a peça principal, mas com o início, por exemplo, do uso de manequins (passadoria automática), a peça principal é a máquina e não o operador. A produtividade aumenta;

- Com relação à sustentabilidade, o reuso do terceiro enxágue já nas máquinas já é uma realidade no exterior, mas, no Brasil ainda não. Ressalto do reúso do plástico e de peças de máquinas (sustentabilidade social associada). Sustentabilidade aumenta a base de clientes, mas deve haver comunicação para o tema repercutir;

- Tecnologia do software controla a base de clientes e a automação do processo; 
- Tecnologia de produtos químicos nacionais evoluiu muito, pois há 15-20 anos atrás não havia tantos fornecedores com a qualidade atual (no passado, só havia multinacionais); e

- Quando se utilizam todas essas inovações, o produto final tem um valor agregado maior e o custo é mais barato, aumentando a lucratividade. A produtividade aumenta se comparada com o processo tradicional.

\section{Arnaldo Afonso Moreira}

- Lavagem a seco e wetcleaning tem mudado muito as lavanderias na área de processo, visando à tecnologia. As lavanderias estão mais conscientes com relação ao meio ambiente (ex.: uso da água);

- Na área doméstica, a sustentabilidade é um desafio. As pessoas até querem mudar, mas os investimentos, às vezes, são elevados;

- Acredito que a inovação é um processo em cascata, os fornecedores parceiros inovam e, consequentemente, a lavanderia inova e atende aos clientes. Seja na área de processo, materiais biodegradáveis e com relação ao uso da água;

- Na área tecnológica, as lavanderias domésticas têm condição de inovar. Os fornecedores de tecnologia (equipamentos, produtos químicos e tecnologia da informação) trabalham junto com as lavanderias, melhorando o processo e aumentando o número de clientes;

- As lavanderias têm inovado na área de equipamentos e produtos quimicos, com os fornecedores capacitando os clientes e estando junto com eles; e

- A área de tecnologia da informação é uma forma barata de alavancar vendas. E o setor de tecnologia está investindo fornecendo não somente dados, mas informação e também na interligação entre os equipamentos (ex.: IP inteligente). Em um futuro próximo, as lavanderias irão utilizar equipamentos que estarão sendo monitorados e fornecerão informação, por exemplo sobre manutenção preventiva. A inovação vem tanto na área de processo como informação (ex.: segmentação de clientes, vendas, informações pontuais, etc.), minimizando tempo.

\section{Ludmila Viana}

- Existem dois campos: produtividade que envolve economia de água (lavar mais roupa com quantidades cada vez menores de água), energia (ex.: identificador de 
umidade para secar no tempo certo, reduzindo gastos na secadora e passadoria). Existe a produtividade quando se utiliza novas máquinas a seco e wetcleaning, que reduzem os danos, reduzem descartes e melhoram a qualidade;

- Na sustentabilidade do processo de lavagem, temos wetcleaning, que utiliza produtos biodegradáveis, usa pouca água ( 35 a 40 litros por processo na lavagem convencional contra 7 a 8 litros na lavagem wetcleaning).

- Temos inovação em sustentabilidade no reúso de água (uso de água da chuva, reúso de água de lavagem) e na devolução dos cabides pelos clientes (temos verificado uma preocupação em devolver tudo, inclusive, o plástico). Na lavanderia, recuperamos o plástico que sobra na embaladora, que volta para ser reciclado;

- Se colocarmos todas essas práticas na "ponta do lápis" vamos encontrar a melhora da produtividade. Com relação a aumento de vendas, temos por exemplo uma redução no custo de lavagem com wetcleaning que possibilita alcançar o cliente sensível a preços. Por outro lado, o mesmo wetcleaning permite alcançar o cliente que é sensível a problemas ambientais;

- Inovações tecnológicas: automação das máquinas e dosagem de produtos (que reduz insumos); inovação em tecnologia da informação; e

- Com inovações tecnológicas conseguimos alcançar o cliente mais sensível a preços (máquinas e produtos químicos), existem melhora da produtividade (cliente orientado a rapidez na entrega) e com os serviços on line alcançamos os cliente que valorizam a conveniência.

\section{Inovação de Marketing}

\section{Adriano de Almeida Gonçalves}

- A inovação de marketing pode aumentar a competitividade através da internet, com suas ferramentas de busca e aplicativos específicos, que já tomaram conta do segmento de lavanderias. O SEBRAE está com estudos avançados nesse sentido.

\section{José Carlos Larocca}

- Algumas lavanderias fazem promoções com baixos preços (canibalismo), que não funciona. Qualidade fideliza o cliente. 


\section{Othon Barcellos}

- As inovações sempre melhoram as vendas. Uma mudança de fachada de loja pode aumentar vendas e produtividade.

\section{$\underline{\text { Rui Sérgio Torres }}$}

- Com relação à competitividade, ainda existe dificuldade dos pequenos se destacar, pois o consumidor das lavanderias domésticas é muito inercial (se está bem atendido continua no mesmo fornecedor). As práticas de apelo ao cliente devem ser mais inovadoras para melhorar a competitividade (alguns poucos se destacam em nichos).

\section{Alaor Chiodin}

- As redes sociais são uma inovação em marketing, embora a conveniência (localização) seja importante ao consumidor.

\section{Cláudia Cristina dos Santos Diniz Meirelles}

- Inovação em marketing: campanhas locais, meios de comunicação (rádios, revistas, folders, panfletos, e-mail marketing), divulgação de novos serviços (ex.: couro e camurça). Hoje, o marketing é mais abrangente em lavanderias.

\section{Maria Ramos Soares}

- A inovação da apresentação do serviço no Brasil ainda é muito padronizada, poderia ser mais explorada e gerar diferenciação. $O$ impacto está na hora que o cliente recebe a roupa. Uma apresentação diferenciada pode seduzir muito (o cliente tem uma relação afetiva com a roupa).

\section{José Carlos Miranda}

- A lavanderia pode inovar em marketing na "vitrine", ou seja, iluminação, logomarca e forma de comunicação. Essa foi uma mudança dos últimos tempos (1994/95 para frente). A lavanderia é uma atividade de manutenção do vestuário, que é um bem pessoal. Deve-se superar as expectativas dos clientes. 


\section{Arnaldo Afonso Moreira}

- A lavanderia tem uma grande possibilidade de inovar porque trabalha diretamente com o cliente final. Pode-se inovar em outras áreas, mas o atendimento (relação) com o cliente é o que tem mais importância. Existem lavanderias que diferenciam e criam resultados muito bons. A melhor oportunidade de aumentar o faturamento não está em como lavar a roupa, mas o relacionamento com o cliente é que dá o maior retorno para as lavanderias.

\section{Ludmila Viana}

- O segmento de lavanderias não está em crescimento elevado (no momento estagnado); se você não diferenciar acaba se tornando uma commodity;

- O site como um todo oferece várias opções. Um ponto importante para melhorar a conveniência foi a assinatura mensal, que reduz custo ao cliente e nos traz maior fidelidade (retém mais o cliente), se comparado com serviços esporádicos;

- Outra prática que alcança o segmento daqueles que utilizam cestos foi associar uma sacola padrão com determinado volume de roupas, possibilitando ao cliente também solicitar on-line e encher o próprio cesto da lavanderia em sua casa;

- O cliente típico da internet é um jovem profissional, solteiro ou casado, tem idade entre 25 e 40 anos, classe A e B (verifica-se pelo tipo de roupa) e hevy user em internet e compras via navegação; e

- A distribuição de panfletos com promoções é importante e o front line deve dar pessoalidade quando entregar ao cliente, mostrando ofertas e deixando seu contato disponível.

\section{Inovação Organizacional (Modelo de Negócios e Linha de Frente e Retaguarda)}

\section{Adriano de Almeida Gonçalves}

- As lavanderias podem aumentar vendas gerando valor a seus clientes através da própria lavagem a seco, que já tem um valor diferenciado refletido nos preços das peças que exigem essa tecnologia na etiqueta. No entanto, há que ser criativo ao se agregar preço ao suposto valor que não afeta o acabamento em si;

- Tudo que oferecer conveniência pode ter o valor reconhecido no preço e no aumento do volume de serviço demandado. Por exemplo, serviços de entrega 
noturno (fora do horário comercial) em casa ou mesmo nas lavanderias com a implantação de "caixas automáticos" de entrega, como os $24 \mathrm{~h}$ de bancos;

- Com relação à participação das linhas de frente e de retaguarda, a recepção personalizada evita possíveis problemas de danos não averiguados antes de se iniciar o processo;

- Com relação ao aumento de vendas, o serviço com conveniência e rapidez faz a diferença neste segmento, e o consumidor migra para a lavanderia que oferece isso;

e

- Com relação à produtividade, nos serviços de domicílio (recepção e entrega), tem que ser adotado o conceito de "uma lavanderia dentro de outra", ou seja, é como se fosse uma filial, com atendentes exclusivas por telefone e internet, WhatsApp, rastreador de veículo, softwares específicos e internamente na lavanderia um caminho crítico totalmente desvinculado dos demais.

\section{José Carlos Larocca}

- Agregar novos negócios em lavanderias domésticas é mais díficil (ex.: lavagem por quilo não prosperou no País), mas a empatia entre cliente e lavanderia é importante e deve haver identificação entre as partes. A lavanderia é um negócio de médio contato com o cliente (não é baixo), é importante interagir com o cliente;

- As linhas de frente e de retaguarda estão interligadas e essa interação aumenta a produtividade. Se existe uma mudança no processamento das roupas na retaguarda a linha de frente precisa saber passar ao cliente; $\mathrm{e}$

- A qualificação da mão de obra em termos de atendimento ao cliente é importante. Se há inovação na linha de frente e de retaguarda existe um aumento de vendas.

\section{Othon Barcellos}

- Criar novos modelos de negócios de lavanderias não é muito fácil, mas ocorreu nos últimos 20 anos com a entrada das lavanderias de franquias. Trouxeram 0 modelo de negócio da descentralização (cada lavanderia é um centro de serviços e não mais uma loja de captação) e também o modelo de negócio com lojas de captação com uma usina central;

- Lavanderias em condomínios é outro exemplo de novo modelo de negócio (ainda em desenvolvimento); 
- Nos próximos anos, poderá haver lojas diferentes com novos modelos (talvez sem balcão de recepção, mesclando outros tipos de serviços); e

- É fundamental a participação na linha de frente e de retaguarda, mas não notou-se muita inovação na linha de frente (talvez uma busca automática de roupa, informática, saco de roupa 24 horas, entrega automática de roupa, etc.), mas não acentuada. Na retaguarda também não houve muitas inovações, talvez menos funcionários e com alguns funcionários polivalentes (um funcionário faz todo o serviço). Essas melhorias trouxeram algum aumento de produtividade e vendas.

\section{$\underline{\text { Rui Sérgio Torres }}$}

- Além dos modelos já referenciados (on line e armários), as lavanderias poderiam no seu dia a dia oferecer um leque maior de serviços a seus clientes (ex.: costura) e utilizar modelos que mostrem a conveniência ao cliente final;

- A linha de frente pode inovar fazendo o uso adequado do software de gerenciamento e para isso deve ser qualificada (treinamento). Deve saber, por exemplo, preencher de maneira adequada o cadastro de clientes, que irá gerar informações importantes que aumentarão as vendas. Saber classificar as roupas e problemas nas peças, minimizando indenizações e melhorando o relacionamento com o cliente, aumentando indiretamente as vendas; e

- A linha de retaguarda deve trabalhar a informação recebida para haver circulação devida, evitando atrasos, organizando a produção e entregando no prazo determinado (melhor produtividade). Se a roupa foi bem lavada e entregue no prazo determinado, o cliente vai trazer mais roupas.

\section{Alaor Chiodin}

- Uma forma de inovar o negócio é fugir da luta de preços e focar na especialização (p.ex.: lavagem de roupas finas) e diferenciação. Detalhes como a qualidade do cabide, do plástico, do papel que embrulha;

- De uma maneira geral, um caminho para a inovação em modelo de negócios em lavanderias deveria estar em atender o público com alguma especificidade e qualidade, com melhor precificação e lucratividade;

- As lavanderias domésticas ganham com treinamento da mão de obra (detalhe nos processos, etc.). A certificação da ISO 9001ajudou nesse aspecto; 
- A inovação começa na recepção do cliente (ali, ele começa a decidir). O delivery é fundamental em São Paulo, pela perda de tempo com trânsito. O serviço deve ser feito com qualidade (expectativa do cliente) no período combinado. No delivery, o manuseio da roupa é fundamental (o motorista deve ser treinado); e

- À medida que satisfaz o cliente e fideliza com qualidade, ele retorna e indica a outros clientes, aumentando as vendas. A produtividade aumenta com o treinamento da mão de obra.

\section{Cláudia Cristina dos Santos Diniz Meirelles}

- Lavanderias podem aumentar suas vendas, entendendo o que é valor para o cliente, entendendo suas necessidades;

- Exemplos de inovação em modelo de negócio: delivery com horário pré-fixado (dia ou noite) com a roupa passada e dobrada para sua viagem, recebimento e entrega da roupa, de acordo com a agenda do cliente, serviços de lavagem dentro das residências (ex.: higienização de sofás e cortinas), atendimento especial com organização do armário de roupas dos clientes;

- Inovação na customização de serviços de costura (reparos e reforma de roupas sob medida);

- O crescimento do negócio de lavanderias domésticas está na organização das linhas de frente e apoio: treinamento e capacitação (menor número de pessoas mais capacitadas e com melhor equipamento com aumento de produtividade), inovação no relacionamento com o cliente e no relacionamento interno entre a linha de frente e de apoio, agregando valor e melhorando a produtividade; e

- A linha de frente "vende" serviços com valor agregado (aumento de tiquet médio), como lavagem de peças especiais (ex.: couro, vestidos de noiva, etc.) e o aumento na variedade de serviços aumenta as vendas com a mesma equipe.

\section{Maria Ramos Soares}

- Ainda falta treinamento do pessoal de operação (linha de frente ou de apoio) e a inovação está baseada no treinamento dessas equipes;

- As operações de acabamento (passadoria) são, muitas vezes, mais valorizadas do que as de lavagem e retirada de manchas, que têm que raciocinar mais para fazer 0 trabalho (escolha do tipo de lavagem, tipo de tira-manchas, bom senso, etc.); 
- A operação da linha de frente deve ser bem treinada, pois é quem interaje em nome do negócio com o cliente. Deve prestar informação correta, mostrar as qualidades da lavanderia, assessorar, sugerir, tirar dúvidas, oferecer outros serviços e manter relação com a linha de apoio, garantindo que o que foi recomendado será cumprido no processamento;

- Novos modelos de negócios como lavagem de roupas sem ponto fixo, em um veículo, caminhão ou container levando o serviço ao cliente; e

- A linha de frente aumenta vendas e a retaguarda aumenta produtividade (com qualidade).

\section{José Carlos Miranda}

- As lavanderias podem aumentar suas vendas através de novos modelos de negócio, agregando novos serviços como costura, entrega e retirada, venda de produtos relacionados e inovando com programas de gerenciamento computadorizado;

- A participação das linhas de frente e de retaguarda na inovação é fundamental para a apresentação dos serviços e, claro, os serviços e produtos agregados que geram mais valor;

- Com relação ao aumento de vendas pela linha de frente, esta é a base para o aumento de vendas, pois além de apresentar os serviços e as novidades é o momento da concretização venda;

- Tanto a linha de frente quanto a retaguarda são elementos vitais na produtividade.

O destaque é para a retaguarda onde o processo é realizado, com métodos e processos controlados e verificados, aliados a equipamentos e insumos com tecnologia de ponta para sempre alcançar os melhores níveis de produtividade; e

- Vale ressaltar que as equipes de frente e retaguarda devem sempre estar treinadas e motivadas.

\section{Arnaldo Afonso Moreira}

- Novos modelos de negócio também é um desafio, mas as lavanderias podem inovar nessa área escutando o cliente, que não é tão simples. O setor de lavanderia ainda é muito tradicional, mas existem alguns exemplos de mudanças; 
- Uma lavanderia, como a limelocker, que coleta e entrega a roupa em armários é um exemplo. Lavanderias tipo self-service estão voltando com outro formato, pois no passado houve uma tentativa que não teve sucesso;

- Lavanderias on-line têm tido sucesso, auxiliadas pela tecnologia da informação. Outro exemplo são aplicativos que temos desenvolvido para celulares e são específicos para clientes de lavanderias, o que pode ajudar na melhora da competitividade;

- O atendimento do cliente é imprescindível. Não somente da recepção e entrega do serviço no balcão, mas, do delivery (algumas lavanderias entregam mais de $50 \%$ do que processam), que deve ser preparado e treinado;

- A lavanderia deve ter uma equipe motivada e integrada porque faz a diferença (inovação). Desde a recepção até a entrega, existe um processo complexo, que depende de mão de obra. $O$ cliente decide quando ele recebe a roupa e não quando entrega; $e$

- A linha de frente e retaguarda estão integradas. A recepção não somente recebe, mas embala, às vezes, lava e passa. Algumas lavanderias têm o modelo de funcionário polivalente, que trabalha em diferentes áreas e deve ser motivado continuamente.

\section{Ludmila Viana}

- Os novos modelos de negócios que irão aumentar as vendas estarão relacionados daqui para frente no "mundo touch" (bom site, aplicativos, skype, WhatsApp e facebook). Devem ser rápidos e adaptar suas ofertas a cada um dos públicos que utilizam essas ferramentas (esse cliente não gosta de falar via telefone);

- No nosso caso, optamos por inovar no modelo de negócio com uma lavanderia on line, para que o cliente não precise ir até o balcão. É o estágio seguinte do delivery; - O nosso diferencial está em "como" chegar no cliente que não tem oportunidade de vir durante a semana (esse público estava mal atendido). Ele não precisa vir no fim de semana e faz sua programação no domingo (pico de vendas no site), quando as lavanderias estão fechadas. No sábado, atendemos aqueles que vêm, têm o hábito de vir ao balcão, ou seja, atendemos dois "mundos" diferentes; e

- É muito difícil encontrar funcionários no front line que consigam vender a empresa (deve ter metas e treinamento para atendimento). O back office deve focar em 
produtividade, mas deve se comunicar com as outras áreas, e o ambiente como um todo deve ser positivo. Os funcionários devem ser polivalentes, mesmo que não seja sua área de especialização.

\section{Adoção de mais de um tipo de inovação e inter-relacionamento entre eles}

\section{Adriano de Almeida Gonçalves}

- Acho muito difícil implantar mais de um tipo de inovação ao mesmo tempo. O ritmo do segmento é frenético, e é como se trocássemos a roda do carro com ele andando. Muito cuidado na hora de inovar para não pôr tudo a perder;

- Existem resistências dos funcionários, e até dos próprios consumidores, como por exemplo, migração da passadoria manual com vinco na camisa para passadoria em manequim sem vinco, já que os clientes querem o vinco porque é símbolo de roupa bem passada; e

- Algumas situações exigem um esforço maior em se realizar várias mudanças ao mesmo tempo, uma delas é a necessidade de fontes alternativas de insumos básicos, como energia elétrica e água, que precisam ter alternativas de inovação urgentes ao mesmo tempo em que se implementa uma nova tecnologia em serviço ou em maquinário ou em processo de gestão. Portanto, nesta hora, as inovações que se inter-relacionam irão certamente forçar uma reengenharia na empresa que esperamos ter frutos no aumento das vendas, redução de custos e na melhora da qualidade do serviço percebido.

\section{José Carlos Larocca}

- Todas as inovações estão ligadas, mas não adianta aplicar tudo ao mesmo tempo de uma só vez, pois deve haver melhora no nível do trabalhador. Deve-se ir devagar, mudando princípios e conceitos; e

- As inovações estão inter-relacionadas, como por exemplo inovação tecnológica, sustentabilidade, marketing (mostrando a inovação ao cliente).

\section{Othon Barcellos}

- Quanto mais inovações e que interagem positivamente favorecem a lavanderias, mas as inovações devem ser implantadas passo a passo e nunca parar; 
- As inovações se inter-relacionam e uma acaba ajudando a outra. Nas lavanderias, o mais dificil é manter as inovações e a constância de melhorias. As franquias têm um grupo que pensa nisso e vai lançando para a rede de franqueados e no caso de um empresário sózinho é mais dificil.

\section{Rui Sérgio Torres}

- O sistema com as inovações deve se comunicar com o cliente e deve interligar os processos (entrada, produção e saída) com seu correto aproveitamento, entregando o serviço com qualidade e no prazo combinado, que é o que o cliente espera. Quem tiver tudo isso interligado, irá ter melhor resultado que aquela que tem um só tipo de inovação; e

- As inovações deveriam se interconectar para ter o melhor resultado em vendas, mas não sei se hoje as lavanderias conseguem isto. Acredito nesse modelo integrado, que é mais uniforme e gera uma proposta de valor (qualidade, eficiência e credibilidade) mais clara ao cliente. Ou seja, o que ele recebe em troca do que está pagando, inclusive se dispondo a pagar mais pelo serviço.

\section{Alaor Chiodin}

- Existe diferença entre a lavanderia que inova em vários tipos, já que inovação é um todo (máquina, produto químico, funcionário treinado, etc.). As lavanderias que adotam um só tipo de inovação tendem a sair do mercado, pois trabalham mais com preços baixos; e

- As inovações se inter-relacionam quando traduzem a mudança no serviço oferecido ao cliente e ele reconhece os benefícios.

\section{Claudia Cristina dos Santos Diniz Meirelles}

- Empresários que adotam vários tipos de inovação ao mesmo tempo tem maior aumento de vendas em comparação com aqueles que inovam com um tipo de cada vez (com intervalos entre a adoção dos tipos de inovação para observar a reação do mercado), trazendo mais valor ao negócio com inovação; e

- Uma "mistura" de inovação (tecnologia de máquinas, informática, modelo de negócio, marketing, sustentabilidade, processos mais rápidos, linha de frente mais preparada) gera o crescimento do negócio (aumento de vendas). 


\section{Maria Ramos Soares}

- Existe diferença entre lavanderias que adotam um só tipo de inovação e aquelas que adotam vários tipos de inovação. As que inovam em várias frentes têm melhor resultado. Exemplos são interação de fornecedores de químicos e equipamentos com novos tipos de lavagem, ao mesmo tempo ações na área de marketing (reformulação do site, etc.), novas ideias a partir de um treinamento da equipe, etc; e - O inter-relacionamento entre as inovações aumentam a produtividade e as vendas (mix de conhecimentos novos que interagem entre si). As inovações no negócio de lavanderias vai sempre permear em todas as áreas discutidas. Quanto maior 0 número de frentes que atuar (inovações), melhores resultados.

\section{José Carlos Miranda}

- As inovações se inter-relacionam. A coleta de roupa é feita, e a recepção deve lançar em um software todas as informações, a lavagem deve ser feita a um bom custo para se pagar no resultado final (equipamentos, produtos químicos, controle do gasto de energia, etc.). Se a lavanderia não tiver tudo isso, pelo menos, com equipamentos que economizem já é um bom começo. Mas não deve parar, pois as inovações estão relacionadas, e o ideal é ter a inovação em todas as áreas.

\section{Arnaldo Afonso Moreira}

- Eu acredito na pulverização das inovações, pois o resultado de uma inovação pode demorar. A inovação é uma cultura e deve haver várias inovações ao mesmo tempo. Inovação é um hábito e, consequentemente, haverá resultados;

- Em um ambiente propício à inovação, inovações, às vezes, pequenas têm melhor resultado; e

- As inovações se inter-relacionam e precisa ser assim. Uma inovação puxa a outra, mas é preciso escutar (essa é a grande ferramenta).

\section{Ludmila Viana}

- Todas inovações devem formar um conjunto, pensando como trabalhar com as várias frentes. Empresários de pequenas lavanderias devem ser polivalentes, já que 
não têm pessoas específicas para pensar em cada área e deve priorizar as áreas que mais são afetadas naquele momento. Deve haver um equilibrio; e

- As inovações inter-relacionam-se para melhorar a produtividade e vendas, deve-se trabalhar em todas as áreas para melhorar vendas e produtividade. 


\section{APÊNDICE B - Instrumento de Pesquisa - Questionário de campo para pesquisa quantitativa com escala Likert aplicado sobre a amostra escolhida (perguntas fechadas)}

Dados Preliminares:

DP 1 Razão Social:

DP 2 Número de Unidades?

DP 3 Pertence a uma Rede de Franquias ? ( ) Sim ( ) Não

DP 4 Número de Anos de Atividade: anos

DP 5 Número de Funcionários: funcionários

DP 6 Porte da Empresa (Micro ou Pequena): ( ) Micro ( ) Pequena

DP 7 Nome do Entrevistado/Cargo:

1) Recursos Atuais da Lavanderia

\begin{tabular}{|l|l|l|}
\hline \multicolumn{1}{|c|}{ Perguntas } & SIM & NÃO \\
\hline 1.1 Possui sistemas de reúso de águas? & & \\
\hline 1.2 Possui lavagem a seco? & & \\
\hline 1.3 Possui wetcleaning? & & \\
\hline 1.4 Utiliza Embalagens recicláveis? & & \\
\hline 1.5 Utiliza Energia solar ou eólica? & & \\
\hline 1.6 Utiliza linha de tira-manchas? & & \\
\hline 1.7 Utiliza propaganda e promoção? & & \\
\hline 1.8 Possui delivery? & & \\
\hline 1.9 Possui entrega via serviços on-line? & & \\
\hline
\end{tabular}

2) Inovação de Processo (Sustentabilidade Ambiental)

\begin{tabular}{|c|c|c|c|c|c|}
\hline Perguntas & $\begin{array}{l}\text { Concordo } \\
\text { Totalmente }\end{array}$ & $\begin{array}{l}\text { Concordo } \\
\text { em Parte }\end{array}$ & Indiferente & $\begin{array}{l}\text { Discordo } \\
\text { em Parte }\end{array}$ & $\begin{array}{l}\text { Discordo } \\
\text { Totalmente }\end{array}$ \\
\hline \multicolumn{6}{|l|}{$\begin{array}{l}2.10 \text { reúso de águas aumenta o faturamento } \\
\text { da lavanderia }\end{array}$} \\
\hline \multicolumn{6}{|l|}{$\begin{array}{l}2.20 \text { reuso de águas aumenta a } \\
\text { produtividade (vendas por funcionário) na } \\
\text { lavanderia }\end{array}$} \\
\hline \multicolumn{6}{|l|}{$\begin{array}{l}2.3 \text { O uso de sistemas de lavagem que } \\
\text { reduza o impacto ao meio ambiente e } \\
\text { economize insumos (ex.: wetcleaning) } \\
\text { aumentam o faturamento da lavanderia }\end{array}$} \\
\hline \multicolumn{6}{|l|}{$\begin{array}{l}2.4 \text { o uso de sistemas de lavagem que } \\
\text { reduza o impacto ao meio ambiente e } \\
\text { economize insumos (ex.: wetcleaning) } \\
\text { aumenta a produtividade (vendas por } \\
\text { funcionário) na lavanderia }\end{array}$} \\
\hline \multicolumn{6}{|l|}{$\begin{array}{l}2.50 \text { uso de embalagens que reduza o } \\
\text { impacto ao meio ambiente aumenta o } \\
\text { faturamento da lavanderia }\end{array}$} \\
\hline \multicolumn{6}{|l|}{$\begin{array}{l}2.6 \text { o uso de embalagens que reduza o } \\
\text { impacto ao meio ambiente aumentam a } \\
\text { produtividade (vendas por funcionário) na } \\
\text { lavanderia }\end{array}$} \\
\hline $\begin{array}{l}2.7 \text { O uso de energias alternativas (ex.: } \\
\text { eólica, solar) aumenta o faturamento da } \\
\text { lavanderia }\end{array}$ & & & & & \\
\hline
\end{tabular}

3) Inovação de Processo (Tecnológica - Equipamentos e Produtos Quimicos)

\begin{tabular}{|c|c|c|c|c|c|}
\hline Perguntas & $\begin{array}{c}\text { Concordo } \\
\text { Totalmente }\end{array}$ & $\begin{array}{c}\text { Concordo } \\
\text { em Parte }\end{array}$ & Indiferente & $\begin{array}{l}\text { Discordo } \\
\text { em Parte }\end{array}$ & $\begin{array}{c}\text { Discordo } \\
\text { Totalmente }\end{array}$ \\
\hline
\end{tabular}




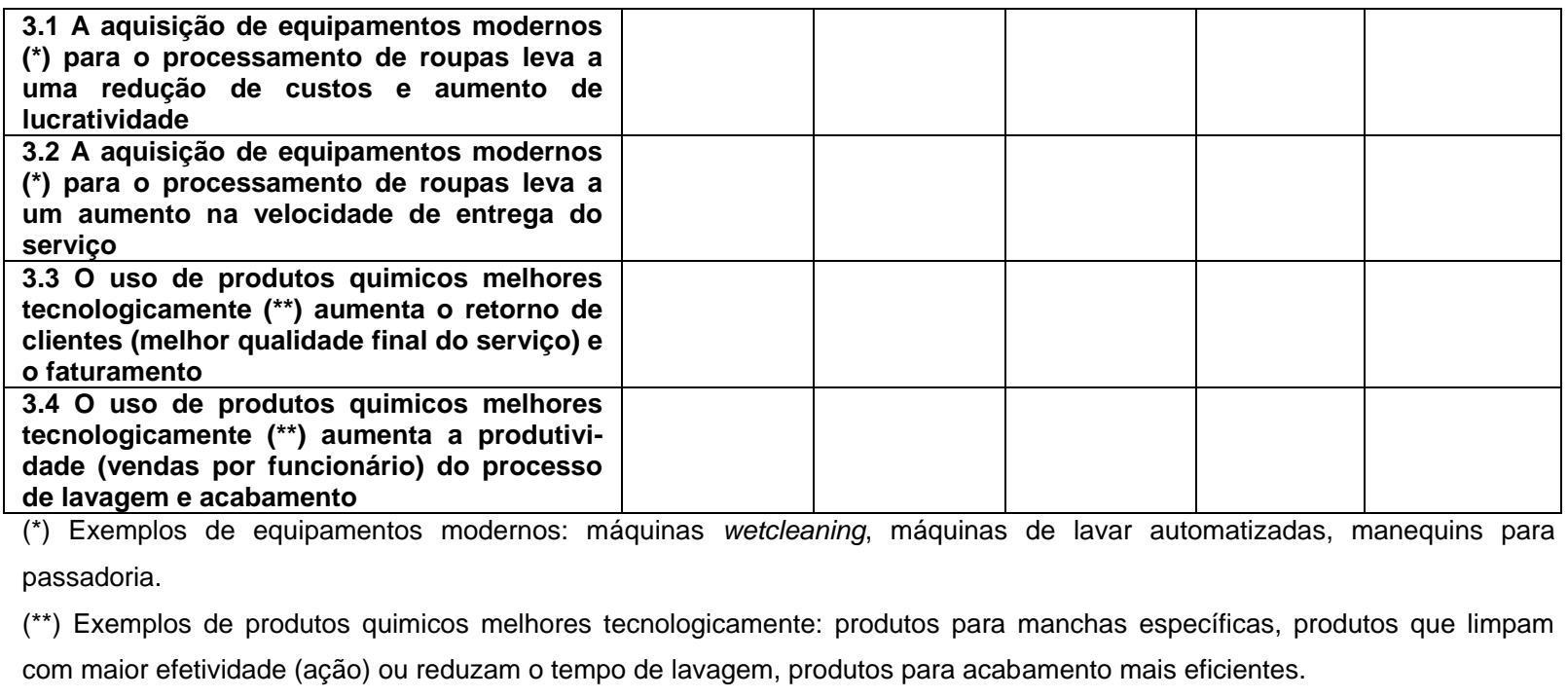

4) Inovação de Marketing

\begin{tabular}{|l|l|l|l|l|l|}
\hline \multicolumn{1}{|c|}{ Perguntas } & $\begin{array}{c}\text { Concordo } \\
\text { Totalmente }\end{array}$ & $\begin{array}{l}\text { Concordo } \\
\text { em Parte }\end{array}$ & Indiferente & $\begin{array}{c}\text { Discordo } \\
\text { em Parte }\end{array}$ & $\begin{array}{c}\text { Discordo } \\
\text { Totalmente }\end{array}$ \\
\hline $\begin{array}{l}\text { 4.1 A promoção e propaganda e o visual da } \\
\text { loja aumentam o número de novos clientes } \\
\text { e, consequentemente, o faturamento. }\end{array}$ & & & & & \\
\hline $\begin{array}{l}\text { 4.2 A introdução de serviços para públicos } \\
\text { específicos (ex.: estudantes, executivos) } \\
\text { aumenta o número de novos clientes e, } \\
\text { consequentemente, o faturamento. }\end{array}$ & & & & & \\
\hline $\begin{array}{l}\text { 4.3 A promoção de um leque maior de } \\
\text { serviços (ex.: costura, delivery) aumenta o } \\
\text { ganho de mercado e a competitividade. }\end{array}$ & & & & & \\
\hline
\end{tabular}

5) Inovação Organizacional (Modelo de Negócio)

\begin{tabular}{|l|l|l|l|l|l|}
\hline Perguntas & $\begin{array}{c}\text { Concordo } \\
\text { Totalmente }\end{array}$ & $\begin{array}{c}\text { Concordo } \\
\text { em Parte }\end{array}$ & Indiferente & $\begin{array}{c}\text { Discordo } \\
\text { em Parte }\end{array}$ & $\begin{array}{c}\text { Discordo } \\
\text { Totalmente }\end{array}$ \\
\hline $\begin{array}{l}\text { 5.1 Uma nova logística de entrega do serviço } \\
\text { (ex.: on line ou delivery) aumenta o } \\
\text { faturamento. }\end{array}$ & & & & & \\
\hline $\begin{array}{l}5.2 \text { A inovação em um serviço mais rápido e } \\
\text { de melhor conveniência para o cliente final } \\
\text { aumenta o faturamento. }\end{array}$ & & & & & \\
\hline
\end{tabular}

6) Inovação Organizacional (Linha de Frente e de Retaguarda)

\begin{tabular}{|l|l|l|l|l|l|}
\hline Perguntas & $\begin{array}{c}\text { Concordo } \\
\text { Totalmente }\end{array}$ & $\begin{array}{c}\text { Concordo } \\
\text { em Parte }\end{array}$ & Indiferente & $\begin{array}{c}\text { Discordo } \\
\text { em Parte }\end{array}$ & $\begin{array}{c}\text { Discordo } \\
\text { Totalmente }\end{array}$ \\
\hline $\begin{array}{l}\text { 6.1 A capacidade de comunicar inovações e } \\
\text { o diferencial da lavanderia por atendentes da } \\
\text { linha de frente aumentam o faturamento. }\end{array}$ & & & & & \\
\hline $\begin{array}{l}6.2 \text { O desempenho dos funcionários da linha } \\
\text { de produção (lavagem e acabamento) } \\
\text { aumentam a produtividade (vendas por } \\
\text { funcionário) da lavanderia. }\end{array}$ & & & & & \\
\hline
\end{tabular}

7) Diversidade e Inter-relação entre Inovações

\begin{tabular}{|c|c|c|c|c|c|}
\hline Perguntas & $\begin{array}{l}\text { Concordo } \\
\text { Totalmente }\end{array}$ & $\begin{array}{l}\text { Concordo } \\
\text { em Parte }\end{array}$ & Indiferente & $\begin{array}{l}\text { Discordo } \\
\text { em Parte }\end{array}$ & $\begin{array}{c}\text { Discordo } \\
\text { Totalmente }\end{array}$ \\
\hline $\begin{array}{l}7.1 \text { A adoção de mais de um tipo de } \\
\text { inovação das citadas, anteriormente, ao } \\
\text { mesmo tempo aumenta o faturamento. }\end{array}$ & & & & & \\
\hline $\begin{array}{l}7.2 \text { A adoção de mais de um tipo de } \\
\text { inovação das citadas anteriormente ao } \\
\text { mesmo tempo aumenta a produtividade } \\
\text { (vendas por funcionário). }\end{array}$ & & & & & \\
\hline
\end{tabular}


APÊNDICE C - Respostas Relativas às Questões Relacionadas às Hipóteses

\begin{tabular}{|c|c|c|c|c|c|c|c|c|c|c|c|}
\hline Lavanderias & $\begin{array}{c}\mathbf{H}_{1} \\
\text { Q2.1 }\end{array}$ & $\begin{array}{c}\mathrm{H}_{2} \\
\text { Q 2.4 }\end{array}$ & $\begin{array}{c}\mathbf{H}_{3} \\
\mathbf{Q} 3.2 \\
\end{array}$ & $\begin{array}{c}\mathrm{H}_{4} \\
\mathrm{Q} 3.4 \\
\end{array}$ & $\begin{array}{c}H_{5} \\
Q 4.1 \\
\end{array}$ & $\begin{array}{c}\mathrm{H}_{6} \\
\mathrm{Q} 4.2\end{array}$ & $\begin{array}{c}\mathrm{H}_{7} \\
\mathbf{Q} 4.3\end{array}$ & $\begin{array}{c}\mathrm{H}_{8} \\
\mathbf{Q} 5.2 \\
\end{array}$ & $\begin{array}{c}H_{9} \\
Q 6.1\end{array}$ & $\begin{array}{c}\mathbf{H}_{10} \\
\text { Q7.1 } \\
\end{array}$ & $\begin{array}{c}\mathbf{H}_{11} \\
\mathbf{Q} 7.2 \\
\end{array}$ \\
\hline L1 & 1 & 3 & 1 & 2 & 1 & 1 & 1 & 1 & 1 & 1 & 1 \\
\hline L2 & 2 & 2 & 2 & 2 & 1 & 2 & 2 & 2 & 1 & 1 & 1 \\
\hline L3 & 3 & 3 & 1 & 2 & 1 & 1 & 1 & 1 & 1 & 1 & 1 \\
\hline $\mathrm{L} 4$ & 2 & 3 & 1 & 1 & 1 & 1 & 2 & 1 & 1 & 1 & 1 \\
\hline L5 & 1 & 4 & 2 & 2 & 1 & 1 & 1 & 2 & 2 & 2 & 2 \\
\hline L6 & 1 & 2 & 1 & 1 & 1 & 2 & 1 & 1 & 1 & 1 & 2 \\
\hline L7 & 3 & 1 & 1 & 1 & 1 & 1 & 1 & 1 & 1 & 1 & 1 \\
\hline L8 & 2 & 1 & 2 & 2 & 1 & 2 & 2 & 2 & 2 & 2 & 2 \\
\hline L9 & 1 & 2 & 1 & 3 & & & & & & & \\
\hline L10 & 2 & 1 & 1 & 1 & 1 & 2 & 2 & 1 & 1 & 1 & 2 \\
\hline L11 & 2 & 5 & 4 & 3 & 1 & 2 & 2 & 2 & 1 & 1 & 3 \\
\hline L13 & 1 & 2 & & & & & & & & & \\
\hline L14 & 1 & 1 & 1 & 1 & 2 & 2 & 1 & 2 & 1 & 1 & 1 \\
\hline L15 & 1 & 2 & 1 & 1 & 2 & 2 & 2 & 1 & 1 & 1 & 1 \\
\hline L16 & 2 & 3 & 1 & 4 & 1 & 2 & 1 & 1 & 1 & 1 & 2 \\
\hline L17 & 1 & 1 & 2 & 1 & 1 & 1 & 1 & 1 & 1 & 1 & 1 \\
\hline L18 & 1 & 2 & 1 & 1 & 1 & 1 & 1 & 1 & 1 & 1 & 1 \\
\hline L19 & 2 & 2 & 5 & 2 & 2 & 2 & 4 & 4 & 2 & 2 & 2 \\
\hline $\mathrm{L} 20$ & 1 & 3 & 2 & 2 & 1 & 1 & 1 & 1 & 1 & 1 & 1 \\
\hline L21 & 1 & 1 & 2 & 1 & 1 & 1 & 1 & 1 & 1 & 1 & 1 \\
\hline L22 & 1 & 3 & 1 & 2 & 1 & 1 & 1 & 1 & 1 & 2 & 1 \\
\hline L23 & 2 & 2 & 1 & 1 & 4 & 2 & 2 & 1 & 1 & 1 & 1 \\
\hline L24 & 2 & 3 & 4 & 5 & 1 & 1 & 2 & 2 & 2 & 2 & 2 \\
\hline L25 & 2 & 2 & 2 & 2 & 2 & 2 & 2 & 1 & 2 & 2 & 2 \\
\hline L26 & 3 & 3 & 4 & 4 & 1 & 1 & 2 & 2 & 2 & 1 & 3 \\
\hline L27 & 1 & 1 & 2 & 1 & 1 & 1 & 1 & 1 & 1 & 1 & 1 \\
\hline L28 & 4 & 3 & 2 & 2 & 2 & 2 & 2 & 2 & 2 & 2 & 2 \\
\hline L29 & 3 & 3 & 2 & 2 & 2 & 4 & 2 & 2 & 1 & 4 & 2 \\
\hline L30 & 1 & 1 & 2 & 1 & 1 & 1 & 1 & 1 & 1 & 1 & 1 \\
\hline L31 & 1 & 2 & 1 & 1 & 1 & 1 & 1 & 1 & 1 & 2 & 2 \\
\hline L32 & 1 & 5 & 2 & 3 & 2 & 2 & 2 & 2 & 2 & 2 & 2 \\
\hline L33 & 1 & 3 & 2 & 2 & 1 & 2 & 1 & 2 & 1 & 1 & 1 \\
\hline L34 & 1 & 1 & 1 & 2 & 2 & 2 & 2 & 2 & 2 & 2 & 2 \\
\hline L35 & 2 & 3 & 4 & 2 & 1 & 1 & 2 & 2 & 2 & 2 & 2 \\
\hline L36 & 2 & 2 & 2 & 2 & 3 & 3 & 1 & 1 & 2 & 2 & 2 \\
\hline L37 & 3 & 3 & 2 & 3 & 2 & 2 & 1 & 1 & 1 & 2 & 2 \\
\hline L38 & 1 & 3 & 1 & 2 & 1 & 1 & 1 & 1 & 1 & 2 & 2 \\
\hline L39 & 2 & 3 & 2 & 2 & 2 & 2 & 2 & 2 & 1 & 2 & 2 \\
\hline L40 & 3 & 3 & 1 & 1 & 1 & 1 & 1 & 1 & 1 & 1 & 1 \\
\hline L41 & 1 & 1 & 2 & 1 & 2 & 1 & 2 & 2 & 1 & 1 & 1 \\
\hline L42 & 2 & 2 & 2 & 1 & 1 & 1 & 1 & 1 & 1 & 2 & 2 \\
\hline L44 & 2 & 3 & 3 & 3 & 1 & 2 & 1 & 1 & 1 & 2 & 2 \\
\hline L45 & 2 & 2 & 1 & 2 & 1 & 1 & 1 & 2 & 1 & 2 & 2 \\
\hline L46 & 3 & 3 & 2 & 2 & 2 & 2 & 2 & 2 & 2 & 2 & 2 \\
\hline L47 & 1 & 2 & 2 & 2 & 2 & 2 & 2 & 2 & 2 & 2 & 2 \\
\hline L48 & 1 & 1 & 1 & 1 & 1 & 1 & 1 & 1 & 1 & 1 & 2 \\
\hline L49 & 3 & 2 & 1 & 1 & 1 & 2 & 1 & 1 & 3 & 2 & 2 \\
\hline L50 & 2 & 3 & 2 & 1 & 2 & 2 & 2 & 1 & 2 & 2 & 1 \\
\hline L51 & 1 & 3 & 3 & 5 & 1 & 1 & 1 & 1 & 1 & 1 & 1 \\
\hline L52 & 2 & 3 & 2 & 3 & 2 & 2 & 2 & 3 & 3 & 3 & 3 \\
\hline L53 & 3 & 3 & 1 & 1 & 1 & 2 & 2 & 2 & 1 & 2 & 2 \\
\hline L54 & 2 & 2 & 1 & 1 & 1 & 1 & 1 & 1 & 1 & 1 & 1 \\
\hline L55 & 2 & 2 & 1 & 2 & 1 & 1 & 1 & 1 & 1 & 1 & 1 \\
\hline L56 & 3 & 3 & 3 & 3 & 2 & 3 & 2 & 3 & 1 & 3 & 3 \\
\hline L57 & 1 & 3 & 2 & 2 & 2 & 3 & 1 & 1 & 1 & 1 & 1 \\
\hline L58 & 2 & 5 & 2 & 2 & 2 & 2 & 4 & 2 & 2 & 2 & 2 \\
\hline L59 & 3 & 3 & 1 & 1 & 1 & 2 & 2 & 1 & 1 & 2 & 2 \\
\hline L60 & 1 & 3 & & & & & & & & . & \\
\hline L61 & 1 & 5 & 1 & 1 & 1 & 1 & 1 & 1 & 1 & 1 & 1 \\
\hline L62 & 2 & 4 & & & & & & & & & \\
\hline L63 & 2 & 3 & 1 & 1 & 1 & 3 & 1 & 1 & 1 & 1 & 1 \\
\hline L64 & 4 & 5 & 2 & 2 & 1 & 1 & 1 & 2 & 1 & 3 & 2 \\
\hline L65 & 1 & 3 & 1 & 2 & 1 & 2 & 1 & 1 & 1 & 1 & 1 \\
\hline L66 & 1 & 4 & 1 & 2 & 1 & 2 & 1 & 2 & 1 & 3 & 2 \\
\hline L67 & 1 & 1 & 1 & 1 & 1 & 1 & 1 & 1 & 1 & 1 & 1 \\
\hline L68 & 1 & 3 & 1 & 1 & 2 & 2 & 2 & 1 & 1 & 2 & 2 \\
\hline L69 & 1 & 3 & 1 & 3 & 1 & 1 & 2 & 1 & 1 & 2 & 3 \\
\hline L70 & 1 & 2 & 2 & 2 & 2 & 2 & 2 & 2 & 2 & 2 & 2 \\
\hline L71 & 5 & 5 & 4 & 2 & 2 & 2 & 2 & 3 & 5 & 2 & 2 \\
\hline L72 & 2 & 2 & 1 & 2 & 1 & 1 & 1 & 1 & 1 & 1 & 1 \\
\hline L73 & 1 & 2 & 1 & 1 & 1 & 1 & 1 & 1 & 1 & 1 & 1 \\
\hline
\end{tabular}

